Software Requirements, Design, and Verification and Validation for the FEHM ApplicationA Finite-Element Heat-and Mass-Transfer Code

Zora V. Dash

Bruce A. Robinson

George A. Zyvoloski

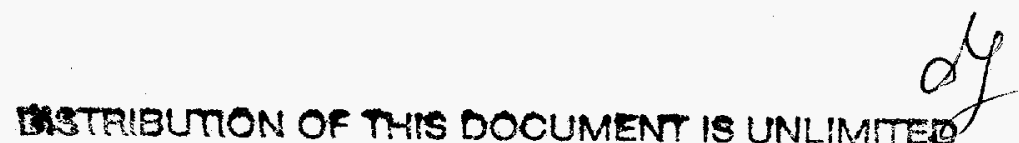





\section{DISCLAIMER}

This report was prepared as an account of work sponsored by an agency of the United States Government. Neither the United States Government nor any agency thereof, nor any of their employees, make any warranty, express or implied, or assumes any legal liability or responsibility for the accuracy, completeness, or usefulness of any information, apparatus, product, or process disclosed, or represents that its use would not infringe privately owned rights. Reference herein to any specific commercial product, process, or service by trade name, trademark, manufacturer, or otherwise does not necessarily constitute or imply its endorsement, recommendation, or favoring by the Uinited States Government or any agency thereof. The views and opinions of authors expressed herein do not necessar. ily state or reflect those of the United States Government or any agency thereof. 


\section{DISCLAIMER}

Portions of this document may be illegible electronic image products. Images are produced from the best available original document. 


\section{TABLE OF CONTENTS}

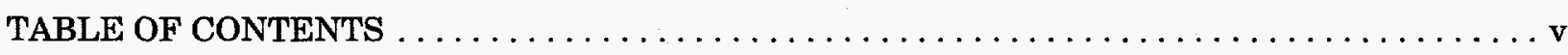

LIST OF FIGURES $\ldots \ldots \ldots \ldots \ldots \ldots \ldots \ldots \ldots \ldots \ldots \ldots \ldots \ldots \ldots \ldots \ldots \ldots \ldots \ldots \ldots$

LIST OF TABLES $\ldots \ldots \ldots \ldots \ldots \ldots \ldots \ldots \ldots \ldots \ldots \ldots \ldots \ldots \ldots \ldots \ldots \ldots \ldots \ldots \ldots$

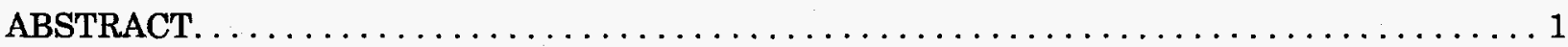

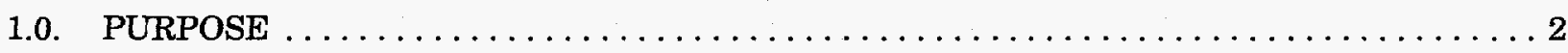

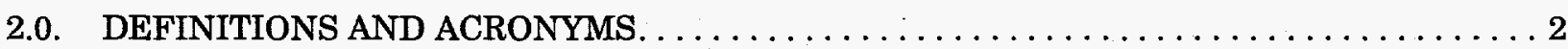

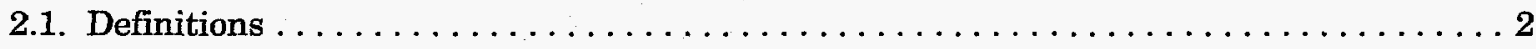

2.2. Acronyms . . . . . . . . . . . .

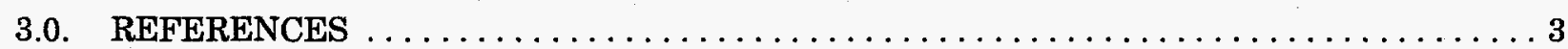

\section{Chapter I: \\ Software Requirements Specification}

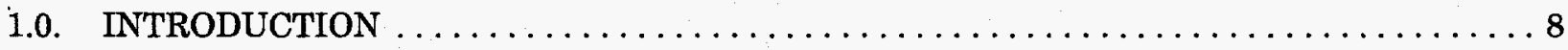

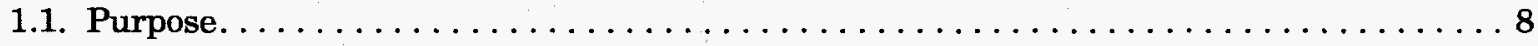

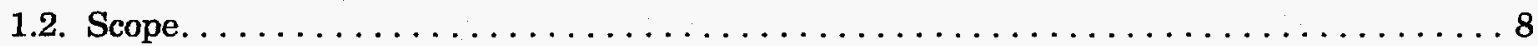

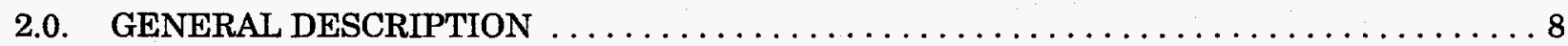

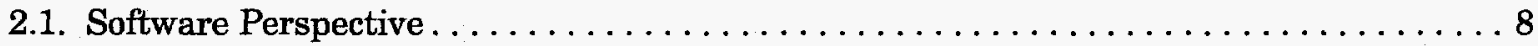

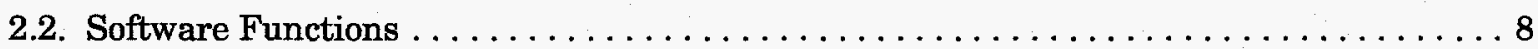

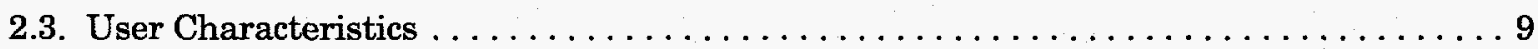

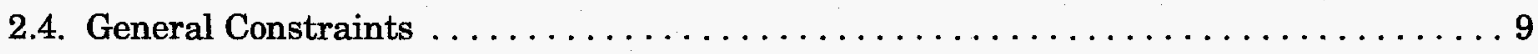

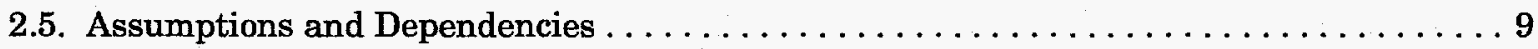

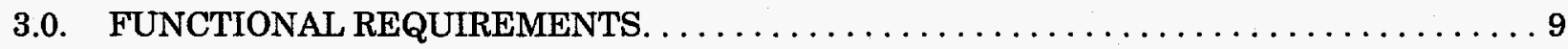

3.1. Finite-Element Coefficient Generation $\ldots \ldots \ldots \ldots \ldots \ldots \ldots \ldots \ldots \ldots \ldots \ldots$

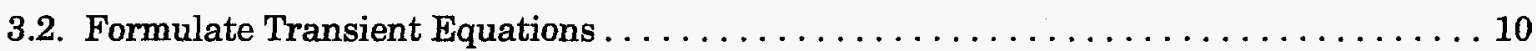

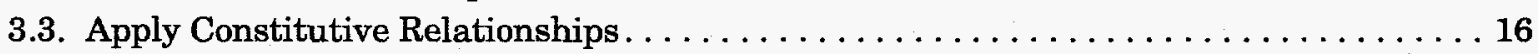

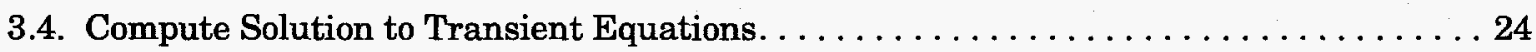

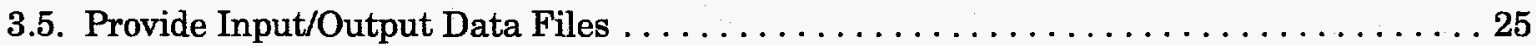

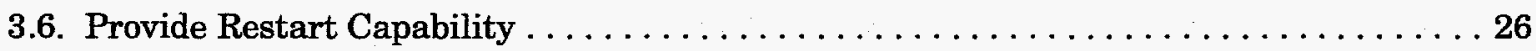

4.0. EXTERNAL INTERFACE REQUIREMENTS $\ldots \ldots \ldots \ldots \ldots \ldots \ldots \ldots \ldots \ldots \ldots \ldots$

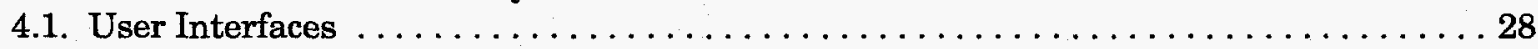

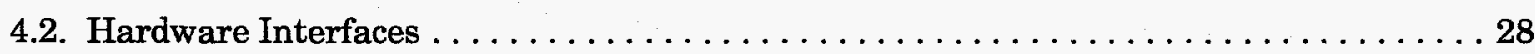

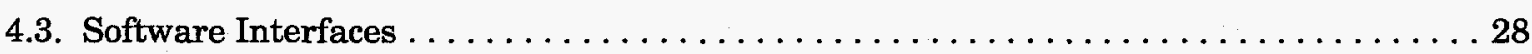

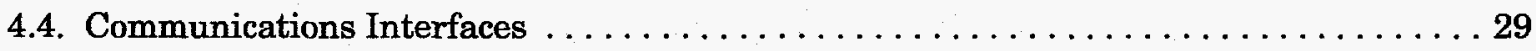




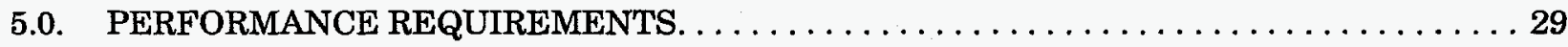

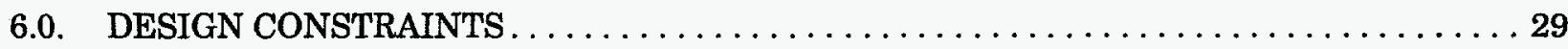

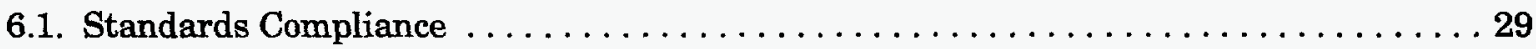

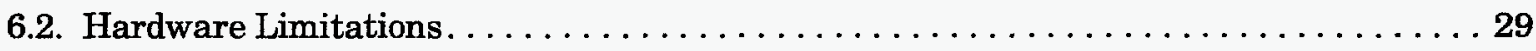

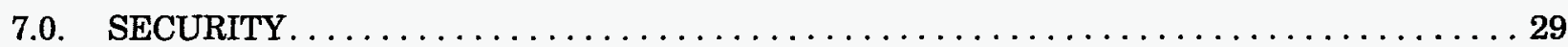

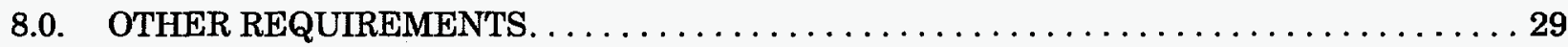

8.1. Data Base. . . . . . . . . . . . . . . . 29

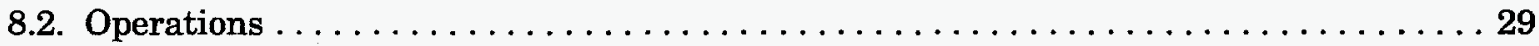

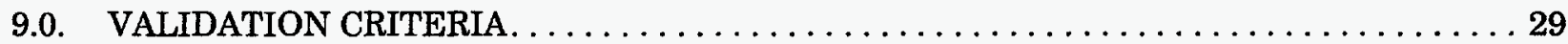

\section{Chapter II: Software Design}

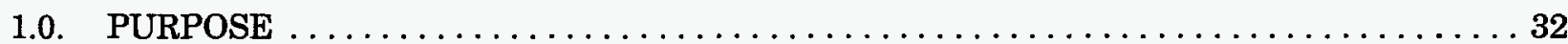

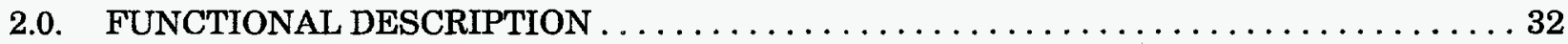

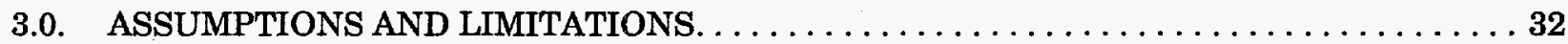

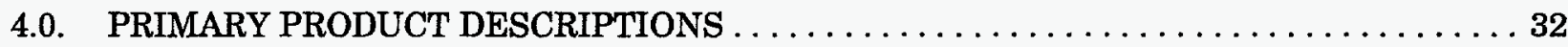

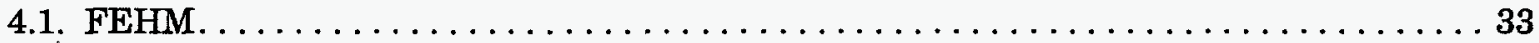

\section{Chapter III: \\ Verification and Validation Plan}

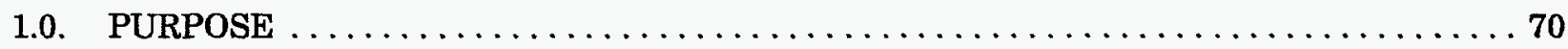

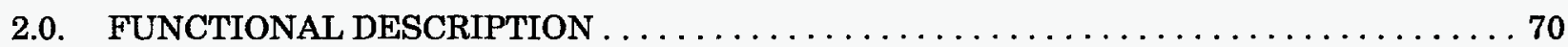

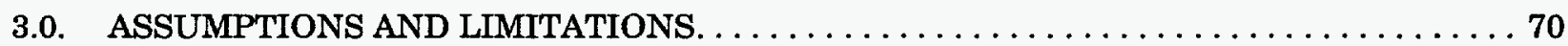

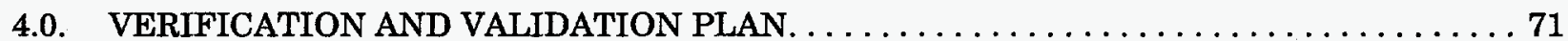

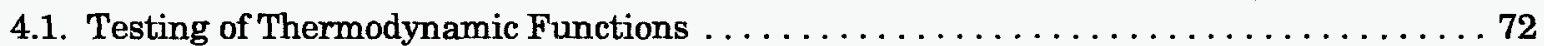

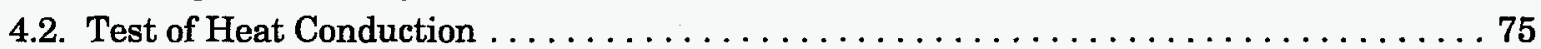

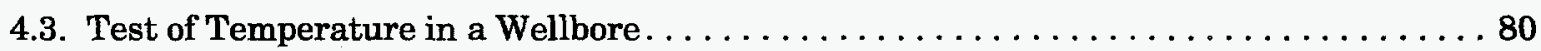

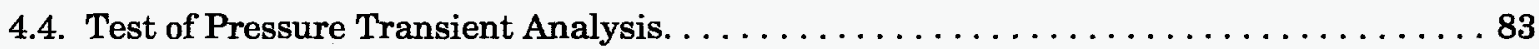

4.5. Test of Infiltration into a One-dimensional, Layered, Unsaturated Medium . . . . . 86

4.6. Test of Vapor Extraction from an Unsaturated Reservoir . . . . . . . . . . . . 91

4.7. Test of Dual Porosity . . . . . . . . . . . . . . . . . . . . . . . . . 95

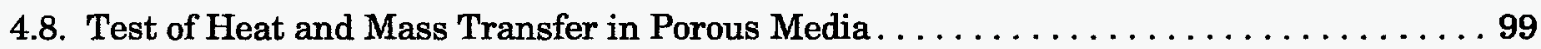

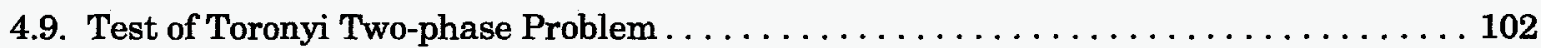

4.10. Test of DOE Code Comparison Project, Problem Five, Case A . . . . . . . . . 105

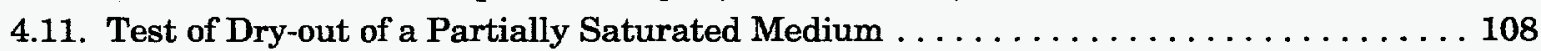

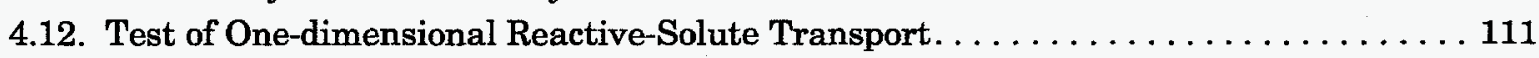

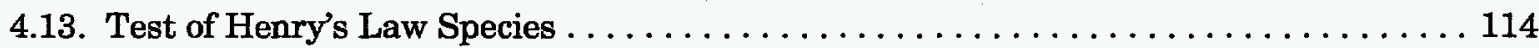


4.14. Test of Fracture Transport with Matrix Diffusion $\ldots \ldots \ldots \ldots \ldots \ldots \ldots \ldots \ldots$

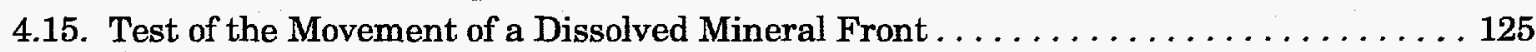

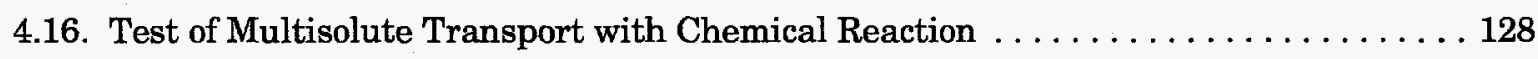

4.17. Test of Three-dimensional Radionuclide Transport $\ldots \ldots \ldots \ldots \ldots \ldots \ldots \ldots \ldots 1$

\section{Chapter IV: \\ Verification and Validation Report}

1.0. SCOPE OF VERIFICATION AND VALIDATION ACTIVITIES $\ldots \ldots \ldots \ldots \ldots \ldots \ldots$

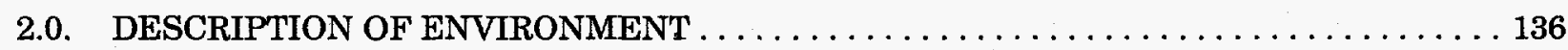

3.0. ADDITIONAL VERIFICATION AND VALIDATION ISSUES $\ldots \ldots \ldots \ldots \ldots \ldots \ldots$

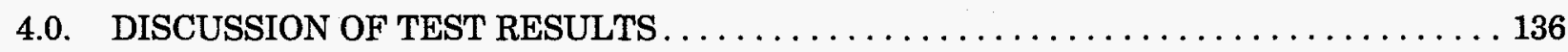

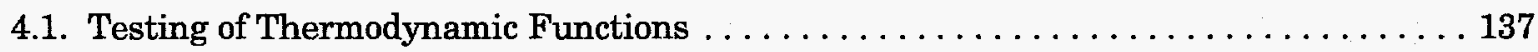

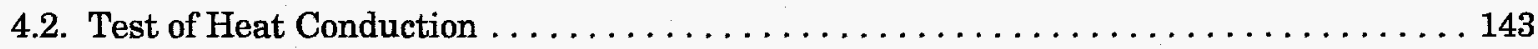

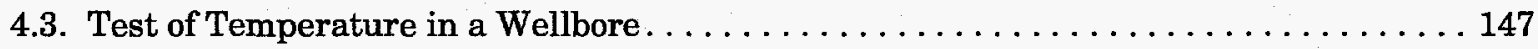

4.4. Test of Pressure Transient Analysis. . . . . . . . . . . . . . . . . . 149

4.5. Test of Infiltration into a One-dimensional, Layered, Unsaturated Medium . . . . . 151

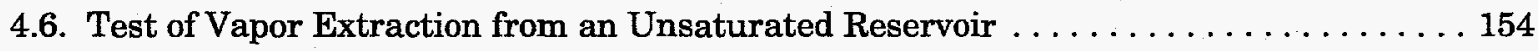

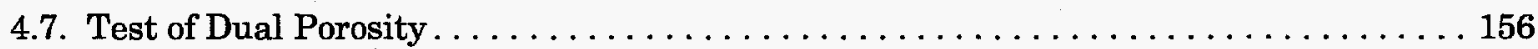

4.8. Test of Heat and Mass Transfer in Porous Media . . . . . . . . . . . . . . 158

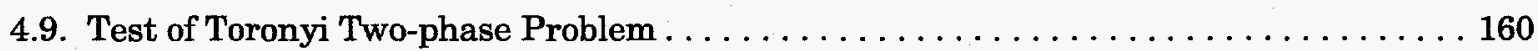

4.10. Test of DOE Code Comparison Project, Problem Five, Case A . . . . . . . . 161

4.11. Test of Dry-out of a Partially Saturated Medium $\ldots \ldots \ldots \ldots \ldots \ldots \ldots \ldots \ldots$

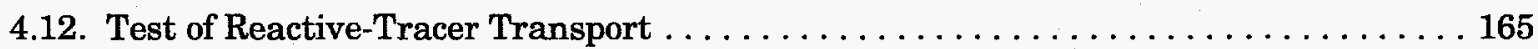

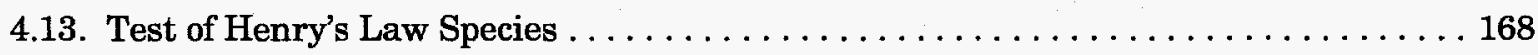

4.14. Test of Fracture Transport With Matrix Diffusion $\ldots \ldots \ldots \ldots \ldots \ldots \ldots \ldots \ldots \ldots$

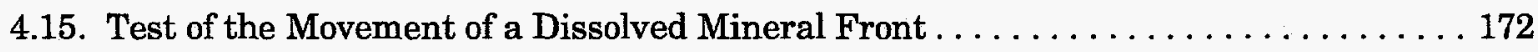

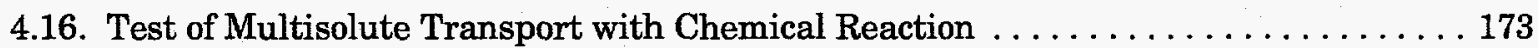

4.17. Test of Three-dimensional Radionuclide Transport with Decay Chain . . . . . . 175

5.0. CONCLUSIONS AND RECOMMENDATIONS $\ldots \ldots \ldots \ldots \ldots \ldots \ldots \ldots \ldots \ldots \ldots$

\section{Appendices}

APPENDIX A: SUBROUTINE AND FUNCTION CALLS WITHIN FEHM $\ldots \ldots \ldots \ldots \ldots \ldots$

APPENDIX B: TESTS OF THE FUNCTIONAL REQUIREMENTS AND MACRO

CONTROL STATEMENTS OF THE FEHM APPLICATION. $\ldots \ldots \ldots \ldots \ldots \ldots \ldots \ldots \ldots 2$ 
Software Requirements, Design, and V\&V for FEHM

LIST OF FIGURES

\section{LIST OF FIGURES}

Figure 1. Schematic diagrams of $2-\mathrm{D}$ and $3-\mathrm{D}$ heat-conduction problems. $\ldots \ldots \ldots \ldots \ldots$

Figure 2. Geometric configurations tested by the $2-\mathrm{D}$ heat-conduction problem. ....... 77

Figure 3. Geometric elements tested by the $3-\mathrm{D}$ heat-conduction problem. . . . . . . . 79

Figure 4. Schematic drawing of the problem geometry and boundary conditions for the temperature-in-a-wellbore problem.

Figure 5. Schematic drawing of the problem geometry and boundary conditions for the transient pressure problem.

Figure 6. Schematic drawing of the problem geometry for the test of the one-dimensional infiltration problem.

Figure 7. Schematic diagram of the geometry and boundary conditions for the vaporextraction problem.

Figure 8. Schematic diagram of the geometry and boundary conditions for the dualporosity problem.

Figure 9. Schematic diagram of the Avdonin problem geometry with boundary and initial conditions.

Figure 10. Solution domain and saturation results for the Toronyi problem

Figure 11. Schematic diagram of the geometry and boundary conditions for the DOE Code Comparison Project problem.

Figure 12. Schematic drawing of the geometry and boundary conditions for the dry-out simulations.

Figure 13. Schematic drawing of the geometry and boundary conditions for the 1-D reactive-tracer transport problem.

Figure 14. Schematic drawing of the geometry and boundary conditions for the tests of Henry's Law species.................................. 115

Figure 15. Schematic drawing of the geometry and boundary conditions for the fracture transport problem.

Figure 16. Schematic drawing of the geometry and boundary conditions for the calcitedissolution problem.

Figure 17. Aqueous and mineral-front profiles modeled by the analytical solution. 126 
Figure 18. Schematic drawing of the geometry and boundary conditions for the cobalt transport problem.

Figure 19. Model domain and flow boundary conditions for test of the radionuclide

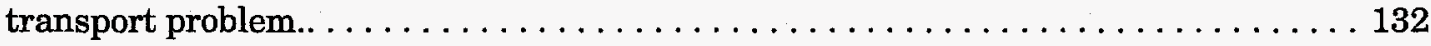

Figure 20. Comparison of FEHM enthalpies to the NBS/NRC Steam Tables data. . . . . . 138

Figure 21. Comparison of FEHM densities to the NBS/NRC Steam Tables data.......... 139

Figure 22. Comparison of FEHM compressibilities to the NBS / NRC Steam Tables data. . . . . 140

Figure 23. Comparison of FEHM viscosities to the NBS / NRC Steam Tables data........ 141

Figure 24. Comparison of FEHM saturation pressures and temperatures to the NBS/NRC

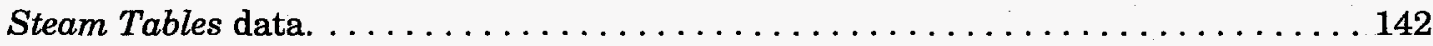

Figure 25. Comparison of FEHM and analytical solutions for 2-D heat conduction at

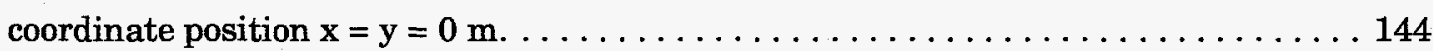

Figure 26. Comparison of FEHM and analytical solutions for 2-D heat conduction at time $t=2.16 \mathrm{e} 4$ seconds.. . . . . . . . . . . . . . . 144

Figure 27. Comparison of FEHM and analytical solutions for 3-D heat conduction at

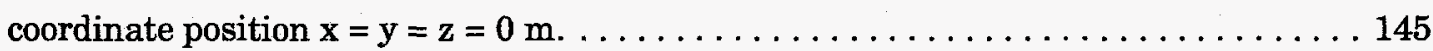

Figure 28. Comparison of FEHM and analytical solutions for 3-D heat conduction at time

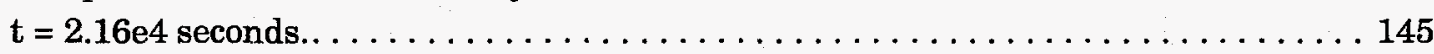

Figure 29. Comparison of FEHM and Ramey analytical solutions for temperature versus time at $\mathrm{d}=\mathbf{1 0 0 0 \mathrm { m } \text { and } \mathrm { d } = 2 0 0 0 \mathrm { m } \ldots \ldots \ldots \ldots \ldots \ldots \ldots \ldots \ldots \ldots \ldots \ldots \ldots \ldots \ldots \ldots}$

Figure 30. Comparison of FEHM and Ramey analytical solutions for temperature versus

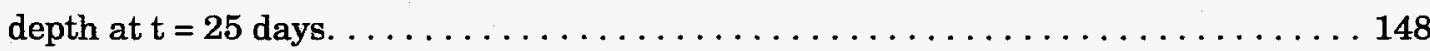

Figure 31. Comparison of FEHM and Theis solutions for pressure versus time at $\mathrm{r}=0.00144 \mathrm{~m}$ and $\mathrm{r}=3.44825 \mathrm{~m}$ from the wellbore.

Figure 32. Comparison of FEHM and Theis solutions for pressure versus position at $t=1$ day.

Figure 33. Comparison of FEHM and TOUGH2 saturations for an equivalent-continuum

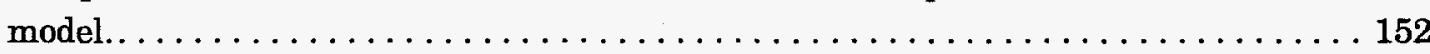

Figure 34. Comparison of FEHM and TOUGH2 matrix saturation for a double-porosity/ double-permeability model.

Figure 35. Comparison of FEHM and TOUGH2 fracture saturation for a double-porosity/ double-permeability model. 
Software Requirements, Design, and V\&V for FEHM

LIST OF FIGURES

Figure 36. Comparison of FEHM steady-state vapor pressure (top) with Shan analytical solution (bottom) for an isotropic reservoir.

Figure 37. Comparison of FEHM steady-state vapor pressure (top) with Shan analytical solution (bottom) for an anisotropic reservoir. . . . . . . . . . . . 155

Figure 38. Comparison of FEHM and analytical solution for dual-porosity case $1 \ldots \ldots \ldots 6$

Figure 39. Comparison of FEHM and analytical solution for dual-porosity case $2 \ldots \ldots \ldots 157$

Figure 40. Comparison of FEHM and analytical solution for dual-porosity case $3 \ldots \ldots \ldots 157$

Figure 41. Comparison of FEHM and Avdonin analytical solutions for temperature versus time at $\mathbf{r}=37.5 \mathrm{~m}$ from injection well. . . . . . . . . . . . . . 159

Figure 42. Comparison of FEHM and Avdonin analytical solutions for temperature versus

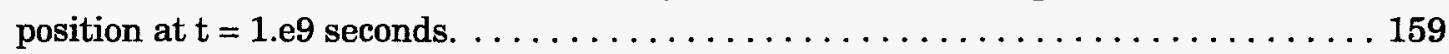

Figure 43. Toronyi saturation field at $t=78.31$ days.. $\ldots \ldots \ldots \ldots \ldots \ldots \ldots \ldots \ldots \ldots \ldots \ldots \ldots \ldots$

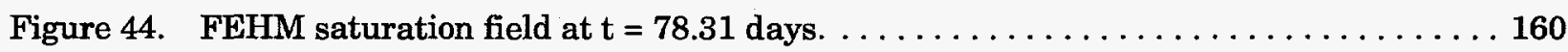

Figure 45. Comparison of FEHM production-well temperatures with results from other codes.

Figure 46. Comparison of FEHM production- and observation-well pressure drops with results from other codes.

Figure 47. Comparison of FEHM and analytical solutions for the position of a dry-out front in a partially saturated medium.

Figure 48. Comparison of FEHM and SORBEQ outlet concentrations for the conservative tracer.

Figure 49. Comparison of FEHM and SORBEQ outlet concentrations for the linear isotherm.

Figure 50. Comparison of FEHM and SORBEQ outlet concentrations for the Langmuir isotherm.

Figure 51. Comparison of FEHM and SORBEQ outlet concentrations for the Freundlich isotherm.

Figure 52. Comparison of FEHM and SORBEQ outlet concentrations for the modified Freundlich isotherm. 167

Figure 53. Comparison of FEHM results with the analytical solution for a mobile air phase. . . 169 
Figure 54. Comparison of FEHM results with the analytical solution for a mobile water phase.

Figure 55. Comparison of FEHM results with the analytical solution for a mobile water phase with reactions.

Figure 56. Comparison of FEHM and Tang analytical solutions for concentration versus time for the matrix-diffusion model..

Figure 57. Comparison of FEHM and the analytical solution for the position of the dissolved mineral front at the final time of the simulation.

Figure 58. Comparison of FEHM and PDREACT for the breakthrough curves of aqueous species.

Figure 59. Comparison of FEHM and PDREACT for the exit concentration versus time for solid species.

Figure 60. Comparison of FEHM and TRACRN results for the concentration-time history at position 1 . . .

Figure 61. Comparison of FEHM and TRACRN results for the concentration-time history at position $2 .$.

Figure 62. Comparison of FEHM and TRACRN results for the concentration-time history at position 3 .

Figure 63. Comparison of FEHM and TRACRN results for the concentration-time history at position 4 . 


\section{LIST OF TABLES}

Table 1. Functional requirements of the FEHM application $\ldots \ldots \ldots \ldots \ldots \ldots \ldots \ldots$

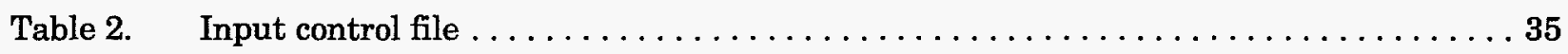

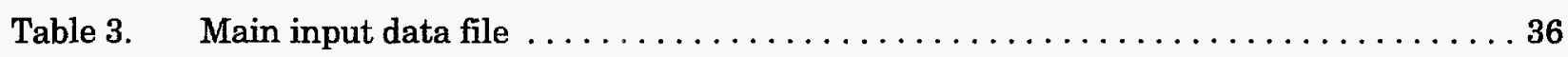

Table 4. Geometry data file. ......................... 49

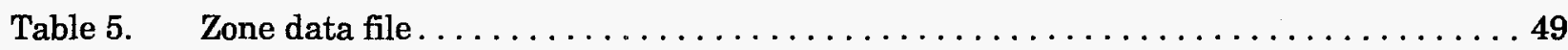

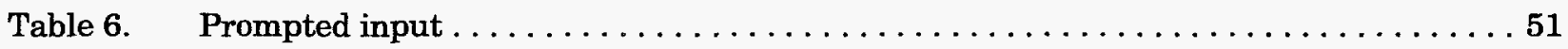

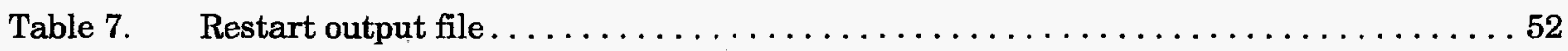

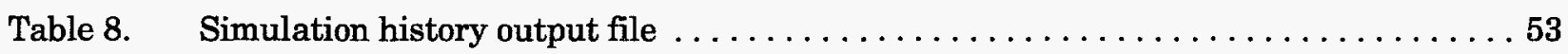

Table 9. Solute history output file $\ldots \ldots \ldots \ldots \ldots \ldots \ldots \ldots \ldots \ldots \ldots \ldots \ldots \ldots \ldots \ldots$

Table 10. Contour plot output file. . . . . . .

Table 11. Coefficient storage file. $\ldots \ldots \ldots \ldots \ldots \ldots \ldots \ldots \ldots \ldots \ldots \ldots \ldots \ldots \ldots \ldots$

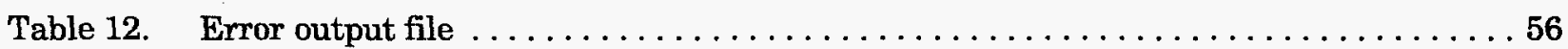

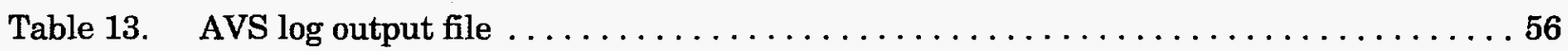

Table 14. AVS ASCII header output files. $\ldots \ldots \ldots \ldots \ldots \ldots \ldots \ldots \ldots \ldots \ldots \ldots \ldots \ldots \ldots \ldots \ldots \ldots$

Table 15. AVS binary header output files $\ldots \ldots \ldots \ldots \ldots \ldots \ldots \ldots \ldots \ldots \ldots \ldots \ldots \ldots$

Table 16. AVS ASCII geometry output file $\ldots \ldots \ldots \ldots \ldots \ldots \ldots \ldots \ldots \ldots \ldots \ldots$

Table 17. AVS binary geometry output file $\ldots \ldots \ldots \ldots \ldots \ldots \ldots \ldots \ldots \ldots \ldots \ldots \ldots$

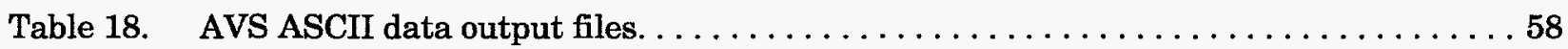

Table 19. AVS binary data output files $\ldots \ldots \ldots \ldots \ldots \ldots \ldots \ldots \ldots \ldots \ldots \ldots \ldots \ldots \ldots$

Table 20. Error conditions that result in program termination $\ldots \ldots \ldots \ldots \ldots \ldots \ldots \ldots \ldots$

Table 21. Warning conditions and messages $\ldots \ldots \ldots \ldots \ldots \ldots \ldots \ldots \ldots \ldots \ldots \ldots \ldots \ldots \ldots \ldots$

Table 22. Input parameters for the $2-\mathrm{D}$ and $3-\mathrm{D}$ heat-conduction problems $\ldots \ldots \ldots \ldots \ldots$

Table 23. Input parameters for the temperature-in-a-wellbore problem $\ldots \ldots \ldots \ldots \ldots \ldots$

Table 24. Input parameters for the transient pressure problem $\ldots \ldots \ldots \ldots \ldots \ldots \ldots \ldots$ 
Table 25. Input parameters for the one-dimensional infiltration problem $\ldots \ldots \ldots \ldots \ldots . \ldots 8$

Table 26. Input parameters for the vapor-extraction problem $\ldots \ldots \ldots \ldots \ldots \ldots \ldots \ldots \ldots$

Table 27. Input parameters for the dual-porosity problem. $\ldots \ldots \ldots \ldots \ldots \ldots \ldots \ldots \ldots$

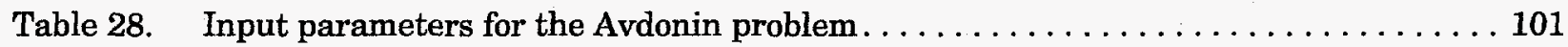

Table 29. Input parameters for the Toronyi two-phase problem $\ldots \ldots \ldots \ldots \ldots \ldots \ldots \ldots$

Table 30. Input parameters for the DOE Code Comparison Project, Problem 5, Case A . . . . 107

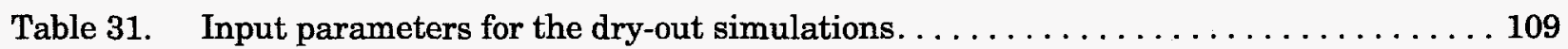

Table 32. Input parameters for the 1-D reactive-tracer transport problem. $\ldots \ldots \ldots \ldots \ldots 112$

Table 33. Adsorption parameters for the reactive-tracer transport problem. . . . . . . . 112

Table 34. Combinations of phenomena exercised in the tests of Henry's Law species . . . . . . 114

Table 35. Input parameters for the tests of Henry's Law species. $\ldots \ldots \ldots \ldots \ldots \ldots \ldots \ldots$

Table 36. Adsorption, Henry's Law, and reaction parameters for the tests of Henry's

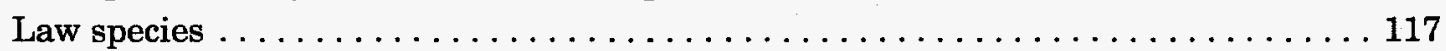

Table 37. Adsorption parameters for the fracture transport problem $\ldots \ldots \ldots \ldots \ldots \ldots \ldots$

Table 38. Input parameters for the test of the matrix-diffusion problem $\ldots \ldots \ldots \ldots \ldots \ldots$

Table 39. Input parameters for the calcite-dissolution problem $\ldots \ldots \ldots \ldots \ldots \ldots \ldots \ldots \ldots$

Table 40. Input parameters for test of the reactive transport problem $\ldots \ldots \ldots \ldots \ldots \ldots$

Table 41. Input parameters and conditions for test of the radionuclide transport problem.... 133

Table 42. Results of tests of thermodynamic functions $\ldots \ldots \ldots \ldots \ldots \ldots \ldots \ldots \ldots \ldots$

Table 43. Results of the test of $2-\mathrm{D}$ heat conduction $\ldots \ldots \ldots \ldots \ldots \ldots \ldots \ldots \ldots \ldots \ldots$

Table 44. Results of the test of $3-\mathrm{D}$ heat conduction $\ldots \ldots \ldots \ldots \ldots \ldots \ldots \ldots \ldots \ldots$

Table $45 . \quad$ Results of the temperature in a wellbore test $\ldots \ldots \ldots \ldots \ldots \ldots \ldots \ldots \ldots \ldots$

Table 46. Results of the test of the pressure transient analysis $\ldots \ldots \ldots \ldots \ldots \ldots \ldots \ldots 149$

Table 47. Results of the test of infiltration into a one-dimensional, layered, unsaturated

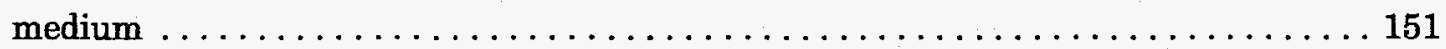

Table 48. Results of the test of vapor extraction from an unsaturated reservoir . . . . . . 155 
Software Requirements, Design, and V\&V for FEHM

LIST OF TABLES

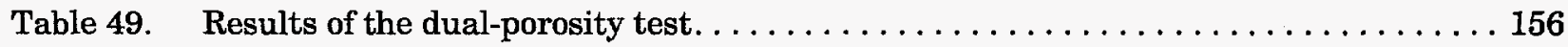

Table 50. Results of the test of heat and mass transfer in porous media $\ldots \ldots \ldots \ldots \ldots$

Table 51. Results of the test of the Toronyi two-phase problem $\ldots \ldots \ldots \ldots \ldots \ldots \ldots \ldots \ldots 160$

Table 52. Results of the test of the DOE Code Comparison Project Problem .......... 161

Table 53. Results of the test of dry-out of a partially saturated medium $\ldots \ldots \ldots \ldots \ldots \ldots$

Table 54. Results of the test of reactive-tracer transport $\ldots \ldots \ldots \ldots \ldots \ldots \ldots \ldots \ldots \ldots 165$

Table 55. Results of the test of Henry's Law species.................... 168

Table 56. Results of the fracture-transport/matrix-diffusion test $\ldots \ldots \ldots \ldots \ldots \ldots \ldots \ldots 171$

Table 57. Results of a test of the movement of a dissolved mineral front $\ldots \ldots \ldots \ldots \ldots \ldots$

Table 58. Results of the test of multisolute reactive transport. $\ldots \ldots \ldots \ldots \ldots \ldots \ldots \ldots$

Table 59. Results of the test of the three-dimensional decay-chain problem. $\ldots \ldots \ldots \ldots \ldots$

Appendix A

Table 1. Subroutine and function calls within FEHMN $\ldots \ldots \ldots \ldots \ldots \ldots \ldots \ldots \ldots$

Appendix B

Table 1. Functional requirements of the FEHM application $\ldots \ldots \ldots \ldots \ldots \ldots \ldots \ldots 2$

Table 2. FEHM macro control statements used by test problems $\ldots \ldots \ldots \ldots \ldots \ldots$ 


\title{
Software Requirements, Design, and Verification and Validation for the FEHM Application- A Finite-Element Heat- and Mass-Transfer Code
}

by

Zora V. Dash, Bruce A. Robinson, and George A. Zyvoloski

\begin{abstract}
The requirements, design, and verification and validation of the software used in the FEHM application, a finite-element heat- and mass-transfer computer code that can simulate nonisothermal multiphase multicomponent flow in porous media, are described. The use of this code is applicable to natural-state studies of geothermal systems and groundwater flow. A primary use of the FEHM application will be to assist in the understanding of flow fields and mass transport in the saturated and unsaturated zones below the proposed Yucca Mountain nuclear waste repository in Nevada. Chapter I describes the software requirements specification for the FEHM application, including the functional and external interface requirements. This specification motivates the software design, discussed in Chapter II, which covers functional requirements, input/output files and associated variables, and error and warning conditions with their associated messages. Chapter III, "Verification and Validation Plan," outlines the manner in which rigorous and complete testing of the model is to be carried out. Whenever possible, the testing will be against known analytical solutions of the same problem, or for more complex test cases for which no analytical solution exists, the code will be benchmarked against the results of other numerical models. The test cases to be performed are detailed and acceptance criteria that must be satisfied are listed. Chapter IV discusses those test cases and describes the results. The cases covered include tests of separate model components, such as the thermodynamic functions or heat conduction, and tests of a more complex nature, such as dry-out of a partially saturated medium, fracture transport with matrix diffusion, multisolute transport with chemical reaction, and three-dimensional radionuclide transport with decay chain. The test of the DOE Code Comparison Project, Problem Five, Case A, which verifies that FEHM has correctly implemented heat and mass transfer and phase partitioning, is also covered.
\end{abstract}




\subsection{PURPOSE}

The FEHM application consists of a finite-element-based numerical simulator of nonisothermal, multiphase, multicomponent flow and solute transport in porous media. The FEHM code will be used for parameter sensitivity studies in the design and specification of field tracer and flow experiments and the interpretation of those field experiments. In addition, it will be used for field-scale simulations of radionuclide migration in the saturated and unsaturated zones below the proposed nuclear waste repository at Yucca Mountain, Nevada.

This document includes the following four main chapters:

- I. Software Requirements Specification. This chapter documents the functional requirements for the FEHM application that are used in designing the application. Subsequent baseline studies (described in Chapter IV, "Verification and Validation Report") are used to verify that the application fully implements these requirements.

- II. Software Design. The design of the FEHM software is described, including functional requirements, input/output files and associated variables, and error and warning conditions with associated messages.

- III. Verification and Validation Plan. The Verification and Validation effort tests the options and features of the FEHM application to verify that the requirements specified in Chapter I, "Software Requirements Specification," are satisfied. The approach is to consist of rigorous and complete testing of the model, whenever possible, against known analytical solutions of the same problem or, for more complex test cases for which no analytical solution exists, of benchmarking the code against the results of other numerical models. This chapter details the test cases to be performed, many of which were developed for prior versions of FEHM (Zyvoloski et al. 1992; Zyvoloski and Dash 1991a, 1991b), and lists the acceptance criteria that must be satisfied.

- IV. Verification and Validation Report. This chapter discusses the test cases described in "Verification and Validation Plan" and details the results of those tests.

\subsection{DEFINITIONS AND ACRONYMS}

\subsection{Definitions}

FEHM: Finite-element heat- and mass-transfer code (Zyvoloski et al. 1988).

FEHMN: an earlier verion of FEHM designed specifically for the Yucca Mountain Site Characterization Project. Both versions are now equivalent, and the use of FEHMN has been dropped.

\subsection{Acronyms}

DOE - U. S. Department of Energy

DKM - double-porosity/double-permeability method

ECM - equivalent continuum method

LANL - Los Alamos National Laboratory 


\author{
LU - lower-upper \\ USGS - United States Geological Survey \\ $\mathbf{V} \& \mathbf{V}$ - verification and validation \\ YMP - Yucca Mountain Site Characterization Project
}

\title{
3.0 REFERENCES
}

Avdonin, N. A. 1964. Some formulas for calculating the temperature field of a stratum subject to thermal injection. Neft' $i$ Gaz 3: 37-41.

Carslaw, H. S., and J. C. Jaeger. 1959. Conduction of Heat in Solids, 2nd edition. Clarendon Press.

Corey, A. T. 1954. The interrelation between gas and oil relative permeabilities. Producers Monthly 19: 38-41.

Engesgaard, P. 1991. Geochemical modelling of contaminant transport in groundwater. Ph.D. thesis, Technical University of Denmark.

Gangi, A. F. 1978. Variation of whole and fractured porous rock permeability with confining pressure. International Journal of Rock Mechanics and Mining Sciences and Geomechanics Abstracts 15: 249-157.

Hinton, E., and D. R. J. Owen. 1979. An Introduction to Finite Element Computations. Swansea, Wales: Pineridge Press.

Harr, L., J. Gallagher, and G. S. Kell. 1984. NBS/NRC Steam Tables, Thermodynamics, and Transport Properties and Computer Programs for Vapor and Liquid States of Water. Washington: Hemisphere Publishing Corporation.

Ho, C.K. 1995a. Assessing alternative conceptual models of fracture flow. In TOUGH Workshop '95, Lawrence Berkeley Laboratory, Berkeley, CA, March 20-22. Lawrence Berkeley National Laboratory report.

Ho, C.K. 1995b. Personal communication regarding Sandia Report in preparation.

Klavetter, E. A., and R. R. Peters. 1986. Estimation of hydrologic properties of an unsaturated fractured rock mass. Sandia National Laboratories report SAND84-2642.

Matthews, C. S., and D. G. Russell. 1967. Pressure Buildup and Flow Tests in Wells, pp. 10-11. Society of Petroleum Engineers of AIME.

Moench, A. F. 1984. Double-porosity models for a fissured groundwater reservoir with fracture skin. Water Resources Research 20: 831-846.

Molloy, M. W. 1980. Geothermal reservoir engineering code-comparison project. In Sixth Workshop on Geothermal Reservoir Engineering. Stanford University.

Polzer, W. L., M. G. Rao, H. R. Fuentes, and R. J. Beckman. 1992. Thermodynamically derived relationships between the modified Langmuir isotherm and experimental parameters. Environmental Science and Technology 26: 1780-1786.

Pritchett, J. W. 1980. The DOE code-comparison study: Summary of results for Problem 5. In Sixth Workshop on Geothermal Reservoir Engineering, Stanford, California. Stanford University. 
Pruess, K. 1991. TOUGH2: A general purpose numerical simulator for multiphase fluid and heat flow. Lawrence Berkeley National Laboratory report LBL-29400.

Ramey, H. J. 1962. Wellbore heat transmission. Journal of Petroleum Technology 14: 427-435 (April).

Robinson, B. 1993. The SORBEQ application. Los Alamos National Laboratory documents SORBEQ SRS, SORBEQ MMS, SORBEQ VVP, SORBEQ VVR, and ECD-20.

Shan, C., R. W. Falta, and I. Javandel. 1992. Analytical solutions of steady-state gas flow to a soil vapor extraction well in the unsaturated zone. Water Resources Research 28(4): 1105-1120.

Tang, D. H., E. O. Frind, and E. A. Sudicky. 1981. Contaminant transport in fractured porous media: Analytical solution for a single fracture. Water Resources Research 17(3): $555-564$.

Theis, C. V. 1935. The relation between the lowering of the piezometric surface and the rate and duration of the discharge of a well using groundwater storage. Eos:

Transactions, American Geophysical Union 16: 519-524.

Thomas, L. K., and R. G. Pierson. 1978. Three-dimensional reservoir simulation. Society of Petroleum Engineers Journal 18: 151-161.

Toronyi, R. M., and S. M. Farouq Ali. 1977. Two-phase two-dimensional simulation of a geothermal reservoir and wellbore system. Society of Petroleum Engineers Journal 17: 171-183.

Travis, B. J., and K. H. Birdsell. 1988. TRACRN 1.0: A model of flow and transport in porous media for the Yucca Mountain Project: Model description and users manual. Los Alamos National Laboratory report LA-UR-88-3986 (November).

Valocchi, A. J., and D.E. Pastor. 1994. PDREACT, version 1.1, description and user's guide. Department of Chemical Engineering, University of Illinois, draft report (May). van Genuchten, M. T. 1980. A closed-form equation for predicting hydraulic conductivity of unsaturated soils. Soil Science Society of America Journal 44: 892-898.

Walsh, M. P., S. L. Bryant, R. S. Schechter, and L. W. Lake. 1984. Precipitation and dissolution of solids attending flow through porous media. American Institute of Chemical Engineers Journal 30: 317-328.

Warren, J. E., and P. J. Root. 1963. The behavior of naturally fractured reservoirs. Society of Petroleum Engineers Journal 3: 245-255.

Wilson, M. L., editor. 1994. Total system performance assessment for Yucca Mountain: SNL second iteration (TSPA-1993). Sandia National Laboratories report SAND93-2675.

Zienkiewicz, O. C. 1977. The Finite Element Method. London: McGraw-Hill.

Zyvoloski, G. A., and Z. V. Dash. 1991a. Software verification and validation plan: FEHMN version 1.0. Los Alamos National Laboratory report LA-UR-91-610.

Zyvoloski, G. A., and Z. V. Dash. 1991b. Software verification report: FEHMN version 1.0. Los Alamos National Laboratory report LA-UR-91-609.

Zyvoloski, G. A., and B. A. Robinson. 1995. Models and methods summary for the GZSOLVE application. Los Alamos National Laboratory software document ECD-97. 
Zyvoloski, G. A., Z. V. Dash, and S. Kelkar. 1988. FEHM: Finite-element heat- and mass-transfer code. Los Alamos National Laboratory report LA-11224-MS.

Zyvoloski, G. A., Z. V. Dash, and S. Kelkar. 1992. FEHMN 1.0: Finite-element heatand mass-transfer code. Los Alamos National Laboratory report LA-12062-MS, Rev. 1.

Zyvoloski, G. A., B. A. Robinson, Z. V. Dash, and L. L. Trease. 1997a. Summary of models and methods for the FEHM application-a finite-element mass- and heattransfer code. Los Alamos National Laboratory report LA-13307-MS (May).

Zyvoloski, G. A., B. A. Robinson, Z. V. Dash, and L. L. Trease. 1997b. User's Manual for the FEHM application-a finite-element mass- and heat-transfer code. Los Alamos National Laboratory report LA-13306-M (May). 
Chapter I:

Software Requirements Specification 


\subsection{INTRODUCTION}

\subsection{Purpose}

This chapter, "Software Requirements Specification," documents the functional and performance requirements for the FEHM application. It shall be used in designing and implementing the requirements for the application and shall be employed in subsequent baselines to verify that the application has fully implemented these requirements.

\subsection{Scope}

The FEHM application is based on a finite-element heat- and mass-transfer code that simulates nonisothermal, multiphase, multicomponent flow, and solute transport in porous media. It is applicable to natural-state studies of geothermal systems and groundwater flow. The FEHM code will be used for parameter sensitivity studies in the design and specification of field tracer and flow experiments and the interpretation of those field experiments. In addition, it will be used for field-scale simulations of radionuclide migration in the saturated and unsaturated zones below Yucca Mountain.

\subsection{GENERAL DESCRIPTION}

\subsection{Software Perspective}

FEHMN is a version of FEHM (Zyvoloski et al. 1988) that was developed for the C-wells project in the mid 1980s when LANL was analyzing the early well test data of the USGS. Most of the development of FEHM was done while one of the authors (Zyvoloski) was a participant of the Los Alamos Hot Dry Rock Project.

FEHM and FEHMN are aliases that represent the same computer code, and henceforth, the code will be referenced by the simpler acronym, FEHM.

\subsection{Software Functions}

The major software functions of FEHM are

- calculate finite-element coefficients for a mesh that represents the porous and permeable medium;

- formulate the transient equations for heat conduction, heat and mass transfer for multiphase flow within porous and permeable media, noncondensible gas flow within porous and permeable media, and transport of multiple solutes within porous and permeable media;

- apply constitutive relationships for pressure- and temperature-dependent fluid properties, air/gas properties, relative permeabilities and capillary pressures, reactive and sorbing solutes, dual porosity, double porosity/double permeability, and stress-dependent properties;

- compute the finite-element solution to the transient equations;

- represent the simulation input and output results in a suite of data files; 
- perform a restart calculation in which the progress of the flow field is simulated starting at the time and conditions at which a previous run terminated.

\subsection{User Characteristics}

The user should have experience in reservoir engineering, hydrology, or porous media flow. The user should also have experience with numerical simulations.

\subsection{General Constraints}

Problem size and limits are dictated by the capabilities of the computer on which the simulation is run. The code shall be able to handle extreme property changes (e.g., large changes in permeability between adjacent strata or highly nonlinear characteristic curves) and systems containing both saturated and unsaturated regions. Provided that the user supplies physically meaningful parameter values, does not violate model assumptions, and runs problems of the type presented in the verification report, results should be reliable.

\subsection{Assumptions and Dependencies}

FEHM will be written in Fortran 77. It will be developed to run on CRAY and SUN computers. (FEHM has been successfully run on CRAY, SUN, VAX, HP (Unix-based) and IBM RISC computers.) FEHM requires 64-bit precision.

\subsection{FUNCTIONAL REQUIREMENTS}

Each section below in this chapter deals with a major function enumerated in Section 2.2 above. After a user formulates a problem to be modeled, a mesh representing the physical media would be generated. Data describing the finite-element mesh would be input (Section 3.5) and the element coefficients computed (Section 3.1). Data describing the physical properties of the media and the fluid/gas system to be modeled would be input (Section 3.5). The appropriate finite-element equations would be formulated (Section 3.2) and constitutive relationships applied (Section 3.3). The solution would then be computed (Section 3.4) and results and restart data output (Sections 3.5 and 3.6).

\subsection{Finite-Element Coefficient Generation}

\subsubsection{Introduction}

The application shall include routines for the generation of finite-element coefficients. These coefficients represent the purely geometric part of the numerical analog of the partial differential equations that describe the coupled flow processes in porous media. These coefficients include the volume associated with each grid point as well as an area/distance term for all internode pairs. In standard finite-element terminology, this process results in the geometric components of the stiffness matrix.

\subsubsection{Inputs}

The following data are required to generate the finite-element coefficients:

- the problem dimension ( 2 or 3 dimensions) and geometry;

- the number of nodes and elements used to define the solution space; 
- the node number and $x-, y^{-}$, and $z$-coordinates of each node in the finiteelement mesh;

- the number of nodes per element (3-noded triangles or 4-noded quadrilaterals for 2-D problems and 4-noded tetrahedrals, 6-noded triangular prisms, or 8-noded quadrilateral polyhedrons for 3-D problems); and

- the element number and nodal connectivity (which nodes define the element) for each element using a right-handed coordinate system.

\subsubsection{Processing}

The calculation of the finite-element coefficients is accomplished by using the coordinate and element data (type and node list) to develop the connectivity of the node points and volumes and areas associated with the node points. These calculations are first done on an element level and then combined on a node level.

\subsubsection{Outputs}

Data structures containing the finite-element coefficients for the input mesh shall be output. The volume of each grid point is contained in an array indexed by node number. The area/distance terms are in arrays indexed by the connectivity structure of the grid. This structure is the same as that containing the neighboring nodes of the grid points.

\subsection{Formulate Transient Equations}

The transient equations shall be formulated, and the system of equations derived from the finite-element representation of the overall mathematical model shall be solved.

\subsubsection{Heat-conduction equations}

\subsubsection{Introduction}

FEHM shall be capable of simulating the conduction of heat without the flow of any fluids. The basic governing equation is

$$
-\bar{\nabla} \cdot(K \bar{\nabla} T)+q+\frac{\partial A_{e}}{\partial t}=0
$$

where $K$ is an effective thermal conductivity, $T$ is the temperature, $A_{e}$ is the energy per unit volume, and $q$ is the specified energy source term.

\subsubsection{Inputs}

All property and parameter values implied by Eqn. (1) are required as inputs: density, enthalpy, specific heat, thermal conductivity, initial temperatures, boundary values, coordinates of the computational mesh points, and element definitions. 


\subsubsection{Processing}

The time derivatives in Eqn. (1) shall be discretized using the standard first-order method (Hinton and Owen 1979) given by

$$
f\left(t^{n+1}\right)=f\left(t^{n}\right)+\Delta t\left[a f^{\prime}\left(t^{n+1}\right)+(1-a) f^{\prime}\left(t^{n}\right)\right]
$$

where $f\left(t^{n+1}\right)$ is the desired function at time $t^{n+1}, f\left(t^{n}\right)$ is the known value of $f$ at time $t^{n}, \Delta t$ is the time step, $f^{\prime}$ is the derivative of $f$ with respect to time, and $a$ is a weighting factor. The space derivatives in the governing equation shall be discretized using the finite-element formulation (Hinton and Owen 1979). Using numerical integration, the shape-function coefficients for the discretized equations shall be generated at each node.

\subsubsection{Outputs}

The outputs shall be the equation coefficients for the finiteelement formulation of the governing equation (Eqn. (1)) at each node.

\subsubsection{Heat- and mass-transfer equations}

\subsubsection{Introduction}

FEHM shall also be capable of simulating the transport of heat and mass within porous and permeable media. The conservation equations for heat and mass transfer are

$$
\begin{gathered}
-\bar{\nabla} \cdot\left(D_{m v} \bar{\nabla} P_{v}\right)-\bar{\nabla} \cdot\left(D_{m l} \bar{\nabla} P_{l}\right)+q_{m}+ \\
\frac{\partial}{\partial z} g\left(D_{m v} \rho_{v}+D_{m l} \rho_{l}\right)+\frac{\partial A_{m}}{\partial t}=0
\end{gathered}
$$

and

$$
\begin{gathered}
-\bar{\nabla} \cdot\left(D_{e v} \bar{\nabla} P_{v}\right)-\bar{\nabla} \cdot\left(D_{e l} \bar{\nabla} P_{l}\right)-\bar{\nabla} \cdot(K \bar{\nabla} T)+ \\
q_{e}+\frac{\partial}{\partial z} g\left(D_{e v} \rho_{v}+D_{e l} \rho_{l}\right)+\frac{\partial A_{e}}{\partial t}=0,
\end{gathered}
$$

where $D$ is the transmissibility, $K$ is an effective thermal conductivity, $P$ is the pressure, $T$ is the temperature, $A_{m}$ is the mass per unit volume, $A_{e}$ is the energy per unit volume, $q$ represents the source and sink terms (such as bores, reinjection wells, or groundwater recharge), $\rho$ is the density, $z$ is oriented in the direction of gravity, and $g$ represents the acceleration due to gravity. Here, also, the subscripts $v$ and $l$ indicate quantities 
for the vapor phase and the liquid phase, respectively, and the subscripts $m$ and $e$ refer to mass and energy, respectively.

\subsubsection{Inputs}

The inputs required are all property and parameter values implied by Eqns. (3) and (4): permeabilities, porosities, viscosities, densities, internal energies, specific heats, enthalpies, thermal conductivities, initial pressures, initial temperatures, initial saturations, boundary values, coordinates of the computational mesh points, and element definitions.

\subsubsection{Processing}

The time derivatives in Eqns. (3) and (4) shall be discretized using Eqn. (2). The space derivatives in the governing equations shall be discretized using the finite-element formulation (Hinton and Owen 1979). Using numerical integration, the shape-function coefficients for the discretized equations shall be generated at each node.

\subsubsection{Outputs}

The outputs shall be the equation coefficients for the finiteelement formulation of the governing equations (Eqns. (3) and (4)) at each node.

\subsubsection{Noncondensible gas flow equations}

\subsubsection{Introduction}

In addition to the flow of heat and mass, FEHM shall also be capable of simulating noncondensible gas flow (usually air). The noncondensible gas conservation equation is given by

$$
\begin{gathered}
-\bar{\nabla} \cdot\left(C_{v} D_{m \nu} \bar{\nabla} P_{\nu}\right)-\bar{\nabla} \cdot\left(C_{l} D_{m l} \bar{\nabla} P_{l}\right)+q_{c}+ \\
\frac{\partial}{\partial z} g\left(C_{v} D_{m \nu} \rho_{v}+C_{l} D_{m l} \rho_{l}\right)+\frac{\partial A_{c}}{\partial t}=0 .
\end{gathered}
$$

Here, $C$ is the concentration of the noncondensible gas, expressed as a fraction of total mass, $q_{c}$ is the source (or sink) strength, and $A_{c}$ is the accumulation term.

\subsubsection{Inputs}

The inputs required are all property and parameter values implied by Eqn. (5): gas concentrations, permeabilities, porosities, viscosities, densities, initial pressures and saturations, boundary values, coordinates of the computational mesh points, and element definitions. 


\subsubsection{Processing}

The time derivatives in Eqn. (5) shall be discretized using

Eqn. (2). The space derivatives in the governing equation shall be discretized using the finite-element formulation (Hinton and Owen 1979). Using numerical integration, the shape-function coefficients for the discretized equations shall be generated at each node.

\subsubsection{Outputs}

The outputs will be the equation coefficients for the finiteelement formulation of the governing equation (Eqn. (5)) at each node.

\subsubsection{Solute-transport equations}

\subsubsection{Introduction}

FEHM shall also be capable of simulating solute transport and shall allow for simultaneous solution of multiple, interacting solutes. The passive solute equations are not directly coupled to the pressure field but use the pressure field obtained by the heat- and mass-transfer solution. The transport equation for a given component is given by

$$
\begin{gathered}
-\bar{\nabla} \cdot\left(C_{v} D_{m v} \bar{\nabla} P_{v}\right)-\bar{\nabla} \cdot\left(C_{l} D_{m l} \bar{\nabla} P_{l}\right)-\bar{\nabla} \cdot\left(D_{c} \bar{\nabla} C_{l}\right)+ \\
q_{c}+\frac{\partial}{\partial z} g\left(C_{v} D_{m v} \rho_{v}+C_{l} D_{m l} \rho_{l}\right)+\rho_{r} \frac{\partial C_{R}}{\partial t}+\frac{\partial A_{c}}{\partial t}=0
\end{gathered}
$$

Here, $C$ is the concentration of the solute. The additional terms from those in Eqn. (5) are $\bar{\nabla} \cdot\left(D_{c} \bar{\nabla} C_{l}\right)$, the dispersion term, and $\rho_{r} \frac{\partial C_{R}}{\partial t}$, the adsorption term. $C_{R}$ represents the adsorption of species onto the porous media. In addition, the term $q_{c}$ includes the source or sink due to chemical reaction. The formulation for multiple interacting species used to compute this term is outlined in Section 3.3.6.

\subsubsection{Inputs}

The required inputs are all property and parameter values implied by Eqn. (6): solute concentrations, permeabilities, porosities, viscosities, densities, initial pressures and saturations, boundary values, coordinates of the computational mesh points, and element definitions.

\subsubsection{Processing}

The time derivatives in Eqn. (6) shall be discretized using Eqn. (2). The space derivatives in the governing equation shall 
be discretized using the finite-element formulation (Hinton and Owen 1979). Using numerical integration, the shape-function coefficients for the discretized equations shall be generated at each node.

\subsubsection{Outputs}

The outputs shall be the equation coefficients for the finiteelement formulation of the governing equation (Eqn. (6)) at each node.

\subsubsection{Particle-tracking module}

\subsubsection{Introduction}

FEHM shall be capable of simulating solute transport in either the liquid or gas phases using a cell-based particle-tracking algorithm. The algorithm shall be developed to handle either steady-state or transient flow fields for either an equivalent continuum or dual-permeability flow field. The algorithm shall include the following transport submodels:

- dispersion, to be simulated by applying a correction to the time of a particle in a cell based on a transfer function described by a solution to the one-dimensional advectivedispersion equation;

- sorption, using an equilibrium, linear sorption or " $K_{d}$ " model;

- matrix diffusion with sorption on either the fracture faces or the matrix rock, implemented using the transfer-function approach similar to the method described above for dispersion, with a one-dimensional matrix-diffusion submodel; and

- radioactive decay.

\subsubsection{Inputs}

The required inputs shall be:

- internode mass fluxes and the fluid storage at each node;

- the injection history for particles; and

- transport parameters for the solute, including sorption coefficients, radioactive decay constants, dispersion coefficients, and diffusion coefficients.

\subsubsection{Processing}

Using the inputs listed above, the code shall track the progress of particles from node to node subject to the transport processes of diffusion, dispersion, and sorption. At specified times, the code shall supply the particle concentrations at each node, and at the final time of the simulation, the code shall output the information on each particle such that a restart of the calculation can be performed. 


\subsubsection{Outputs}

The outputs shall be the time-varying locations and concentrations of particles.

\subsubsection{Sources and sinks}

\subsubsection{Introduction}

The following types of sources and sinks shall be implemented:

- specified flow rate;

- specified pressure condition;

- specified heat flux;

- specified temperature;

- specified flux and saturation;

- specified water flux and air pressure;

- specified air flux (no water flow);

- specified water flux (no air flow);

- specified relative humidity of the gas phase; and

- specified air pressure and saturation.

\subsubsection{Inputs}

For each source/sink (depending on source/sink type), the required inputs are

- source/sink location;

- source/sink strength;

- flowing pressure;

- enthalpy or temperature of the fluid injected;

- species concentration in the fluid injected;

- impedance;

- thermal resistance;

- saturation;

- relative humidity; and

- air pressure.

\subsubsection{Processing}

Processing shall consist of determine the pressure, mass flow rate, heat flow, species concentration, saturation, or air flux at each source/sink.

\subsubsection{Outputs}

The outputs shall be pressure, mass flow rate, heat flow, species concentration, saturation, or air flow at each source/sink. 


\subsection{Apply Constitutive Relationships}

The following constitutive relations shall be available.

\subsubsection{Pressure- and temperature-dependent water properties}

\subsubsection{Introduction}

In the governing equations described above (Eqns. (1), (3), (4), (5), and (6)), physical properties such as the density, enthalpy, and viscosity can be strong functions of pressure $(P)$ and temperature $(T)$ making the governing equations very nonlinear. Rational-function approximations (Zyvoloski and Dash 1991b) shall be used to estimate the thermodynamic variables in FEHM over the ranges $0.001 \leq P \leq 110.0 \mathrm{MPa}$ and $0.001 \leq T \leq 360^{\circ} \mathrm{C}$ : In addition, a second set of rational-function approximations shall be provided for low pressures to give better estimates of the thermodynamic variables over the ranges $0.001 \leq P \leq 20.0$ $\mathrm{MPa}$ and $0.5 \leq T \leq 360^{\circ} \mathrm{C}$.

\subsubsection{Inputs}

The required inputs shall be pressure and temperature at each node at each time step.

\subsubsection{Processing}

The processing shall compute the water properties and their derivatives, using the rational-function approximations, as a function of pressure and temperature at each node at each time step.

\subsubsection{Outputs}

The outputs shall be water density, enthalpy, and viscosity (and their derivatives) at each node at each time step.

\subsubsection{Properties of air and air/water vapor mixtures}

\subsubsection{Introduction}

The flow of air and air/water vapor mixtures in the porous media shall also be modeled. Appropriate thermodynamic information (density, enthalpy, viscosity, mass fractions) for air and air/water vapor mixtures shall be provided.

\subsubsection{Inputs}

The required inputs will be pressure, temperature, and air/ vapor/liquid mass fractions at each node at each time step.

\subsubsection{Processing}

The processing will compute the air and mixture properties at each node at each time step. 


\subsubsection{Outputs}

The outputs shall be air and mixture properties (densities, enthalpies, and viscosities) at each node at each time step.

\subsubsection{Equation-of-state models}

\subsubsection{Introduction}

The ability to use liquids other than water and to use gases other than air in the porous media model shall be provided. The use of equation-of-state models with user-defined parameters allows the introduction of alternate fluids, ideal gases, etc. The models can also be used to provide simplified state relations for water and air.

\subsubsection{Inputs}

The required inputs shall be liquid and vapor reference pressure, temperature, density, enthalpy, and viscosity and their derivatives with respect to temperature and pressure at the reference conditions.

\subsubsection{Processing}

The processing shall compute the fluid properties based on equation-of-state data at each node at each time step.

\subsubsection{Outputs}

The outputs shall be fluid properties (densities, enthalpies, and viscosities) at each node at each time step.

\subsubsection{Relative-permeability and capillary-pressure functions}

\subsubsection{Introduction}

Relative permeabilities and capillary pressures can be strong functions of saturation. Several well-known relativepermeability functions shall be made available to the user. These functions are the simple linear functions, the Corey (1954) relationships, and the van Genuchten (1980) functions. Composite relative-permeability curves, as described by Klavetter and Peters (1986), shall also be a user option. The capillary functions considered are the linear function and the van Genuchten (1980) capillary-pressure model.

\subsubsection{Inputs}

The required inputs are saturations, pressures, and model parameters implied by the constitutive model to be used.

\subsubsection{Processing}

The processing shall compute relative permeabilities and capillary pressures based on the selected constitutive model. 


\subsubsection{Outputs}

The outputs shall be relative permeabilities and capillary pressures at each node.

\subsubsection{Adsorbing solutes}

\subsubsection{Introduction}

FEHM shall have provisions for adsorbing solutes. The general equilibrium model for adsorption of species onto the reservoir rock is given by (Polzer et al. 1992):

$$
C_{R}=\frac{\alpha_{1} C_{l}^{\beta}}{1+\alpha_{2} C_{l}^{\beta}}
$$

The parameters $\alpha_{1}, \alpha_{2}$, and $\beta$ are associated with the sorption models.

\subsubsection{Inputs}

The required inputs shall be all property and parameter values implied by Eqn. (7): concentrations and sorption parameters.

\subsubsection{Processing}

The processing will compute adsorption based on the appropriate model and compute the modified coefficients of the tracer transport equation that account for adsorption reactions.

\subsubsection{Outputs}

The outputs shall be equation coefficients for the finite-element formulation of the tracer transport equations at each node modified to account for adsorption reactions.

\subsubsection{Multiple, interacting solutes}

\subsubsection{Introduction}

FEHM shall have provisions for multiple, interacting solutes in which chemical reactions involving one or more components are specified. Any number of reactions may be specified with the following form:

$$
\begin{aligned}
& a_{1} S_{1}+a_{2} S_{2}+\ldots+a_{m} S_{m}= \\
& \quad a_{m+1} S_{m+1}+a_{m+2} S_{m+2}+\ldots+a_{n} S_{n},
\end{aligned}
$$

where the $a$ 's are the stoichiometric coefficients and the $S$ 's denote each solute present in a particular reaction. This relationship is formulated for each reaction being modeled, and 
a solute may be present in any number of reactions as either a reactant or a product.

The rate law governing each reversible reaction shall be specified as follows:

$$
\frac{\partial}{\partial t}\left[S_{j}\right]= \pm a_{j}\left\{k_{f o r} \prod_{i=1}^{m}\left[S_{i}\right]^{b(i)}-k_{r e v} \prod_{i=m+1}^{n}\left[S_{i}\right]^{b(i)}\right\}
$$

where the square brackets [ ] denote concentration, the $b(i)$ are exponents in the reaction rate equation (specified for every reactant in each reaction), and the forward and reverse reaction rate constants, $k_{\text {for }}$ and $k_{\text {rev }}$, are governed by the Arrhenius equation. An option shall be provided to allow or disallow chemical reaction for solute residing on the rock for the case of a sorbing component. Finally, an input option shall be developed so that the user may specify an equilibrium constant for the chemical reaction with the code generating the rate constants $k_{\text {for }}$ and $k_{r e v}$ such that equilibrium is attained at each time step.

\subsubsection{Inputs}

The required inputs are all property and parameter values implied by Eqns. (8) and (9): concentrations and chemicalreaction model parameters.

\subsubsection{Processing}

The processing shall compute the chemical-reaction source/sink term for each solute.

\subsubsection{Outputs}

The outputs shall be equation coefficients for the finite-element formulation of the tracer transport equations at each node modified to account for chemical reactions.

\subsubsection{Dual-porosity formulation}

\subsubsection{Introduction}

Many porous-medium problems are dominated by fracture flow. In these cases, the fracture permeability controls the pressure communication in the reservoir even though local storage around the fracture may be dominated by the porous rock, which communicates only with the closest fractures.

Computationally, a volume fraction and length scale shall be used to create one-dimensional versions of Eqns. (3), (4), (5), and (6). The length scale shall be used to modify spatial difference terms, and the volume factors shall be used to modify the 
accumulation terms. The volume fractions for the dual-porosity formulation shall satisfy the following relationship:

$$
V_{f}+V_{f 1}+V_{f 2}=1
$$

where $V_{f}$ is the volume fraction of fractures, $V_{f 1}$ is the fraction of the first matrix volume, and $V_{f 2}$ is the fraction of the second matrix volume. Note that two nodes shall be used to model the porous rock (matrix). The length scales shall be given by

$$
\begin{aligned}
L_{f} & =L_{f 0} V_{f} \\
L_{f 1} & =L_{f 0} V_{f 1}, \\
L_{f 2} & =L_{f 0} V_{f 2}
\end{aligned}
$$

where $L_{f}$ is the length scale for the fracture volume, $L_{f 1}$ is the length scale of the first matrix volume, $L_{f 2}$ is the length scale of the second matrix volume, and $L_{f 0}$ is a characteristic length scale.

\subsubsection{Inputs}

The required inputs shall be:

- volume fraction of the fracture $\left(V_{f}\right)$ and matrix volumes $\left(V_{f 1}, V_{f 2}\right)$ and

- characteristic length scale for fracture spacing $\left(L_{f 0}\right)$.

\subsubsection{Processing}

The processing shall modify the equation coefficients (from the finite-element formulation of Eqns. (3), (4), (5), and (6)) at each node using the volume fractions and length scales.

\subsubsection{Outputs}

The outputs shall be the modified equation coefficients at each dual-porosity node.

\subsubsection{Double-porosity/double-permeability formulation}

\subsubsection{Introduction}

In a partially saturated porous medium, flow is often dominated by capillary suction. In a medium comprised of fractures and matrix, the matrix material has the highest capillary suction, and under relatively static conditions, the moisture resides in the matrix material. Infiltration events, such as severe rainfall, can saturate the porous medium allowing rapid flow in the fractures. To capture this flow phenomena, a system of equations allowing communication between the fractures and 
matrix blocks in the reservoir, in addition to the flow within the fractures and matrix blocks, is necessary.

A volume fraction and length scale (different from the dualporosity formulation) shall be used to characterize the system. Equations (3), (4), (5), and (6) are formulated for both the fracture and matrix computational grids. One-dimensional versions are created to couple locally the two sets of equations. As in the dual-porosity formulation, matrix material communicates only with the local fractures.

The volume fractions for the double-porosity/double-permeability formulation shall satisfy the following relationship:

$$
V_{f}+V_{f 1}=1
$$

where $V_{f}$ is the volume fraction of fractures and $V_{f 1}$ is the fraction of the matrix volume. The length scales shall be partitioned for the fracture and matrix volumes using

$$
\begin{aligned}
L_{f} & =L_{f 0} V_{f} \\
L_{f 1} & =L_{f 0} V_{f 1}
\end{aligned}
$$

where $L_{f}$ is the length scale for the fracture volume, $L_{f 1}$ is the length scale of the matrix volume, and $L_{f 0}$ is a characteristic length scale.

\subsubsection{Inputs}

The required inputs shall be:

- volume fraction of the fracture $\left(V_{f}\right)$ and

- characteristic length scale for fracture spacing $\left(L_{f 0}\right)$.

\subsubsection{Processing}

The processing shall modify the equation coefficients (from the finite-element formulation of Eqns. (3), (4), (5), and (6)) at each node using the volume fractions and length scales.

\subsubsection{Outputs}

The outputs shall be the modified equation coefficients at each double-porosity/double-permeability node.

\subsubsection{Stress-dependent properties}

\subsubsection{Introduction}

Often, it is necessary to accommodate changes in the rock porosity and permeability due to changes in effective stress caused by temperature and pore-fluid pressure changes. A 
linear and nonlinear model shall be incorporated in the code for this purpose.

The linear pore-pressure model for porosity is given by

$$
\phi=\phi_{0}+\left(1-\phi_{0}\right)\left(c_{r}-c_{g}\right)\left(P-P_{0}\right) \text {, }
$$

where $\phi$ is the porosity at pressure $P, \phi_{0}$ is the porosity at pressure $P_{0}, c_{r}$ is the pore volume compressibility of the rock, and $c_{g}$ is the compressibility of the matrix grain material.

The nonlinear model for porosity (Gangi 1978) is given by

$$
\phi=\phi_{0}\left[1-\left(\frac{P_{c}}{P_{x}}\right)^{m}\right]
$$

and

$$
P_{c}=\sigma-P-\alpha E \Delta T,
$$

where $P_{c}$ is the closure stress, $\sigma$ is the in situ stress (assumed isotropic), $\alpha$ is the coefficient of thermal expansion of the rock, $E$ is Young's modulus, $\Delta T$ is the temperature change of the rock, and $P_{x}$ and $m$ are parameters in the model.

For either case, the effect of stress and temperature changes on permeability shall be modeled with

$$
k=k_{0}\left(\frac{\phi}{\phi_{0}}\right)^{3}
$$

where $k$ is the permeability at porosity $\phi$.

\subsubsection{Inputs}

The required inputs shall be the parameters of the appropriate pressure- and temperature-dependent matrix-properties model: pressure, porosity, compressibility, closure stress, in situ stress, coefficient of thermal expansion of the rock, Young's modulus, temperature change of the rock, and permeability.

\subsubsection{Processing}

The processing shall compute the fracture and matrix property values using the appropriate pressure- and temperaturedependent matrix-properties model at each node for porousmedia, dual-porosity, or double-porosity/double-permeability formulations. 


\subsubsection{Outputs}

The outputs shall be the porosity and permeability of each matrix cell.

\subsubsection{Variable thermal conductivity}

\subsubsection{Introduction}

The thermal conductivity of the solid is often more accurately characterized as a function of temperature or liquid saturation. A linear temperature-dependent model and a relation based upon the square root of liquid saturation shall be incorporated in the code for this reason.

The linear temperature-dependent model is given by

$$
K_{T}=K_{r e f}+K_{s}\left(T-T_{r e f}\right)
$$

where $K_{T}$ is the temperature-dependent thermal conductivity, $K_{r e f}$ is the thermal conductivity at the reference temperature $T_{r e f}$, and $K_{s}$ is the slope of the linear relation.

The saturation-dependent thermal-conductivity model is given by

$$
K_{s a t}=K_{d r y}+K_{s, s} \sqrt{S}
$$

where $K_{\text {sat }}$ is the saturation-dependent thermal conductivity, $K_{d r y}$ is the conductivity at zero saturation, and $K_{s, s}$ is the slope of the linear relationship. Note that the conductivity at complete saturation is $K_{d r y}+K_{s, s}$.

\subsubsection{Inputs}

The required inputs shall be the parameters of the appropriate saturation or temperature-dependent thermal conductivity model: temperature, liquid saturation, and the parameters in the above equations.

\subsubsection{Processing}

The processing shall compute the thermal conductivity based on the above relations.

\subsubsection{Outputs}

The output shall be the rock thermal conductivity at each cell. 


\subsection{Compute Solution to Transient Equations}

\subsubsection{Implement time-step mechanism}

\subsubsection{Introduction}

Transient finite-element solutions proceed forward in time, computing the solution at each time step. A mechanism shall be implemented in which the user can control the initial size of the time step, the maximum allowable time step, and the rate of increase of the time step from one time to the next. This mechanism shall also allow the user to reinitialize the time step, if desired, during the simulation (e.g., a pressure at a source/sink changes dramatically and increased detail is desired or needed for convergence). The time-step mechanism shall also be developed so that the time step is automatically reduced if the solution at a time step does not converge within a specified number of iterations.

\subsubsection{Inputs}

The required inputs shall be:

- the initial time-step size;

- the minimum and maximum time-step values;

- the multiplication factor for increasing the size of the time step;

- a data structure specifying when to set the time step to a new value, what that value is, and what to use for a new multiplication factor;

- the maximum number of iterations to be taken within a time step before the time step is reduced; and

- the maximum number of iterations to be taken for the solution of the total problem.

\subsubsection{Processing}

The processing shall determine the new time step after convergence is achieved for the solution at the current time, and this time step will be added to the current time to obtain the new time. The time step shall not be increased above the maximum specified value. If convergence is not achieved, the time step will be reduced and the step repeated. The time step shall not be reduced below the minimum time-step value.

\subsubsection{Outputs}

The outputs shall be the new time step, the new time, and the number of iterations used to achieve convergence. If the time step has been reduced to the minimum time-step value and convergence is not achieved or the maximum number of 
iterations for the total problem has been reached and convergence is not achieved, an error message shall be issued and the program shall exit.

\subsubsection{Solve nonlinear equation set at each time step}

\subsubsection{Introduction}

In general, the result of the finite-element formulation (Zienkiewicz 1977) of the transient problem shall be a set of nonlinear algebraic equations with unknown values such as pressure, temperature, and concentration that shall be solved at each time step. The equations shall be solved with a NewtonRaphson iterative-solution scheme.

\subsubsection{Inputs}

The required inputs shall be:

- the residual equation for each unknown;

- the derivative of each residual with respect to each unknown; and

- the convergence criterion for solving the system of equations.

\subsubsection{Processing}

The processing shall iteratively determine the pressure/ temperature/concentration (solute or air) field by solving the nonlinear equation set using the Newton-Raphson technique until a solution is obtained to the desired degree of accuracy. At each iteration, the system of linear algebraic equations shall be solved using the GZSOLVE application (Zyvoloski and Robinson 1995).

For simulations involving solute transport, it shall be possible to disable the heat and mass portion of the solution and just solve the solute-transport equations.

\subsubsection{Outputs}

The outputs shall be the pressure/temperature/concentration field at the new time.

\subsection{Provide Input/Output Data Files}

\subsubsection{Introduction}

All input necessary to perform the finite-element simulation of the model shall be read from one or more input data files. The input data shall be organized in groups of related parameters. The information produced by the program shall be written to one or more output data files so that it may be read by programs using the data, such as plotting or data-analysis routines. 


\subsubsection{Inputs}

The required inputs shall be:

- the finite-element mesh data;

- the initial pressures, temperatures, saturations, and concentrations (solute or gas) within the model domain;

- rock property values within the model domain (conductivity, heat capacity, density);

- data used to set heat- and mass-source/sink strength or pressure;

- data used to set concentration (solute or gas) source strength;

- properties of the finite-element mesh representing the matrix (porosity, permeability);

- finite-element parameters used to control the accuracy of the solution, such as the initial and maximum time steps, the time-step multiplication factor, and convergence criterion; and

- model parameters for selected constitutive relations.

\subsubsection{Processing}

The processing shall read in all parameter values and generate the finiteelement solution to the model. It shall also write the solution to output data files.

\subsubsection{Outputs}

The outputs shall be:

- pressure, temperature, concentration, and flow field at selected intervals and final time;

- geometric information needed to view the pressure, temperature, concentration, or flow field (i.e., coordinate locations for all nodes); and

- time-varying values of the pressures, temperatures, concentrations, and flow rates of each source/sink or specified matrix location.

\subsection{Provide Restart Capability}

In large-scale transient simulations, it is often desirable to resume a computation starting at the final time of a previous run or to start with a previously established flow field. This procedure may be done to verify that the run is progressing as desired, to establish a steady-state flow field for a subsequent solute simulation, or to allow modification or inclusion of source/sink conditions starting at this time. The FEHM application shall provide this capability.

\subsubsection{Write information needed for restart to output file}

\subsubsection{Introduction}

All information needed to resume the computation at the final time of a simulation must first be written to an output file. 


\subsubsection{Inputs}

The data needed in a subsequent restart are

- final time of simulation and

- the pressures, temperatures, saturations, and concentrations (solute or noncondensible gas) at the final time step.

\subsubsection{Processing}

The processing shall write all needed data to the output restart file.

\subsubsection{Outputs}

The output shall be a restart file that can be subsequently read to restart a previous simulation or to start a new simulation with an established pressure, temperature, saturation, or concentration field.

\subsubsection{Read information needed for restart from restart file}

\subsubsection{Introduction}

The information needed to resume the simulation or start a new simulation with an existing pressure and temperature field shall be read in from the restart and primary input files.

\subsubsection{Inputs}

The required inputs are data needed in the restart, including all information written to the restart file in the previous simulation and new information such as source/sink flow rates or pressures for the restart found in the primary input files.

\subsubsection{Processing}

The processing shall read all data from the input files.

\subsubsection{Outputs}

The output shall be a data structure appropriate for resuming the computations, beginning at the final time and the conditions of the previous simulation.

\subsubsection{Resume the calculation}

\subsubsection{Introduction}

When all input information is read in, the calculation shall resume.

\subsubsection{Inputs}

The required inputs are all input parameter values from the restart and primary input files. 


\subsubsection{Processing}

The processing shall perform the calculations as it would in the case of a starting time of 0 with the following exceptions:

- set the start time based on the value from the restart file, rather than 0 ;

- set the pressure field based on values from the restart file, rather than from the initial pressures;

- set the temperature field based on values from the restart file, rather than from the initial temperatures;

- set the saturations based on values from the restart file; and

- set the concentrations (solute or noncondensible gas) based on values from the restart file.

\subsubsection{Outputs}

The outputs shall be the computational results of a simulation starting at the time and conditions reached at the end of the previous execution of the program.

\subsection{EXTERNAL INTERFACE REQUIREMENTS}

\subsection{User Interfaces}

The names of input and output data files used by the programs shall be input interactively at the terminal when the programs are executed or shall be provided in optional configuration data files. All other user interfaces with the programs comprising the FEHM application shall be in the form of ASCII or binary data files. The data files employed by the application are

- an optional configuration data file specifying the names of input and output data files used by each program of the application;

- one or more input data files containing the finite-element mesh information;

- one or more input data files that specify the control parameters, physical parameters, and the source/sink specifications for the model simulation;

- one or more output data files containing the results of the model simulation; and

- a restart data file that contains the information needed to resume a model computation at the termination time of a previous simulation (it becomes an input data file during the restart run).

\subsection{Hardware Interfaces}

N/A

\subsection{Software Interfaces}

\subsubsection{Linear equation solver}

In finite-element simulations, a set of residual equations is usually solved at each time step. When the equations are nonlinear, as in the FEHM 
application, the procedure normally employed is iterative, in which a set of linear algebraic equations is solved at each iteration until convergence of the nonlinear equations is achieved. In the FEHM application, the linear equation set at each iteration shall be solved with a reuse component, GZSOLVE, that provides a robust solution method for sparse systems of equations. The FEHM application shall supply the solver with the matrix equation set in a form suitable for the solver, and the solver shall return the solution vector for that iteration.

\subsection{Communications Interfaces}

N/A

\subsection{PERFORMANCE REQUIREMENTS}

N/A

\subsection{DESIGN CONSTRAINTS}

\subsection{Standards Compliance}

N/A

\subsection{Hardware Limitations}

N/A

\subsection{SECURITY}

N/A

\subsection{OTHER REQUIREMENTS}

\subsection{Data Base}

N/A

\subsection{Operations}

N/A

\subsection{VALIDATION CRITERIA}

Validation criteria shall be developed in Chapter III, "Verification and Validation Plan," of this report. 
Chapter II: Software Design 


\subsection{PURPOSE}

In this chapter, the FEHM software is described, including functional requirements, input/output files and their associated variables, and error and warning conditions with their associated messages.

\subsection{FUNCTIONAL DESCRIPTION}

After a user formulates a problem to be modeled, a mesh representing the physical media is generated. It should be noted that mesh generation is not a primary function of the FEHM application and auxilliary mesh-generation programs are generally used to obtain this input. Data describing the mesh and physical properties of the media and the fluid/gas system to be modeled are input. The appropriate finite-element equations are formulated and constitutive relationships applied. The solution is then computed, and results and restart data are output.

\subsection{ASSUMPTIONS AND LIMITATIONS}

The assumptions and limitations inherent in FEHM can be categorized as follows:

- The validity of the underlying partial differential equations used to describe the physics of the coupled processes of heat and mass flow in a porous media (see Zyvoloski et al. 1997a). This limitation includes the difficulty in obtaining appropriate input parameters to model given experimental and field data.

- The validity of the computer code used to solve the partial differential equations that describe the physics of flow. This assumption is described further in the last two chapters: "Verification and Validation Plan" and "Verification and Validation Report."

- The ability of the computer code to obtain the advertised performance. This limitation is both machine dependent and user dependent. FEHM is state of the art in both numerical performance and memory management. The numerical performance allows very large (100,000-node) 3-D problems to be run in a workstation environment. Thus, the numerical accuracy needed for typically fine-resolution problems such as contaminant transport can be realized. The memory management allows many jobs to be run on a single workstation and allows quick analysis of problem sensitivities. In our experience, the largest source of poor code performance, both in accuracy and CPU speed, is user error. FEHM is a complicated tool and requires a high level of user experience in simulation and groundwater applications. The FEHM "User's Manual" and other documents (Zyvoloski et al. 1997b) are updated regularly with major input from users.

\subsection{PRIMARY PRODUCT DESCRIPTIONS}

The FEHM application consists of one primary product, program fehm, which is used to formulate a transient problem that generates a set of nonlinear algebraic equations. The nonlinear equations are solved using the GZSOLVE application (Zyvoloski and Robinson 1995). 


\subsection{FEHM}

\subsubsection{Purpose}

See Section 1.0 of this chapter.

The functional requirements satisfied by the fehm program are summarized in Table 1, where the section numbers refer to the previous chapter, "Software Requirements Specification."

\begin{tabular}{|c|c|c|}
\hline Requirement & Section & Implemented by \\
\hline Finite-element coefficient generation & 3.1 & $\begin{array}{l}\text { anonp, area2d_tri, check_sx, determ, gencof, } \\
\text { gncf2, gncf3, mdnodes, pebi, pebi3, radius, } \\
\text { setzone, sfn2r, sfn3r, shap2r, shap3p, shap3r, } \\
\text { split, sx_combine, thickness }\end{array}$ \\
\hline Formulate transient equations & 3.2 & \\
\hline Heat-conduction equations & 3.2 .1 & bnswer, geneq3, gensi3 \\
\hline Heat- and mass-transfer equations & 3.2 .2 & $\begin{array}{l}\text { air_rdof, airctr, bnswer, co2ctr, dpdp3, dpdpfa, } \\
\text { dpdpfh, dualex, dualfa, dualfh, geneq1, geneq2, } \\
\text { geneqc, geneqmdnode, gensdp, gensdp3, gensi1, } \\
\text { gensl2, gensl4, interblock_iso, mod_eqs_ngas, } \\
\text { thermw, thrair, thrmwc, varchk, zeolites }\end{array}$ \\
\hline Noncondensible-gas flow equations & 3.2 .3 & $\begin{array}{l}\text { air_rdof, airctr, bnswer, co2ctr, dualfa, geneq2, } \\
\text { geneqc, geneqmdnode, gensdp, gens/2, gensi4, } \\
\text { interblock_iso, thrair, thrmwc, varchk }\end{array}$ \\
\hline Solute-transport equations & 3.2 .4 & $\begin{array}{l}\text { angle3, cnswer, concadiff, concen, coneq1, } \\
\text { coneq1mdnode, csolve, dpdpta, dualta, dualtx, } \\
\text { eullag3, gencon, gentdp, node_rxn, react, rotate, } \\
\text { solstore, thermc, varchk }\end{array}$ \\
\hline Particle-tracking module & 3.2 .5 & $\begin{array}{l}\text { cell_time, getconc, inptrk, inverf, part_track, } \\
\text { set_ptrk, time_diff, time_disp2, wrtptrk }\end{array}$ \\
\hline Sources and sinks & 3.2 .6 & $\begin{array}{l}\text { bcon, inflo2, inflow, inhflx, thermw, thermc, thrair, } \\
\text { thrmwc, zeolites }\end{array}$ \\
\hline Apply constitutive relationships & 3.3 & \\
\hline $\begin{array}{l}\text { Pressure- and temperature-dependent } \\
\text { water properties }\end{array}$ & 3.3.1 & $\begin{array}{l}\text { data, enthp, outbnd, psat, psatl, thermw, thrmwc, } \\
\text { thrair, varchk }\end{array}$ \\
\hline $\begin{array}{l}\text { Properties of air and air/water vapor } \\
\text { mixtures }\end{array}$ & 3.3 .2 & $\begin{array}{l}\text { air_cp, dvacalc, outbnd, psatl, thrair, thrmwc, } \\
\text { vaporl, varchk }\end{array}$ \\
\hline Equation-of-state models & 3.3.3 & coeffc, sther, varchk \\
\hline $\begin{array}{l}\text { Relative-permeability and capillary- } \\
\text { pressure functions }\end{array}$ & 3.3.4 & cappr, rlperm, vgcap, vgcap_fit, vgrlp \\
\hline Adsorbing solutes & 3.3 .5 & mult_rxn, rdcon, read_rxn, solstore, thermc \\
\hline Multiple, interacting solutes & 3.3.6 & $\begin{array}{l}\text { mult_rxn, node_rxn, react, read_rxn, rxn_product, } \\
\text { setup_rxn, thermc }\end{array}$ \\
\hline
\end{tabular}




\begin{tabular}{|c|c|c|}
\hline Requirement & Section & Implemented by \\
\hline Dual-porosity formulation & 3.3 .7 & dual, dualex, dualfa, dualfh, dualta, dualtx \\
\hline $\begin{array}{l}\text { Double-porosity/double-permeability } \\
\text { formulation }\end{array}$ & 3.3 .8 & $\begin{array}{l}\text { crdpdp, ctdpdp, dpdp, dpdp3, dpdpfa, dpdpfh, } \\
\text { dpdpta, indpdp, rddpdp }\end{array}$ \\
\hline Stress-dependent properties & 3.3 .9 & porosi, vfcal \\
\hline Variable thermal conductivity & 3.3.10 & vcon \\
\hline Compute solution to transient equations & 3.4 & \\
\hline Implement time-step mechanism & 3.4 .1 & $\begin{array}{l}\text { csolve, daycrl, fehmn, intime, resettrc, resetv, } \\
\text { timcrl }\end{array}$ \\
\hline $\begin{array}{l}\text { Solve nonlinear equation set at each time } \\
\text { step }\end{array}$ & 3.4 .2 & $\begin{array}{l}\text { bnswer, cnswer, gencon, gensdp, gensdp3, } \\
\text { gensl1, gensl2, gensi3, gens } 14 \text {, gentdp, } \\
\text { mod_eqs_ngas, normal, normal_dof, nrmlz4, } \\
\text { rd1dof, rdof_new, setord, solve, switch, switchb, } \\
\text { and GZSOLVE application (Zyvoloski and } \\
\text { Robinson 1995) }\end{array}$ \\
\hline Provide input/output data files & 3.5 & $\begin{array}{l}\text { avs_io, cntlin, cntlio, done_macro, file_prefix, } \\
\text { infiles, iofile, namefile2, setunits, start_macro, } \\
\text { termin, termio, writeio }\end{array}$ \\
\hline Inputs & 3.5 .2 & $\begin{array}{l}\text { airctr, co2ctr, concen, disk, diskc, diskp, dpdp, } \\
\text { dual, flxo, gendat, geoin, incond, incoord, inctrl, } \\
\text { inflo2, inflow, inhflx, initdata, inmentat, innode, } \\
\text { inpatran, inperm, inpres, inptrk, input, inrock, } \\
\text { intime, inzeol, mdnodes, porosi, rdcon, rddpdp, } \\
\text { rdthick, read_avs_io, read_rxn, read_sx, renum, } \\
\text { rlperm, scanin, setparams, sice, sther, storsx, } \\
\text { user, vcon, welbor, zone }\end{array}$ \\
\hline Outputs & 3.5 .4 & $\begin{array}{l}\text { avs_write_cord, avs_write_struc, contr, contrc, } \\
\text { contrj, datchk, diagnostics, disk, diskc, diskp, } \\
\text { elem_type, elem_type_binary, flxo, input, outbnd, } \\
\text { plot, plotc1, storsx, write_avs_node_con, } \\
\text { write_avs_node_mat, write_avs_node_s, } \\
\text { write_avs_node_v, write_avs_ucd_header, } \\
\text { write_binary_geo, write_binary_header, } \\
\text { write_binary_node_con, write_binary_node_mat, } \\
\text { write_binary_node_s, write_binary_node_v, } \\
\text { wrtcon, wrtout, wrtptrk, zone }\end{array}$ \\
\hline Provide restart capability & 3.6 & \\
\hline $\begin{array}{l}\text { Write information needed for a restart to } \\
\text { an output file }\end{array}$ & 3.6 .1 & disk, diskc, diskp, timcrl \\
\hline $\begin{array}{l}\text { Read information needed for a restart } \\
\text { from a restart file }\end{array}$ & 3.6 .2 & disk, diskc, diskp, startup \\
\hline Resume the calculation & 3.6 .3 & concen, fehmn, startup \\
\hline
\end{tabular}




\subsubsection{Functional description}

See Section 2.0 of this chapter.

A simplified flow chart illustrating the segmentation of the application is provided in the FEHM document "Summary of Models and Methods" (Zyvoloski et al 1997a). A summary listing of the subroutines and functions invoked by the fehm program is given in Appendix A of this report.

\subsubsection{Assumptions and limitations}

See Section 3.0 of this chapter.

\subsubsection{Input/output}

\subsubsection{Configuration interface table} N/A

\subsubsection{Other input data files}

4.1.4.2.1 Input control file. The input control file provides the fehm program with the names of input/output (I/O) files to be used by the program, the terminal output control flag, and the user subroutine number (Table 2). Names for the files, which may include subdirectories or paths, are entered one per line followed by the terminal output control flag and user subroutine number. A blank line may be entered for any item not required by the user. Variable $n m f i l(1)$ contains the name of the input control file. The default control file name is fehmn.files.

\begin{tabular}{|c|c|c|}
\hline \multicolumn{3}{|r|}{ Table 2. Input control file } \\
\hline Input variable & Format & Description \\
\hline$n m f i l(2)$ & character ${ }^{*} 100$ & Main input file name \\
\hline$n m f i l(3)$ & character ${ }^{*} 100$ & Geometry-data input file name \\
\hline$n m f i l(4)$ & character* 100 & Zone-data input file name \\
\hline$n m f i l(5)$ & character*100 & Main output file name \\
\hline$n$ mfil( 6) & character ${ }^{*} 100$ & Restart input file name \\
\hline$n m f i l(7)$ & character ${ }^{*} 100$ & Restart output file name \\
\hline$n$ mfil( (8) & character ${ }^{*} 100$ & Simulation-history output file name \\
\hline$n m f i l(9)$ & character ${ }^{*} 100$ & Solute-history output file name \\
\hline$n m f i l(10)$ & character ${ }^{*} 100$ & Contour-plot output file name \\
\hline$n m f i l(11)$ & character $* 100$ & $\begin{array}{l}\text { Dual-porosity or double-porosity/double-permeability contour plot } \\
\text { output file name }\end{array}$ \\
\hline$n m f i l(12)$ & character $* 100$ & Coefficient-storage file name \\
\hline$n m f i l(13)$ & character ${ }^{*} 100$ & Input-check output file name \\
\hline
\end{tabular}




\begin{tabular}{|lll|}
\hline & \multicolumn{2}{c|}{ Table 2. } \\
\hline Input variable & Format & Description \\
\hline tty_flag & character 4 & Terminal output flag: all, some, none \\
usub_num & integer & User subroutine call number \\
\hline \hline
\end{tabular}

4.1.4.2. Main input data file. The main input file contains user parameter initialization values and problem control information (Table 3). The default input data file name is fehmn.dat.

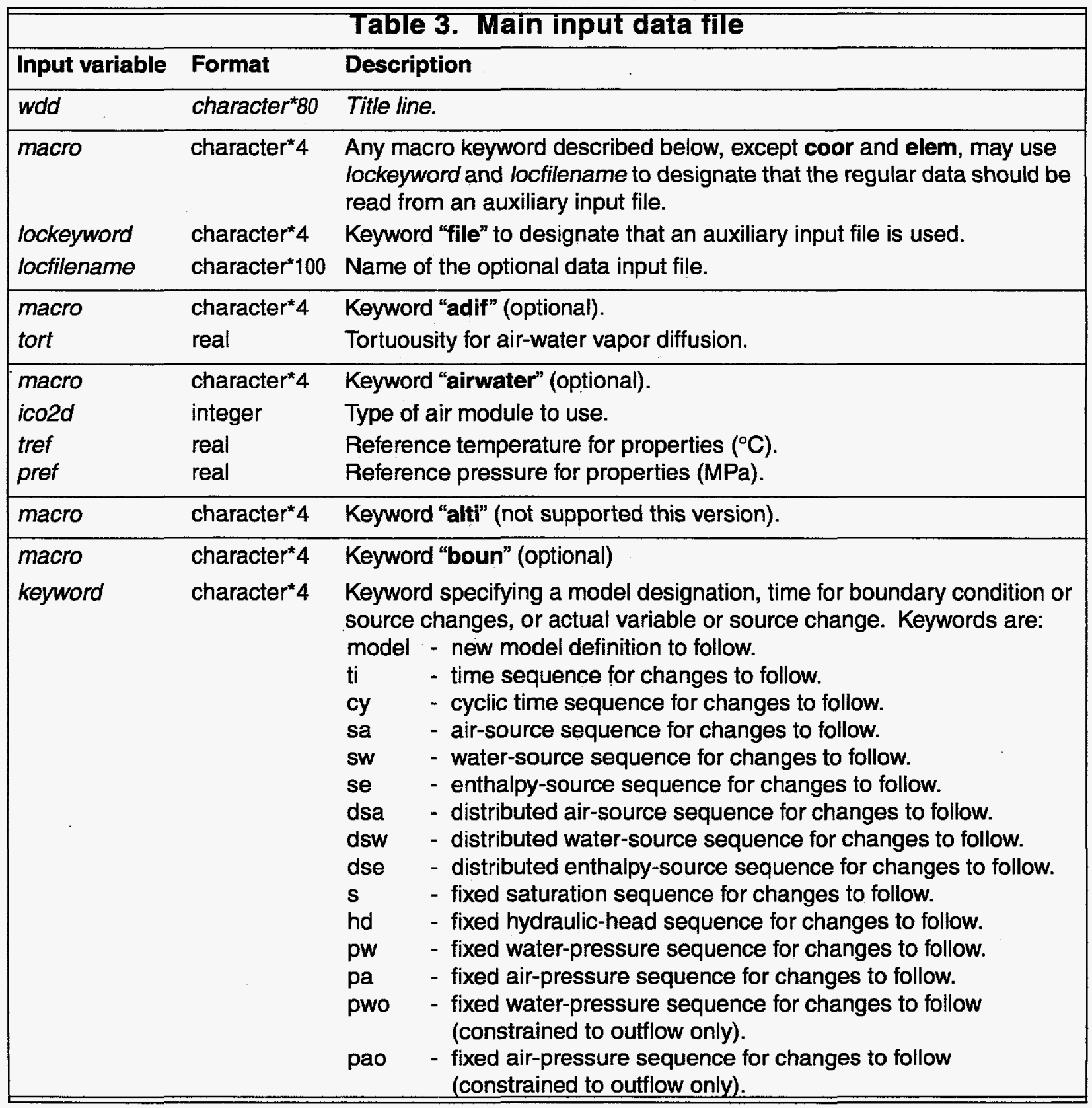




\begin{tabular}{|c|c|c|}
\hline \multicolumn{3}{|c|}{ Table 3. Main input data file (continued) } \\
\hline Input variable & Format & Description \\
\hline & & $\begin{array}{ll}\text { en } & \text { - fixed enthalpy-sequence for changes to follow. } \\
\mathrm{t} & \text { - fixed temperature-sequence for changes to follow. } \\
\mathrm{h} & \text { - fixed humidity-sequence for changes to follow (must be used } \\
& \text { with van Genucthen relative-permeability model). } \\
\mathrm{ft} & \text { - fixed flowing-temperature-sequence for change to follow. By } \\
& \text { flowing temperature, we mean the temperature of the inflow } \\
& \text { stream for a specified source. If no influx source occurs } \\
& \text { where this condition is applied, it will be ignored. } \\
& \text { - impedance factor for use with fixed water-pressure boundary } \\
\text { if } & \text { condition. If left out, the impedance factor will be set to the } \\
& \text { volume of the grid cell. } \\
\text { ts } & \text { - timestep sequence for changes to follow. } \\
\text { end } & \text { - signifies end of keyword input (a blank line will also work). } \\
\text { NOTE: Either KEYWORD 'ti' or 'cy' must be the first KEYWORD after a } \\
\text { new model (KEYWORD 'model') is started. }\end{array}$ \\
\hline ntimes & & $\begin{array}{l}\text { Number of time changes for boundary condition or source specification. } \\
\text { This parameter is only associated with KEYWORDs 'ti' and 'cy', i.e., } \\
\text { those that are associated with time sequences. }\end{array}$ \\
\hline time_model & & Times for changes in boundary conditions or sources. \\
\hline variable_model & & New values for boundary conditions or sources. \\
\hline ja & integer & $\begin{array}{l}\text { First node to be assigned properties. If } j a<0 \text {, the zone to be assigned } \\
\text { properties. }\end{array}$ \\
\hline$j b$ & integer & Last node to be assigned properties. \\
\hline & integer & Loop increment for assigning properties. \\
\hline model_number & integer & $\begin{array}{l}\text { Number referring to the numerical order in which the models were input } \\
\text { (begin with KEYWORD 'model'). }\end{array}$ \\
\hline \multicolumn{3}{|c|}{ A blank line to signal end of boundary condition input. } \\
\hline $\begin{array}{l}\text { macro } \\
\text { ibous }\end{array}$ & $\begin{array}{l}\text { character*4 } \\
\text { real }\end{array}$ & $\begin{array}{l}\text { Keyword "bous" (optional). } \\
\text { To enable constant density and viscosity for the flow terms (Boussinesq- } \\
\text { type approximation), ibous }=1 \text {. }\end{array}$ \\
\hline $\begin{array}{l}\text { macro } \\
\text { ja, jb, jc } \\
\text { thxd } \\
\text { thyd } \\
\text { thzd }\end{array}$ & $\begin{array}{l}\text { character* } 4 \\
\text { integer } \\
\text { real } \\
\text { real } \\
\text { real }\end{array}$ & $\begin{array}{l}\text { Keyword "cond" (required). } \\
\text { See description above under keyword "boun". } \\
\text { Thermal conductivities in the x-direction, y-direction, and z-direction } \\
\left(\frac{W}{m \cdot K}\right) \text {. }\end{array}$ \\
\hline \multicolumn{3}{|c|}{ A blank line to signal end of conductivity input. } \\
\hline macro & character*4 & Keyword "cont" (optional). \\
\hline $\begin{array}{l}\text { nentr } \\
\text { contim } \\
\text { or }\end{array}$ & $\begin{array}{l}\text { integer } \\
\text { real }\end{array}$ & $\begin{array}{l}\text { Time-step interval for contour plots (number of time steps). } \\
\text { Time interval for contour plots (days). }\end{array}$ \\
\hline altc & character 4 & $\begin{array}{l}\text { Keyword specifying the type of contour output wanted: "avs", "fehm", } \\
\text { "free", "ment", "ptrn". }\end{array}$ \\
\hline $\begin{array}{l}\text { nentr } \\
\text { contim }\end{array}$ & $\begin{array}{l}\text { integer } \\
\text { real }\end{array}$ & $\begin{array}{l}\text { Same as above. } \\
\text { Same as above. }\end{array}$ \\
\hline
\end{tabular}




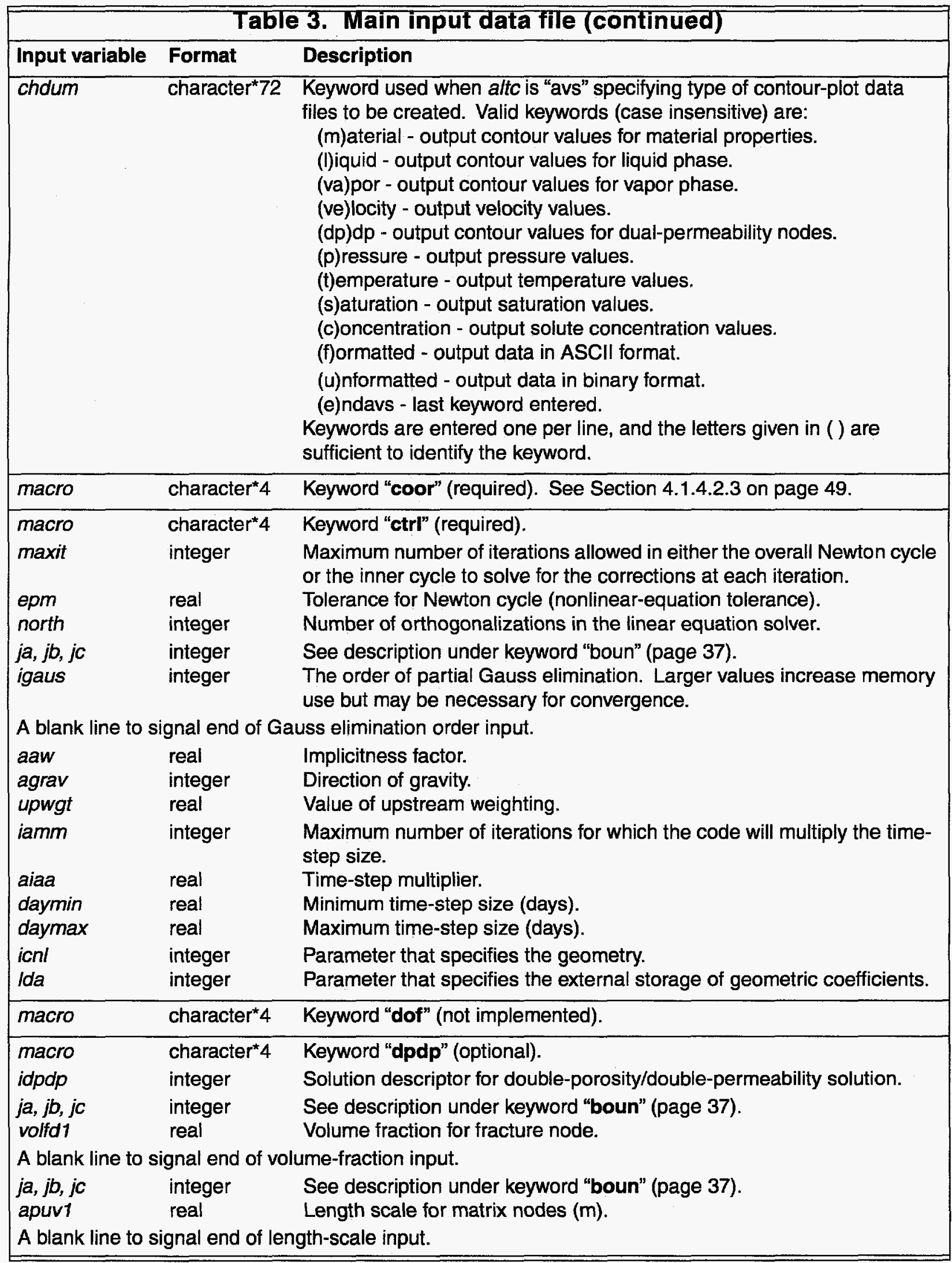




\begin{tabular}{|c|c|c|}
\hline \multicolumn{3}{|c|}{ ( Table 3. Main input data file (continued) } \\
\hline Input variable & Format & Description \\
\hline macro & character*4 & Keyword "dual" (optional). \\
\hline idualp & integer & Solution descriptor for dual-porosity solution. \\
\hline $\begin{array}{l}\text { ja, } j b, j c \\
\text { volfd1 }\end{array}$ & $\begin{array}{l}\text { integer } \\
\text { real }\end{array}$ & $\begin{array}{l}\text { See description under keyword "boun" (page } 37 \text { ). } \\
\text { Volume fraction for fracture portion of the continuum. }\end{array}$ \\
\hline \multicolumn{3}{|c|}{ A blank line to signal end of volume fraction for fracture input. } \\
\hline $\begin{array}{l}j a, j b, j c \\
\text { volfd2 }\end{array}$ & $\begin{array}{l}\text { integer } \\
\text { real }\end{array}$ & $\begin{array}{l}\text { See description under keyword "boun" (page } 37 \text { ). } \\
\text { Volume fraction for the first matrix portion of the continuum. }\end{array}$ \\
\hline \multicolumn{3}{|c|}{ A blank line to signal end of volume fraction for matrix input. } \\
\hline $\begin{array}{l}j a, j b, j c \\
\text { apuvd }\end{array}$ & $\begin{array}{l}\text { integer } \\
\text { real }\end{array}$ & $\begin{array}{l}\text { See description under keyword "boun" (page } 37 \text { ). } \\
\text { Length scale for matrix nodes }(\mathrm{m}) \text {. }\end{array}$ \\
\hline \multicolumn{3}{|c|}{ A blank line to signal end of length-scale input. } \\
\hline macro & character*4 & Keyword "elem" (required). See Section 4.1.4.2.3 on page 49. \\
\hline macro & character ${ }^{\star} 4$ & Keyword "eos" (optional). \\
\hline $\begin{array}{l}\text { iieosd } \\
\text { ipsat } \\
\text { itsat }\end{array}$ & $\begin{array}{l}\text { integer } \\
\text { integer } \\
\text { integer }\end{array}$ & $\begin{array}{l}\text { Equation-of-state reference number. } \\
\text { Parameter to set vapor pressure to zero. } \\
\text { Parameter to adjust the saturation temperature. }\end{array}$ \\
\hline ewt & real & Liquid reference pressure (MPa). \\
\hline ew2 & real & Liquid reference temperature $\left({ }^{\circ} \mathrm{C}\right)$. \\
\hline ew3 & real & Liquid reference density $\left(\mathrm{kg} / \mathrm{m}^{3}\right)$ \\
\hline ew4 & real & $\begin{array}{l}\text { Derivative of liquid density with respect to pressure at reference } \\
\text { conditions. }\end{array}$ \\
\hline ew5 & real & $\begin{array}{l}\text { Derivative of liquid density with respect to temperature at reference } \\
\text { conditions. }\end{array}$ \\
\hline ew6 & real & Liquid reference enthalpy (MJ/kg). \\
\hline ew7 & real & $\begin{array}{l}\text { Derivative of liquid enthalpy with respect to pressure at reference } \\
\text { conditions. }\end{array}$ \\
\hline ew8 & real & $\begin{array}{l}\text { Derivative of liquid enthalpy with respect to temperature at reference } \\
\text { conditions. }\end{array}$ \\
\hline ew9 & real & Liquid reference viscosity. \\
\hline ew10 & real & $\begin{array}{l}\text { Derivative of liquid viscosity with respect to pressure at reference } \\
\text { conditions. }\end{array}$ \\
\hline ew11 & real & $\begin{array}{l}\text { Derivative of liquid viscosity with respect to temperature at reference } \\
\text { conditions. }\end{array}$ \\
\hline ev1 & real & Vapor reference pressure $(\mathrm{MPa})$ \\
\hline ev2 & real & Vapor reference temperature $\left({ }^{\circ} \mathrm{C}\right)$. \\
\hline ev3 & real & Vapor reference density $\left(\mathrm{kg} / \mathrm{m}^{3}\right)$ \\
\hline ev4 & real & Not used, included only to maintain a similar format to liquid parameters. \\
\hline ev5 & real & Not used, included only to maintain a similar format to liquid parameters. \\
\hline ev6 & real & Vapor reference enthalpy (MJ/kg). \\
\hline ev7 & real & $\begin{array}{l}\text { Derivative of vapor enthalpy with respect to pressure at reference } \\
\text { conditions. }\end{array}$ \\
\hline ev8 & real & $\begin{array}{l}\text { Derivative of vapor enthalpy with respect to temperature at reference } \\
\text { conditions. }\end{array}$ \\
\hline
\end{tabular}




\begin{tabular}{|c|c|c|}
\hline \multicolumn{3}{|c|}{ Table 3. Maín input data file (continued) } \\
\hline Input variable & Format & Description \\
\hline $\begin{array}{l}\text { ev9 } \\
\text { ev10 } \\
\text { ev11 }\end{array}$ & $\begin{array}{l}\text { real } \\
\text { real } \\
\text { real }\end{array}$ & $\begin{array}{l}\text { Vapor reference viscosity. } \\
\text { Derivative of vapor viscosity with respect to pressure at reference } \\
\text { conditions. } \\
\text { Derivative of vapor viscosity with respect to temperature at reference } \\
\text { conditions. }\end{array}$ \\
\hline $\begin{array}{l}\text { macro } \\
\text { iexrlp }\end{array}$ & $\begin{array}{l}\text { character } 4 \\
\text { integer }\end{array}$ & $\begin{array}{l}\text { Keyword "exrl" (optional) } \\
\text { To enable explicit relative permeability, iexrlp = } 1 \text {. }\end{array}$ \\
\hline macro & character ${ }^{\star} 4$ & Keyword "finv" (optional; no input is associated with this macro). \\
\hline $\begin{array}{l}\text { macro } \\
j a, j b, j c \\
s k d\end{array}$ & $\begin{array}{l}\text { character* } 4 \\
\text { integer } \\
\text { real }\end{array}$ & $\begin{array}{l}\text { Keyword "flow" (required if flow problem). } \\
\text { See description under keyword "boun" (page 37). } \\
\text { Depending on problem type: Heat- and/or mass-source strength (kg/s), } \\
\text { heat only (MJ/s); Specified source air pressure (MPa); or Pressure } \\
\text { above which outflow occurs (MPa). }\end{array}$ \\
\hline $\begin{array}{l}\text { aiped } \\
\text { A blank line to s }\end{array}$ & $\begin{array}{l}\text { real } \\
\text { real } \\
\text { ignal end of } \mathrm{fl}\end{array}$ & $\begin{array}{l}\text { Depending on problem type: Enthalpy of fluid injected }(\mathrm{MJ} / \mathrm{kg}) \text {; } \\
\text { Temperature }\left({ }^{\circ} \mathrm{C}\right) \text {; Source liquid saturation }(\mathrm{kg} / \mathrm{s}) \text {; or Source air pressure } \\
(\mathrm{MPa}) \text {. } \\
\text { Impedance parameter. } \\
\mathrm{v} \text { input. }\end{array}$ \\
\hline $\begin{array}{l}\text { macro } \\
\text { ja, jb, jc, jd } \\
\text { skd } \\
\text { eflow } \\
\text { aiped } \\
\text { A blank line to }\end{array}$ & $\begin{array}{l}\text { character* } 4 \\
\text { integer } \\
\text { real } \\
\text { real } \\
\text { real } \\
\text { ignal end of fl }\end{array}$ & $\begin{array}{l}\text { Keyword "flo2" (optional). } \\
\text { See description under keyword "boun" (page 37). } \\
\text { Same as above for keyword "flow". } \\
\text { Same as above for keyword "flow". } \\
\text { Same as above for keyword "flow". } \\
\text { input. }\end{array}$ \\
\hline $\begin{array}{l}\text { macro } \\
\text { nflx } \\
\text { iflx1 } \\
\text { iflx2 }\end{array}$ & $\begin{array}{l}\text { character* } 4 \\
\text { integer } \\
\text { integer } \\
\text { integer }\end{array}$ & $\begin{array}{l}\text { Keyword "flxo" (optional). } \\
\text { Number of internode fluxes to be calculated. } \\
\text { First node to be used in flux calculation. } \\
\text { Second node to be used in flux calculation. If ifl } 2=0 \text {, then the node } \\
\text { connected to ifl } 11 \text { with the greatest internodal distance is used to } \\
\text { calculate the mass flux. }\end{array}$ \\
\hline $\begin{array}{l}x 1 \\
y 1 \\
z 1 \\
x 2 \\
y 2 \\
z 2\end{array}$ & $\begin{array}{l}\text { real } \\
\text { real } \\
\text { real } \\
\text { real } \\
\text { real } \\
\text { real }\end{array}$ & $\begin{array}{l}X-, y-, \text { and } z \text {-coordinates of the first node to be used in flux calculation. } \\
\text { Used only for those nodes where IFLX } 1<0 \text {. } \\
X-, y-\text {, and } z \text {-coordinates of the second node to be used in flux } \\
\text { calculation. Used only for those nodes where IFLX } 2<0 \text {. }\end{array}$ \\
\hline macro & character ${ }^{*} 4$ & Keyword "head" (optional). (No input is associated with this macro.) \\
\hline $\begin{array}{l}\text { macro } \\
j a, j b, j c \\
q f l u x\end{array}$ & $\begin{array}{l}\text { character } 4 \\
\text { integer } \\
\text { real }\end{array}$ & $\begin{array}{l}\text { Keyword "hflx" (optional). } \\
\text { See description under keyword "boun" (page } 37 \text { ). } \\
\text { If } q f(x m=0 \text {, then qflux is the heat flux (MW). If qflxm } \neq 0 \text {, then qflux is a } \\
\text { temperature }\left({ }^{\circ} \mathrm{C}\right) \text { and the heat flux is calculated according to the } \\
\text { formula: } Q_{H}=q f l x m(T L-q f l u x \text { ) (MW). }\end{array}$ \\
\hline $\begin{array}{l}q f l \times m \\
\text { A blank line to }\end{array}$ & real & If $q f\left(x m \neq 0\right.$, multiplier for heat-flux equation given in description $\left(\mathrm{MW} /{ }^{\circ} \mathrm{C}\right)$ \\
\hline
\end{tabular}




\begin{tabular}{|c|c|c|}
\hline \multicolumn{3}{|c|}{ Table 3. Main input data file (continued) } \\
\hline Input variable & Format & Description \\
\hline macro & character ${ }^{*} 4$ & Keyword "ice" (optional). \\
\hline & integer & Solution descriptor for ice solution. \\
\hline & real & Default value for ice saturation. \\
\hline tmelt & real & Freezing temperature of water $\left({ }^{\circ} \mathrm{C}\right)$ \\
\hline $\begin{array}{l}j a, j b, j c \\
s i i\end{array}$ & $\begin{array}{l}\text { integer } \\
\text { real }\end{array}$ & $\begin{array}{l}\text { See description under keyword "boun" (page 37). } \\
\text { lce saturation. }\end{array}$ \\
\hline \multicolumn{3}{|c|}{ A blank line to signal end of ice-saturation input. } \\
\hline \multirow{9}{*}{$\begin{array}{l}\text { macro } \\
\text { pein } \\
\text { tin } \\
\text { tin1 } \\
\text { grad1 } \\
\text { depth } \\
\text { tin2 } \\
\text { grad2 } \\
\text { quad }\end{array}$} & character*4 & Keyword "init" (required if "pres" not used). \\
\hline & real & Initial value of pressure (MPa). \\
\hline & real & Initial value of temperature $\left({ }^{\circ} \mathrm{C}\right)$ \\
\hline & real & Temperature-gradient linear formula parameter $\left({ }^{\circ} \mathrm{C}\right)$ \\
\hline & real & Temperature-gradient linear formula parameter $\left({ }^{\circ} \mathrm{C} / \mathrm{m}\right)$. \\
\hline & real & Temperature-gradient formula parameter $(\mathrm{m})$ \\
\hline & real & Temperature-gradient quadratic formula parameter $\left({ }^{\circ} \mathrm{C}\right)$ \\
\hline & real & Temperature-gradient quadratic formula parameter $\left({ }^{\circ} \mathrm{C} / \mathrm{m}\right)$ \\
\hline & real & Temperature-gradient quadratic formula parameter $\left({ }^{\circ} \mathrm{C} / \mathrm{m}^{2}\right)$. \\
\hline \multirow{2}{*}{$\begin{array}{l}\text { macro } \\
g 1\end{array}$} & character*4 & Keyword "iter" (optional). \\
\hline & real & $\begin{array}{l}\text { Multiplier for the linear convergence region of the Newton-Raphson } \\
\text { iteration. }\end{array}$ \\
\hline$g 2$ & real & $\begin{array}{l}\text { Multiplier for the quadratic convergence region of the Newton-Raphson } \\
\text { iteration. }\end{array}$ \\
\hline$g 3$ & real & $\begin{array}{l}\text { Tolerance for the adaptive implicit method (multiplying factor for Newton- } \\
\text { Raphson tolerance). }\end{array}$ \\
\hline tmch & real & $\begin{array}{l}\text { Machine tolerance. If satisfied by the residual norm, the Newton } \\
\text { iteration is assumed to be complete. }\end{array}$ \\
\hline overf & real & Over-relaxation factor for passive nodes in adaptive implicit method. \\
\hline \multirow{5}{*}{$\begin{array}{l}\text { irdof } \\
\text { islord } \\
\text { iback } \\
\text { icoupl } \\
\text { rnmax }\end{array}$} & integer & Enables the reduced degree-of-freedom method. \\
\hline & integer & Reordering parameter. \\
\hline & integer & IRDOF parameter. \\
\hline & integer & Number of SOR iterations used in reduced degree-of-freedom methods. \\
\hline & real & $\begin{array}{l}\text { Maximum running time for problem before the solution is stopped (cpu } \\
\text { minutes). }\end{array}$ \\
\hline \multirow{2}{*}{$\begin{array}{l}\text { macro } \\
\text { iad_up }\end{array}$} & character*4 & Keyword "itup" (optional). \\
\hline & integer & Number of iterations after which the upwind directions are held constant. \\
\hline macro & character*4 & Keyword "iupk" (optional; no input is associated with this macro). \\
\hline macro & character*4 & Keyword "ivfc" (not supported this version). \\
\hline \multirow{5}{*}{$\begin{array}{l}\text { macro } \\
\text { num_md } \\
\text { max_con } \\
\text { ielim } \\
s x \_m u l t\end{array}$} & character*4 & Keyword "mdnode" (optional). \\
\hline & integer & Number of new connections to be entered. \\
\hline & integer & Maximum number of new connections to a given node. \\
\hline & integer & Redundant nodal connections are eliminated as needed if ielm $<0$. \\
\hline & real & Multiplier for equilibrium conditions. \\
\hline \multicolumn{3}{|c|}{ For each new connection (num_mo): } \\
\hline \multirow{2}{*}{$\begin{array}{l}\text { node } \\
\text { ipar }\end{array}$} & integer & Node to which new connection is established. \\
\hline & integer & $\begin{array}{l}\text { Not used at present. Its value is ignored but the number entered must } \\
\text { be an integer. }\end{array}$ \\
\hline npar & integer & The new connected node. If $n p a r=$ node, no new connection is established. \\
\hline
\end{tabular}




\begin{tabular}{|c|c|c|}
\hline & & 3. Main input data file (continued) \\
\hline Input variable & Format & Description \\
\hline macro & character*4 & Keyword "ngas" (optional). \\
\hline ico2d & integer & Solution descriptor for noncondensible gas transport. \\
\hline $\begin{array}{l}j a, j b, j c \\
p c 02\end{array}$ & $\begin{array}{l}\text { integer } \\
\text { real }\end{array}$ & $\begin{array}{l}\text { See description under keyword "boun" (page } 37 \text { ). } \\
\text { Initial partial pressure of noncondensible gas. If } p c o 2<0 \text {, then ABS } \\
\text { (pco2) is interpreted as a temperature and the partial pressure of the } \\
\text { noncondensible gas is calculated. }\end{array}$ \\
\hline A blank line to $s$ & ignal end of $p$ & tial-pressure input. \\
\hline $\begin{array}{l}j a, j b, j c \\
c p n k\end{array}$ & $\begin{array}{l}\text { integer } \\
\text { real }\end{array}$ & $\begin{array}{l}\text { See description under keyword "boun" (page } 37 \text { ). } \\
\text { If cpnk }<0 \text {, then ABS (cpnk) is the specified noncondensible pressure } \\
\text { and will be held at that value. If } c p n k>0 \text {, then cpnk is the specified } \\
\text { relative humidity and the saturation is calculated using the vapor- } \\
\text { pressure lowering formula and the capillary-pressure formula. }\end{array}$ \\
\hline A blank line to $s$ & ignal end of se & uration input. \\
\hline $\begin{array}{l}j a, j b, j c \\
q c d\end{array}$ & $\begin{array}{l}\text { integer } \\
\text { real }\end{array}$ & $\begin{array}{l}\text { See description under keyword "boun" (page } 37) \text {. } \\
\text { Specified air flow rate }(\mathrm{kg} / \mathrm{s}) \text {. }\end{array}$ \\
\hline A blank line to $s$ & ignal end of ai & flow-rate input. \\
\hline macro & character*4 & Keyword "nod2" (required if macro node is not used). \\
\hline & $\begin{array}{l}\text { integer } \\
\text { integer }\end{array}$ & $\begin{array}{l}\text { Number of nodes for which information will be printed to output files. } \\
\text { Number of nodes for short list (terminal printout). }\end{array}$ \\
\hline$m n(i)$ & integer & $\begin{array}{l}m \text { node numbers for which information will be printed on the output file } \\
(i=1 \text { to } m) \text {. If a } m n(i)<0 \text {, then coordinates are used to define that node. }\end{array}$ \\
\hline$x, y, z$ & real & $\begin{array}{l}\text { Coordinates of node for which information will be printed. One line for } \\
\text { each } m n<0 \text {. The code finds the node closest to the coordinate given. }\end{array}$ \\
\hline mni(i) & integer & $\begin{array}{l}m 2 \text { node numbers for which information will be printed on the output file } \\
(i=1 \text { to } m 2) \text {. If a } m \text { ni }(i)<0 \text {, then coordinates are used to define that node. }\end{array}$ \\
\hline$x, y, z$ & real & $\begin{array}{l}\text { Coordinates of node for which information will be printed. One line for } \\
\text { each } m n i<0 \text {. The code finds the node closest to the coordinate given. }\end{array}$ \\
\hline macro & character ${ }^{*} 4$ & Keyword "node" (required if macro nod2 is not used). \\
\hline$m$ & integer & Number of nodes for which information will be printed to output files. \\
\hline$m n(i)$ & integer & $\begin{array}{l}m \text { node numbers for which information will be printed on the output file } \\
(i=1 \text { to } m) \text {. If a } m n(i)<0 \text {, then coordinates are used to define that node. }\end{array}$ \\
\hline$x, y, z$ & real & $\begin{array}{l}\text { Coordinates of node for which information will be printed. One line for } \\
\text { each } m n<0 \text {. The code finds the node closest to the coordinate given. }\end{array}$ \\
\hline or & & \\
\hline keyword & character*5 & Keyword "block" to invoke node specification by ja, jb, jc format. \\
\hline$j a, j b, j c$ & integer & See description under keyword "boun" (page 37). \\
\hline A blank line to & ignal end of $n$ & de-block input. \\
\hline macro & character*4 & Keyword "num" (not implemented). \\
\hline macro & character*4 & Keyword "perm" (required). \\
\hline$j a, j b, j c$ & integer & See description under keyword "boun" (page 37). \\
\hline pnxd & real & Permeability in the $x$-direction $\left(\mathrm{m}^{2}\right)$ \\
\hline pnyd & real & Permeability in the $y$-direction $\left(\mathrm{m}^{2}\right)$ \\
\hline pnzd & real & Permeability in the $z$-direction $\left(\mathrm{m}^{2}\right)$. \\
\hline A blank & gnal e & meability input. \\
\hline
\end{tabular}




\begin{tabular}{|c|c|c|}
\hline \multicolumn{3}{|c|}{ Table 3. Main input data file (continued) } \\
\hline Input variable & Format & Description \\
\hline macro & character*4 & Keyword "pest" (optional). \\
\hline mpest & integer & $\begin{array}{l}\text { Number of nodes for PEST output (pressures, saturations, } \\
\text { temperatures). }\end{array}$ \\
\hline npest & integer & Node numbers whose values are printed to output file (suffix .pest). \\
\hline$x, y, z$ & real & $\begin{array}{l}\text { Coordinates of node for which information will be printed. One line for } \\
\text { each npest }<0 \text {. The code finds the node closest to the coordinate given. }\end{array}$ \\
\hline macro & character*4 & Keyword "ppor" (optional). \\
\hline iporos & integer & $\begin{array}{l}\text { Porosity/permeability type: iporos }=-1 \text {, specific storage model; iporos = } \\
1, \text { aquifer compressibility model; and iporos }=-2 \text {, Gangi model. }\end{array}$ \\
\hline$j a, j b, j c$ & integer & See description under keyword "boun" (page 37). \\
\hline por1 & real & $\begin{array}{l}\text { Specific storage (iporos }=-1 \text { ), aquifer compressibility (iporos }=1 \text { ), or } \\
\text { Gangi model exponent } m \text { (iporos }=-2 \text { ). }\end{array}$ \\
\hline por2 & real & Gangi model pressure, $P_{x}(\mathrm{MPa})$ \\
\hline por3 & real & Gangi model in-situ stress, $\sigma(\mathrm{MPa})$ \\
\hline por4 & real & $\begin{array}{l}\text { Gangi model product of the coefficient of thermal expansion for the rock } \\
\text { and Young's modules, }(\alpha E)\left(\mathrm{MPa} /{ }^{\circ} \mathrm{C}\right) \text {. }\end{array}$ \\
\hline \multicolumn{3}{|c|}{ A blank line to signal end of ppor model parameter input } \\
\hline macro & character*4 & Keyword "pres" (required if macro init not used). \\
\hline $\begin{array}{l}\text { ja, jb, jc } \\
\text { phrd }\end{array}$ & $\begin{array}{l}\text { integer } \\
\text { real }\end{array}$ & $\begin{array}{l}\text { See description under keyword "boun" (page 37). } \\
\text { Initial pressure (MPa). }\end{array}$ \\
\hline tind & real & $\begin{array}{l}\text { Initial temperature }\left({ }^{\circ} \mathrm{C}\right) \text { or initial saturation depending on thermodynamic } \\
\text { region. }\end{array}$ \\
\hline ieosd & integer & Thermodynamic-region parameter. \\
\hline \multicolumn{3}{|c|}{ A blank line to signal end of initial-value input. } \\
\hline macro & character ${ }^{\star} 4$ & Keyword "ptrk" (optional). \\
\hline $\begin{array}{l}\text { npart } \\
\text { rseed }\end{array}$ & $\begin{array}{l}\text { integer } \\
\text { integer }\end{array}$ & $\begin{array}{l}\text { Number of particles in the simulation. } \\
6 \text {-digit integer random-number seed. }\end{array}$ \\
\hline daycs & real & Time for which the particle-tracking solution is enabled (days). \\
\hline daycf & real & Time for which the particle-tracking solution is disabled (days). \\
\hline dayhf & real & Time for which the flow solution is disabled (days). \\
\hline dayhs & real & Time for which the flow solution is enabled (days). \\
\hline trak_type & integer & Flag to denote the fluid phase of the particles. \\
\hline half_life & real & Half-life for irreversible first-order decay reaction (s). \\
\hline pout & integer & Flag to specify the concentration output. \\
\hline prnt rst & integer & Flag to specify whether particle information is written to the ".fin" file. \\
\hline $\begin{array}{l}\text { transflag } \\
k d\end{array}$ & $\begin{array}{l}\text { integer } \\
\text { real }\end{array}$ & $\begin{array}{l}\text { Flag to specify which transport mechanisms apply. } \\
\text { Sorption coefficient (linear, reversible, equilibrium sorption) } \\
\text { (kg-fluid/kg-rock). }\end{array}$ \\
\hline tclx & real & Dispersivity in the $x$-direction $(m)$ \\
\hline tcly & real & Dispersivity in the y-direction (m). \\
\hline tclz & real & Dispersivity in the $z$-direction (m). \\
\hline diffmat & real & Molecular diffusion coefficient in the rock matrix $\left(\mathrm{m}^{2} / \mathrm{s}\right)$ \\
\hline rd_frac & real & $\begin{array}{l}\text { Retardation factor within the primary porosity (fractures) for a matrix- } \\
\text { diffusion particle-tracking simulation. }\end{array}$ \\
\hline
\end{tabular}




\begin{tabular}{|c|c|c|}
\hline \multicolumn{3}{|c|}{ Table 3. Main input data file (continued) } \\
\hline Input variable & Format & Description \\
\hline $\begin{array}{l}\text { matrix_por } \\
\text { fspacing }\end{array}$ & $\begin{array}{l}\text { real } \\
\text { real }\end{array}$ & $\begin{array}{l}\text { Porosity of the rock matrix. } \\
\text { Mean fracture spacing }(\mathrm{m}) \text {. }\end{array}$ \\
\hline $\begin{array}{l}j a, j b, j c \\
i t r c\end{array}$ & $\begin{array}{l}\text { integer } \\
\text { integer }\end{array}$ & $\begin{array}{l}\text { See description under keyword "boun" (page } 37 \text { ). } \\
\text { Model number for parameters defined above. }\end{array}$ \\
\hline \multicolumn{3}{|c|}{ A blank line to signal end of model-number input. } \\
\hline $\begin{array}{l}j a, j b, j c \\
\text { pcnsk }\end{array}$ & $\begin{array}{l}\text { integer } \\
\text { real }\end{array}$ & $\begin{array}{l}\text { See description under keyword “boun" (page 37). } \\
\text { Particle-injection parameter. }\end{array}$ \\
\hline t1sk & real & Time (days) when particle injection begins. \\
\hline t2sk & real & Time (days) when particle injection ends. \\
\hline \multicolumn{3}{|c|}{ A blank line to signal end of particle-injection parameter input. } \\
\hline macro & character 4 & Keyword "renm" (optional). \\
\hline $\begin{array}{l}j a, j b, j c \\
i g d\end{array}$ & $\begin{array}{l}\text { integer } \\
\text { integer }\end{array}$ & $\begin{array}{l}\text { See description under keyword "boun" (page } 37 \text { ). } \\
\text { New node number for given node. }\end{array}$ \\
\hline \multicolumn{3}{|c|}{ A blank line to signal end of renumbering input. } \\
\hline macro & character ${ }^{*} 4$ & Keyword "rflx" (not implemented in this version of FEHM). \\
\hline macro & character*4 & Keyword "rlp" (optional). \\
\hline $\operatorname{irlp}(i)$ & integer & Relative-permeability model type. \\
\hline rp1 & real & $\begin{array}{l}\text { Parameter used in all models. For models } 1 \text { and } 2 \text {, irreducible liquid } \\
\text { saturation. For models } 3 \text { and } 4 \text {, residual liquid saturation. }\end{array}$ \\
\hline rp2 & real & $\begin{array}{l}\text { Parameter used in all models. For models } 1 \text { and } 2 \text {, irreducible vapor } \\
\text { saturation. For models } 3 \text { and } 4 \text {, maximum liquid saturation. }\end{array}$ \\
\hline rp3 & real & $\begin{array}{l}\text { Parameter used in models } 1,3 \text {, and } 4 \text {. For model } 1 \text {, maximum liquid } \\
\text { saturation. For models } 3 \text { and } 4, \alpha_{G} \text { parameter }(1 / \mathrm{m}) \text { (note: some data }\end{array}$ \\
\hline rp4 & real & $\begin{array}{l}\text { are given in }(1 / \mathrm{Pa}) \text {; convert using pressure }=\rho g \Delta h) \\
\text { Parameter used in models } 1,3 \text {, and } 4 \text {. For model } 1 \text {, maximum vapor } \\
\text { saturation. For models } 3 \text { and } 4 \text {, parameter } n \text {. }\end{array}$ \\
\hline rp5 & real & $\begin{array}{l}\text { Parameter used in models } 3 \text { and } 4 \text {. Multiple of cutoff capillary pressure } \\
\text { assigned as maximum capillary pressure. }\end{array}$ \\
\hline rp6 & real & Parameter used in models 3 and 4 . Cutoff saturation rp1. \\
\hline$r p 7$ & real & Parameter used in model 4 . Residual liquid saturation for fracture. \\
\hline rp8 & real & Parameter used in model 4. Maximum liquid saturation for fracture. \\
\hline rp9 & real & Parameter used in model $4 . \alpha_{G}$ for fractures. \\
\hline rp10 & real & Parameter used in model $4 . \mathrm{n}$ for fractures. \\
\hline rp11 & real & Parameter used in model 4 . Same as $r p 5$ except for fractures. \\
\hline rp12 & real & Parameter used in model 4 . Same as rp6 except for fractures. \\
\hline rp13 & real & Parameter used in model 4. Fracture intrinsic permeability $\left(\mathrm{m}^{2}\right)$. \\
\hline $\begin{array}{l}r p 14 \\
r p 15\end{array}$ & $\begin{array}{l}\text { real } \\
\text { real }\end{array}$ & $\begin{array}{l}\text { Parameter used in model } 4 \text {. Matrix intrinsic permeability }\left(\mathrm{m}^{2}\right) \text {. } \\
\text { Parameter used in model } 4 \text {. Fracture porosity. }\end{array}$ \\
\hline$j a, j b, j c$ & $\begin{array}{l}\text { integer } \\
\text { integer }\end{array}$ & $\begin{array}{l}\text { See description under keyword "boun" (page } 37 \text { ). } \\
\text { Number referring to the sequence of models read. }\end{array}$ \\
\hline \multicolumn{3}{|c|}{ A blank line to signal end of relative-permeability model input. } \\
\hline rlpfile & character ${ }^{*} 100$ & Name of the optional rlp data file used when $\operatorname{irlp}(i)=5$. \\
\hline
\end{tabular}




\begin{tabular}{|c|c|c|}
\hline \multicolumn{3}{|c|}{ Table 3. Main input data file (continued) } \\
\hline Input variable & Format & Description \\
\hline macro & character ${ }^{*} 4$ & Keyword "rock" (required). \\
\hline$j a, j b, j c$ & integer & See description under keyword "boun" (page 37). \\
\hline denrd & real & Rock density $\left(\mathrm{kg} / \mathrm{m}^{3}\right)$ \\
\hline cprd & real & Rock specific heat $\left(\frac{\mathrm{MJ}}{\mathrm{kg} \cdot \mathrm{K}}\right)$. \\
\hline psd & real & Porosity. \\
\hline \multicolumn{3}{|c|}{ A blank line to signal end of rock input. } \\
\hline macro & character $* 4$ & Keyword "rxn" (optional). \\
\hline key_group & character & $\begin{array}{l}\text { Key word to specify that species are to be placed into groups that are } \\
\text { solved simultaneously. }\end{array}$ \\
\hline ngroups & integer & Number of groups of species. \\
\hline group & integer & $\begin{array}{l}\text { nspecies values are entered for each line of input, and ngroups lines of } \\
\text { input are required, one for each group. }\end{array}$ \\
\hline$n r x n s$ & integer & Number of chemical reactions. \\
\hline rxn_interval & real & Time between each iteration. \\
\hline key_rxn & character ${ }^{\star} 4$ & $\begin{array}{l}\text { Denotes the type of reaction. The first letter of the keyword is all that is } \\
\text { required. }\end{array}$ \\
\hline equil_model & integer & $\begin{array}{l}\text { Flag denoting which model is to be used for defining the temperature } \\
\text { dependence of the equilibrium constant. }\end{array}$ \\
\hline equil_const25 & real & The term $A_{r x n}$ in equilibrium constant-temperature-dependence model. \\
\hline enthalpy25 & real & The term $\Delta H_{H}$ in equilibrium constant-temperature-dependence model. \\
\hline gamma_check & real & Equilibrium-tolerance parameter $\gamma_{\text {tol }}$ \\
\hline $\begin{array}{l}\text { rate_factor } \\
\text { round_tol } \\
\text { or }\end{array}$ & $\begin{array}{l}\text { real } \\
\text { real }\end{array}$ & $\begin{array}{l}\text { Parameter for scaling the rate constants. } \\
\text { Cut-off parameter for forward reaction rate. }\end{array}$ \\
\hline key_rxn & character ${ }^{*} 4$ & Same as above. \\
\hline equil_model & integer & Same as above. \\
\hline awwa(1) & real & The term $A_{r \times n, 1}$ in equilibrium constant-temperature-dependence model. \\
\hline awwa(2) & real & The term $A_{r x n, 2}$ in equilibrium constant-temperature-dependence model. \\
\hline awwa(3) & real & The term $A_{r x n, 3}$ in equilibrium constant-temperature-dependence model. \\
\hline awwa(4) & real & The term $A_{r \times n, 4}$ in equilibrium constant-temperature-dependence model. \\
\hline awwa(5) & real & The term $A_{r x n, 5}$ in equilibrium constant-temperature-dependence model. \\
\hline gamma_check & real & Same as above. \\
\hline rate_factor & real & Same as above. \\
\hline round_tol & real & Same as above. \\
\hline \multicolumn{3}{|l|}{ or } \\
\hline key_rxn & character*4 & Same as above. \\
\hline ar_for & real & Pre-exponential factor of the forward reaction. \\
\hline ea_for & real & Activation energy of the forward reaction ( $\mathrm{kJ} / \mathrm{mol})$. \\
\hline ar_rev & real & Pre-exponential factor of the reverse reaction. \\
\hline ea_rev & real & Activation energy of the reverse reaction $(\mathrm{kJ} / \mathrm{mol})$. \\
\hline stoic & real & The stoichiometric coefficient. \\
\hline rate_power & real & The exponent in the rate law. \\
\hline
\end{tabular}




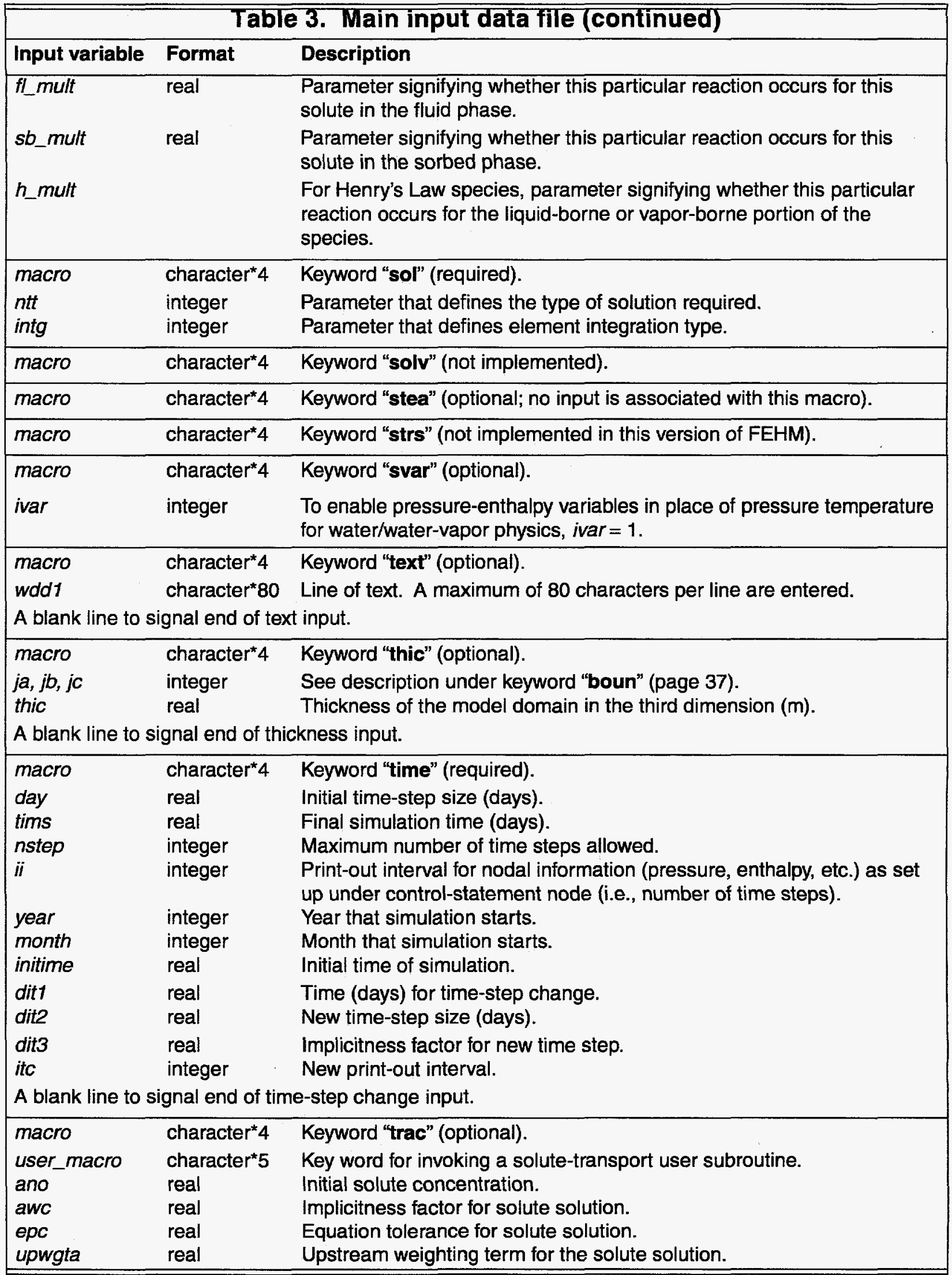




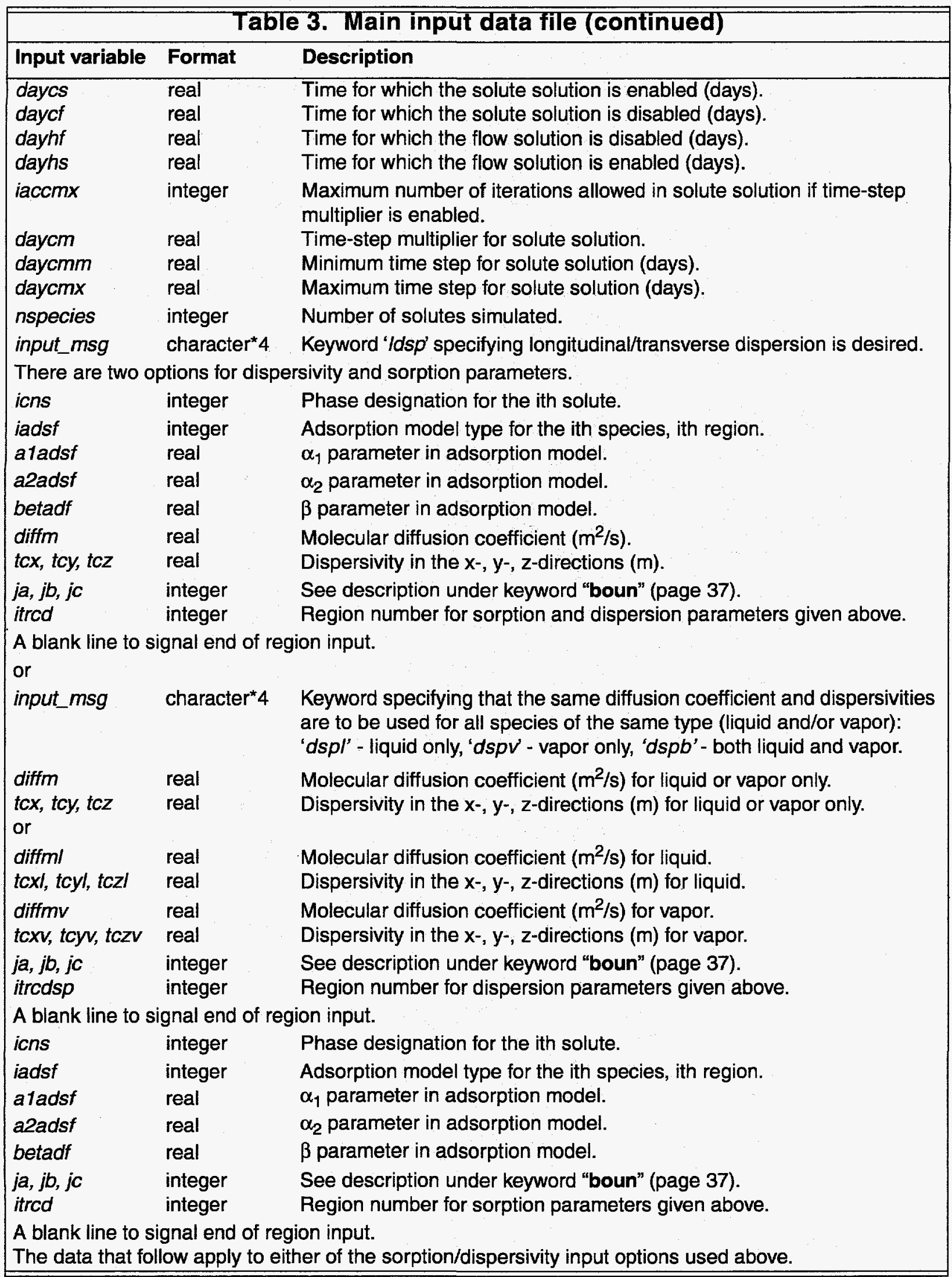




\begin{tabular}{|c|c|c|}
\hline \multicolumn{3}{|c|}{ Table 3. Main input data file (continued) } \\
\hline Input variable & Format & Description \\
\hline henry_model & integer & $\begin{array}{l}\text { Flag denoting which model is to be used for defining the temperature } \\
\text { dependence of the Henry's Law constant. } \\
\text { Term in Henry's Law temperature-dependence model: model } 1 \text { - } A_{H} \text {, } \\
\text { model } 2 \text { - } A_{H, 1}\end{array}$ \\
\hline hawwa(2) & real & $\begin{array}{l}\text { Term in Henry's Law temperature-dependence model: model } 1-\Delta H_{H} \text {, } \\
\text { model } 2-\mathrm{A}_{H, 2}\end{array}$ \\
\hline hawwa(3) & real & Term in Henry's Law temperature-dependence model $2-A_{H, 3}$ \\
\hline hawwa(4) & real & Term in Henry's Law temperature-dependence model $2-A_{H, 4}$. \\
\hline hawwa(5) & real & Term in Henry's Law temperature-dependence model 2 - $A_{H, 5}$ \\
\hline $\begin{array}{l}j a, j b, j c \\
\text { anqo }\end{array}$ & $\begin{array}{l}\text { integer } \\
\text { real }\end{array}$ & $\begin{array}{l}\text { See description under keyword "boun" (page } 37 \text { ). } \\
\text { Initial concentration of tracer, which will supersede the value given by } \\
\text { ano. }\end{array}$ \\
\hline \multicolumn{3}{|c|}{ A blank line to signal end of concentration input. } \\
\hline $\begin{array}{l}j a, j b, j c \\
\text { cnsk } \\
\text { t1sk } \\
\text { t2sk }\end{array}$ & $\begin{array}{l}\text { integer } \\
\text { real } \\
\text { real } \\
\text { real }\end{array}$ & $\begin{array}{l}\text { See description under keyword "boun" (page } 37 \text { ). } \\
\text { Injection concentration at inlet node (moles per kg liquid or vapor). } \\
\text { Time (days) when tracer injection begins. } \\
\text { Time (days) when tracer injection ends. }\end{array}$ \\
\hline \multicolumn{3}{|c|}{ A blank line to signal end of tracer injection input. } \\
\hline $\begin{array}{l}\text { macro } \\
k k\end{array}$ & $\begin{array}{l}\text { character* } 4 \\
\text { integer }\end{array}$ & $\begin{array}{l}\text { Keyword "user". } \\
\text { Integer number passed to subroutine user for user-defined input } \\
\text { parameters. }\end{array}$ \\
\hline macro & character*4 & Keyword "vcon". \\
\hline ivcon(i) & integer & $\begin{array}{l}\text { Model type for ith conductivity model: linear variation of thermal } \\
\text { conductivity with temperature or square-root variation of thermal } \\
\text { conductivity with liquid saturation. }\end{array}$ \\
\hline $\operatorname{vetf}(i)$ & real & $\begin{array}{l}\text { Reference temperature }\left({ }^{\circ} \mathrm{C}\right) \text { or conductivity }\left(\frac{\mathrm{W}}{\mathrm{m} \cdot \mathrm{K}}\right) \text { at liquid } \\
\text { saturation }=1 \text {, depending on model. }\end{array}$ \\
\hline$v c 2 f(i)$ & real & $\begin{array}{l}\text { Reference conductivity }\left(\frac{W}{m \cdot K}\right) \text { or conductivity }\left(\frac{W}{m \cdot K}\right) \text { at liquid } \\
\text { saturation }=0 \text {, depending on model. }\end{array}$ \\
\hline $\operatorname{vc3f}(i)$ & real & $\begin{array}{l}\text { Change in conductivity with respect to temperature or not used, } \\
\text { depending on model. }\end{array}$ \\
\hline \multicolumn{3}{|c|}{ A blank line to signal end of conductivity-model input. } \\
\hline $\begin{array}{l}j a, j b, j c \\
i v c n d\end{array}$ & $\begin{array}{l}\text { integer } \\
\text { integer }\end{array}$ & $\begin{array}{l}\text { See description under keyword "boun" (page } 37 \text { ). } \\
\text { Number referring to the sequence of models read. }\end{array}$ \\
\hline \multicolumn{3}{|c|}{ A blank line to signal end of conductivity-model desingator input. } \\
\hline macro & character ${ }^{*} 4$ & $\begin{array}{l}\text { Keyword "velo". } \\
\text { The input is identical to "flxo" except that velocities instead of fluxes are } \\
\text { calculated (see page } 40 \text { ). }\end{array}$ \\
\hline macro & character* 4 & Keyword "wlbr" (not supported this version). \\
\hline macro & character*4 & Keyword "zone" (optional). See Section 4.1.4.2.4 on page 49. \\
\hline macro & character*4 & Keyword "stop". \\
\hline
\end{tabular}


4.1.4.2.3 Geometry data file. The geometry data file contains the mesh element and coordinate data (Table 4). This information can either be part of the main input file or a separate file.

\begin{tabular}{|c|c|c|}
\hline & & able 4. Geometry data file \\
\hline Input variable & Format & Description \\
\hline macro & character*4 & Keyword "coor". \\
\hline$n$ & integer & Number of nodes in the grid. \\
\hline For each node: & & \\
\hline$m b$ & integer & $\begin{array}{l}\text { Node number. If } m b<0 \text {, then the difference between the absolute } \\
\text { value of } m b \text { and the previously read absolute value of } m b \text { is used to } \\
\text { generate intermediate values by interpolation. }\end{array}$ \\
\hline $\operatorname{cord}(m b, 1)$ & real & X-coordinate of node $m b(\mathrm{~m})$ \\
\hline $\operatorname{cord}(m b, 2)$ & real & Y-coordinate of node $m b(\mathrm{~m})$. \\
\hline $\operatorname{cord}(m b, 3)$ & real & Z-coordinate of node $m b(m)$. \\
\hline A blank line to s & gnal end of no & input. \\
\hline macro & character*4 & Keyword "elem". \\
\hline $\begin{array}{l}n s \\
\text { nei }\end{array}$ & $\begin{array}{l}\text { integer } \\
\text { integer }\end{array}$ & $\begin{array}{l}\text { Number of nodes per element. } \\
\text { Number of elements. }\end{array}$ \\
\hline For each eleme & & \\
\hline$m b$ & integer & $\begin{array}{l}\text { Element number. If } m b<0 \text {, then the difference between the absolute } \\
\text { value of } m b \text { and the previous absolute value of } m b \text { is used to } \\
\text { generate intermediate values by interpolation in the code. }\end{array}$ \\
\hline nelm $(k)$ & integer & $\begin{array}{l}\text { ns node numbers for the nodes in element } m b\left(k=(m b-1)^{\star} n s+i \text {, }\right. \\
i=1 \text { to } n s) \text {. }\end{array}$ \\
\hline A blank line to $s$ & unal end of ele & ent input. \\
\hline macro & character ${ }^{*} 4$ & Keyword "stop". \\
\hline
\end{tabular}

4.1.4.2.4 Zone data file. The zone data file contains the zone information, which can either be part of the main input file or a separate file (Table 5).

\begin{tabular}{|c|c|c|}
\hline & & Table 5. Zone data file \\
\hline Input variable & Format & Description \\
\hline macro & character ${ }^{\star} 4$ & Keyword "zone". \\
\hline For each geom & ric zone: & \\
\hline izone & integer & Zone identification number. \\
\hline Followed by: & & \\
\hline$x z(i)$ & real & X-coordinates defining zone izone. \\
\hline$y z(i)$ & real & Y-coordinates defining zone izone. \\
\hline$z z(i)$ & real & $\begin{array}{l}Z \text {-coordinates defining zone } i z o n e \\
\text { Note: } i=1 \text { to } 4 \text { for } 2-D \text { and } z z \text { is not input, } i=1 \text { to } 8 \text { for } 3-D \text {. }\end{array}$ \\
\hline or & & \\
\hline macro & character*4 & Keyword "list". \\
\hline$x g$ & real & A list of $x-, y-, z$-coordinates, one set per line until a blank line is \\
\hline$y g$ & real & encountered ( $z g$ is not input for 2D). The nodes corresponding to \\
\hline$z g$ & real & these coordinates make up izone. \\
\hline
\end{tabular}




\begin{tabular}{|c|c|c|}
\hline \multicolumn{3}{|c|}{ Table 5. Zone data file (continued) } \\
\hline Input variable & Format & Description \\
\hline \multicolumn{3}{|l|}{ or } \\
\hline macro & character*4 & Keyword "nnum". \\
\hline & integer & Specified number of nodes. \\
\hline node(i) & integer & nin node numbers of the nodes to be included in izone $(i=1$ to $\operatorname{nin})$. \\
\hline \multicolumn{3}{|c|}{ A blank line to signal end of zone input. } \\
\hline macro & character ${ }^{\star} 4$ & Keyword "stop". \\
\hline
\end{tabular}

4.1.4.2.5 Optional input files. The optional input files contain data for specified macros using the macro formats described above in Section 4.1.4.2.2 and Section 4.1.4.2.4 of this chapter.

4.1.4.2.6 Restart input file. The restart input data file provides fehm initial values of pressure, temperature, saturation, and simulation or starting time. See Section 4.1.4.4.2 (Table 7) for variable names, format, and description. The code version, date, time, and problem title contained in the file are nat used for input, but that information or two blank lines must be present for the file to be read correctly.

4.1.4.2.7 Coefficient storage file. The coefficient storage input file contains finite-element coefficients calculated by the code during a previous run. See Section 4.1.4.4.7 (Table 9) of this chapter for variable names, format, and description. The code version, date, time, and problem title contained in the file are not used for input, but that information or two blank lines must be present for the file to be read correctly.

\subsubsection{Prompted input}

Input prompts are used only when the default control file (fehmn.files) is not present in the directory from which the code is being executed. Table 6 below lists the prompts and expected responses. If the initial prompt is answered with the name of an input control file (see Section 4.1.4.2.1 in this chapter above), no further prompts will be issued and the remainder of the $I / O$ data will be read from the control file. If the I/O data is not accepted (final prompt answered "no"), the prompts will be repeated starting with request for the control file name. The terminal display that accompanies input prompting is shown in Section 4.1.4.5.1 of this chapter.

A carriage return, $<c r>$, refers to a return with no input that accepts the displayed default value. Responses to file name queries may be the name of a file (including path or subdirectories), <cr>, or either "na" or "not using", to indicate the file is not required by the user. Prompts that use the input file name response are denoted <input> or < root> (input file name without suffix). 


\begin{tabular}{|c|c|c|}
\hline \multicolumn{3}{|c|}{ Table 6. Prompted input } \\
\hline Input prompt & Format & Expected response \\
\hline $\begin{array}{l}\text { Enter name for iocntl -- default file name: not using } \\
\text { [(name/na or not using), RETURN = DEFAULT] }\end{array}$ & character ${ }^{\star} 100$ & $\begin{array}{l}\text { Input control file name, }<\mathrm{cr}>\text {, } \\
\text { or either "na" or "not using". }\end{array}$ \\
\hline $\begin{array}{l}\text { Enter name for inpt -- default file name: fehmn.dat } \\
\text { [(name/na or not using), RETURN = DEFAULT] }\end{array}$ & character*100 & $\begin{array}{l}\text { Input file name or }<c r>\text { to use } \\
\text { the default name. }\end{array}$ \\
\hline $\begin{array}{l}\text { Do you want all file names of the form <root of input } \\
\text { file name } .^{*} ?[(y / n), \text { RETURN }=y] \\
{ }^{\star * \star} \text { Note: If " } y \text { " incoor and inzone will equal inpt }\end{array}$ & character ${ }^{\star} 100$ & "y" or "n". \\
\hline \multicolumn{3}{|c|}{ Note: The next 11 filename prompts are issued only if the previous prompt was answered with " $\mathrm{n}$ ". } \\
\hline $\begin{array}{l}\text { Enter name for incoor -- default file name: <input> } \\
{[\text { (name/na or not using), RETURN = DEFAULT] }}\end{array}$ & character*100 & $\begin{array}{l}\text { Geometry data file name, } \\
<c r>\text {, or either "na" or "not } \\
\text { using". }\end{array}$ \\
\hline $\begin{array}{l}\text { Enter name for inzone -- default file name: <input> } \\
\text { [(name/na or not using), RETURN = DEFAULT] }\end{array}$ & character ${ }^{\star} 100$ & $\begin{array}{l}\text { Zone data file name, }<c r>\text {, or } \\
\text { either "na" or "not using". }\end{array}$ \\
\hline $\begin{array}{l}\text { Enter name for iout }-- \text { default file name: <root>.out } \\
\text { [(name/na or not using), RETURN = DEFAULT] }\end{array}$ & character*100 & $\begin{array}{l}\text { Output file name or }<c r>\text { to } \\
\text { use the default name. }\end{array}$ \\
\hline $\begin{array}{l}\text { Enter name for iread -- default file name: <root>.ini } \\
\text { [(name/na or not using), RETURN = DEFAULT] }\end{array}$ & character ${ }^{*} 100$ & $\begin{array}{l}\text { Restart input file name, }<c r>\text {, } \\
\text { or either "na" or "not using". }\end{array}$ \\
\hline $\begin{array}{l}\text { Enter name for isave -- default file name: }<\text { root>.fin } \\
\text { [(name/na or not using), RETURN = DEFAULT] }\end{array}$ & character ${ }^{\star} 100$ & $\begin{array}{l}\text { Restart output file name, } \\
<c r>\text {, or either "na" or "not } \\
\text { using". }\end{array}$ \\
\hline $\begin{array}{l}\text { Enter name for ishis }- \text { default file name: <root>. his } \\
\text { [(name/na or not using), RETURN = DEFAULT] }\end{array}$ & character ${ }^{*} 100$ & $\begin{array}{l}\text { History plot file name, }<c r>\text {, } \\
\text { or either "na" or "not using". }\end{array}$ \\
\hline $\begin{array}{l}\text { Enter name for istrc }- \text { default file name: <root>.trc } \\
{[\text { (name/na or not using), RETURN = DEFAULT] }}\end{array}$ & character ${ }^{*} 100$ & $\begin{array}{l}\text { Solute plot file name, }<c r>\text {, or } \\
\text { either "na" or "not using". }\end{array}$ \\
\hline $\begin{array}{l}\text { Enter name for iscon -- default file name: <root>.con } \\
{[\text { (name/na or not using), RETURN = DEFAULT] }}\end{array}$ & character ${ }^{*} 100$ & $\begin{array}{l}\text { Contour plot file name, }<c r>\text {, } \\
\text { or either "na" or "not using". }\end{array}$ \\
\hline $\begin{array}{l}\text { Enter name for iscon1 -- default file name: }<\text { root }>\text {.dp } \\
\text { [(name/na or not using), RETURN = DEFAULT] }\end{array}$ & character ${ }^{*} 100$ & $\begin{array}{l}\text { Contour plot file name for } \\
\text { dual or dpdp, <cr>, or either } \\
\text { "na" or "not using". }\end{array}$ \\
\hline $\begin{array}{l}\text { Enter name for isstor -- default file name: <root>.stor } \\
\text { [(name/na or not using), RETURN = DEFAULT] }\end{array}$ & character*100 & $\begin{array}{l}\text { Coefficient storage file name, } \\
<c r>\text {, or either "na" or "not } \\
\text { using". }\end{array}$ \\
\hline $\begin{array}{l}\text { Enter name for ischk -- default file name: }<\text { root }>\text {.chk } \\
\text { [(name/na or not using), RETURN = DEFAULT] }\end{array}$ & character* 100 & $\begin{array}{l}\text { Input check output file name, } \\
<c r>\text {, or either "na" or "not } \\
\text { using". }\end{array}$ \\
\hline $\begin{array}{l}\text { tty output -- show all reference nodes, selected } \\
\text { reference nodes, or none: } \\
\text { [(all/some/none), RETURN = none] }\end{array}$ & character*4 & "all", "some", or "none". \\
\hline
\end{tabular}




\begin{tabular}{|lll|}
\hline \hline \multicolumn{2}{|c|}{ Table 6. Prompted input (continued) } \\
\hline Input prompt & Format & Expected response \\
\hline $\begin{array}{l}\text { user subroutine number (provided to subroutine } \\
\text { USER betore every time step): [RETURN = none] }\end{array}$ & integer & $\begin{array}{l}\text { Number of user subroutine, } \\
<\mathrm{cr} \text {, or "0" for not using. }\end{array}$ \\
$\begin{array}{l}\text { If data is OK enter yes to continue, no to restart } \\
\text { terminal input, or stop to end program: [(yes/no/stop), } \\
\text { RETURN = yes] }\end{array}$ & character*4 & "yes", "no", or "stop". \\
\hline \hline
\end{tabular}

\subsubsection{Output files}

4.1.4.4.1 Main output file. The main output file records the code version, date, and time followed by the user-input problem title. A summary of the $1 / O$ files used, macro control statements read, and array storage follow. Timing, equation performance, nodal (for user-specified nodes), and global mass- and energybalance information at user-selected time intervals is written in a narrative format. See Section 4.1.4.5.2 in this chapter for an example of the information output and narrative style. The file ends with a summary of simulation time, number of time steps in the problem, the number of iterations taken, and total cpu time. The default output file name is fehmn.out.

4.1.4.4.2 Restart output file. The restart output data file stores fehm final values of pressure, temperature, saturation, and simulation time (Table 7). The default restart output file name is fehmn.fin.

\begin{tabular}{|c|c|c|}
\hline \multicolumn{3}{|r|}{ Table 7. Restart output file } \\
\hline Output variable & Format & Description \\
\hline $\begin{array}{l}\text { verno } \\
\text { jdate } \\
\text { jtime }\end{array}$ & $\begin{array}{l}\text { character }^{\star} 20 \\
\text { character }^{\star} 11 \\
\text { character }^{\star} 8\end{array}$ & $\begin{array}{l}\text { Code version } \\
\text { Date } \\
\text { Time }\end{array}$ \\
\hline wdd & character ${ }^{*} 80$ & Problem title \\
\hline days & real*8 & Simulation time (days) \\
\hline wdd1(1:4) & character 4 & Gas problem flag (ngas, h20, air) \\
\hline wdd1 $1(5: 8)$ & character*4 & Tracer problem flag (trac, ntra) \\
\hline wdd1(9:12) & character ${ }^{*} 4$ & Stress problem flag (strs, nstr) \\
\hline wdd1(13:16) & character*4 & Double-porosity/double-permeability problem flag (dpdp, ndpd) \\
\hline wdd1(17:20) & character*4 & Dual-porosity problem flag (dual, ndua) \\
\hline $\mathrm{t}$ (ncount) & real $^{*} 8$ & $\begin{array}{l}\text { Temperature (not present when air flag is set, isothermal air/water } \\
\text { problem) }\end{array}$ \\
\hline s(ncount) & real*$^{*} 8$ & Liquid saturation \\
\hline phi(ncount) & real*8 & Pressure \\
\hline pci(ncount) & real $^{\star} 8$ & $\begin{array}{l}\text { Gas pressure (only present if noncondensible gas problem, ngas } \\
\text { flag is set). }\end{array}$ \\
\hline
\end{tabular}


4.1.4.4.3 Simulation history output file. The history plot file records parameter values at selected nodes for each time step of the simulation (Table 8). The default history output file name is fehmn.his.

\begin{tabular}{|c|c|c|}
\hline \multicolumn{3}{|c|}{ Table 8. Simulation history output file } \\
\hline Output variable & Format & Description \\
\hline $\begin{array}{l}\text { verno } \\
\text { jdate } \\
\text { jtime }\end{array}$ & $\begin{array}{l}\text { character }^{\star} 20 \\
\text { character }^{*} 11 \\
\text { character }^{\star} 8\end{array}$ & $\begin{array}{l}\text { Code version } \\
\text { Date } \\
\text { Time }\end{array}$ \\
\hline wdd & character ${ }^{*} 80$ & Problem title \\
\hline N/A & character ${ }^{\star} 4$ & Tracer problem flag ('trac' or blank) \\
\hline N/A & character*4 & Stress problem flag ('strs' or blank) \\
\hline m & integer & Number of nodes for which data are output \\
\hline $\begin{array}{l}\operatorname{mi} \\
\operatorname{cord}\left(m i,{ }^{*}\right)\end{array}$ & $\begin{array}{l}\text { integer } \\
\text { real* } 8\end{array}$ & $\begin{array}{l}\text { Node number } \\
X-, y-, \text { and } z \text {-coordinate of each node for which data are output ( } m \text { sets) }\end{array}$ \\
\hline N/A & character & $\begin{array}{l}\text { Data headings ( } 3 \text { lines) as follows: } \\
\text { headings } \\
\text { node flow enthalpy }(\mathrm{Mj} / \mathrm{kg}) \text { flow }(\mathrm{kg} / \mathrm{s}) \text { temperature }(\mathrm{deg} \mathrm{C}) \text { total } \\
\text { pressure }(\mathrm{Mpa}) \\
\text { capillary pressure }(\mathrm{Mpa}) \text { saturation }(\mathrm{kg} / \mathrm{kg})\end{array}$ \\
\hline \multicolumn{3}{|c|}{ For each time step: } \\
\hline days & real*8 & Simulation time \\
\hline \multicolumn{3}{|c|}{ followed by (for each specified output node): } \\
\hline $\begin{array}{l}\text { mi } \\
\text { qh(mi) } \\
\text { sk(mi) }\end{array}$ & $\begin{array}{l}\text { integer } \\
\text { real }^{*} 8 \\
\text { real }^{*} 8\end{array}$ & $\begin{array}{l}\text { Node number } \\
\text { Energy source }(\mathrm{MJ} / \mathrm{s}) \\
\text { Source strength }(\mathrm{kg} / \mathrm{s})\end{array}$ \\
\hline $\mathrm{t}(\mathrm{mi})$ & rea $^{\star} 8$ & Temperature $\left({ }^{\circ} \mathrm{C}\right)$ \\
\hline phi(mi) & real $^{*} 8$ & Pressure (MPa) \\
\hline pcp(mi) & real $^{*} 8$ & Capillary pressure (MPa) \\
\hline $\mathrm{s}(\mathrm{mi})$ & real*8 & Saturation (dimensionless) \\
\hline
\end{tabular}

4.1.4.4.4 Solute history output file. The solute history plot file records solute parameter values at selected nodes for each time step of the simulation (Table 9). The default solute history output file name is fehmn.trc.

\begin{tabular}{|lll|}
\hline \hline & \multicolumn{2}{c|}{ Table 9. Solute history output file } \\
\hline Output variable & Format & Description \\
\hline verno & character $^{*} 20$ & Code version \\
jdate & character $^{*} 11$ & Date \\
jtime & character $^{*} 8$ & Time \\
wdd & character 80 & Problem title \\
$\mathrm{m}$ & integer & Number of nodes for which data are output \\
mi & integer & Node number \\
cord $\left(\mathrm{mi}_{,}^{*}\right)$ & real ${ }^{*} 8$ & $X-, y-$, and $z$-coordinate of each node for which data are output (m sets) \\
nspeci & integer & Number of different species for tracer solution \\
\hline \hline
\end{tabular}




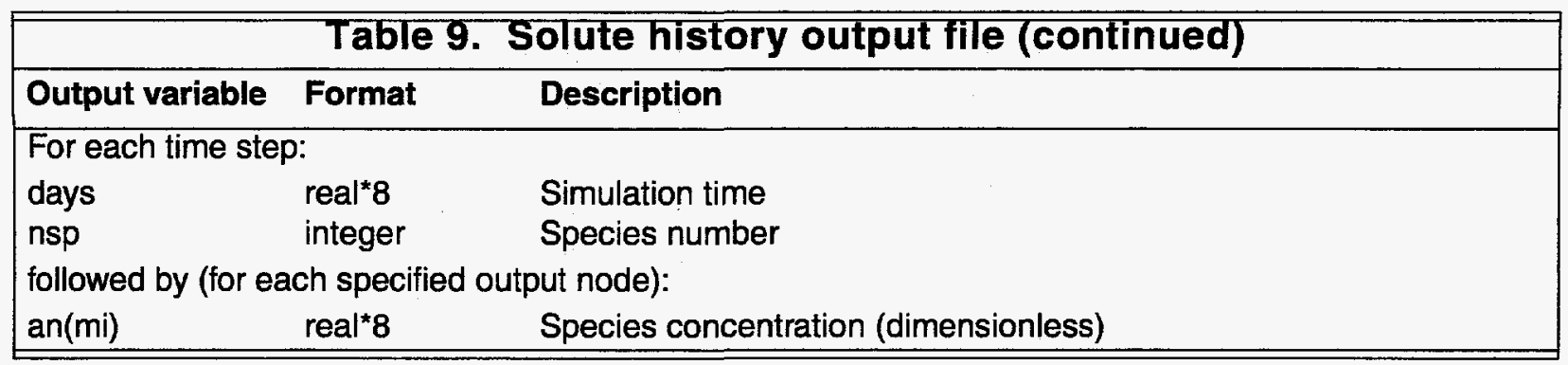

4.1.4.4.5 Contour plot output file. The contour plot records parameter values for each node at selected time steps of the simulation (Table 10). The default contour plot output file name is fehmn.con.

\begin{tabular}{|c|c|c|}
\hline \multicolumn{3}{|c|}{ Table 10. Contour plot output file } \\
\hline Output variable & Format & Description \\
\hline $\begin{array}{l}\text { verno } \\
\text { jdate } \\
\text { jtime }\end{array}$ & $\begin{array}{l}\text { character }^{\star} 20 \\
\text { character }^{*} 11 \\
\text { character }^{*} 8\end{array}$ & $\begin{array}{l}\text { Code version } \\
\text { Date } \\
\text { Time }\end{array}$ \\
\hline wdd & character ${ }^{*} 80$ & Problem title \\
\hline N/A & character 4 & Tracer problem flag ('trac' or blank) \\
\hline N/A & character*4 & Stress problem flag ('strs' or blank) \\
\hline neq & integer & Number of nodes for which data are output \\
\hline $\operatorname{cord}\left(i,{ }^{*}\right)$ & real*8 & $\begin{array}{l}X-, y-\text {, and } z \text {-coordinate of each node for which data is output (neq } \\
\text { sets) }\end{array}$ \\
\hline $\begin{array}{l}\text { ns } \\
\text { nei }\end{array}$ & $\begin{array}{l}\text { integer } \\
\text { integer }\end{array}$ & Number of nodes per element, total number of elements \\
\hline nelm(ns) & integer & Nodal connectivity information for each node of each element \\
\hline $\begin{array}{l}\text { pnx(neq) } \\
\text { pny(neq) } \\
\text { pnz(neq) }\end{array}$ & $\begin{array}{l}\text { real }{ }^{\star} 8 \\
\text { real }{ }^{*} 8 \\
\text { real }\end{array}$ & $x-, y-, z-p e r m e a b i l i t y ~\left(m^{2}\right)$ for each node \\
\hline $\begin{array}{l}\text { thx(neq) } \\
\text { thy(neq) } \\
\text { thz(neq) }\end{array}$ & $\begin{array}{l}\text { real }^{*} 8 \\
\text { real }^{*} 8 \\
\text { real }^{*} 8\end{array}$ & $X-, y-, z$-thermal conductivity $\left(\frac{W}{m \cdot K}\right)$ for each node \\
\hline $\begin{array}{l}\text { ps(neq) } \\
\text { cpr(neq) } \\
\text { pcp(neq) }\end{array}$ & $\begin{array}{l}\text { real }^{\star} 8 \\
\text { real }^{\star} 8 \\
\text { real }^{\star} 8\end{array}$ & $\begin{array}{l}\text { Porosity, rock specific heat }\left(\frac{\mathrm{MJ}}{\mathrm{kg} \cdot \mathrm{K}}\right) \text {, capillary pressure }(\mathrm{MPa}) \text { for } \\
\text { each node }\end{array}$ \\
\hline $\begin{array}{l}\text { idof } \\
\text { igrav } \\
\text { grav }\end{array}$ & $\begin{array}{l}\text { integer } \\
\text { integer } \\
\text { real*8 }\end{array}$ & $\begin{array}{l}\text { Number of degrees of freedom per node for the current problem } \\
\text { Direction of gravity in problem } \\
\text { Value of gravity }\end{array}$ \\
\hline nspeci & integer & Number of species if tracer solution is present \\
\hline \multicolumn{3}{|c|}{ For each specified time step: } \\
\hline $\begin{array}{l}\text { days } \\
\text { inj }\end{array}$ & $\begin{array}{l}\text { real }^{*} 8 \\
\text { real }^{*} 8\end{array}$ & $\begin{array}{l}\text { Simulation time } \\
\text { Injection phase ( } \geq 0 \text { : liquid; }<0 \text { : vapor) }\end{array}$ \\
\hline
\end{tabular}




\begin{tabular}{|c|c|c|}
\hline & Table & Contour plot output file (continued) \\
\hline Output variable & Format & Description \\
\hline If injection phase & s liquid, fo & node: \\
\hline N/A & real*8 & Liquid transmissibility/density [dil(neq)/rolf(neq)] \\
\hline rolf(neq) & real $^{*} 8$ & Liquid density \\
\hline N/A & real $^{*} 8$ & Pressure - capillary pressure [phi(neq) - pcp(neq)] \\
\hline$t($ neq) & real $^{*} 8$ & Temperature \\
\hline If injection phase & s vapor, fo & node: \\
\hline N/A & real ${ }^{*} 8$ & Vapor transmissibility/density [div(neq)/rovt(neq)] \\
\hline $\operatorname{rovf}(n e q)$ & real $^{\star} 8$ & Vapor density \\
\hline phi(neq) & real $^{*} 8$ & Pressure \\
\hline t(neq) & real*8 & Temperature \\
\hline If tracer solution is & present, & h species, for each node: \\
\hline $\begin{array}{l}\text { an(neq) or } \\
\text { anv(neq) }\end{array}$ & $\begin{array}{l}\text { real }^{*} 8 \\
\text { real*8 } 8\end{array}$ & Species concentration of liquid phase or vapor phase \\
\hline
\end{tabular}

4.1.4.4.6 Dual-porosity or double-porosity/doublepermeability contour plot output file. The dual-porosity or double-porosity/double-permeability contour plot file records parameter values for each dpdp (neq +1 to $2^{*}$ neq) or dual (neq +1 to $3 *$ neq) node at selected time steps of the simulation (Table 11). This file contains the same information as the regular contour plot file (see Table 10 above). The default dualporosity or double-porosity/double-permeability contour plot output file name is fehmn.dp.

4.1.4.4.7 Coefficient storage file. The coefficient storage output file contains finite-element coefficients calculated by the code. The default coefficient storage file name is fehmn.stor.

\begin{tabular}{|lll|}
\hline \hline & \multicolumn{2}{c|}{ Table 11. Coefficient storage file } \\
\hline Output variable & Format & Description \\
\hline verno & ${\text { character }{ }^{*} 20}$ Code version \\
jdate & character $11^{*}$ & Date \\
jtime & character $8^{*}$ & Time \\
wdd & character 80 & Problem title \\
iwtotl & integer & Number of storage locations needed to store geometric input types \\
neq & integer & Number of nodes \\
ncont & integer & Number of positions for which information needs to be stored \\
sx1(neq) & real ${ }^{*} 8$ & Volume associated with each node \\
nelm(ncont) & integer & Nodal-connectivity information for each connection \\
istrw(ncont) & integer & Starting position for each connection \\
nelmdg(neq) & integer & Position of element in connectivity array for each node \\
sx(iwtotl) & real ${ }^{*} 8$ & Finite-element geometric coefficient for each storage location \\
sxs(iwtotl) & real ${ }^{*} 8$ & Finite-element geometric coefficient for each storage location for \\
& & stress module if enabled \\
\hline \hline
\end{tabular}


4.1.4.4.8 Input check output file. The input check output file contains a summary of input information that may be of use in debugging or memory management of the code. The positions of maximum and minimum values of input parameters and derived quantities are given. Also provided is an analysis of array storage requirements. The default input check output file name is fehmn.chk.

4.1.4.4.9 Error output file. The error output file contains any error or warning messages issued by the code during a run (Table 12). The default error output file name is fehmn.err.

\begin{tabular}{|lll|}
\hline \hline & & Table 12. Error output file \\
\hline Output variable & Format & Description \\
\hline verno & character $^{*} 20$ & Code version \\
jdate & character $^{*} 11$ & Date \\
jtime & character $^{*} 8$ & Time \\
wdd & character $^{*} 80$ & Problem title \\
N/A & character & Warning and/or error messages issued during code execution (see \\
& & Section 4.1.4.6 for a summary of possible messages) \\
\hline
\end{tabular}

4.1.4.4.10 AVS log output file. The AVS log output file provides a record of AVS data output files names and corresponding simulation time (Table 13).

\begin{tabular}{|lll|}
\hline \hline & \multicolumn{1}{c|}{ Table 13. AVS Iog Output file } \\
\hline Output variable & Format & Description \\
\hline verno & character*2 & "\#" \\
jdate & character*20 & Code version \\
jtime & character"11 & Date \\
N/A & character*8 & Time \\
& character*80 & Heading : \# LOG AVS OUTPUT \\
wdd & character*2 & "\#" \\
Blank line followed by (for each AVS data file written): \\
root & character*80 & Problem title \\
icall & character*95 & Filename root \\
days & integer & File number (appended to root) \\
\hline
\end{tabular}

4.1.4.4.11 AVS header output files. The AVS ASCII header file contains information about the AVS output files and one line of header data as follows (Table 14).

\begin{tabular}{|c|c|c|}
\hline \multicolumn{3}{|c|}{ Table 14. AVS ASCII header output files } \\
\hline Output variable & Format & Description \\
\hline $\begin{array}{l}\text { verno } \\
\text { jdate }\end{array}$ & $\begin{array}{l}\text { character }^{*} 2 \\
\text { character }^{*} 20 \\
\text { character }^{*} 11\end{array}$ & $\begin{array}{l}\text { "\#" } \\
\text { Code version } \\
\text { Date }\end{array}$ \\
\hline
\end{tabular}




\begin{tabular}{|c|c|c|}
\hline \multicolumn{3}{|c|}{ Table 14. AVS ASCII header output files (continued) } \\
\hline Output variable & Format & Description \\
\hline $\begin{array}{l}\text { wdd } \\
\text { N/A }\end{array}$ & $\begin{array}{l}\text { character }{ }^{\star} 80 \\
\text { character }^{*} 2 \\
\text { character }^{\star} 80 \\
\text { character }\end{array}$ & 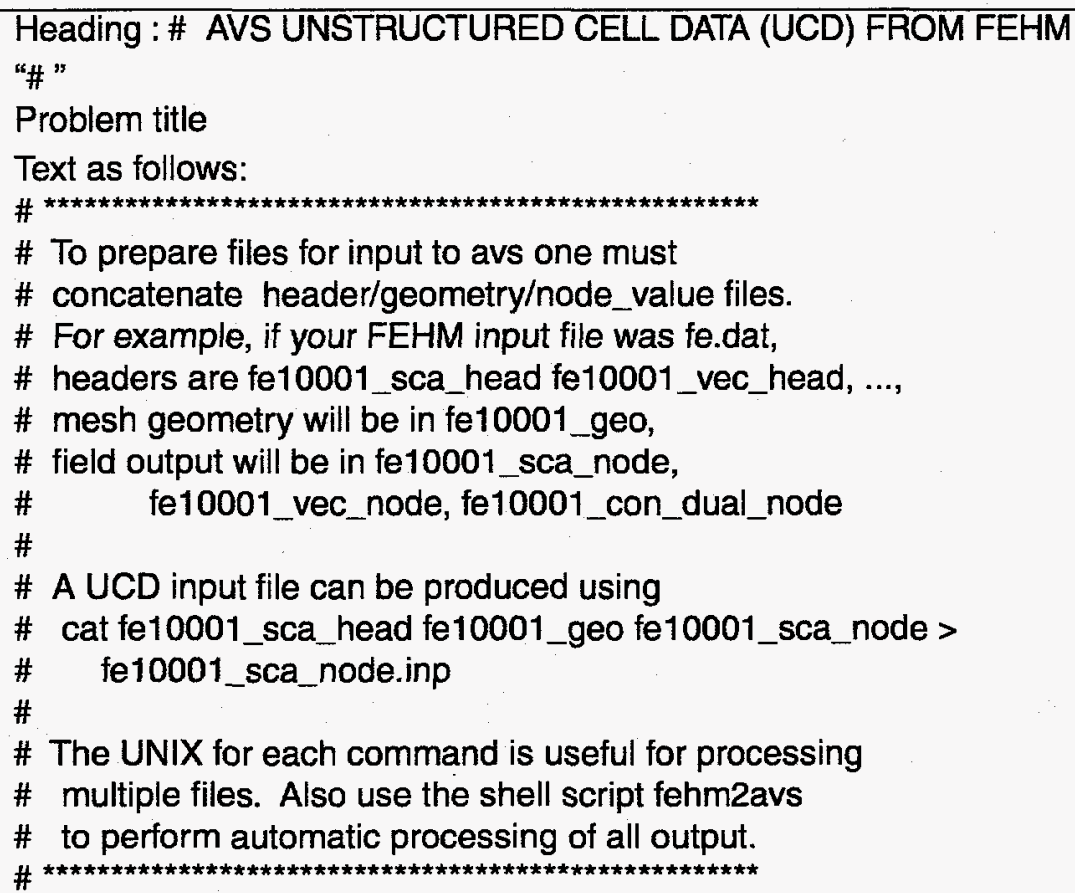 \\
\hline $\begin{array}{l}\text { neq } \\
\text { nei } \\
\text { num_ndata } \\
\text { num_cdata } \\
\text { num_mdatar }\end{array}$ & $\begin{array}{l}\text { integer } \\
\text { integer } \\
\text { integer } \\
\text { integer } \\
\text { integer }\end{array}$ & $\begin{array}{l}\text { Number of nodes } \\
\text { Number of cells (elements) } \\
\text { Number of data components for the nodes } \\
\text { Number of data components for the cells (0) } \\
\text { Number of data components for the model }(0)\end{array}$ \\
\hline
\end{tabular}

The AVS binary header file contains only the header data as follows in 21 bytes (Table 15).

\begin{tabular}{|lll|}
\hline & \multicolumn{2}{c|}{ Table 15. AVS binary header output files } \\
\hline Output variable & Format & Description \\
\hline num_nodes & 1 byte int & The number "7" indicating binary file \\
num_cells & 4 byte int & Number of nodes \\
num_node_data & 4 byte int & Number of cells (elements) \\
num_cell_data & 4 byte int & Number of data components for the nodes \\
num_model_data & 4 byte int & Number of data components for the cells (0) \\
\hline \hline
\end{tabular}

4.1.4.4.12 AVS geometry output file. The AVS geometry file contains node, coordinate, cell, and material data. The ASCII file contains the data as follows (Table 16). 


\begin{tabular}{|lll|}
\hline \hline & \multicolumn{2}{c|}{ Table 16. AVS ASCII geometry output file } \\
\hline Output variable & Format & Description \\
\hline $\mathrm{i}$ & integer & Node id \\
$\mathrm{x}, \mathrm{y}, \mathrm{z}$ & real*8 & $\mathrm{X}-, \mathrm{y}-, \mathrm{z}$-coordinate for each node \\
$\mathrm{i}$ & integer & Cell id \\
ipropelm & integer & Material id \\
char_type & character`5 & Cell type \\
neim & integer & List of cell vertices for each cell \\
\hline \hline
\end{tabular}

The binary (unformatted) file contains the data as follows (Table 17).

\begin{tabular}{|lll|}
\hline & \multicolumn{2}{c|}{ Table 17. AVS binary geometry output file } \\
\hline Output variable & Format & Description \\
\hline num_nlist & 4 byte int & Number of nodes in connection list \\
i & 4 byte int & Cell id \\
ipropm & 4 byte int & Material id \\
ns & 4 byte int & Num nodes \\
elem_type & 4 byte int & Cell type - cell information for each cell \\
np & num_nlist 4 byte ints & Node list - cell topology (connectivity list) \\
$x$ & num_nodes 4 byte & X-coordinates \\
y & floats & \\
& num_nodes 4 byte & Y-coordinates \\
$z$ & floats & \\
& num_nodes 4 byte & Z-coordinates \\
\hline \hline
\end{tabular}

4.1.4.4.13 AVS data output files. The ASCII node data files contain the number of data components and size, a label/unit description for each data component, and the associated data for each node as follows (Table 18).

\begin{tabular}{|c|c|c|}
\hline \multicolumn{3}{|c|}{ Table 18. AVS ASCII data output files } \\
\hline Output variable & Format & Description \\
\hline $\begin{array}{l}\text { N/A } \\
\text { title }\end{array}$ & $\begin{array}{l}\text { integer } \\
\text { character } 80\end{array}$ & $\begin{array}{l}\text { Number of data components and size } \\
\text { Variable label and output units for each data component }\end{array}$ \\
\hline \multicolumn{3}{|c|}{ Material properties data output for each node. } \\
\hline i & integer & Node \\
\hline pnx, pny, pnz & real*8 & Permeability in $x-, y-$, and $z$-direction $\left(\mathrm{m}^{2}\right)$ \\
\hline thx, thy, thz & real $^{*} 8$ & Thermal conductivity in $x-, y-$, and $z$-direction $\left(\frac{w}{m \cdot K}\right)$ \\
\hline ps & real $^{*} 8$ & Porosity \\
\hline cpr & real ${ }^{\star} 8$ & Rock specific heat $\left(\frac{\mathrm{MJ}}{\mathrm{kg} \cdot \mathrm{K}}\right)$ \\
\hline pcp & real $^{\star} 8$ & Capillary pressure (MPa) \\
\hline irlp & real*8 & Relative-permeability model \\
\hline icap & real $^{*} 8$ & Capillary-pressure model \\
\hline
\end{tabular}




\begin{tabular}{|c|c|c|}
\hline & Table & S ASCII data output files (continu \\
\hline Output variable & Format & Description \\
\hline Scalar parameter & that mas & ut for each node (up to 4). \\
\hline i & integer & Node \\
\hline $\mathbf{s}$ & real & Saturation \\
\hline $\mathrm{t}$ & real & Temperature $\left({ }^{\circ} \mathrm{C}\right)$ \\
\hline phi & real & Liquid pressure (MPa) \\
\hline phi - pcp & real & Vapor pressure (MPa) \\
\hline Vector parameter & that may & ut for each node. \\
\hline $\begin{array}{l}\text { pnxl, pnyl, pnzl } \\
\text { pnxv, pnyv, pnzv }\end{array}$ & $\begin{array}{l}\text { real } \\
\text { real }\end{array}$ & $\begin{array}{l}\text { Liquid velocity }(\mathrm{m} / \mathrm{s}), x-, y-\text {, and } z \text {-component } \\
\text { Vapor velocity }(\mathrm{m} / \mathrm{s}), x-, y-\text {, and } z \text {-component }\end{array}$ \\
\hline Solute concentrat & ons that & utput for each node (up to 20 ). \\
\hline an & real & Tracer concentration \\
\hline
\end{tabular}

The binary (unformatted) AVS data files use the following format for the data types described above (Table 19).

\begin{tabular}{|lll|}
\hline \hline & \multicolumn{2}{c|}{ Table 19. AVS binary data output files } \\
\hline Output variable & Format & Description \\
\hline $\begin{array}{l}\text { See previous } \\
\text { table }\end{array}$ & $\begin{array}{l}\text { 1024 byte } \\
\text { string }\end{array}$ & Node data labels \\
& 1024 byte & Node data units \\
& string & \\
& 4 byte int & Number of node components \\
& 4 byte floats & Node-component list \\
& 4 byte floats & Minimums for node data \\
& 4 byte floats & Maximums for node data \\
& 4 byte floats & Data blocks with values for each node \\
\hline \hline
\end{tabular}

\subsubsection{Displays and reports}

4.1.4.5.1 I/O prompt display. The following file description display appears on the screen when fehm is executed and I/O prompts are invoked (see Section 4.1.4.3 in this chapter above).

version FEHM 01.00 [machine] 96/05/29 15:34:29

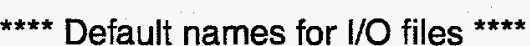

control file : fehmn.files

input file : filen.*

geometry data file: filen.*

zone data file : filen.*

output file : filen.out

read file (if it exists): filen.ini

write file (if it exists): filen.fin

history plot file : filen.his

tracer history plot file: filen trc 
contour plot file: filen.con

dual or dpdp contour plot file: filen.dp

stiffness matrix data read/write file: filen.stor

input check file : filen.chk

${ }^{\star \star \star *}$ where ${ }^{\star \star \star \star}$

"filen." may be 100 characters maximum. If a name is not entered when prompted for, a default file name is used. "fehmn.dat" is the default used for the input file name.

${ }^{* \star * *}$ note ${ }^{* * \star \star}$

A save file and input check file are always written. If you do not provide a name for these files, the following defaults will be used: fehmn.fin, fehmn.chk.

After terminal I/O has been completed, the following display reporting what was input (user-input responses shown in $\langle>$ ) is shown prior to the prompt asking if the I/O data are OK.

Not using thy output <none $>$ or First reference output node will be written to tty <some> or All reference output nodes will be written to tty <all>

File purpose - Variable - Unit number - File name

control - iocntl - 0 - not using

input $\quad$ - inpt- $11 \quad-$ <input file name>

geometry - incoor-11- <geometry data file name>

zone - inzone- 11 - <zone data file name>

output - iout-14 - <output data file name>

initial state $\quad$ - iread- $0 \quad-<$ restart input file name $>$

final state $\quad$ - isave- $16 \quad-<$ restart output file name>

time history - ishis- 17 - <history plot file name>

time his.(tr) - istrc- $18 \quad-<$ solute history plot file name>

contour plot - iscon- $19-<$ contour plot file name>

con plot (dp) - iscon1- 20 - <dp contour plot file name> 


$$
\begin{aligned}
& \text { fe coef stor } \quad \text { - isstor- } 21 \quad \text { - <coefficient storage file name> } \\
& \text { input check - ischk- } 22 \text { - <input check output file name> }
\end{aligned}
$$

Value provided to subroutine user: <user subroutine number>

4.1.4.5.2 Terminal run time display. If terminal output is invoked (tty_flag "all" or "some"), a summary of the I/O files used (as shown above in Section 4.1.4.5.1 of this chapter) is displayed. This information is followed by the maximum number of nodes in the problem, the problem title, macro control statements read, and array storage parameters as shown in the example on the next page. The output marked with a "bar" is displayed only when the "all" flag is used.

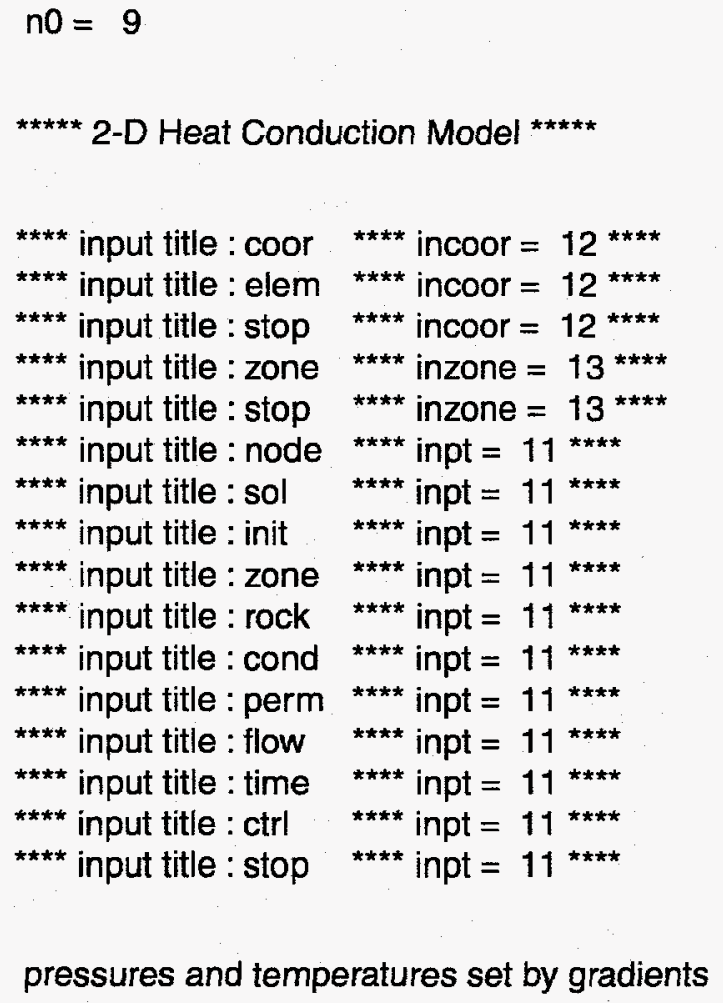


time for reading input, forming coefficients $0.667 \mathrm{E}-01$

${ }^{\star * * \star}$ analysis of input data on file fehmn.chk

volumes and fe coefficients checked

storage for fe coefficients 12 allocated $\quad 12$

Information that is displayed at each time step if either tty_flag is used is illustrated below. This information includes timing, equation performance, and mass and energy balances. The output marked with a "bar" is displayed at selected time steps for the selected output nodes only when the "all" flag is used. Additional parameters may be displayed depending on the type of problem (i.e., transport or double porosity) being executed.

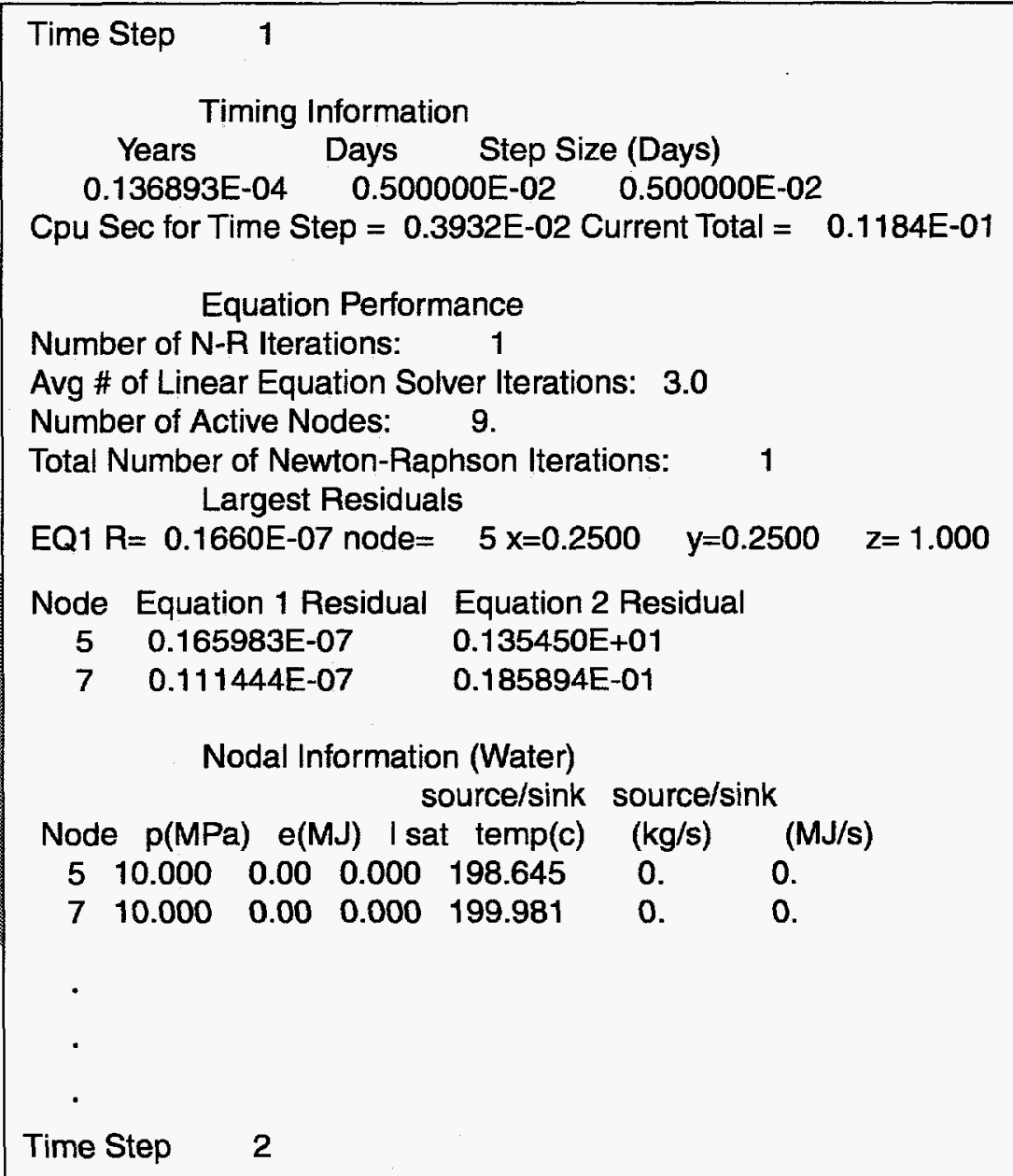




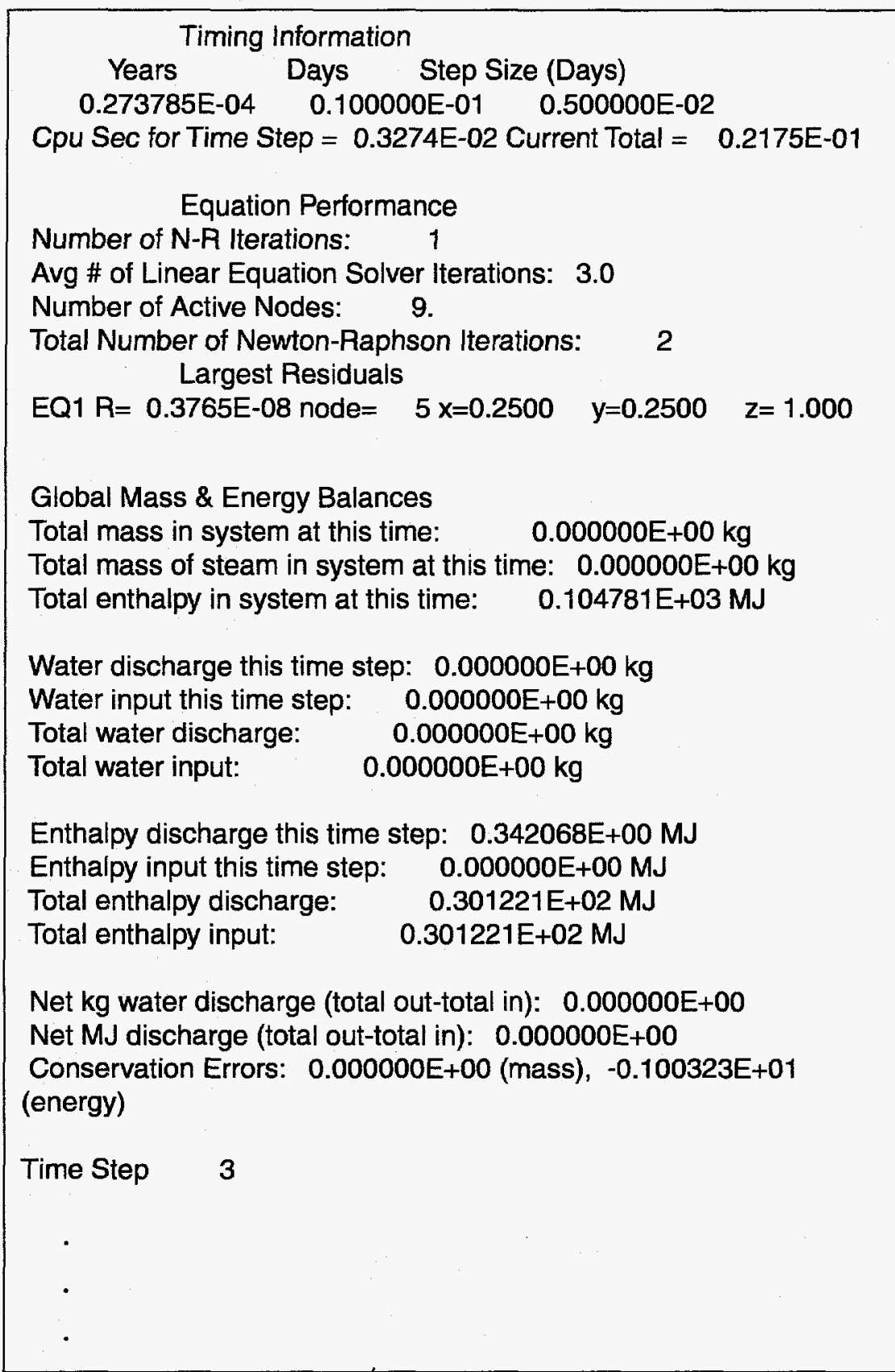

\subsubsection{Messages}

Fatal error conditions and messages for the fehm program are given in Table 20. Warning messages (nonfatal errors or informational messages) are given in Table 21. 
II. Software Design

PRIMARY PRODUCT DESCRIPTIONS

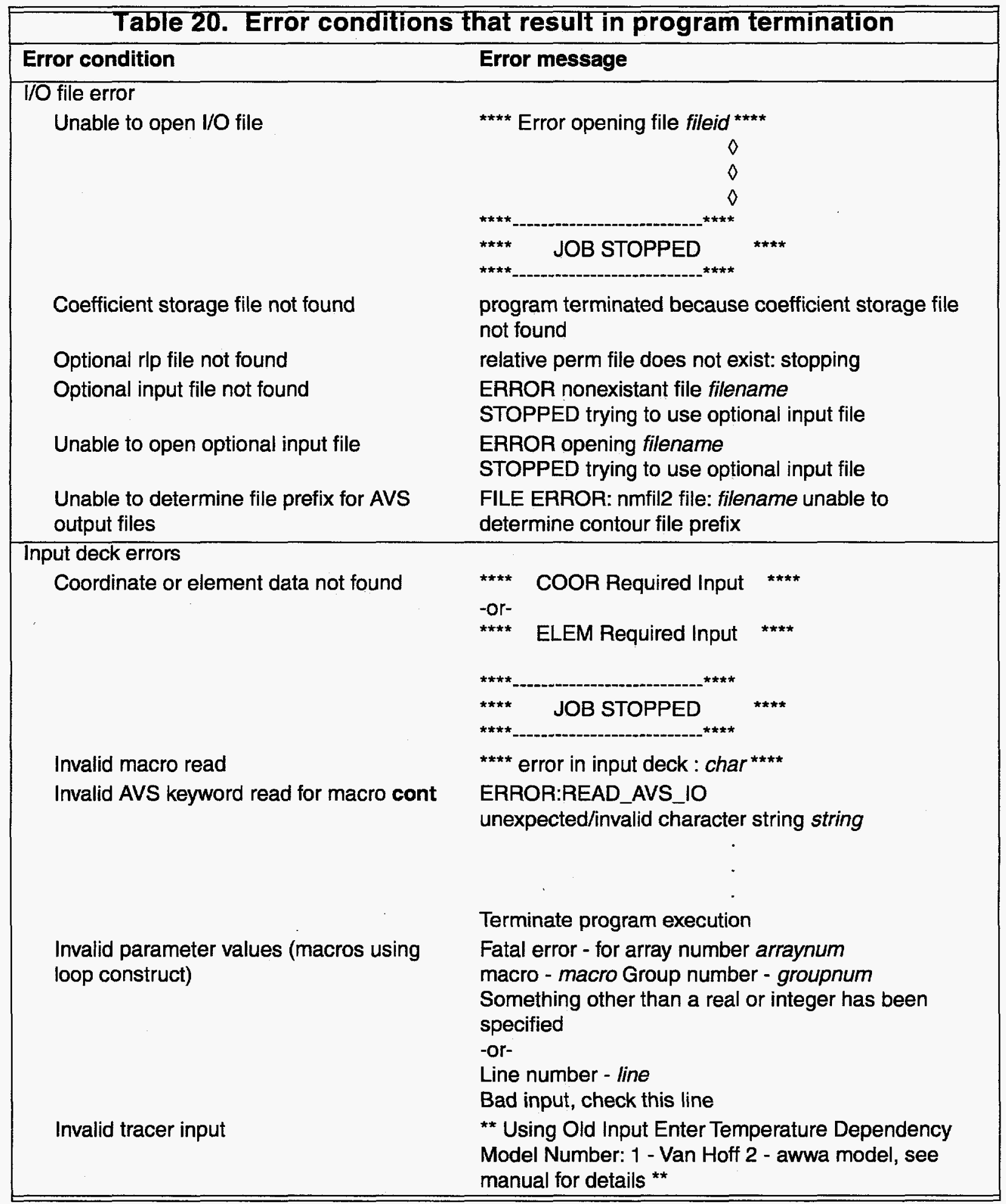




\begin{tabular}{|c|c|}
\hline \multicolumn{2}{|c|}{ Table 20. Error conditions that result in program termination (continued) } \\
\hline Error condition & Error message \\
\hline Invalid transport conditions & $\begin{array}{l}\text { Fatal error. You specified a Henrys Law species with } \\
\text { initial concentrations input for the vapor phase (icns = } \\
-2 \text { ), yet the Henrys Constant is computed as } 0 \text { for } \\
\text { species number speciesnum and node number } \\
\text { nodenum. If you want to simulate a vapor-borne } \\
\text { species with no interphase transport, then you must } \\
\text { specify a gaseous species (icns = -1). }\end{array}$ \\
\hline $\begin{array}{l}\text { Invalid flag specified for diffusion } \\
\text { coefficient calculation }\end{array}$ & $\begin{array}{l}\text { ERROR -- Illegal Flag to concadiff } \\
\text { Code Aborted in concadiff }\end{array}$ \\
\hline $\begin{array}{l}\text { Optional input file contains data for wrong } \\
\text { macro }\end{array}$ & $\begin{array}{l}\text { ERROR --> Macro name in file for macro macroname } \\
\text { is wrong_macroname } \\
\text { STOPPED trying to use optional input file }\end{array}$ \\
\hline \multicolumn{2}{|l|}{ Invalid parameters set } \\
\hline Dual porosity & $\begin{array}{l}{ }^{\star \star \star \star *} \text { check fracture volumes, stopping } \\
\star * \star \star * * \\
\text { check equivalent continuum VGs }\end{array}$ \\
\hline Noncondensible gas & $\begin{array}{l}\text { cannot input ngas temp in single phase } \\
\text {-or- } \\
\text { ngas pressure it } 0 \text { at temp and total press given } \\
\text { max allowable temperature temp } \\
\text {-or- } \\
\text { ngas pressure gt total pressure } i=i \\
\text {-or- } \\
\text { ngas pressure it } 0 \text {. }\end{array}$ \\
\hline Particle tracking & $\begin{array}{l}\text { ERROR: Pcnsk in ptrk must be either always positive } \\
\text { or always negative. } \\
\text { Code aborted in set_ptrk.f }\end{array}$ \\
\hline Tracer & $\begin{array}{l}\text { ERROR: Can not have both particle tracking (ptrk) and } \\
\text { tracer input (trac). } \\
\text { Code Aborted in concen.f }\end{array}$ \\
\hline \multicolumn{2}{|l|}{ Insufficient storage } \\
\hline Geometric coefficients & program terminated because of insufficient storage \\
\hline Dual porosity & 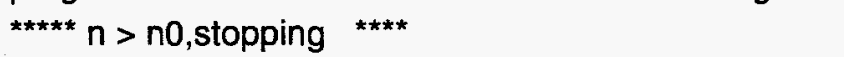 \\
\hline $\begin{array}{l}\text { Too many negative volumes or finite-element } \\
\text { coefficients }\end{array}$ & $\begin{array}{l}\text { too many negative volumes: stopping } \\
\text {-or- } \\
\text { too many negative coefficients : stopping }\end{array}$ \\
\hline Unable to compute local coordinates & $\begin{array}{l}\text { iteration in zone did not converge, izone = zone please } \\
\text { check icnl in macro CTRL }\end{array}$ \\
\hline Singular matrix in LU decomposition & singular matrix in ludemp \\
\hline Solution failed to converge & $\begin{array}{l}\text { timestep less than daymin timestep_number } \\
\text { current_timestep_size current_simulation_time } \\
\text {-or- } \\
\text { Tracer Time Step Smaller Than Minimum Step } \\
\text { Stop in resettrc }\end{array}$ \\
\hline
\end{tabular}




\begin{tabular}{|c|c|}
\hline \multicolumn{2}{|c|}{ Table 21. Warning conditions and messages } \\
\hline Warning condition & Message \\
\hline $\begin{array}{l}\text { Thermodynamic variables out of bounds } \\
\text { (Note: The code will cut the time step until it can } \\
\text { successfully finish a time step. Halving of the time } \\
\text { step could eventually result in code termination if } \\
\text { the solution fails to converge.) }\end{array}$ & $\begin{array}{l}\text { out of bounds:node node_number } \\
\mathrm{p}=\text { current_fluid_pressure } \mathrm{t}=\mathrm{current} \text { _temperature } \\
\text {-or- } \\
\mathrm{p}=\text { current_fluid_pressure } \mathrm{s}=\text { current_saturation }\end{array}$ \\
\hline Improper parameter set for reacting species & $\begin{array}{l}\text { Warning rate_power is not zero for solid species } \\
\text {-or- } \\
\text { You must specify either } 1 \text { or }-1 \text { for } h \_m u l t . \text { Check your } \\
\text { input. Default is to let the liquid in Henrys law react } \\
\text {-or- } \\
\text { ERROR: FEHM cannot simulate a solid-liquid-vapor } \\
\text { rxn } \\
\text {-or- } \\
\text { No species have been specified for rxn number irxn }\end{array}$ \\
\hline Negative volume or finite-element coefficient & $\begin{array}{l}\text { warning : negative volume at node } i \text { volume }=s \times 1(i) \\
\text { maximum volume }=\text { vol_max } \\
\text {-or- } \\
\text { warning : negative fe coefficient at node i neighbor } \\
\text { node } n c o n(j) \text { coeff sum }=\text { sumsx } \\
\text { maximum area divided by length }=\text { vol_max }\end{array}$ \\
\hline \multicolumn{2}{|l|}{ Error writing AVS output } \\
\hline Error opening file & OPEN ERROR: filename \\
\hline Binary geometry file & $\begin{array}{l}\text { WRITE ERROR: geo geometry_file } \\
\text { CLOSE ERROR: geo geometry_file }\end{array}$ \\
\hline Binary header file & $\begin{array}{l}\text { WRITE ERROR: binary header header_file_type } \\
\text { CLOSE ERROR: binary header header_file_type }\end{array}$ \\
\hline Binary node file & $\begin{array}{l}\text { WRITE ERROR: binary node node_file_type } \\
\text { CLOSE ERROR: binary node node_file_type }\end{array}$ \\
\hline $\begin{array}{l}\text { ASCIl geometry file (wrong format } \\
\text { specified) }\end{array}$ & $\begin{array}{l}\text { AVS_WRITE_CORD } \\
\text { Unformatted IO not implemented } \\
\text { No action }\end{array}$ \\
\hline & $\begin{array}{l}\text { AVS_WRITE_STRUC } \\
\text { Unformatted IO not implemented } \\
\text { No action }\end{array}$ \\
\hline ASCII geometry file (invalid output format) & $\begin{array}{l}\text { AVS_WRITE_CORD } \\
\text { Invalid output format } \\
\text { No action }\end{array}$ \\
\hline & $\begin{array}{l}\text { AVS_WRITE_STRUC } \\
\text { Invalid output format } \\
\text { No action }\end{array}$ \\
\hline ASCII scalar node file & $\begin{array}{l}\text { ERROR:WRITE_AVS_NODE_S } \\
\text { nscalar = scalars_requested is greater than } \\
\text { maxscalar = max_number_of_scalars } \\
\text { Subroutine only able to handle up to } 8 \text { scalars }\end{array}$ \\
\hline
\end{tabular}




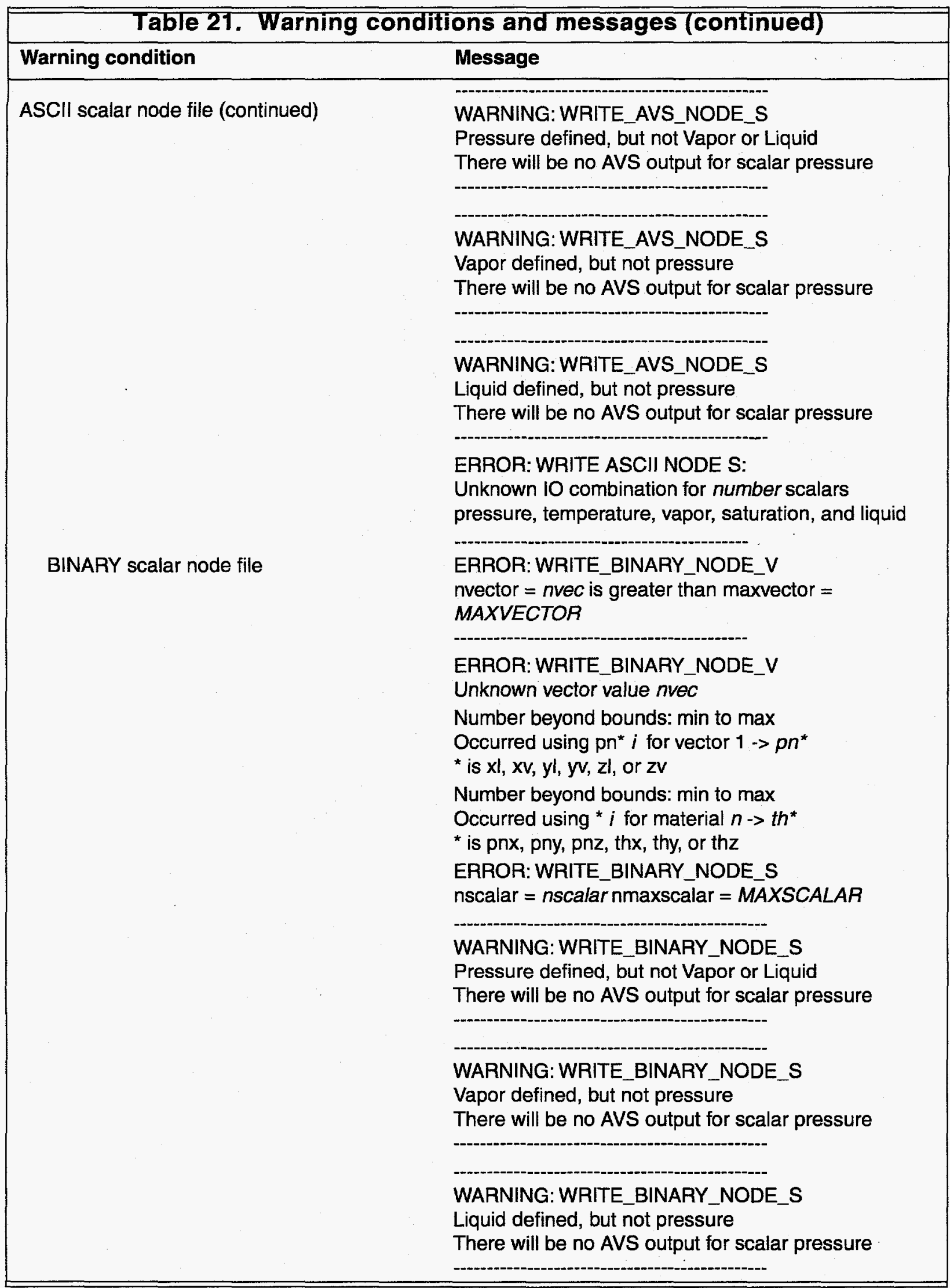




\begin{tabular}{|ll|}
\hline \hline \multicolumn{2}{|c|}{ Table 21. Warning conditions and messages (continued) } \\
\hline Warning condition & Message \\
\hline BINARY scalar node file (continued) & ERROR:WRITE_BINARY_NODE_S: \\
& Unknown IO combination for number scalars \\
& pressure, temperature, vapor, saturation, and liquid \\
& ERROR: WRITE_BINARY_NODE_S \\
Unknown scalar value $n s c a l a r$ \\
Number beyond bounds: min to max \\
Occurred using * $i$ for ? > pn* \\
* scalar parameter, ? description \\
ERROR: WRITE_BINARY_NODE_CON \\
nspeci $=$ nspeci is greater than max con $=$ \\
\hline
\end{tabular}

\subsubsection{Other input/output N/A}


Chapter III:

\section{Verification and Validation Plan}




\subsection{PURPOSE}

The goal of the Verification and Validation (V\&V) effort is to test the options and features of the FEHM application that satisfy the requirements specified in Chapter I, "Software Requirements Specification." The current chapter, "Verification and Validation Plan," details the test cases to be performed, many of which were developed for prior versions of FEHM (Zyvoloski et al. 1992; Zyvoloski and Dash 1991a and 1991b), and lists the acceptance criteria that must be satisfied.

\subsection{FUNCTIONAL DESCRIPTION}

The goal of the verification part of the $V \& V$ effort is to check the operation of the code for a variety of simulations. These simulations will encompass the options and features of FEHM that will be used in actual simulations of flow and transport in the unsaturated zone and in modeling and interpreting pressure transient tests, temperature logs, and tracer tests (both conservative and reactive tracers) performed in the saturated zone. The overall verification of FEHM will be accomplished by comparison of results with published analytical solutions and with results from other codes. Because of the nonlinear nature of the water and steam properties, additional verification of the thermodynamics package is included. The verification test cases in Section 4.0 of this chapter are organized in groups based on the functions and features being tested and include: testing of the thermodynamic functions (Section 4.1); heat transfer tests (Sections 4.2 and 4.3); isothermal fluid flow tests (Sections 4.4-4.7); combined heat and mass transfer tests (Sections 4.8-4.11); and solute transport tests (Sections 4.12-4.17).

The model validation part of the V\&V effort is in an early stage of development. The goals of validation include modeling of appropriate field tests when experimental data are available from the Yucca Mountain Site Characterization Project. Model validation will not explicitly be discussed in this document but will be included in a later revision when data become available.

\subsection{ASSUMPTIONS AND LIMITATIONS}

The verification effort assumes that the FEHM application is installed on systems running the UNIX operating system (i.e., Sun Workstations, HP, Cray, IBM, SGI) and that dynamic memory allocation is supported.

When comparing against an analytical solution or other code, it is assumed that close agreement between FEHM and the analytical solution or alternate-model results constitutes a verification of both. Fortuitous agreement between models using entirely different mathematical solution procedures is judged to be extremely unlikely.

The acceptance criteria are based on maximum error, percent error, or root-mean-square (RMS) error. These are standard error measures used in mathematics and the physical sciences. The RMS error indicates average error over the solution domain, and the maximum and percent errors represent the largest errors in the domain. The maximum error is defined to be the absolute value of the maximum difference (error) between the values of the FEHM solution $(F S)$ and the analytical or alternate-model solution $(A S)$, where the error between each point is computed as Error $=a b s(A S-F S)$. The percent error $(P E)$ is defined as the error divided by the analytical or alternate-model solution times 100 and is computed for 
each point using $P E=a b s\left(\frac{A S-F S}{A S}\right) \times 100$. The $R M S$ error is calculated using the following: $R M S=\sqrt{\sum\left(\frac{A S-F S}{A S}\right)^{2}} /($ Number of points compared $)$

A relatively new module has been included that simulates solute transport using particle tracking. A series of test cases are being developed but are not yet ready to be included in this version of the V\&V documentation. The full set of verification tests for particle tracking will be included in the next version of this document.

Test cases for some other capabilities (such as air/water diffusion and use of unstructured grids) and some constitutive relationships (such as rock compressibility, variable thermal conductivity, and equation-of-state models) still need to be developed.

The validation effort assumes that the data will be collected to perform the validation within the LANL YMP. In particular, there are plans to collect suitable data for this validation exercise within the YMP Reactive Tracer Study Task and Dynamic Transport Task.

\subsection{VERIFICATION AND VALIDATION PLAN}

The V\&V tests outlined in this section will apply in their entirety to any version of the code, no matter what platform is being used. The results from different platforms should be identical to within three significant digits, because the only differences in the versions should be differences in machine precision. Table 1 in Appendix B provides a summary of the FEHM requirements and a listing of which problems test them. 


\subsection{Testing of Thermodynamic Functions}

\subsubsection{Purpose}

Density, viscosity, and enthalpy are strong functions of pressure $(P)$ and temperature $(T)$. Because FEHM is an implicit code that uses a NewtonRaphson iteration, derivatives of the thermodynamic functions with respect to $P$ and $T$ are also required. The equations for all water properties listed in Section 4.1.4 will be evaluated over the full range of pressure and temperature for which they were created.

The equation for the saturation line is important for the determination of the phase state of the liquid vapor system. The saturation functions will also be evaluated over the full range of pressure and temperature for which they were created.

\subsubsection{Functional description}

The test suite consists of a set of simple programs that call the FEHM thermodynamic functions with pressures and temperatures in the prescribed ranges. An agreement between values generated by FEHM and values in the NBS / NRC Steam Tables (Harr et al. 1984) with a deviation of less than $2 \%$ over the entire range of temperatures and pressures will constitute a verification of the FEHM thermodynamics functions.

\subsubsection{Assumptions and limitations}

The FEHM thermodynamics functions were created for a specified range of temperatures and pressures. The tests are conducted only within the specified range. Valid ranges for each function are given below under the sections entitled Required Inputs.

The thermodynamics functions are being tested independently of the FEHM code, so they do not test the response of the code when pressures or temperatures are out of range. For further discussion of code behavior in these cases, see the previous chapter and the FEHM document "Summary of Models and Methods" (Zyvoloski et al. 1997a).

\subsubsection{Summary of test cases}

\subsubsection{Enthalpy}

4.1.4.1.1 Function Tested. This test verifies that the rational polynomial expression implemented in FEHM correctly computes the enthalpy as a function of pressure and temperature.

4.1.4.1.2 Test Scope. This test is a verification test.

4.1.4.1.3 Requirements Tested. Requirement 3.3.1, "Pressure- and temperature-dependent water properties," of Chapter I is verified by this test.

4.1.4.1.4 Required Inputs. The pressures $(P)$ and temperatures $(T)$ at which to calculate enthalpy are required: for liquid enthalpies, the range of $0.001 \leq P \leq 110.0 \mathrm{MPa}$ and 
$15 \leq T \leq 360^{\circ} \mathrm{C}$; for vapor enthalpies, the range of $0.001 \leq P \leq 20.0 \mathrm{MPa}$ and $15 \leq T \leq 360^{\circ} \mathrm{C}$.

4.1.4.1.5 Expected Outputs. Values for enthalpy from the FEHM thermodynamics functions will be output and compared to values obtained from the NBS / NRC Steam Tables. Values within $2 \%$ of the Steam Tables data will be considered acceptable.

\subsubsection{Density}

4.1.4.2.1 Function Tested. This test verifies that the rational polynomial expression implemented in FEHM correctly computes the density as a function of pressure and temperature.

4.1.4.2.2 Test Scope. This test is a verification test.

4.1.4.2.3 Requirements Tested. Requirement 3.3.1, "Pressure- and temperature-dependent water properties," of Chapter I is verified by this test.

4.1.4.2.4 Required Inputs. The pressures $(P)$ and temperatures $(T)$ at which to calculate density are required: for liquid densities, the range of $0.001 \leq P \leq 110.0 \mathrm{MPa}$ and $15 \leq T \leq 360^{\circ} \mathrm{C}$; for vapor densities, the range of $0.001 \leq P \leq 20.0 \mathrm{MPa}$ and $15 \leq T \leq 360^{\circ} \mathrm{C}$.

4.1.4.2.5 Expected Outputs. Values for density from the FEHM thermodynamics functions will be output and compared to values obtained from the NBS/NRC Steam Tables. Values within $2 \%$ of the Steam Tables data will be considered acceptable.

\subsubsection{Compressibility (derivative of density with respect to pressure)}

4.1.4.3.1 Function Tested. This test verifies that the rational polynomial expression implemented in FEHM correctly computes the compressibility (derivative of density with respect to pressure) as a function of pressure and temperature.

4.1.4.3.2 Test Scope. This test is a verification test.

4.1.4.3.3 Requirements Tested. Requirement 3.3.1, "Pressure- and temperature-dependent water properties," of Chapter I is verified by this test.

4.1.4.3.4 Required Inputs. The pressures $(P)$ and temperatures $(T)$ at which to calculate compressibility are required: for liquid compressibilities, the range of $0.001 \leq P \leq 110.0 \mathrm{MPa}$ and $15 \leq T \leq 360^{\circ} \mathrm{C}$; for vapor compressibilities, the range of $0.001 \leq P \leq 20.0 \mathrm{MPa}$ and $15 \leq T \leq 360^{\circ} \mathrm{C}$.

4.1.4.3.5 Expected Outputs. Values for compressibility from the FEHM thermodynamics functions will be output and compared to values obtained from the NBS/NRC Steam Tables.

Compressibility is a commonly used property of the fluid but 
does not appear directly in the equations that are solved and does not affect the solution. The compressibility is not directly derived from the Steam Tables data but is computed from the derivative of the density function. Therefore, values within $10 \%$ of the Steam Tables data will be considered acceptable.

\subsubsection{Viscosity}

4.1.4.4.1 Function Tested. This test verifies that the rational polynomial expression implemented in FEHM correctly computes the viscosity as a function of pressure and temperature.

4.1.4.4.2 Test Scope. This test is a verification test.

4.1.4.4.3 Requirements Tested. Requirement 3.3.1, "Pressure- and temperature-dependent water properties," of Chapter I is verified by this test.

4.1.4.4.4 Required Inputs. The pressures $(P)$ and temperatures $(T)$ at which to calculate viscosity are required: for liquid viscosities, the range of $0.001 \leq P \leq 110.0 \mathrm{MPa}$ and $15 \leq T \leq 360^{\circ} \mathrm{C}$; for vapor viscosities, the range of $0.001 \leq P \leq 20.0 \mathrm{MPa}$ and $15 \leq T \leq 360^{\circ} \mathrm{C}$.

4.1.4.4.5 Expected Outputs. Values for viscosity from the FEHM thermodynamics functions will be output and compared to values obtained from the NBS/NRC Steam Tables. Values within $2 \%$ of the Steam Tables data will be considered acceptable.

\subsubsection{Saturation pressure and temperature}

4.1.4.5.1 Function Tested. This test verifies that the rational polynomial expression implemented in FEHM correctly computes the pressure as a function of saturation temperature and the temperature as a function of saturation pressure.

4.1.4.5.2 Test Scope. This test is a verification test.

4.1.4.5.3 Requirements Tested. Requirement 3.3.2, "Properties of air and air/water vapor mixtures," of Chapter I is verified by this test.

4.1.4.5.4 Required Inputs. The temperatures $(T)$ at which to calculate saturation pressure and the pressures $(P)$ for which to calculate saturation temperature are required: in the range of $0.00123 \leq P \leq 14.59410 \mathrm{MPa}$ and $10 \leq T \leq 340^{\circ} \mathrm{C}$.

4.1.4.5.5 Expected Outputs. Values for saturation pressure and temperature from the FEHM thermodynamics functions will be output and compared to values obtained from the NBS / NRC Steam Tables. Values within $2 \%$ of the Steam Tables data will be considered acceptable. 


\subsection{Test of Heat Conduction}

\subsubsection{Purpose}

Though simple heat-conduction simulations without flow are not used in the modeling studies of Yucca Mountain, heat transfer is an important process in many calculations, including potential repository-heating calculations. Furthermore, it is convenient to use the analytical solutions available for 2-D and 3-D heat conduction in solids. The solutions give an excellent check on the purely geometric aspects of the code as well as the finite-element representation of second-order partial differential equations.

The code will be checked against both 2-D and 3-D analytical solutions with regular grid spacing for triangular, rectangular, prism, brick, tetrahedral, and mixed elements. All solutions will be for linear (constant parameter) problems.

\subsubsection{Functional description}

The test suite consists of a set of simulations, with heat conduction only, that model the same problem using different finite-element meshes. In addition to demonstrating that the heat-conduction problem has been correctly formulated, the test suite will demonstrate that the various element types have been correctly implemented.

\subsubsection{Assumptions and limitations}

The analytical solutions for 2-D and 3-D heat conduction are provided by Carslaw and Jaeger (1959). For two-dimensional heat conduction in a rectangle, the analytical solution takes the form:

$$
T=T_{s}+\frac{16\left(T_{0}-T_{s}\right)}{\pi^{2}}\left(\sum_{m=0}^{\infty} \sum_{n=0}^{\infty} \frac{(-1)^{m+n}}{(2 m+1)(2 n+1)} \cos \frac{(2 m+1) \pi x}{2 a} \cos \frac{(2 n+1) \pi y}{2 b} e^{-\alpha_{m, n} t}\right),
$$

where $\alpha_{m, n}=\frac{\kappa \pi^{2}}{4}\left[\frac{(2 m+1)^{2}}{a^{2}}+\frac{(2 n+1)^{2}}{b^{2}}\right]$ and the region is taken to be $-a<x<a,-b<y<b$.

Extended to three-dimensional heat conduction in a cube:

$$
T=T_{s}+\frac{64\left(T_{0}-T_{s}\right)}{\pi^{3}}\left(\sum_{l=0}^{\infty} \sum_{m=0}^{\infty} \sum_{n=0}^{\infty} \frac{(-1)^{l+m+n}}{(2 l+1)(2 m+1))(2 n+1)} \cos \frac{(2 l+1) \pi x}{2 a} \cos \frac{(2 m+1) \pi y}{2 b} \cos \frac{(2 n+1) \pi z}{2 c} e^{-\alpha_{l, m, n^{t}}}\right),
$$

where $\alpha_{l, m, n}=\frac{\kappa \pi^{2}}{4}\left[\frac{(2 l+1)^{2}}{a^{2}}+\frac{(2 m+1)^{2}}{b^{2}}+\frac{(2 n+1)^{2}}{c^{2}}\right]$ and the rectangular region is taken to be $-a<x<a,-b<y<b,-c<z<c$.

Heat conduction in a solid 1-meter square/cube with an initial temperature $T_{0}=200^{\circ} \mathrm{C}$ is modeled after a surface temperature $T_{s}=100^{\circ} \mathrm{C}$ is imposed at time $t=0$. Due to symmetry, only a quarter of the square, or an eighth of the cube ( 0.5 meters on a side), needs to be modeled (see Fig. 1). Table 22 
summarizes the rock properties and problem dimensions used for the heatconduction problem.
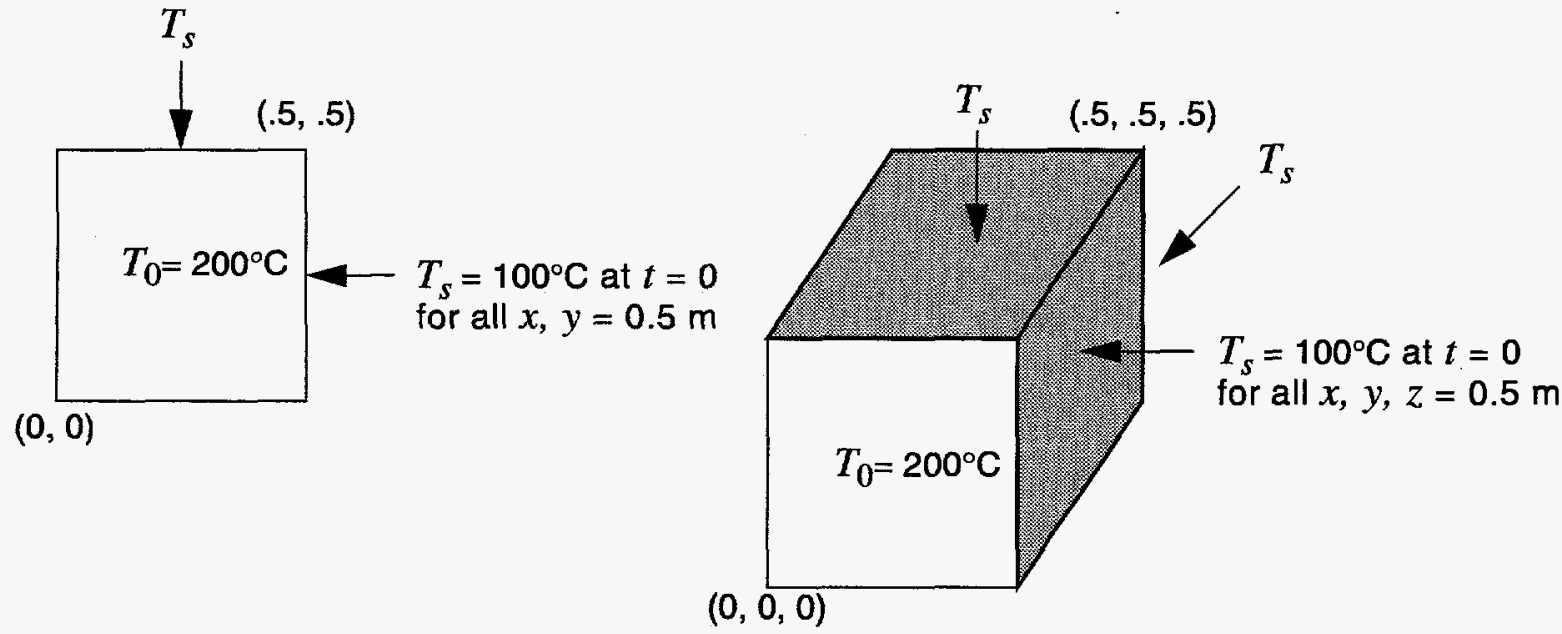

Figure 1. Schematic diagrams of 2-D and 3-D heat-conduction problems.

\begin{tabular}{|c|c|c|}
\hline \multicolumn{3}{|c|}{$\begin{array}{l}\text { Table 22. Input parameters for the 2-D and 3-D heat } \\
\text { conduction problems }\end{array}$} \\
\hline Parameter & Symbol & Value \\
\hline Rock thermal conductivity & $\kappa_{r}$ & $2.7 \frac{\mathrm{W}}{\mathrm{m} \cdot \mathrm{K}}$ \\
\hline Rock density & $\rho_{r}$ & $2700 \mathrm{~kg} / \mathrm{m}^{3}$ \\
\hline Rock specific heat & $C_{r}$ & $1000 \frac{\mathrm{J}}{\mathrm{kg} \cdot \mathrm{K}}$ \\
\hline Rock thermal diffusivity & $\kappa=\frac{\kappa_{r}}{\rho_{r} C_{r}}$ & $10^{-6} \mathrm{~m}^{2} / \mathrm{s}$ \\
\hline Width & $a$ & $0.5 \mathrm{~m}$ \\
\hline Length & $b$ & $0.5 \mathrm{~m}$ \\
\hline Height & $c$ & $0.5 \mathrm{~m}$ \\
\hline Node spacing & $\Delta x, \Delta y, \Delta z$ & $0.05 \mathrm{~m}$ \\
\hline Time step & $\Delta t$ & 0.005 days \\
\hline Total elapsed time & $t$ & $\begin{array}{l}4 \text { days }(2-D) \\
3 \text { days }(3-D)\end{array}$ \\
\hline Initial temperature & $T_{0}$ & $200^{\circ} \mathrm{C}$ \\
\hline Boundary conditions: & $=0.5 \mathrm{~m}$ & $100^{\circ} \mathrm{C}$ \\
\hline
\end{tabular}




\subsubsection{Summary of test cases}

\subsubsection{2-D heat conduction in a square}

4.2.4.1.1 Function Tested. This test verifies that FEHM correctly models two-dimensional heat conduction. It also verifies that the 2-D finite-element representation of 3-node triangles (triangular-element meshes), 4-node quadrilaterals (rectangular-element meshes), mixed-element meshes (containing both triangular and rectangular elements), and refined-element meshes (containing rectangular and trapezoidal elements) have been correctly implemented (see Fig. 2).
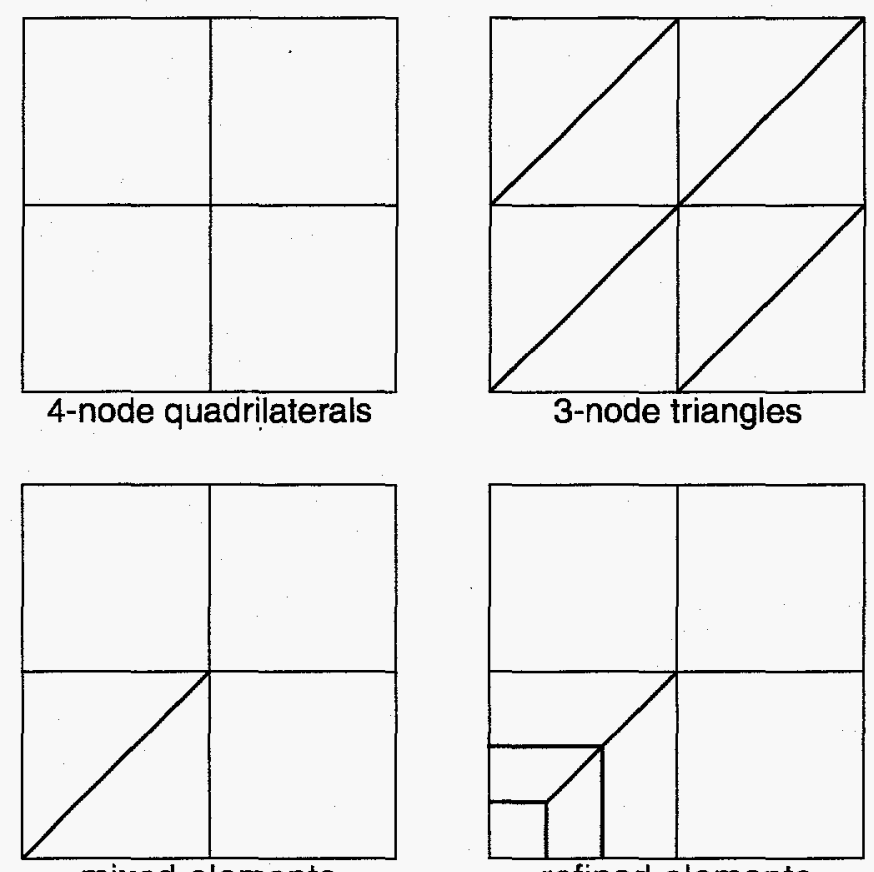

mixed elements

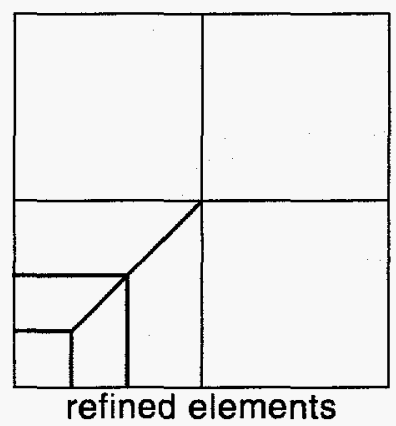

Figure 2. Geometric configurations tested by the 2-D heat-conduction problem.

\subsection{Test Scope. This test case is a verification test.}

4.2.4.1.3 Requirements Tested. Requirements 3.1, "Finite-Element Coefficient Generation," 3.2, "Formulate Transient Equations" (specifically Section 3.2.1), 3.4, "Compute Solution to Transient Equations," and 3.5, "Provide Input/Output Data Files," of Chapter I are verified by this test.

4.2.4.1.4 Required Inputs. Input is provided in the following files:

- heat2d.in: basic input data file used in conjunction with the following geometry data files:

- heat2d.geom.2d_tri: 3-node triangles (121 nodes, 200 elements), 
- heat2d.geom.2d_quad: 4-node quadrilaterals (121 nodes, 100 elements),

- heat2d.geom.2d_mix: mixed elements, 3-node triangles and 4node quadrilaterals (121 nodes, 104 elements), or

- heat2d.geom.2d_ref: refined elements, 4-node quadrilaterals with refinement about the node at $\mathrm{x}=\mathrm{y}=0 \mathrm{~m}$ (127 nodes, 104 elements).

4.2.4.1.5 Expected Outputs. Values from FEHM for temperature versus time at the center of the square $(x=y=0 \mathrm{~m})$ and values for temperature versus position $(x=y)$ at a specified time (time $=0.25$ days) will be output and compared to the analytical solution. Values within $5 \%$ of the analytical solution will be considered acceptable.

\subsubsection{3-D heat conduction in a cube}

4.2.4.2.1 Function Tested. This test verifies that FEHM correctly models three-dimensional heat conduction. It also verifies that the finite-element representation of 3-D, 6-node triangular prisms (prism elements), 8-node quadrilateral polyhedrons (brick elements), 4-node tetrahedrals, mixed-element meshes (containing both triangular prisms and quadrilateral polyhedrons), and refined-element meshes (containing quadrilateral polyhedrons and trapezoidal polyhedrons) have been correctly implemented (see Fig. 3). In addition, the finitevolume option, in which the code subdivides brick elements into tetrahedrals, is tested.

4.2.4.2.2 Test Scope. This test case is a verification test.

4.2.4.2.3 Requirements Tested. Requirements 3.1, "Finite-Element Coefficient Generation," 3.2, "Formulate Transient Equations" (specifically Section 3.2.1), 3.4, "Compute Solution to Transient Equations," and 3.5, "Provide Input/Output Data Files," of Chapter I are verified by this test.

4.2.4.2.4 Required Inputs. Problem input is provided in the following files:

- heat3d.in: basic input data file used in conjunction with the following geometry data files:

- heat3d.geom.3d_tri: 6-node triangular prisms (1331 nodes, 2000 elements),

- heat3d.geom.3d_quad: 8-node quadrilateral polyhedrons (1331 nodes, 1000 elements),

- heat3d.geom.3d_tets: 4-node tetrahedrals (1331 nodes, 6000 elements), 

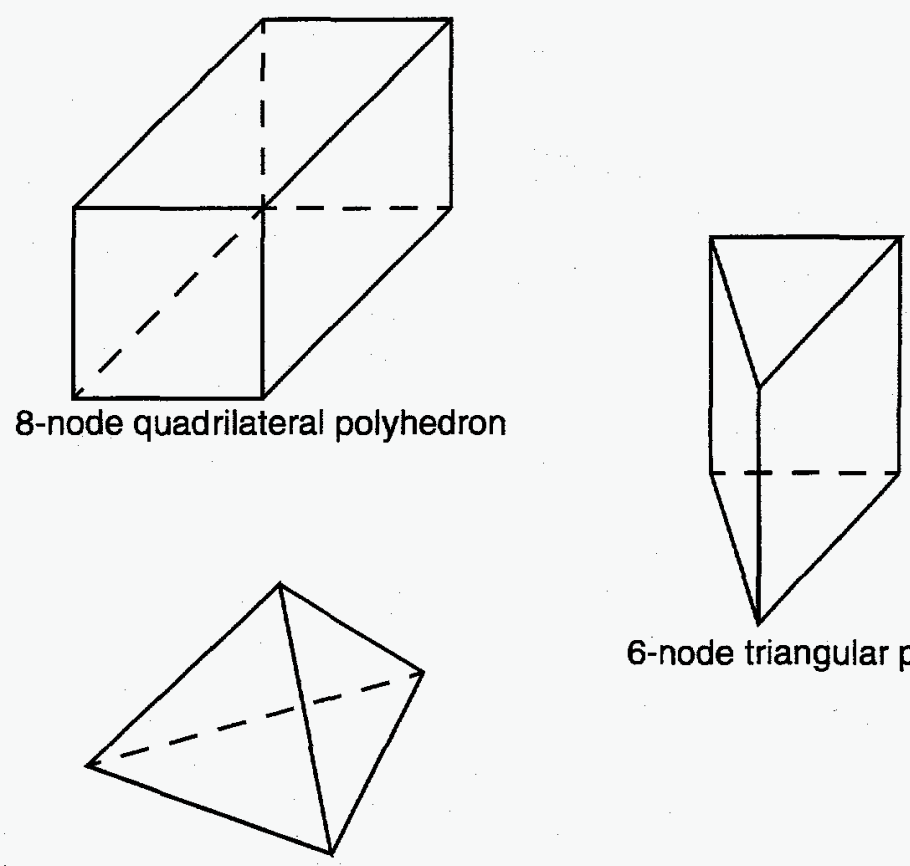

6-node triangular prism

4-node tetrahedral

Figure 3. Geometric elements tested by the 3-D heat-conduction problem.

- heat3d.geom.3d_mix: mixed elements, 6-node triangular prisms and 8-node quadrilateral polyhedrons (1331 nodes, 1020 elements), or

- heat3d.geom.3d_ref: refined elements, 8-node quadrilateral polyhedrons with refinement about node at $\mathrm{x}=\mathrm{y}=0 \mathrm{~m}$ for $\mathrm{z}=0$ to $0.5 \mathrm{~m}$ (1364 nodes, 1020 elements); and

- heat3d.finv.in: basic input data file using the finite-volume option used in conjunction with the following geometry data files:

- heat3d.geom.3d_quad or

- heat3d.geom.3d_ref.

4.2.4.2.5 Expected Outputs. Values from FEHM for temperature versus time at the center of the cube $(x=y=z=0 \mathrm{~m})$ and values for temperature versus position $(x=y=z)$ at a specified time (time $=\mathbf{0 . 2 5}$ days) will be output and compared to the analytical solution. Values within $5 \%$ of the analytical solution will be considered acceptable. 


\subsection{Test of Temperature in a Wellbore}

\subsubsection{Purpose}

The ability to model temperature changes in a wellbore is important to the interpretation of temperature surveys. Ramey (1962) has developed a semianalytical technique for predicting the thermal drawdown in a wellbore. Comparison with this solution will help verify that the code is capable of analyzing temperature logs and, more generally, of handling a thermal-conduction problem coupled to advective heat transport.

\subsubsection{Functional description}

The test suite consists of a simulation of fluid injection into a wellbore. In addition to demonstrating that the heat- and mass-transfer problem has been correctly formulated, the test suite will demonstrate that the 2-D radial geometry has been correctly implemented.

\subsubsection{Assumptions and limitations}

Fluid injection at constant temperature, $T_{i n j}$, into a wellbore is modeled (Fig. 4). Flow is confined to the wellbore, i.e., there is no flow between the wellbore and the surrounding rock. The semianalytical solution is given by

$$
\begin{aligned}
& T_{f}(z, t)=b+a z-a A+\left(T_{i n j}-b+a A\right) e^{-\frac{z}{A}}, \\
& \text { where } A=\frac{q c f(t)}{2 \pi \kappa} \text { and } f(t)=\frac{1}{\frac{4}{\pi^{2}} \int_{0}^{\infty} \frac{e^{-\alpha u^{2} t} d u}{u\left(J_{0}{ }^{2}\left(r_{w} u\right)+Y_{0}{ }^{2}\left(r_{w} u\right)\right)}}
\end{aligned}
$$

$J_{0}$ and $Y_{0}$ are Bessel functions of the first and second kind, of order 0 , respectively. The initial temperature distribution in the medium is given by a linear geothermal gradient $T_{r}=b+a z$, where $b$ is the surface rock temperature and $a$ is the geothermal gradient. Although the Ramey solution models a semi-infinite reservoir in the radial direction, for the FEHM model, the reservoir radius has been set to $40 \mathrm{~m}$. Table 23 defines the input parameters used for FEHM and the Ramey analytical solution.

\subsubsection{Summary of test cases}

\subsubsection{Constant-temperature injection into a wellbore}

4.3.4.1.1 Function Tested. This test verifies that FEHM has correctly implemented the heat- and mass-transfer problem and 2-D radial geometry.

4.3.4.1.2 Test Scope. This test case is a verification test. 


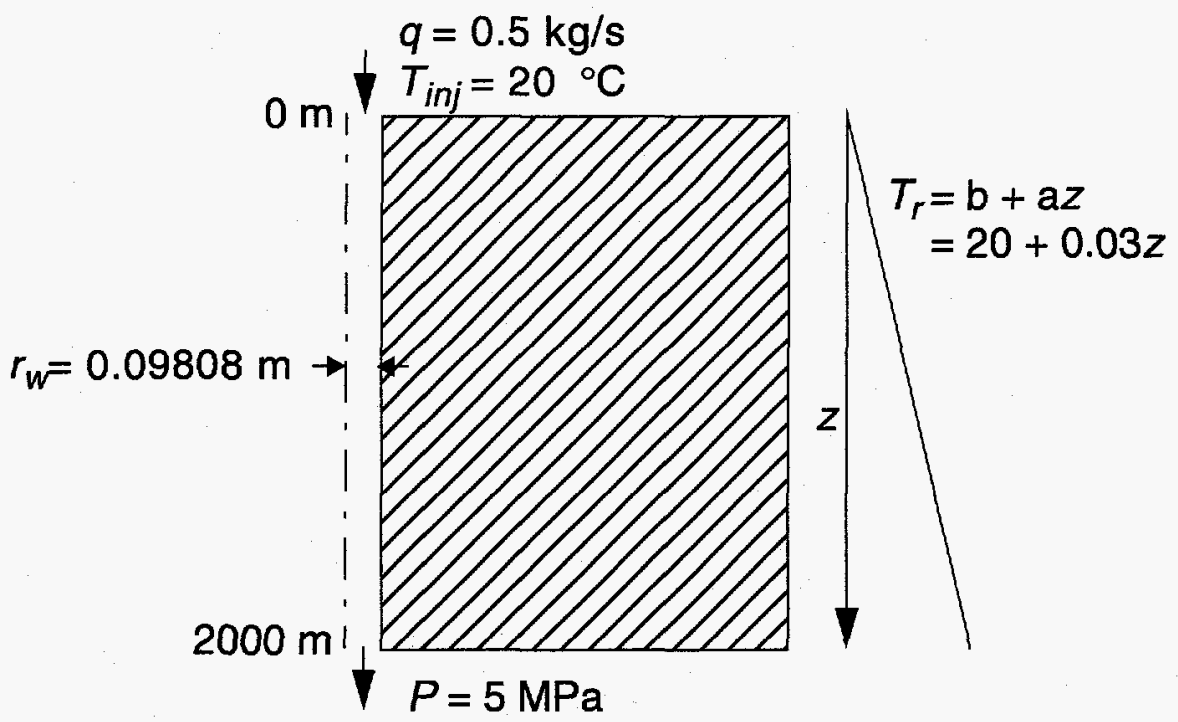

Figure 4. Schematic drawing of the problem geometry and boundary conditions for the temperature-in-awellbore problem.

4.3.4.1.3 Requirements Tested. Requirements 3.1, "Finite-Element Coefficient Generation," 3.2, "Formulate Transient Equations" (specifically Sections 3.2.2 and 3.2.6), 3.3, "Apply Constitutive Relationships" (specifically Section 3.3.1), 3.4, "Compute Solution to Transient Equations," and 3.5, "Provide Input/ Output Data Files," of Chapter I are verified by this test.

4.3.4.1.4 Required Inputs. Problem input is provided in the following files:

- ramey.in: basic input data and

- ramey.geom: geometry data (1010 nodes, 900 elements).

4.3.4.1.5 Expected Outputs. Values from FEHM for temperature versus time at fixed depth $(d=1000$ and $2000 \mathrm{~m})$ and values for temperature versus depth ( $d=0$ to $2000 \mathrm{~m}$ ) at a specified time ( $t=25$ days) will be output and compared to the analytical solution. Values within $5 \%$ of the analytical solution will be considered acceptable. 


\begin{tabular}{|c|c|c|}
\hline \multicolumn{3}{|c|}{$\begin{array}{l}\text { Table 23. Input parameters for the temperature-in-a- } \\
\text { wellbore problem }\end{array}$} \\
\hline Parameter & Symbol & Value \\
\hline Rock thermal conductivity & $\kappa_{r}$ & $2.7 \frac{\mathrm{w}}{\mathrm{m} \cdot \mathrm{K}}$ \\
\hline Rock density & $\rho_{r}$ & $2700 \mathrm{~kg} / \mathrm{m}^{3}$ \\
\hline Rock specific heat & $C_{r}$ & $1000 \frac{\mathrm{J}}{\mathrm{kg} \cdot \mathrm{K}}$ \\
\hline Rock thermal diffusivity & $\alpha_{r}=\frac{\kappa_{r}}{\rho_{r} C_{r}}$ & $10^{-6} \mathrm{~m}^{2} / \mathrm{s}$ \\
\hline Rock (matrix) permeability & $k$ & $10^{-20} \mathrm{~m}^{2}$ \\
\hline Porosity & $f$ & 0 \\
\hline Fluid heat capacity & $C_{f}$ & $4200 \frac{\mathrm{J}}{\mathrm{kg} \cdot \mathrm{K}}$ \\
\hline Wellbore radius & $r_{w}$ & $0.09808 \mathrm{~m}$ \\
\hline Radial extent & $r$ & $40 \mathrm{~m}$ \\
\hline Node spacing (radial) & $\Delta r$ & $0.19616-17.25495 \mathrm{~m}$ \\
\hline Well depth & $z$ & $2000 \mathrm{~m}$ \\
\hline Node spacing (vertical) & $\Delta z$ & $20 \mathrm{~m}$ \\
\hline Surface rock temperature & $b$ & $20^{\circ} \mathrm{C}$ \\
\hline Geothermal gradient & $a$ & $0.03^{\circ} \mathrm{C} / \mathrm{m}$ \\
\hline Injection rate & $q$ & $0.5 \mathrm{~kg} / \mathrm{s}$ \\
\hline Injection temperature & $T_{i n j}$ & $20^{\circ} \mathrm{C}$ \\
\hline Time step & $\Delta t$ & $0.001-1$ days \\
\hline Total elapsed time & $t$ & 25 days \\
\hline \multicolumn{3}{|c|}{$\begin{array}{l}\text { Initial temperature distribution }\left(T \text { in }{ }^{\circ} \mathrm{C}, z \text { in } m\right) \text { : } \\
\qquad T(z)=20+0.03 z\end{array}$} \\
\hline Boundary conditions: & $\begin{array}{l}=0 \mathrm{~m}, \quad q \\
=2000 \mathrm{~m}, F\end{array}$ & $\begin{array}{l}\mathrm{kg} / \mathrm{s}, T_{\mathrm{inj}}=20^{\circ} \mathrm{C} \\
\mathrm{MPa}\end{array}$ \\
\hline
\end{tabular}




\subsection{Test of Pressure Transient Analysis}

\subsubsection{Purpose}

Properties of underground reservoirs are often determined by pressure tests. Theis (1935) developed a solution for radial flow to a well in the form of pressure as a function of time and the spatial coordinates. Comparison with this solution will help demonstrate that the pressure equation (the conservation of mass with Darcy's law) is implemented correctly.

\subsubsection{Functional description}

The test suite consists of a simulation of 1-D radial flow into an infinite aquifer. In addition to demonstrating that the transient pressure equation has been correctly formulated, the test suite will demonstrate that the radial geometry has been correctly implemented.

\subsubsection{Assumptions and limitations}

Injection into a centrally located well at a constant volumetric rate, $q$, is modeled. The well (modeled as a line source) is assumed to be situated in a porous medium of infinite radial extent. The analytical solution (from Matthews and Russell 1967) is given by

$$
p(r, t)=p_{i}-\frac{q \mu}{2 \pi k h}\left[-\frac{1}{2} E_{i}\left(-\frac{\phi \mu c r^{2}}{4 k t}\right)\right],
$$

where the exponential integral function is $-E_{i}(-x)=\int_{x}^{\infty} \frac{e^{-u}}{u} d u$.

Figure 5 shows the problem geometry and boundary conditions. This problem is isothermal. Input parameters defining the problem are given in Table 24.

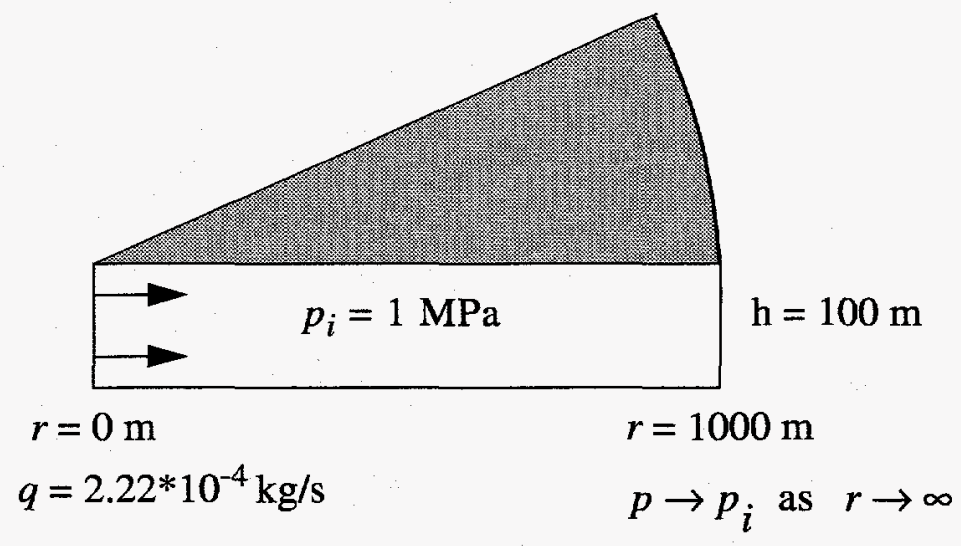

Figure 5. Schematic drawing of the problem geometry and boundary conditions for the transient pressure problem. 


\begin{tabular}{|c|c|c|}
\hline \multicolumn{3}{|c|}{$\begin{array}{l}\text { Table 24. Input parameters for the transient pressure } \\
\text { problem }\end{array}$} \\
\hline Parameter & Symbol & Value \\
\hline $\begin{array}{l}\text { Reservoir permeability in radial } \\
\text { direction }\end{array}$ & $k$ & $10^{-14} \mathrm{~m}^{2}$ \\
\hline Reservoir porosity & $\phi$ & 0.4 \\
\hline Fluid compressibility & $c$ & $5.06^{\star} 10^{-4} \mathrm{MPa}^{-1}$ \\
\hline Fluid viscosity & $\mu$ & $5.48^{\star} 10^{-4} \mathrm{~Pa} \cdot \mathrm{s}$ \\
\hline Reservoir thickness & $h$ & $100 \mathrm{~m}$ \\
\hline Node spacing (vertical) & $\Delta h$ & $100 \mathrm{~m}$ \\
\hline Reservoir length (radial) & $r$ & $0-1000 \mathrm{~m}$ \\
\hline Node spacing (radial) & $\Delta r$ & $0.00144-107 m$ \\
\hline Flow rate & $q$ & $2.22^{*} 10^{-4} \mathrm{~kg} / \mathrm{s}$ \\
\hline Initial pressure & $p_{i}$ & $1 \mathrm{MPa}$ \\
\hline Temperature (isothermal) & $T$ & $50^{\circ} \mathrm{C}$ \\
\hline Time step & $\Delta t$ & $300 \mathrm{~s}$ \\
\hline Total elapsed time & $t$ & 1 day \\
\hline $\begin{array}{ll}\text { Boundary conditions: } & p \rightarrow p \\
& \lim _{r \rightarrow 0} r \frac{\partial}{\partial}\end{array}$ & $\frac{\mu}{k h}$ (cons & at $r=0$, line source) \\
\hline
\end{tabular}

\subsubsection{Summary of test cases}

\subsubsection{Radial flow from a well}

4.4.4.1.1 Function Tested. This test verifies that FEHM has correctly implemented the pressure equations, i.e., the conservation of mass with Darcy's law.

4.4.4.1.2 Test Scope. This test case is a verification test.

4.4.4.1.3 Requirements Tested. Requirements 3.1, "Finite-Element Coefficient Generation," 3.2, "Formulate Transient Equations" (specifically Sections 3.2.2 and 3.2.6), 3.4, "Compute Solution to Transient Equations," and 3.5, "Provide Input/Output Data Files," of Chapter I are verified by this test. 
4.4.4.1.4 Required Inputs. Problem input is provided in the following file:

- theis.in: basic input and geometry data (202 nodes, 100 elements).

4.4.4.1.5 Expected Outputs. Values from FEHM, for pressure versus time, at fixed radii $(r=0.00144$ and $3.44825 \mathrm{~m})$, and values for pressure versus radius ( $r=0$ to $1000 \mathrm{~m}$ ), at a specified time ( $t=1$ day), will be output and compared to the analytical solution. Values within $5 \%$ of the analytical solution will be considered acceptable. 


\subsection{Test of Infiltration into a One-dimensional, Layered, Unsaturated Medium}

\subsubsection{Purpose}

Modeling infiltration into an unsaturated medium can be performed by implementing either the equivalent-continuum method (ECM) or the double-porosity/double-permeability method (DKM). The ECM provides a lumped set of properties for the material that are derived from the separate matrix and fracture properties along with hydrologic conditions such as saturation and pressure. The DKM considers the fractures as a continuous medium and the matrix as another continuous medium and provides for conductance between the two. See the FEHM document "Summary of Methods and Models" (Zyvoloski et al. 1997a, Section 8.2) for more details of the double-porosity/double-permeability method. The DKM requires twice as many finite-element nodes and hence takes longer to run than the ECM. Both methods use the same set of van Genuchten capillary-pressure model parameters to describe the hydrologic properties. The two methods are often compared with each other to assess whether the additional computational burden associated with the DKM is necessary to capture behavior such as fast flow paths in fractures, which are smoothed out in the composite-property model of the ECM. This set of tests verifies that each method, the ECM and the DKM, are implemented properly.

\subsubsection{Functional description}

The test problem, described by Ho (1995a, 1995b), consists of simulations of infiltration into a one-dimensional column. The column is a transect through a system of four stratigraphic units, each characterized by a unique set of parameters describing the matrix and fracture properties. The stratigraphic system is a representation of the lithologic layering at Yucca Mountain. The four units are the Tiva Canyon welded tuff (TCw), the Paintbrush nonwelded tuff (PTn), the Topopah Springs welded tuff (TSw), and the Calico Hills nonwelded vitrophere (CHnv). A schematic of the thicknesses and layering of the four units considered is shown in Fig. 6. The properties for these four units were taken from YMP total system performance assessment of 1993 (Wilson 1994) and are located in the required inputs files. Key aspects of this data set include matrix intrinsic permeabilities and matrix residual saturations, each of which span four orders of magnitude over the various units.

The test will demonstrate that the equivalent-continuum method and the double-porosity/double-permeability method have been correctly implemented through comparison with simulations performed with TOUGH2, another well-documented model capable of solving this problem (Pruess 1991). 


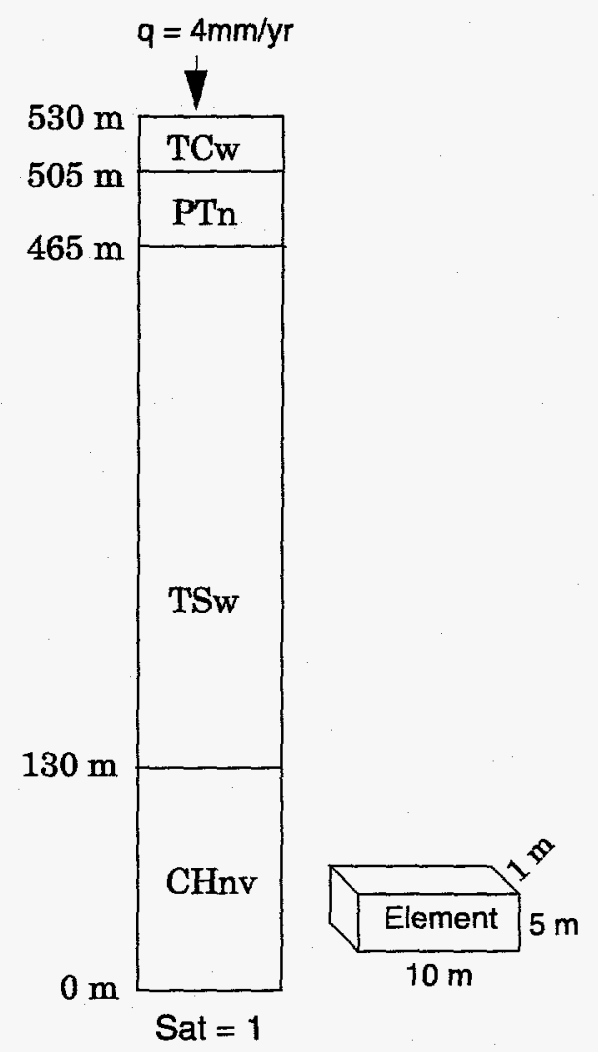

Figure 6. Schematic drawing of the problem geometry for the test of the one-dimensional infiltration problem.

\subsubsection{Assumptions and limitations}

Infiltration of $4 \mathrm{~mm} / \mathrm{yr}$ is applied at the top of the system. For the DKM simulations, it is applied to the fracture nodes only. The bottom boundary for all tests is assumed to be the water table, so full saturation is set there. The TOUGH2 simulations with which FEHM will be compared were run at Sandia National Laboratories using TOUGH2 - version 1.1 (April 1993). This is an isothermal air-water problem. Input parameters defining the problem are given in Table 25.

\subsubsection{Summary of test cases}

4.5.4.1 Test of infiltration into a one-dimensional, layered, unsaturated medium using the equivalent-continuum method (ECM)

4.5.4.1.1 Function Tested. This test verifies that FEHM has correctly implemented for simulations of infiltration into a onedimensional, layered, unsaturated medium using ECM.

4.5.4.1.2 Test Scope. This test case is a verification test. 


\begin{tabular}{|c|c|c|}
\hline \multicolumn{3}{|c|}{$\begin{array}{l}\text { Table 25. Input parameters for the one-dimensional } \\
\text { infiltration problem }\end{array}$} \\
\hline Parameter & Symbol & Value \\
\hline $\begin{array}{l}\text { Fracture permeability } \\
\text { TCw } \\
\text { PTn } \\
\text { TSw } \\
\text { CHnv }\end{array}$ & $k_{f}$ & $\begin{array}{l}2.04^{*} 10^{-18} \mathrm{~m}^{2} \\
2.51^{*} 10^{-14} \mathrm{~m}^{2} \\
2.09^{\star} 10^{-18} \mathrm{~m}^{2} \\
1.10^{*} 10^{-16} \mathrm{~m}^{2}\end{array}$ \\
\hline $\begin{array}{l}\text { Matrix permeability } \\
\text { TCw } \\
\text { PTn } \\
\text { TSw } \\
\text { CHnv }\end{array}$ & $k_{m}$ & $\begin{array}{l}4.06^{*} 10^{-9} \mathrm{~m}^{2} \\
7.14^{*} 10^{-9} \mathrm{~m}^{2} \\
4.57^{*} 10^{-9} \mathrm{~m}^{2} \\
6.53^{*} 10^{-9} \mathrm{~m}^{2}\end{array}$ \\
\hline $\begin{array}{l}\text { Fracture porosity (volume fra } \\
\text { for fracture node) } \\
\text { TCw } \\
\text { PTn } \\
\text { TSw } \\
\text { CHnv }\end{array}$ & $\phi_{f}\left(V_{f}\right)$ & $\begin{array}{l}2.93^{*} 10^{-4} \\
9.27^{*} 10^{-5} \\
2.43^{*} 10^{-4} \\
1.11^{*} 10^{-4}\end{array}$ \\
\hline $\begin{array}{l}\text { Matrix porosity } \\
\text { TCw } \\
\text { PTn } \\
\text { TSw } \\
\text { CHnv }\end{array}$ & $\phi_{m}$ & $\begin{array}{l}0.087 \\
0.421 \\
0.139 \\
0.331\end{array}$ \\
\hline $\begin{array}{l}\text { Matrix-node length scale } \\
\text { TCw } \\
\text { PTn } \\
\text { TSw } \\
\text { CHnv }\end{array}$ & $L_{f 1}$ & $\begin{array}{l}0.18 \mathrm{~m} \\
0.64 \mathrm{~m} \\
0.21 \mathrm{~m} \\
0.46 \mathrm{~m}\end{array}$ \\
\hline Column width & $w$ & $10 \mathrm{~m}$ \\
\hline Node spacing (horizontal) & $\Delta w$ & $10 \mathrm{~m}$ \\
\hline Column height (elevation) & $h$ & $0-530 \mathrm{~m}$ \\
\hline Node spacing (vertical) ${ }^{\ddagger}$ & $\Delta h$ & $5 \mathrm{~m}$ \\
\hline Reference pressure & $P_{r}$ & $0.1 \mathrm{MPa}$ \\
\hline Reference temperature & $T_{r}$ & $20^{\circ} \mathrm{C}$ \\
\hline Maximum saturation & $S_{\operatorname{lmax}}$ & 1.0 \\
\hline Fracture residual saturation & $S_{l r, f}$ & 0.03 \\
\hline
\end{tabular}




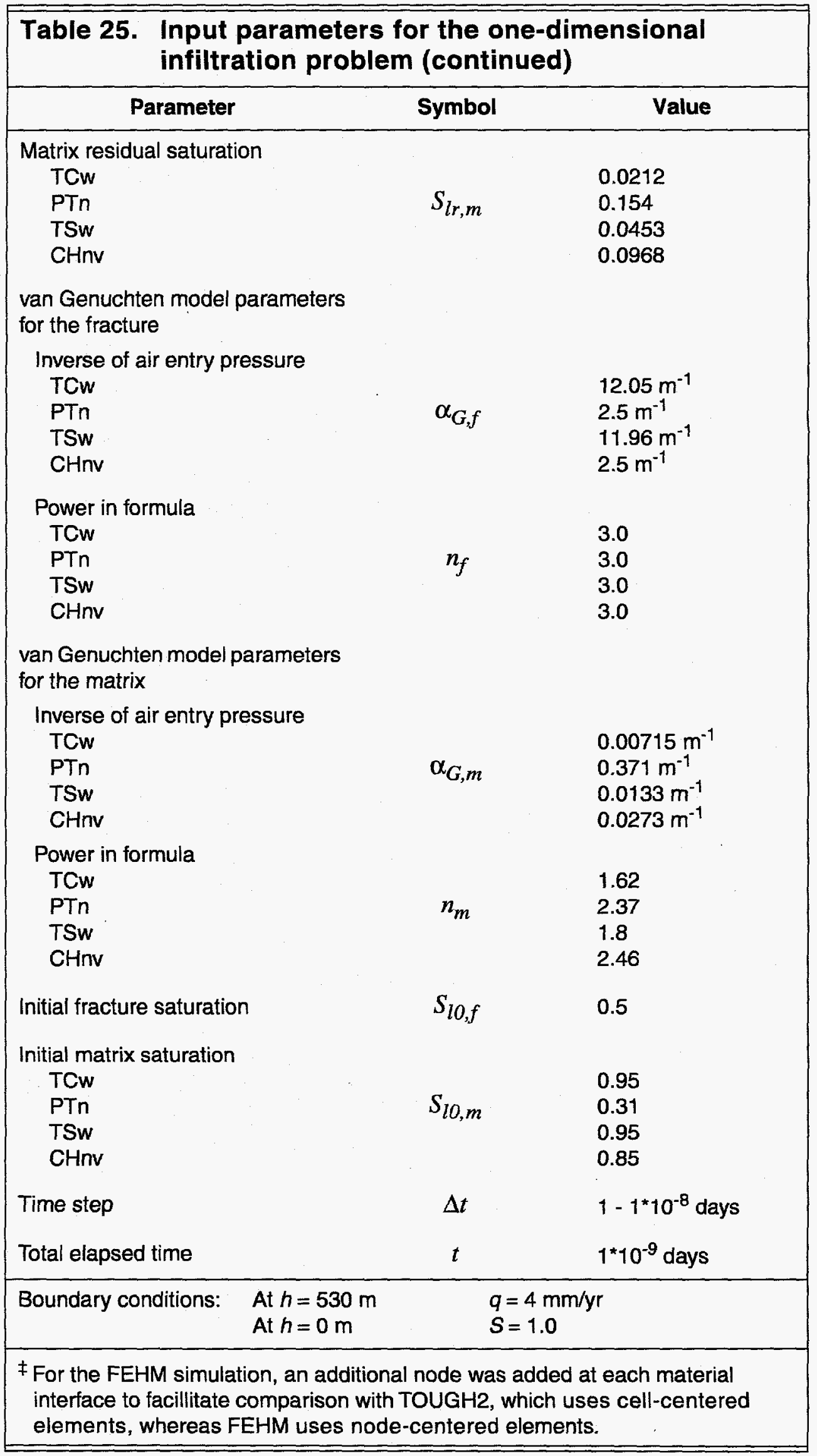


4.5.4.1.3 Requirements Tested. Requirements 3.1, "Finite-Element Coefficient Generation," 3.2, "Formulate Transient Equations" (specifically Sections 3.2.2 and 3.2.6), 3.3, "Apply Constitutive Relationships" (specifically Section 3.3.4), 3.4, "Compute Solution to Transient Equations," and 3.5, "Provide Input/ Output Data Files," of Chapter I are verified by this test. 4.5.4.1.4 Required Inputs. Problem input is provided in the following files:

- infiltration.ecm.in: basic input data, case 1, and

- infiltration.geom: geometry data used for the above cases.

4.5.4.1.5 Expected Outputs. Values from FEHM for saturation versus elevation will be output, nondimensionalized, and compared to the TOUGH2 solution. A root-mean-square error of the difference between the two simulations less than or equal to 0.05 will be considered acceptable.

\subsubsection{Test of infiltration into a one-dimensional, layered, unsaturated medium using the double-porosity/double- permeability method (DKM)}

4.5.4.2.1 Function Tested. This test verifies that FEHM has been correctly implemented for simulations of infiltration into a onedimensional, layered, unsaturated medium using DKM.

4.5.4.2.2 Test Scope. This test case is a verification test.

4.5.4.2.3 Requirements Tested. Requirements 3.1, "Finite-Element Coefficient Generation," 3.2, "Formulate Transient Equations" (specifically Sections 3.2.2 and 3.2.6), 3.3, "Apply Constitutive Relationships" (specifically Sections 3.3.4 and 3.3.8), 3.4, "Compute Solution to Transient Equations," and 3.5, "Provide Input/Output Data Files," of Chapter I are verified by this test.

4.5.4.2.4 Required Inputs. Problem input is provided in the following files:

- infiltration.dpm.in: basic input data, case 2, and

- infiltration.geom: geometry data used for the above cases.

4.5.4.2.5 Expected Outputs. Values from FEHM for saturation versus elevation will be output, nondimensionalized, and compared to the TOUGH2 solution. A root-mean-square error of the difference between the two simulations less than or equal to 0.05 will be considered acceptable. 


\subsection{Test of Vapor Extraction from an Unsaturated Reservoir}

\subsubsection{Purpose}

The ability to model vapor/gas transport in unsaturated media is important to the design of vapor-extraction sytems and interpretation of their performance. Analytical solutions of steady-state gas flow to a soil vaporextraction well in the unsaturated zone have been described by Shan et al. (1992). Comparison with this solution will help verify that vapor/gas transport has been correctly implemented in FEHM.

\subsubsection{Functional description}

The test suite consists of two simulations of steady, 2-D radial soil-vapor flow to a well in an unsaturated reservoir. The first case uses an isotropic permeability model, whereas the second case models an anisotropic reservoir. In addition to demonstrating that the gas-flow problem has been correctly formulated for isotropic and anisotropic permeability models, the test suite will demonstrate that the 2-D radial coordinate geometry has been correctly implemented.

\subsubsection{Assumptions and limitations}

The analytical solution for pressure for this test case is expressed as an infinite series:

$$
\begin{gathered}
P=\frac{\bar{q}}{4 \pi \alpha_{r}}\left[\ln \left(\frac{a-z+\left[\hat{r}^{2}+(a-z)^{2}\right]^{-1 / 2}}{b-z+\left[\hat{r}^{2}+(b-z)^{2}\right]^{-1 / 2}} \cdot \frac{b+z+\left[\hat{r}^{2}+(b+z)^{2}\right]^{-1 / 2}}{a+z+\left[\hat{r}^{2}+(a+z)^{2}\right]^{-1 / 2}}\right)-\right. \\
\sum_{n=1}^{\infty}(-1)^{n} \ln \left(\frac{a+z+2 n h+\left[\hat{r}^{2}+(a+z+2 n h)^{2}\right]^{-1 / 2}}{b+z+2 n h+\left[\hat{r}^{2}+(b+z+2 n h)^{2}\right]^{-1 / 2}} \cdot\right. \\
\frac{a+z-2 n h+\left[\hat{r}^{2}+(a+z-2 n h)^{2}\right]^{-1 / 2}}{b+z-2 n h+\left[\hat{r}^{2}+(b+z-2 n h)^{2}\right]^{-1 / 2}} \\
\frac{-a+z+2 n h+\left[\hat{r}^{2}+(-a+z+2 n h)^{2}\right]^{-1 / 2}}{-b+z+2 n h+\left[\hat{r}^{2}+(-b+z+2 n h)^{2}\right]^{-1 / 2}} \\
\\
\left.\left.-a+z-2 n h+\left[\hat{r}^{2}+(-a+z-2 n h)^{2}\right]^{-1 / 2}\right)\right] \\
\left.\left.-b+z-2 n h+\left[\hat{r}^{2}+(-b+z-2 n h)^{2}\right]^{-1 / 2}\right)\right]
\end{gathered}
$$

where $\bar{q}=\frac{2 P_{a} q_{m}}{(a-b) \phi \rho_{g}}, \alpha_{r}=\frac{k_{r} P_{a}}{\phi \mu_{g}}, \hat{r}=\left(\frac{k_{z}}{k_{r}}\right)^{1 / 2} r$ 
$r$ is the radial distance, $z$ is the vertical distance, $h$ is the depth to the water table (impermeable boundary), and $a$ and $b$ are the depths to the bottom and top of the open wellbore interval, respectively. A sensitivity study of the number of terms required for the solution to achieve a precision of $10^{-3}$ Pa shows that no more than $\mathbf{5 0}$ terms are needed.

The geometry and boundary conditions are shown in Fig. 7. The upper surface is at atmospheric pressure and the remaining edges are impermeable; there are no flow boundaries, with the exception of the extraction wellbore. The problem is isothermal. Values of the analytical solution are inaccurate in the region surrounding the extraction wellbore $(\mathrm{r} \leq 0.05 \mathrm{~m}, 2.8 \leq \mathrm{z} \leq 7.2 \mathrm{~m})$, so they are excluded from the results used for comparison. Table 26 lists the input parameters for the vapor-extraction problem. The solution is verified by comparison of FEHM results to the analytical solution.

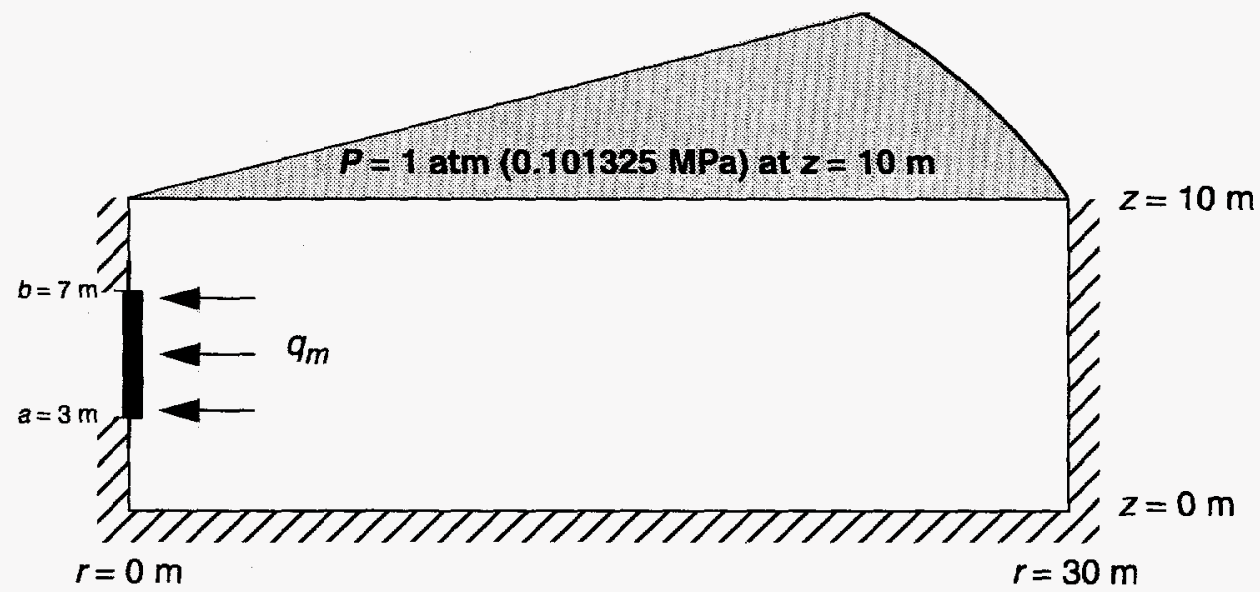

Figure 7. Schematic diagram of the geometry and boundary conditions for the vapor-extraction problem.

\begin{tabular}{|ccc|}
\hline \hline \multicolumn{1}{|c|}{$\begin{array}{c}\text { Table 26. } \\
\text { problem }\end{array}$} & \begin{tabular}{l} 
Input parameters for the vapor-extraction \\
\hline \multicolumn{1}{|c|}{ Parameter }
\end{tabular} & Value \\
\hline $\begin{array}{l}\text { Reservoir permeability } \\
\text { Isotropic case }\end{array}$ & $k_{r}, k_{z}$ & $10^{-11} \mathrm{~m}^{2}$ \\
Anisotropic case -radial & $k_{r}$ & $10^{-11} \mathrm{~m}^{2}$ \\
Anisotropic case -vertical & $k_{z}$ & $10^{-12} \mathrm{~m}^{2}$ \\
Reservoir porosity & $\phi$ & 0.4 \\
Reservoir length & $r$ & $0-30 \mathrm{~m}$ \\
\hline
\end{tabular}




\begin{tabular}{|c|c|c|c|}
\hline \multicolumn{4}{|c|}{$\begin{array}{l}\text { Table 26. Input parameters for the vapor-extraction } \\
\text { problem (continued) }\end{array}$} \\
\hline \multicolumn{2}{|c|}{ Node spacing (radial) } & $\Delta r$ & $0.0001-1 \mathrm{~m}$ \\
\hline \multicolumn{2}{|c|}{ Reservoir thickness (elevation) } & $h$ & $0-10 \mathrm{~m}$ \\
\hline \multicolumn{2}{|c|}{ Node spacing (vertical) } & $\Delta h$ & $0.5 \mathrm{~m}$ \\
\hline \multicolumn{2}{|c|}{ Extraction interval, bottom } & $a$ & $3 m$ \\
\hline \multicolumn{2}{|c|}{ Extraction interval, top } & $b$ & $7 \mathrm{~m}$ \\
\hline \multicolumn{2}{|c|}{ Ambient (reference) temperature } & $T_{a}$ & $10^{\circ} \mathrm{C}$ \\
\hline \multicolumn{2}{|l|}{ Ambient pressure } & $P_{a}$ & $0.101325 \mathrm{MPa}$ \\
\hline \multicolumn{2}{|l|}{ Initial pressure } & $P_{0}$ & $0.101325 \mathrm{MPa}$ \\
\hline \multicolumn{2}{|l|}{ Initial saturation } & $S_{0}$ & 0.05 \\
\hline \multicolumn{2}{|c|}{ Residual liquid saturation } & $S_{l r}$ & 0.10 \\
\hline \multicolumn{2}{|c|}{ Maximum liquid saturation } & $S_{l \max }$ & 0.99 \\
\hline \multicolumn{2}{|c|}{$\begin{array}{l}\text { Inverse of air entry pressure } \\
\text { Power in formula }\end{array}$} & $\alpha_{G}$ & $\begin{array}{l}0.005 \mathrm{~m}^{-1} \\
1.8\end{array}$ \\
\hline \multicolumn{2}{|l|}{ Gas density } & $\rho_{g}$ & $1.24 \mathrm{~kg} / \mathrm{m}^{3}$ \\
\hline \multicolumn{2}{|l|}{ Gas viscosity } & $\mu_{g}$ & $1.76 \times 10^{-5}$ Pa.s \\
\hline \multicolumn{2}{|l|}{$\begin{array}{l}\text { Isotropic case } \\
\text { Anisotropic case }\end{array}$} & $q_{m}$ & $\begin{array}{l}0.0825 \mathrm{~kg} / \mathrm{s} \\
0.05 \mathrm{~kg} / \mathrm{s}\end{array}$ \\
\hline \multicolumn{2}{|l|}{ Time step } & $\Delta t$ & $0.001-75$ days \\
\hline $\begin{array}{l}\text { Isotropic case } \\
\text { Anisotropic case }\end{array}$ & & $t$ & $\begin{array}{l}365 \text { days } \\
730 \text { days }\end{array}$ \\
\hline Boundary conditions: & $\begin{array}{l}\text { At } z=10 \\
\text { At } r=0 \mathrm{~m} \\
\text { (Line sink }\end{array}$ & $\begin{array}{r}F \\
7 \mathrm{~m} \mathrm{q} \\
z \text { pos }\end{array}$ & $\begin{array}{l}325 \mathrm{MPa}, \mathrm{S}=0.05 \\
\text { rards) }\end{array}$ \\
\hline
\end{tabular}

\subsubsection{Summary of test cases}

\subsubsection{Vapor extraction from an unsaturated reservoir}

4.6.4.1.1 Function Tested. This test verifies that FEHM has correctly implemented the gas-flow option of the code for radial flow.

4.6.4.1.2 Test Scope. This test case is a verification test. 
4.6.4.1.3 Requirements Tested. Requirements 3.1, "Finite-Element Coefficient Generation," 3.2, "Formulate Transient Equations" (specifically Sections 3.2.3 and 3.2.6), 3.3, "Apply Constitutive Relationships" (specifically Sections 3.3.2 and 3.3.4), 3.4, "Compute Solution to Transient Equations," and 3.5, "Provide Input/Output Data Files," of Chapter I are verified by this test. 4.6.4.1.4 Required Inputs. Problem input is provided in the following files:

- vapextract_iso.in: basic input data, isotropic case,

- vapextract_aniso.in: basic input data, anisotropic case, and

- vapextract.geom: geometry data used for the above cases.

4.6.4.1.5 Expected Outputs. Values from FEHM for the steadystate vapor pressure at each node (reached after 365 days for the isotropic case, 730 days for the anisotropic case) will be output and compared to the analytical solution from Shan et al. (1992). Values within 5\% of the analytical solution or a rootmean-square error of the difference between the two simulations less than or equal to 0.01 will be considered acceptable. 


\subsection{Test of Dual Porosity}

\subsubsection{Purpose}

The dual-porosity formulation is a computationally efficient way to model flow in a porous media with high-permeability fractures embedded in lowpermeability matrix material. It has previously been shown by Moench (1984) that dual-porosity flow can explain some of the well test data at Yucca Mountain. Warren and Root (1963) provide an analytical solution for dual-porosity flow to a wellbore. This test will check the pressure solution for the dual-porosity coding in FEHM.

\subsubsection{Functional description}

The test suite consists of a set of simulations of dual-porosity flow to a wellbore. It will demonstrate that the dual-porosity formulation has been correctly implemented.

\subsubsection{Assumptions and limitations}

Warren and Root have defined the dimensionless pressure drop as

$$
\begin{aligned}
& \qquad \Psi_{f}(1, \tau) \approx \frac{1}{2}\left\{\ln \tau+0.80908+E i\left[\frac{-\lambda \tau}{\omega(1-\omega)}\right]-E i\left[\frac{-\lambda \tau}{1-\omega}\right]\right\}, \\
& \text { where } \tau=\frac{\overline{k_{f}} t}{\phi_{m} c_{m}+\phi_{f} c_{f}},
\end{aligned}
$$

$\overline{k_{f}}=\sqrt{k_{f x} k_{f y}}$,

$\lambda=\frac{\alpha k_{m} r_{w}^{2}}{\overline{k_{f}}}$,

$\omega=\frac{\phi_{f} c_{f}}{\phi_{m} c_{m}+\phi_{f} c_{f}}$,

and $E i$ is the exponential integral function (see Section 4.4.3). In this solution, $\tau$ is dimensionless time, $\bar{k}_{f}$ is the effective permeability of the anisotropic medium, $\lambda$ is a measure of the size of the matrix region, $\omega$ represents the strength of coupling between the fracture and the matrix, and $\alpha$ is a characteristic dimension.

Figure 8 illustrates the problem geometry and boundary conditions. The input parameters are defined in Table 27. The analytical solution uses a steady-state approximation for the matrix flow (only one matrix node exists per fracture node), so no transient effects are possible in the matrix. The FEHM dual-porosity implementation uses a transient approximation for the matrix material (two matrix nodes exist for each fracture node), so crude transient responses are possible because of flow between two matrix nodes. See the FEHM document "Methods and Models" (Zyvoloski et al. 1997a, Section 8.2) for more details and a description of the model 
parameters $\left(L_{f}\right.$ and $\left.V_{f}\right)$. The steady-state approximation is known to be inaccurate at small times (see Warren and Root 1963, p. 248) and is only valid for $\tau$ greater than $\sim 100$.

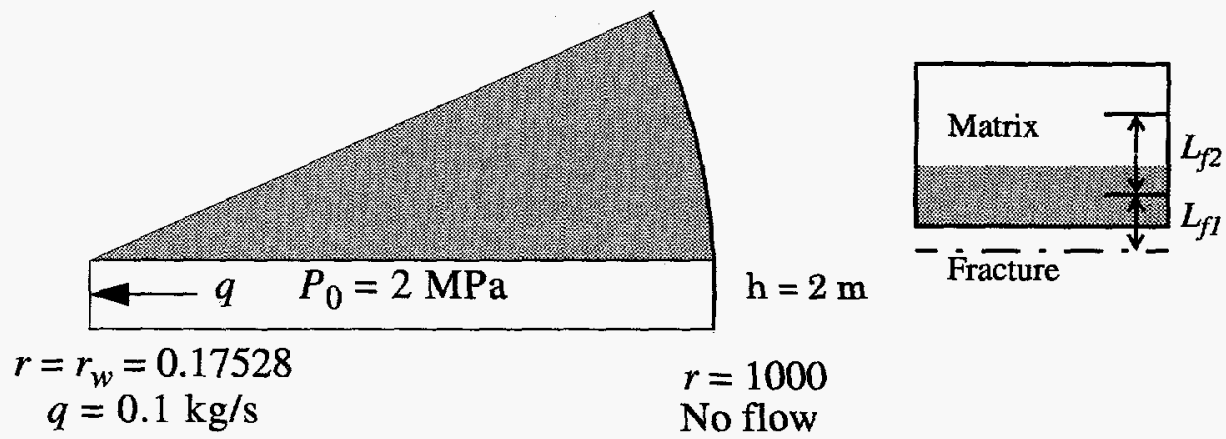

Figure 8. Schematic diagram of the geometry and boundary conditions for the dual-porosity problem.

\section{Table 27. Input parameters for the dual-porosity problem}

\begin{tabular}{|c|c|c|}
\hline Parameter & Symbol & Value \\
\hline $\begin{array}{l}\text { Permeability } \\
\text { fracture } \\
\text { matrix }\left\{\begin{array}{l}(1) \\
(2) \\
(3)\end{array}\right.\end{array}$ & $k_{f}$ & $\begin{array}{l}0.4 \times 10^{-12} \mathrm{~m}^{2} \\
1.904 \times 10^{-16} \mathrm{~m}^{2} \\
1.904 \times 10^{-13} \mathrm{~m}^{2} \\
1.194 \times 10^{-14} \mathrm{~m}^{2}\end{array}$ \\
\hline $\begin{array}{l}\text { Porosity } \\
\text { fracture } \\
\text { matrix }\left\{\begin{array}{l}(1) \\
(2) \\
(3)\end{array}\right.\end{array}$ & $\phi_{f}$ & $\begin{array}{l}1.0 \\
0.06081 \\
0.6081 \\
0.47\end{array}$ \\
\hline $\begin{array}{l}\text { Volume fraction } \\
\text { fracture node }\left\{\begin{array}{c}(1)(2) \\
(3)\end{array}\right.\end{array}$ & $V_{f}$ & $\begin{array}{l}0.006711409 \\
0.000476417\end{array}$ \\
\hline first matrix node $\left\{\begin{array}{c}(1)(2) \\
(3)\end{array}\right.$ & $V_{f 1}$ & $\begin{array}{l}0.335570470 \\
0.333492139\end{array}$ \\
\hline
\end{tabular}




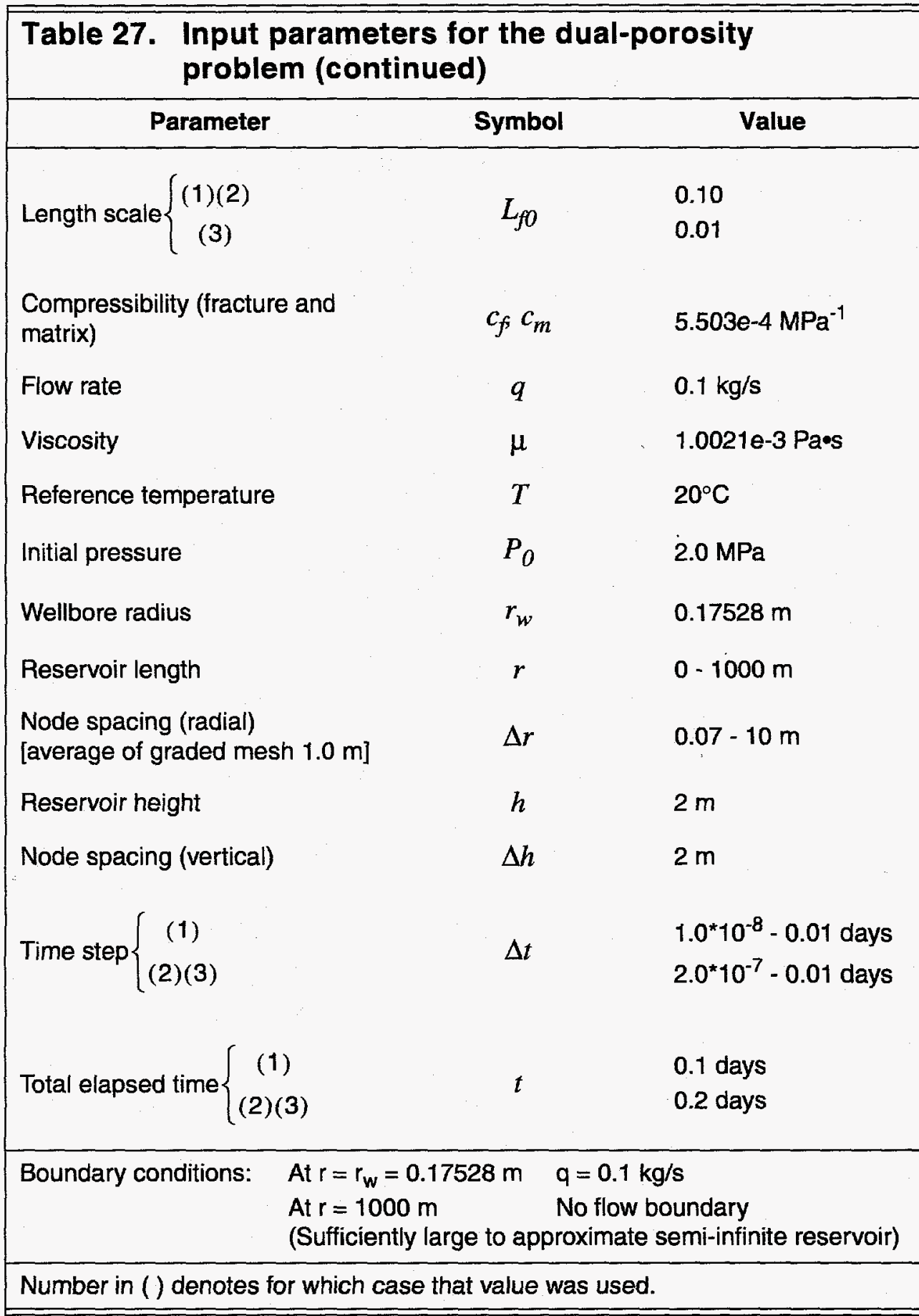

\subsubsection{Summary of test cases}

\subsubsection{Dual-porosity problem}

4.7.4.1.1 Function Tested. This test verifies that FEHM has correctly implemented the dual-porosity formulation.

4.7.4.1.2 Test Scope. This test case is a verification test.

4.7.4.1.3 Requirements Tested. Requirements 3.1, "Finite-Element Coefficient Generation," 3.2, "Formulate Transient Equations" 
(specifically Sections 3.2.2 and 3.2.6), 3.3, "Apply Constitutive Relationships" (specifically Sections 3.3.1 and 3.3.7), 3.4, "Compute Solution to Transient Equations," and 3.5, "Provide Input/Output Data Files," of Chapter I are verified by this test. 4.7.4.1.4 Required Inputs. Problem input is provided in the following files:

- dual1.in: basic input data, case 1,

- dual2.in: basic input data, case 2 ,

- dual3.in: basic input data, case 3, and

- dual.geom: geometry data used for the above cases.

4.7.4.1.5 Expected Outputs. Values from FEHM for pressure versus time at the wellbore fracture node, $r=0.1398$ (i.e., interior node closest to $r_{w}=0.17528$ ), will be output, nondimensionalized, and compared to the Warren and Root analytical solution. Values within $5 \%$ of the analytical solution for $\tau>100$ will be considered acceptable. 


\subsection{Test of Heat and Mass Transfer in Porous Media}

\subsubsection{Purpose}

In some special instances, the flow of a hot fluid in a confined aquifer may be described by an analytical expression. Avdonin (1964) presents an analytical solution for one-dimensional, radial fluid flow with heat conduction in the orthogonal direction. In addition to testing the coupled heat- and mass-transfer implementation for a single-phase system, the results will also demonstrate that the radial geometry is correctly implemented with different grid spacings.

\subsubsection{Functional description}

The test suite consists of a set of simulations of $1-D$ radial flow into a confined aquifer. The same flow problem is run with the domain divided into 84 nodes (41 elements), 400 nodes (199 elements), and 800 nodes ( 399 elements). In addition to demonstrating that the heat- and mass-transfer problem has been correctly formulated and that the radial geometry has been correctly implemented, this test will assess the impact of finer spatial discretization on accuracy.

\subsubsection{Assumptions and limitations}

The analytical solution presented by Avdonin (1964) takes the form:

$$
\begin{aligned}
& u(\omega, \tau)=\frac{1}{\Gamma(v)}\left(\frac{\omega^{2}}{4 \tau}\right)^{v} \int_{0}^{1} \exp \left(-\frac{\omega^{2}}{4 \tau s}\right) \operatorname{erfc}\left(\frac{\alpha s \sqrt{\tau}}{2 \sqrt{1-s}}\right) \frac{d s}{v+1}, \\
& \text { where } \omega=\frac{2 r}{b} \\
& \tau=\frac{4 \kappa_{t} t}{c_{t} \rho_{t} b^{2}}, \\
& v=\frac{q c_{w} \rho_{w}}{4 \pi b \kappa_{t}}, \\
& \alpha=\left(\frac{\kappa_{r} c_{r} \rho_{r}}{\kappa_{t} c_{t} \rho_{t}}\right)^{1 / 2},
\end{aligned}
$$

erfc is the complimentary error function, $\Gamma$ is the gamma function, $r$ is the radial coordinate, $q$ is the injection flow rate, $u$ is a dimensionless temperature change, and the integration variable $s$ represents a dimensionless time. The subscripts $r, w$, and $t$ refer to rock, water, and total (rock and water), respectively. The temperature is computed using:

$$
T=T_{0}-u(\omega, \tau) \cdot\left(T_{0}-T_{i n}\right)
$$

This problem assumes one-dimensional, radial, steady-state flow and unsteady heat transport in a single-phase liquid. It simulates the injection 
of cool water into a geothermal reservoir. Figure 9 shows the problem geometry with boundary and initial conditions. Input parameters defining the problem are given in Table 28.

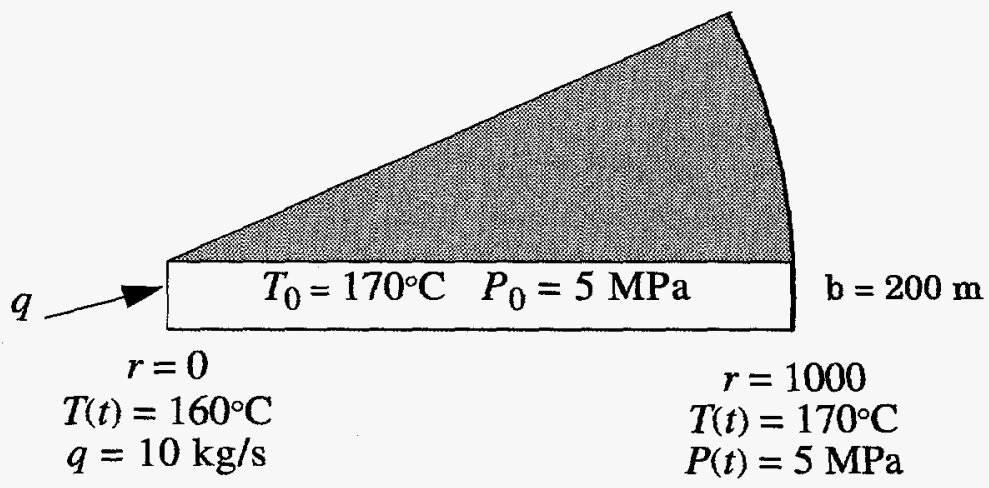

Figure 9. Schematic diagram of the Avdonin problem geometry with boundary and initial conditions.

\subsubsection{Summary of test cases}

\subsubsection{Heat and mass transfer in a 1-D radial aquifer}

4.8.4.1.1 Function Tested. This test verifies that FEHM correctly models 1-dimensional heat and mass transport for radial flow and demonstrates the impact of finer spatial discretization on accuracy.

4.8.4.1.2 Test Scope. This test case is a verification test.

4.8.4.1.3 Requirements Tested. Requirements 3.1, "Finite-Element Coefficient Generation," 3.2, "Formulate Transient Equations" (specifically Sections 3.2.2 and 3.2.6), 3.3, "Apply Constitutive Relationships" (specifically Section 3.3.1), 3.4, "Compute Solution to Transient Equations," and 3.5, "Provide Input/ Output Data Files," of Chapter I are verified by this test.

4.8.4.1.4 Required Inputs. Problem input is provided in the following files:

- avdonin.in: basic input data used in conjunction with the following geometry data files:

- avdonin.geom.84: (84 nodes, 42 elements),

- avdonin.geom.400: (400 nodes, 199 elements), or

- avdonin.geom.800: (800 nodes, 399 elements).

4.8.4.1.5 Expected Outputs. Values from FEHM, for temperature versus time at a fixed radius ( $r=37.5 \mathrm{~m}$ ), and values for temperature versus radius $(r=0$ to $1000 \mathrm{~m})$ at a specified time, $(t=1 . e 9 \mathrm{~s})$ will be output and compared to the analytical solution. Values within $5 \%$ of the analytical solution will be considered acceptable. 


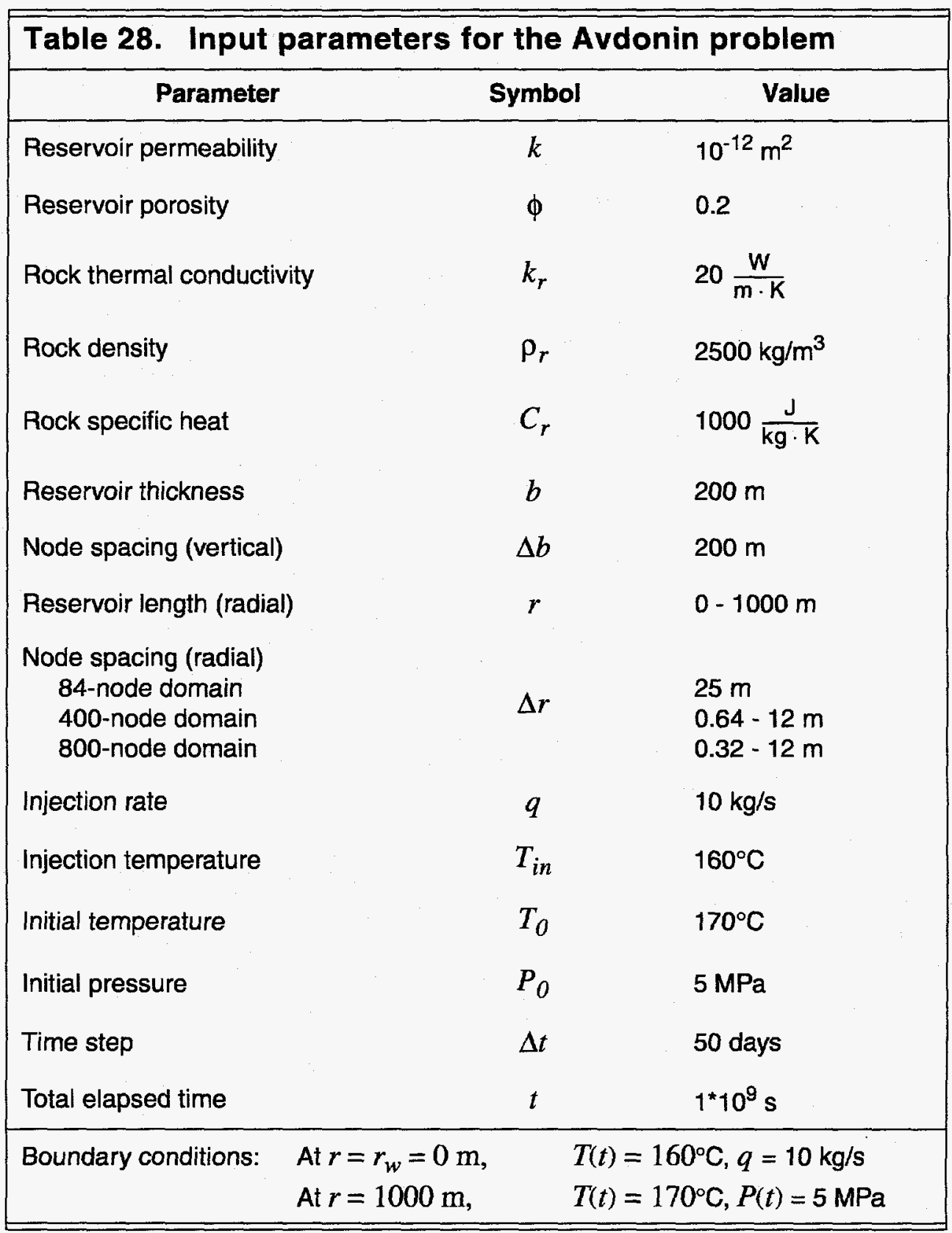




\subsection{Test of Toronyi Two-phase Problem}

\subsubsection{Purpose}

This problem has evolved into a standard test case for checking two-phase heat and mass transfer (Toronyi and Farouq Ali 1977). Fluid is discharged from a two-phase geothermal reservoir, and the saturation at each node is simulated. There is no analytical solution for this problem; comparisons must be made with other transient heat- and mass-transfer codes. The problem tests the multiphase capabilities severely, and in doing so, verifies that the liquid- and vapor-phase-transport submodels of FEHM are working properly.

\subsubsection{Functional description}

The test suite consists of a simulation of fluid discharge from a two-phase aquifer. In addition to demonstrating that the heat- and mass-transfer problem has been correctly formulated, it will demonstrate that phase partitioning has been correctly implemented.

\subsubsection{Assumptions and limitations}

Fluid is discharged at a constant rate from the two-phase geothermal reservoir until $19 \%$ of the original water mass has been removed (78.31 days). There is no flow across the peripheral boundaries. Temperature is controlled by the saturation pressure/temperature curve.

The solution is verified by comparison of FEHM results to those found by Thomas and Pierson (1978). Thomas and Pierson used cell-centered elements, wheras FEHM uses node-centered elements, so boundary elements were adjusted to provide matching central nodes. The reservoir model (solution domain) is shown in Fig. 10 along with the node saturations obtained by Thomas and Pierson. The asymmetry in the solution is due to the off-center location of the discharge node. Table 29 lists the input parameters for the Toronyi problem.

\subsubsection{Summary of test cases}

\subsubsection{Toronyi two-phase problem}

4.9.4.1.1 Function Tested. This test verifies that FEHM has correctly implemented heat and mass transfer and phase partitioning.

4.9.4.1.2 Test Scope. This test case is a verification test.

4.9.4.1.3 Requirements Tested. Requirements 3.1, "Finite-Element Coefficient Generation," 3.2, "Formulate Transient Equations" (specifically Sections 3.2.2 and 3.2.6), 3.3, "Apply Constitutive Relationships" (specifically Section 3.3.1), 3.4, "Compute Solution to Transient Equations," and 3.5, "Provide Input/ Output Data Files," of Chapter I are verified by this test. 


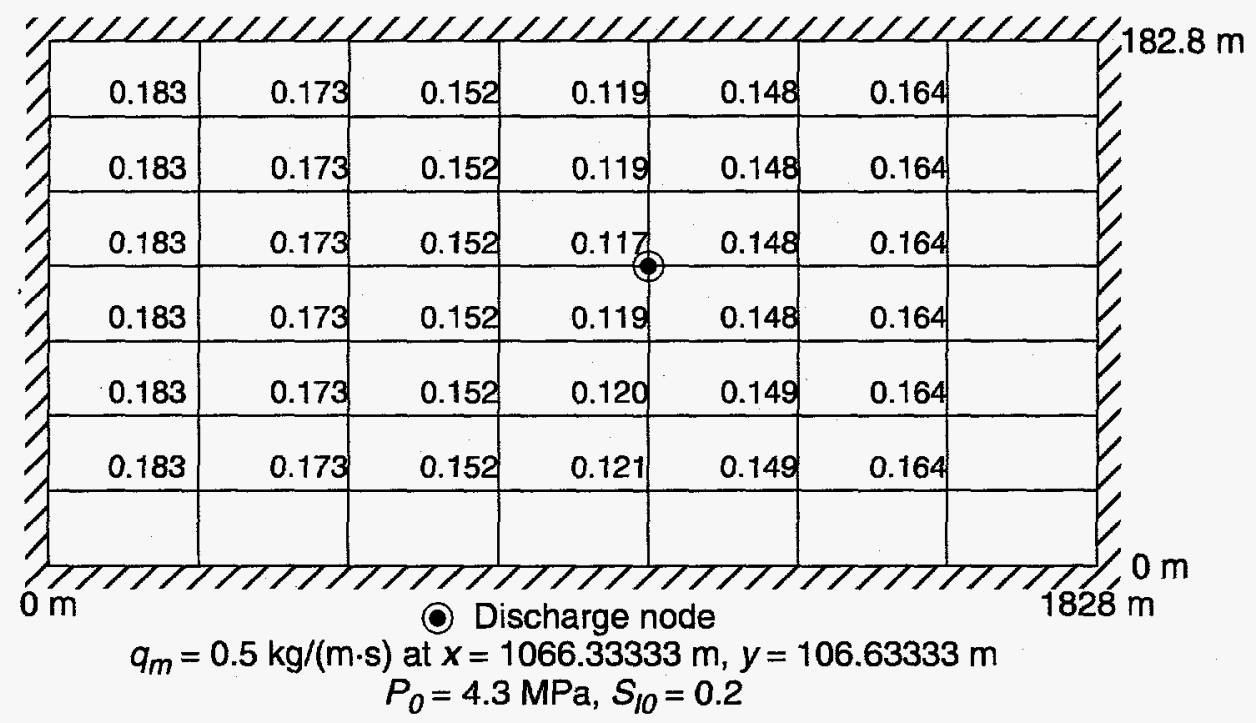

Figure 10. Solution domain and saturation results for the Toronyi problem.

4.9.4.1.4 Required Inputs. Problem input is provided in the following file:

- toronyi.in: basic input and geometry data (64 nodes, 49 elements).

4.9.4.1.5 Expected Outputs. Values from FEHM, for saturation at each interior node at time $t=78.31$ days, will be output and compared to the Thomas and Pierson (1978) saturation data. Values within $5 \%$ of the Thomas and Pierson solution will be considered acceptable. 


\begin{tabular}{|c|c|c|}
\hline \multicolumn{3}{|c|}{$\begin{array}{l}\text { Table 29. Input parameters for the Toronyi two-phase } \\
\text { problem }\end{array}$} \\
\hline Parameter & Symbol & Value \\
\hline Reservoir permeability & $k$ & $9.869 \times 10^{-13} \mathrm{~m}^{2}$ \\
\hline Reservoir porosity & $\phi$ & 0.05 \\
\hline Rock thermal conductivity & $\kappa_{r}$ & $1.73 \frac{\mathrm{W}}{\mathrm{m} \cdot \mathrm{K}}$ \\
\hline Rock density & $\rho_{r}$ & $2500 \mathrm{~kg} / \mathrm{m}^{3}$ \\
\hline Rock specific heat & $C_{r}$ & $1000 \frac{\mathrm{J}}{\mathrm{kg} \cdot \mathrm{K}}$ \\
\hline Aquifer length & $x$ & $1828 \mathrm{~m}$ \\
\hline Node spacing $(x)^{\ddagger}$ & $\Delta x$ & 304.666 \\
\hline Aquifer width & $y$ & $182.8 \mathrm{~m}$ \\
\hline Node spacing $(y)^{\ddagger}$ & $\Delta y$ & 30.4666 \\
\hline Reference temperature & $T$ & $250^{\circ} \mathrm{C}$ \\
\hline Initial pressure & $P_{0}$ & 4.3 $\mathrm{MPa}$ \\
\hline Initial water saturation & $S_{l o}$ & 0.2 \\
\hline Residual liquid saturation & $S_{l r}$ & 0.05 \\
\hline Residual vapor saturation & $S_{l v}$ & 0.05 \\
\hline $\begin{array}{l}\text { Capillary pressure at zero } \\
\text { saturation }\end{array}$ & $P_{\text {capmax }}$ & $1.0 \mathrm{MPa}$ \\
\hline $\begin{array}{l}\text { Saturation at which capillary } \\
\text { pressure goes to zero }\end{array}$ & $S_{\operatorname{lmax}}$ & 1.0 \\
\hline Aquifer discharge & $q_{m}$ & $0.5 \frac{\mathrm{kg}}{\mathrm{m} \cdot \mathrm{s}}$ \\
\hline Initial pressure & $P_{0}$ & $4.4816 \mathrm{MPa}$ \\
\hline Time step & $\Delta t$ & 10 days \\
\hline Total elapsed time & $t$ & 78.31 days \\
\hline Boundary conditions: & $\begin{array}{l}333, y=10 \\
\text { peripheral }\end{array}$ & $q_{m}=0.5 \frac{\mathrm{kg}}{\mathrm{m} \cdot \mathrm{s}}$ \\
\hline \multicolumn{3}{|c|}{$\begin{array}{l}\text { F For the FEHM simulation, node spacing around the periphery is half the general } \\
\text { spacing to facillitate comparison with Thomas and Pierson who used cell- } \\
\text { centered elements, whereas FEHM uses node-centered elements. }\end{array}$} \\
\hline
\end{tabular}




\subsection{Test of DOE Code Comparison Project, Problem Five, Case A}

\subsubsection{Purpose}

This model of a 2-D areal reservoir with multiphase flow was developed as part of the DOE Code Comparison Project (Molloy 1980). The two-phase (water/water vapor), heat- and mass-transfer problem is characterized by a moving two-phase boundary. The modeled region has a cold fluid boundary that provides fluid to the system as discharge occurs through a well.

Numerical difficulties can occur as nodes go from two-phase to compressed water. This problem is a good test for the two-phase routines, as well as the phase-change algorithm. In addition, this problem provides a test of the code restart capabilities as the initial temperature field is input through use of a restart file. There is no analytical solution for this problem, but results from other codes (Pritchett 1980) are available as a check for FEHM.

\subsubsection{Functional description}

The test suite consists of a simulation of fluid discharge from a two-phase, 2-D aquifer. Fluid produced at the production well is replaced by coldwater recharge over the length of one of the lateral boundaries. In addition to demonstrating that the heat- and mass-transfer problem has been correctly formulated, the test suite will demonstrate that phase partitioning has been correctly implemented.

\subsubsection{Assumptions and limitations}

Fluid is discharged from the two-phase geothermal reservoir whereas coldwater recharge occurs over one lateral boundary. The other three boundaries are considered to be impermable and nonconductive. The geometry and boundary conditions are shown in Fig. 11. Of particular note is the variable initial-temperature field and the prescribed pressure and temperature boundary. Table 30 lists the input parameters for the DOE Code Comparison Project problem. A Corey-type relative permeability function is used for this model (see Zyvoloski 1997a, "Relative Permeability and Capillary Pressure Functions" in Section 8.4.3). The reader is referred to Pritchett (1980) for a more detailed discussion of this problem and the code comparison. The solution is verified by comparison of FEHM results to other codes (obtained from Pritchett).

\subsubsection{Summary of test cases}

\subsubsection{DOE Code Comparison Project, Problem Five}

4.10.4.1.1 Function Tested. This test verifies that FEHM has correctly implemented heat and mass transfer and phase partitioning.

4.10.4.1.2 Test Scope. This test case is a verification test. 


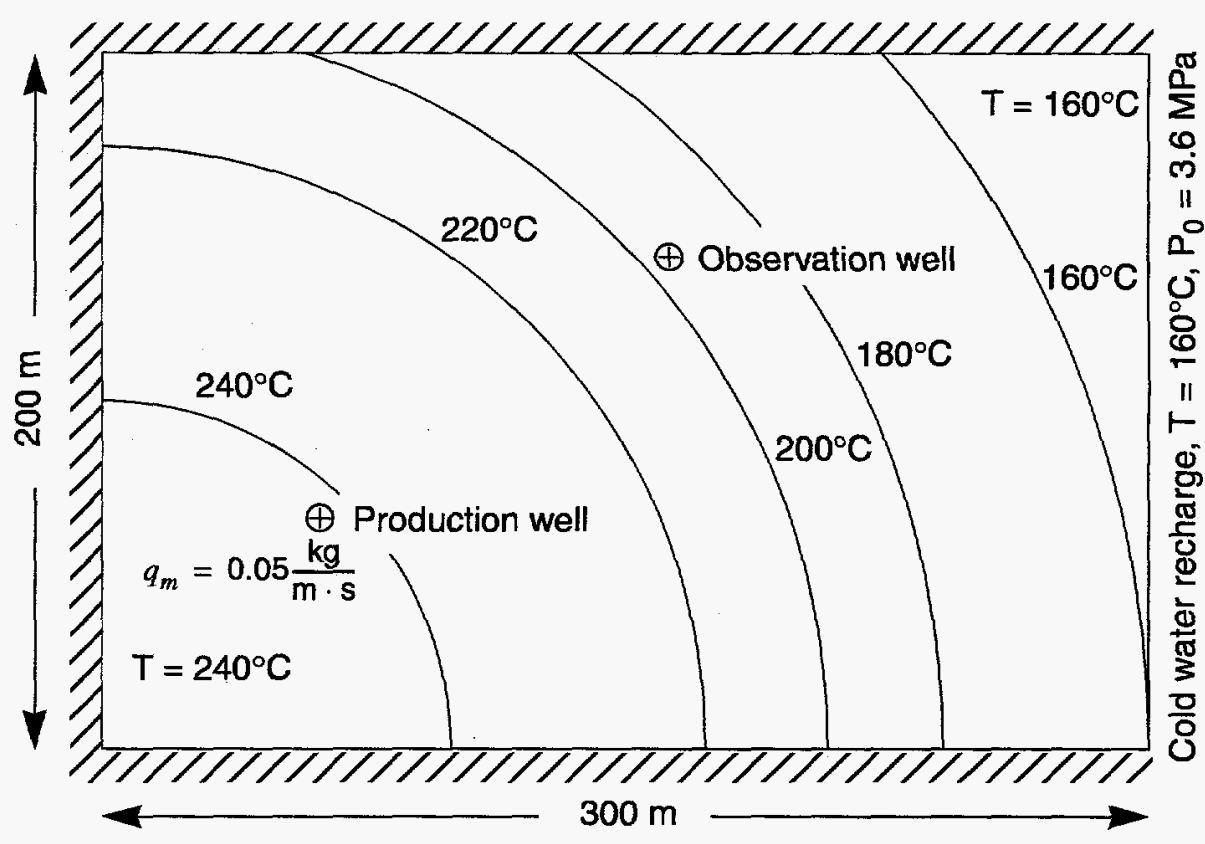

Figure 11. Schematic diagram of the geometry and boundary conditions for the DOE Code Comparison Project problem.

4.10.4.1.3 Requirements Tested. Requirements 3.1, "Finite-Element Coefficient Generation," 3.2, "Formulate Transient Equations" (specifically Sections 3.2.2 and 3.2.6), 3.3, "Apply Constitutive Relationships" (specifically Section 3.3.1), 3.4, "Compute Solution to Transient Equations," 3.5, "Provide Input/Output Data Files," and 3.6, "Provide Restart Capability" (specifically Sections 3.6.2 and 3.6.3), of Chapter I are verified by this test. 4.10.4.1.4 Required Inputs. Problem input is provided in the following files:

- doe.dat: basic input and geometry data (140 nodes, 117 elements) and

- doe.ini: initial temperature field, pressure, and saturation.

4.10.4.1.5 Expected Outputs. Values from FEHM for productionwell temperature and pressure and pressure at the observation well versus time will be output and compared to the data from other codes. Values within $5 \%$ of those obtained by the other codes will be considered acceptable. 


\section{Table 30. Input parameters for the DOE Code Comparison Project, Problem 5, Case A}

\begin{tabular}{lcl}
\hline \multicolumn{1}{c}{ Parameter } & Symbol & \multicolumn{1}{c}{ Value } \\
\hline Reservoir permeability & $k$ & $2.5 \times 10^{-14} \mathrm{~m}^{2}$ \\
Reservoir porosity & $\phi$ & 0.35 \\
Rock thermal conductivity & $\kappa_{r}$ & $1 \frac{\mathrm{W}}{\mathrm{m} \cdot \mathrm{K}}$ \\
Rock density & $\rho_{r}$ & $2563 \mathrm{~kg} / \mathrm{m}^{3}$ \\
Rock specific heat & $C_{r}$ & $1010 \frac{\mathrm{J}}{\mathrm{kg} \cdot \mathrm{K}}$ \\
Reservoir length & $x$ & $300 \mathrm{~m}$ \\
Reservoir thickness & $y$ & $200 \mathrm{~m}$ \\
Node spacing & & $25 \mathrm{~m}$ \\
Liquid residual saturation & $\Delta x, \Delta y$ & 0.3 \\
Gas residual saturation & $S_{l r}$ & 0.1 \\
Reservoir discharge & $S_{v r}$ & $0.05 \frac{\mathrm{kg}}{\mathrm{m} \cdot \mathrm{s}}$ \\
Initial pressure & $q_{m}$ & $3.6 \mathrm{MPa}$ \\
Time step & $P_{0}$ & $30-60 \mathrm{days}$ \\
Total elapsed time & $\Delta t$ & $10 \mathrm{years}$ \\
\hline
\end{tabular}

Production-well coordinates: $\quad x=62.5 \mathrm{~m}, y=62.5 \mathrm{~m}$

Observation-well coordinates: $\quad x=162.5 \mathrm{~m}, y=137.5 \mathrm{~m}$

Initial temperature distribution: $\left[T\right.$ in ${ }^{\circ} \mathrm{C}, r$ in $\left.\mathrm{m}\left(r=\sqrt{x^{2}+y^{2}}\right)\right]$ :

$$
T(x, y, 0)=\left\{\begin{array}{c}
240 \\
240-160\left(\frac{r-100}{200}\right)^{2}+80\left(\frac{r-100}{200}\right)^{4} \\
160
\end{array}\right\} \begin{gathered}
0 \leq r \\
100<r<300 \\
r \geq 300
\end{gathered}
$$

Boundary conditions: At $x=62.5 \mathrm{~m}, y=62.5 \mathrm{~m} \quad q_{m}=0.5 \frac{\mathrm{kg}}{\mathrm{m} \cdot \mathrm{s}}$

At $x=300 \mathrm{~m}, y=0-200 \mathrm{~m} \quad T=160^{\circ} \mathrm{C}, P=P_{0}=3.6 \mathrm{MPa}$ At $x=0 \mathrm{~m}, y=0 \mathrm{~m}, y=200 \mathrm{~m}$ Impermable, nonconductive

${ }^{\ddagger}$ For the FEHM simulation, node spacing around the periphery is half the general spacing $(12.5 \mathrm{~m})$. 


\subsection{Test of Dry-out of a Partially Saturated Medium}

\subsubsection{Purpose}

Calculations of fluid flow in the presence of repository heat require the simultaneous solution of a heat- and mass-transfer system consisting of water, water vapor, and air. This test case exercises the code option that solves this type of flow and heat-transport problem by passing air through a one-dimensional, partially saturated medium. The air evaporates water and removes it from the system. A dry-out zone progresses from the injection region through the flow path at a rate that can be predicted using an analytical solution.

\subsubsection{Functional description}

The test suite consists of a simulation of the rate of movement of a dry region, starting at a condition of constant saturation throughout the flow path. Two cases are considered: a system without vapor-pressure lowering and one with vapor-pressure lowering, which lowers the water-vapor carrying capacity of the injected air.

\subsubsection{Assumptions and limitations}

If dry air is injected into a partially saturated medium containing immobile liquid water, the water evaporates until the partial pressure of water vapor in the gas reaches its equilibrium vapor pressure. For a mass flow rate of air of $\dot{m}_{a}$ and assuming ideal-gas-mixture conditions, the corresponding rate of removal of water in the gas $\dot{m}_{w}$ is given by

$$
\dot{m}_{w}=\frac{M_{w} P_{w} \dot{m}_{a}}{M_{a} P_{a}},
$$

where $M_{w}$ and $M_{a}$ are molecular weights and $P_{w}$ and $P_{a}$ are partial pressures with the subscripts $w$ and $a$ referring to the water and air, respectively. Assuming that the dry-out occurs as a sharp front, the rate of progression of this front can be shown to be

$$
r_{d r y}=\frac{L \dot{m}_{a} M_{w} P_{w}}{\phi S V \rho_{w} M_{a} P_{a}}
$$

In this equation, $L$ is the flow path length, $V$ is the volume, and $S$ is the liquid saturation. The problem is depicted in Fig. 12. Table 31 lists the input parameters used in this comparison. When vapor-pressure lowering is included, the value of $P_{w}$ in the equation is lower than it would be in the absence of this effect. The capillary pressure in these simulations is adjusted so that it is a constant value throughout the column, regardless of saturation. Its value is set using the linear capillary-pressure model such that the water vapor pressure is lowered by a factor of 2 . 


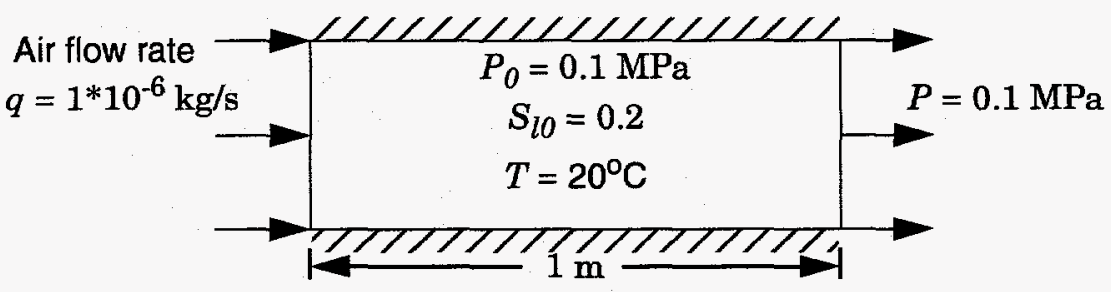

Figure 12. Schematic drawing of the geometry and boundary conditions for the dry-out simulations.

\begin{tabular}{|c|c|c|}
\hline Parameter & Symbol & Value \\
\hline Air flow rate & $q$ & $1.0^{*} 10^{-6} \mathrm{~kg} / \mathrm{s}$ \\
\hline Volume of path & $V$ & $1 \mathrm{~m}^{3}$ \\
\hline Length of path & $L$ & $1 \mathrm{~m}$ \\
\hline Node spacing & $\Delta l$ & $0.005 \mathrm{~m}$ \\
\hline Porosity & $\phi$ & 0.05 \\
\hline $\begin{array}{l}\text { Time step } \\
\text { w/o vapor-pressure lowering } \\
\text { with vapor-pressure lowering }\end{array}$ & $\Delta t$ & $\begin{array}{l}0.001-1.5 \text { days } \\
0.001-3 \text { days }\end{array}$ \\
\hline $\begin{array}{l}\text { Total elapsed time } \\
\text { w/o vapor-pressure lowering } \\
\text { with vapor-pressure lowering }\end{array}$ & $t$ & $\begin{array}{l}500 \text { days } \\
1000 \text { days }\end{array}$ \\
\hline Total system pressure & $P_{0}$ & $0.1 \mathrm{MPa}$ \\
\hline $\begin{array}{l}\text { Temperature (from which } P_{w} \text { is } \\
\text { computed) }\end{array}$ & $T$ & $20^{\circ} \mathrm{C}$ \\
\hline Initial water saturation & $S_{l 0}$ & 0.2 \\
\hline Residual liquid saturation & $S_{l r}$ & 0.3 \\
\hline Residual vapor saturation & $S_{l v}$ & 0.3 \\
\hline Maximum liquid saturation & $S_{l \max }$ & 1.0 \\
\hline Maximum vapor saturation & $S_{v \max }$ & 1.0 \\
\hline $\begin{array}{ll}\text { Boundary conditions: } & \text { At } l=0 \\
& \text { At } l=1\end{array}$ & \multicolumn{2}{|c|}{$\begin{array}{l}q=1^{*} 10^{-6} \mathrm{~kg} / \mathrm{s} \\
P=0.1 \mathrm{MPa}\end{array}$} \\
\hline
\end{tabular}




\subsubsection{Summary of test cases}

\subsubsection{Dry-out without vapor-pressure lowering}

4.11.4.1.1 Function Tested. This test verifies that FEHM correctly simulates the dry-out of a partially saturated medium in the absence of vapor-pressure lowering.

4.11.4.1.2 Test Scope. This test case is a verification test.

4.11.4.1.3 Requirements Tested. Requirements 3.1, "Finite-Element Coefficient Generation," 3.2, "Formulate Transient Equations" (specifically Sections 3.2.3 and 3.2.6), 3.3, "Apply Constitutive Relationships" (specifically Sections 3.3.2 and 3.3.4), 3.4, "Compute Solution to Transient Equations," and 3.5, "Provide Input/Output Data Files," of Chapter I are verified by this test. 4.11.4.1.4 Required Inputs. Problem input is provided in the following files:

- dryout1.in: basic input data and

- dryout.geom: geometry data (the grid consists of $201 \times 2$ nodes, thus simulating a one-dimensional flow system).

4.11.4.1.5 Expected Outputs. Values from FEHM for the position of the dry-out front at five different times should agree with the analytical solution. Position within 5\% of the predicted value will be considered acceptable.

\subsubsection{Dry-out with vapor-pressure lowering}

4.11.4.2.1 Function Tested. This test verifies that FEHM correctly simulates the dry-out of a partially saturated medium when vapor-pressure lowering is included.

4.11.4.2.2 Test Scope. This test case is a verification test.

4.11.4.2.3 Requirements Tested. Requirements 3.1, "Finite-Element Coefficient Generation," 3.2, "Formulate Transient Equations" (specifically Sections 3.2.3 and 3.2.6), 3.3, "Apply Constitutive Relationships" (specifically Sections 3.3.2 and 3.3.4), 3.4, "Compute Solution to Transient Equations," and 3.5, "Provide Input/Output Data Files," of Chapter I are verified by this test. 4.11.4.2.4 Required Inputs. Problem input is provided in the following files:

- dryout2.in: basic input data and

- dryout.geom: geometry data (the grid consists of $201 \times 2$ nodes, thus simulating a one-dimensional flow system).

4.11.4.2.5 Expected Outputs. Values from FEHM for the position of the dry-out front at five different times should agree with the analytical solution. Position within 5\% of the predicted value will be considered acceptable. 


\subsection{Test of One-dimensional Reactive-Solute Transport}

\subsubsection{Purpose}

Tracers are used extensively to determine travel times and reservoir volumes. Reactive tracers can be used to infer reservoir properties such as temperature and geochemical composition. Reactive tracers will be used in the C-wells testing at Yucca Mountain. Of course, solute transport capabilities are also used to simulate radionuclide migration. A YMP code, SORBEQ (Robinson 1993), has been developed and validated to model onedimensional reactive-solute flow and adsorption. FEHM will be compared with SORBEQ on a one-dimensional solute problem with equilibrium sorption. This comparison will verify the species transport in one dimension, and because the codes use different numerical techniques (finite differences versus finite elements), this test suite provides an independent check of both codes.

\subsubsection{Functional Description}

The test suite consists of a simulation of solute transport for five independent species: a conservative solute and species governed by the linear, Langmuir, Freundlich, and modified Fruendlich isotherms.

\subsubsection{Assumptions and limitations}

The problem is depicted in Fig. 13. Table 32 defines the input parameters used for FEHM and SORBEQ simulations. The adsorption parameters are given in Table 33. A fluid-flow steady state is established by injecting fluid at a fixed flow rate at the inlet and applying a constant-pressure boundary condition at the outlet. The solute transport simulation is executed assuming an initial concentration of zero everywhere in the column and injecting fluid with a concentration of unity at the start of the solute transport phase of the simulation. For each solute, the same dispersivity is assumed $(0.033 \mathrm{~m}$, equivalent to a dimensionless Peclet number $L / \alpha$ of 30 ). The inlet concentration remains at unity for the entire simulation.

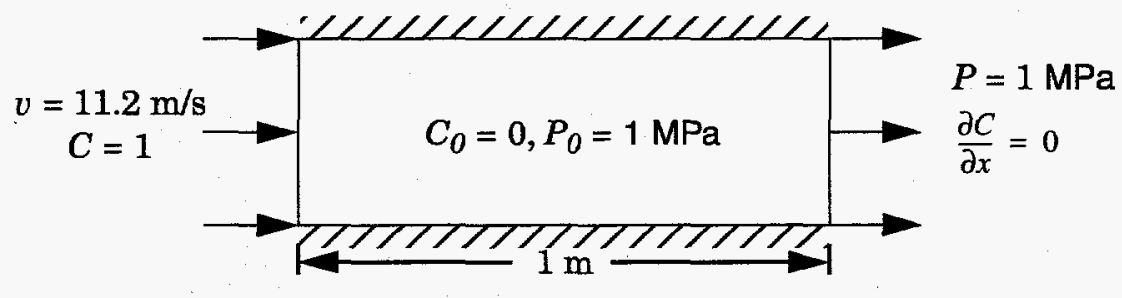

Figure 13. Schematic drawing of the geometry and boundary conditions for the 1-D reactive-tracer transport problem. 


\begin{tabular}{|c|c|c|c|}
\hline \multicolumn{4}{|c|}{$\begin{array}{l}\text { Table 32. Input parameters for the 1-D reactive-trace } \\
\text { transport problem }\end{array}$} \\
\hline \multicolumn{2}{|l|}{ Parameter } & Symbol & Value \\
\hline \multicolumn{2}{|l|}{ Fluid velocity } & $v$ & $11.2 \mathrm{~m} / \mathrm{s}$ \\
\hline \multicolumn{2}{|l|}{ Flow path length } & $L$ & $1 \mathrm{~m}$ \\
\hline \multicolumn{2}{|l|}{ Node spacing } & $\Delta l$ & $0.005 \mathrm{~m}$ \\
\hline \multicolumn{2}{|l|}{ Dispersivity } & $\alpha$ & $0.033 \mathrm{~m}$ \\
\hline \multicolumn{2}{|l|}{ Porosity } & $\phi$ & 0.3 \\
\hline \multicolumn{2}{|l|}{ Bulk-rock density } & $\rho_{b}$ & $2500 \mathrm{~kg} / \mathrm{m}^{3}$ \\
\hline \multicolumn{2}{|l|}{ Time step (tracer) } & $\Delta t$ & $0.09-0.43 \mathrm{~s}$ \\
\hline \multicolumn{2}{|l|}{ Total elapsed time } & $t$ & $100 \mathrm{~s}$ \\
\hline \multicolumn{2}{|l|}{ Pressure } & $P_{0}$ & $1.0 \mathrm{MPa}$ \\
\hline \multicolumn{2}{|l|}{ Initial concentration } & $C_{0}$ & 0.0 \\
\hline \multicolumn{2}{|l|}{ Inlet concentration } & $C_{\text {in }}$ & 1 \\
\hline \multirow[t]{2}{*}{ Boundary conditions: } & At $l=0$ & \multicolumn{2}{|c|}{$C=1$} \\
\hline & At $l=1$ & \multicolumn{2}{|c|}{$P=1 \mathrm{MPa}, \frac{\partial C}{\partial x}=0$} \\
\hline
\end{tabular}

\begin{tabular}{|c|c|c|c|}
\hline \multicolumn{4}{|c|}{$\begin{array}{l}\text { Table 33. Adsorption parameters for the reactive-tracer } \\
\text { transport problem }\end{array}$} \\
\hline Adsorption isotherm & $\alpha_{1}$ & $\alpha_{2}$ & $\beta$ \\
\hline Conservative & 0.0 & 0.0 & 1.0 \\
\hline Linear & 0.25 & 0.0 & 1.0 \\
\hline Langmuir & 0.24 & 1.0 & 1.0 \\
\hline Freundlich & 0.12 & 0.0 & 0.8 \\
\hline Modified Freundlich & 0.48 & 1.0 & 0.8 \\
\hline
\end{tabular}

\subsubsection{Summary of test cases}

\subsubsection{Reactive-tracer transport}

4.12.4.1.1 Function Tested. This test verifies that FEHM has correctly implemented reactive-tracer transport.

4.12.4.1.2 Test Scope. This test case is a verification test. 
4.12.4.1.3 Requirements Tested. Requirements 3.1, "Finite-Element Coefficient Generation," 3.2, "Formulate Transient Equations" (specifically Sections 3.2.4 and 3.2.6), 3.3, "Apply Constitutive Relationships" (specifically Section 3.3.5), 3.4, "Compute Solution to Transient Equations," and 3.5, "Provide Input/ Output Data Files," of Chapter I are verified by this test.

4.12.4.1.4 Required Inputs. Problem input is provided in the following file:

- sorption.in: basic input and geometry data (402 nodes, 200 elements). A single simulation is performed that contains five noninteracting solutes with sorption parameters defined in Table 33.

4.12.4.1.5 Expected Outputs. Breakthrough curves (concentration at the outlet node for each species versus time) from FEHM will be output and compared to the SORBEQ solutions. When concentrations are close to zero, percent errors are misleading. Furthermore, considerable concentration errors result from only a small displacement of a breakthrough curve along the time axis because of the steep rise of the concentration-time curve for a typical case. Therefore, concentrations within 0.01 of the SORBEQ solutions and percent errors less than $10 \%$ when concentrations are greater than 0.1 will be considered acceptable. 


\subsection{Test of Henry's Law Species}

\subsubsection{Purpose}

This set of verification runs tests the numerous combinations of effects possible for Henry's Law solutes that may sorb or undergo chemical reaction. Two extremes for the one-dimensional flow field are employed: 1) air moving through a stagnant fluid phase and 2) water moving through a stagnant air phase. The solute will partition into the stagnant fluid, resulting in a decrease in the overall solute transport velocity similar to that observed with equilibrium sorption.

\subsubsection{Functional description}

The problem set has been divided into three segments. Segment 1 covers air moving through a stagnant fluid phase, and Segment 2 covers water moving through a stagnant air phase. Segment 3 contains problems similar to those of Segments 1 and 2 except that chemical reaction is also included for the Henry's Law species. The approach here is to check the results of a Henry's Law species against tests of a liquid- or vapor-only species under conditions designed to give similar breakthrough times. Table 34 outlines the combinations of chemical phenomena exercised in each problem

\begin{tabular}{|c|c|c|c|}
\hline \multicolumn{4}{|c|}{$\begin{array}{l}\text { Table 34. Combinations of phenomena exercised in the } \\
\text { tests of Henry's Law species }\end{array}$} \\
\hline Problem & Mobile phase & Sorption & Reaction \\
\hline $1-1$ & air & none & none \\
\hline $1-2$ & air & liquid-rock & none \\
\hline $1-3$ & air & vapor-rock & none \\
\hline $2-1$ & water & none & none \\
\hline $2-2$ & water & liquid-rock & none \\
\hline $2-3$ & water & vapor-rock & none \\
\hline $3-1$ & water & none & liquid and vapor \\
\hline $3-2$ & water & liquid-rock & liquid and vapor \\
\hline 3-3 & air & vapor-rock & liquid and vapor \\
\hline
\end{tabular}

\subsubsection{Assumptions and limitations}

Problem 1-1: A Henry's Law constant $\left(K_{H}\right)$ was chosen so that at any location half of the species resides in the vapor and half in the liquid. In the simulation, the tracer is exchanged between the flowing vapor and stagnant liquid. Therefore, this solute should behave identically to a linearly sorbing solute (see verification in the previous section, 
Section 4.12) with a sorption parameter that yields a velocity of one-half the conservative tracer velocity.

Problem 1-2: A Henry's Law constant of twice that of Problem 1-1, combined with an appropriate liquid-borne solute-rock sorption parameter, results in a partitioning of the solute of one-half vapor, one-fourth liquid, and one-fourth sorbed from liquid to rock. The results should be virtually identical to those of Problem 1-1, showing that the coupling of liquid to solid sorption is implemented properly for a Henry's Law species.

Problem 1-3: This problem is similar to Problem 1-2 except that sorption occurs from the vapor to the rock. The results should be virtually identical to those of Problem 1-1.

Problems 2-1, 2-2, and 2-3: These runs are similar to their counterparts in Segment 1 , except that the water phase is moving. The breakthrough curves should agree closely with that obtained for a liquid-only species undergoing sorption.

Problem 3-1: This problem tests a Henry's Law species with no sorption but with chemical reaction taking place in both the vapor and liquid (implemented as two independent chemical reactions). The steady-state concentration exiting the reactor is compared to that of a liquid-only species that reacts at twice the rate. Because the solute remains in the system twice as long for the Henry's Law species, rate constants lower by a factor of two for both the liquid and vapor should yield the same steadystate concentration as the liquid-only species.

Problem 3-2: This problem is an extension of Problem 3-1 that includes sorption from liquid to rock. Chemical reaction is specified as taking place in the liquid, vapor, and sorbed phase, with rate constants selected so that the results should agree with those of Problem 3-1. Two cases are tested: Henry's Law with sorption and liquid-only with sorption.

Problem 3-3: This problem is the same as Problem 3-2 except that the air is the moving phase and sorption is from vapor to rock.

The problem geometry is depicted in Fig. 14. Table 35 defines the input parameters, and the adsorption, Henry's law, and reaction parameters are given in Table 36 . The problems are isothermal.

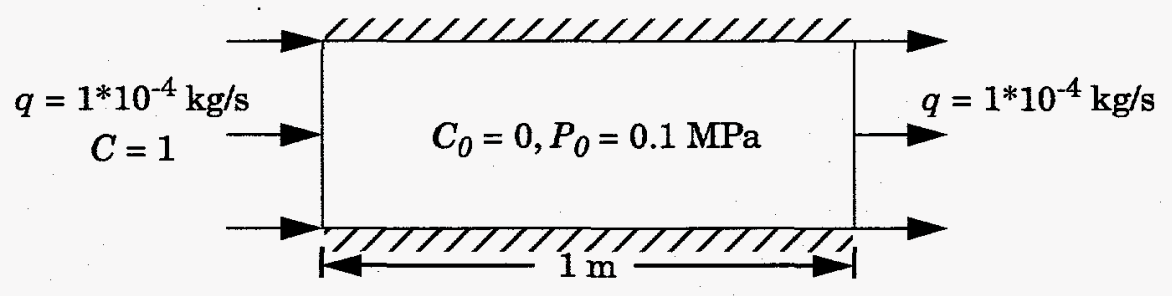

Figure 14. Schematic drawing of the geometry and boundary conditions for the tests of Henry's Law species. 


\section{Table 35. Input parameters for the tests of Henry's Law species}

\begin{tabular}{|c|c|c|}
\hline Parameter & Symbol & Value \\
\hline $\begin{array}{l}\text { Fow rate (liquid flow rate for } \\
\text { mobile-liquid case, air flow rate for } \\
\text { mobile-air case) }\end{array}$ & $q$ & $1.0^{\star} 10^{-4} \mathrm{~kg} / \mathrm{s}$ \\
\hline Flow path length & $L$ & $1 \mathrm{~m}$ \\
\hline Node spacing & $\Delta l$ & $0.005 \mathrm{~m}$ \\
\hline Dispersivity & $\alpha$ & $0.033 \mathrm{~m}$ \\
\hline Porosity & $\phi$ & 0.05 \\
\hline $\begin{array}{l}\text { Permeability } \\
\text { Mobile air phase } \\
\text { Mobile water phase }\end{array}$ & $k$ & $\begin{array}{l}1^{*} 10^{-11} \mathrm{~m}^{2} \\
1^{*} 10^{-12} \mathrm{~m}^{2}\end{array}$ \\
\hline Bulk-rock density & $\rho_{b}$ & $2500 \mathrm{~kg} / \mathrm{m}^{3}$ \\
\hline $\begin{array}{l}\text { Time step (tracer) } \\
\text { Mobile air phase } \\
\text { Mobile water phase }\end{array}$ & $\Delta t$ & $\begin{array}{l}0.09-0.43 \mathrm{~s} \\
500 \mathrm{~s}\end{array}$ \\
\hline $\begin{array}{l}\text { Total elapsed time (tracer) } \\
\text { Mobile air phase } \\
\text { Mobile water phase }\end{array}$ & $t$ & $\begin{array}{l}864 \mathrm{~s} \\
6 \text { days }\end{array}$ \\
\hline Pressure & $P_{0}$ & $0.1 \mathrm{MPa}$ \\
\hline Reference pressure & $P_{r e f}$ & $0.1 \mathrm{MPa}$ \\
\hline Reference temperature & $T_{r e f}$ & $20^{\circ} \mathrm{C}$ \\
\hline $\begin{array}{l}\text { Initial water saturation } \\
\text { Mobile air phase } \\
\text { Mobile water phase }\end{array}$ & $S_{l 0}$ & $\begin{array}{l}0.2 \\
0.5\end{array}$ \\
\hline $\begin{array}{l}\text { Residual liquid saturation } \\
\text { Mobile air phase } \\
\text { Mobile water phase }\end{array}$ & $S_{l r}$ & $\begin{array}{l}0.3 \\
0.0\end{array}$ \\
\hline $\begin{array}{l}\text { Residual vapor saturation } \\
\text { Mobile air phase } \\
\text { Mobile water phase }\end{array}$ & $S_{l v}$ & $\begin{array}{l}0.3 \\
0.6\end{array}$ \\
\hline $\begin{array}{l}\text { Maximum liquid saturation } \\
\text { Mobile air phase } \\
\text { Mobile water phase }\end{array}$ & $S_{l \max }$ & $\begin{array}{l}1.0 \\
0.3\end{array}$ \\
\hline $\begin{array}{l}\text { Maximum vapor saturation } \\
\text { Mobile air phase } \\
\text { Mobile water phase }\end{array}$ & $S_{v \max }$ & $\begin{array}{l}1.0 \\
0.0\end{array}$ \\
\hline
\end{tabular}




\begin{tabular}{|c|c|c|c|}
\hline \multicolumn{4}{|c|}{$\begin{array}{l}\text { Table 35. Input parameters for the tests of Henry's Law } \\
\text { species (continued) }\end{array}$} \\
\hline Parameter & & Symbol & Value \\
\hline Initial concentration & & $C_{0}$ & 0.0 \\
\hline Inlet concentration & & $C_{i n}$ & 1 \\
\hline Boundary conditions: & $\begin{array}{l}\text { At } l=0 \\
\text { At } l=1\end{array}$ & & $\begin{array}{l}1.0^{*} 10^{-4} \mathrm{~kg} / \mathrm{s} \\
0^{-4} \mathrm{~kg} / \mathrm{s}\end{array}$ \\
\hline
\end{tabular}
Table 36. Adsorption, Henry's Law, and reaction parameters for the tests
of Henry's Law species

\begin{tabular}{|c|c|c|c|c|c|}
\hline Problem & $\alpha_{1}$ & $\alpha_{2}$ & $\beta$ & $\boldsymbol{K}_{\boldsymbol{H}}$ & Reaction \\
\hline 1-1 (both phases) & 0.0 & 0.0 & 1.0 & 33.64 & N/A \\
\hline $1-2$ & & & & 67.24 & \\
\hline vapor phase & 0.0 & 0.0 & 1.0 & & $N / A$ \\
\hline liquid phase & $9.4972^{*} 10^{-6}$ & 0.0 & 1.0 & & \\
\hline $1-3$ & & & & 67.24 & \\
\hline vapor phase & $3.991 * 10^{-3}$ & 0.0 & 1.0 & & N/A \\
\hline liquid phase & 0.0 & 0.0 & 1.0 & & \\
\hline 2-1 (both phases) & 0.0 & 0.0 & 1.0 & 134.0127 & N/A \\
\hline $2-2$ & & & & 67.00635 & \\
\hline vapor phase & 0.0 & 0.0 & 1.0 & & N/A \\
\hline liquid phase & $4.989^{*} 10^{-3}$ & 0.0 & 1.0 & & \\
\hline $2-3$ & & & & 67.00635 & \\
\hline vapor phase & $1.191 * 10^{-5}$ & 0.0 & 1.0 & & N/A \\
\hline liquid phase & 0.0 & 0.0 & 1.0 & & \\
\hline $3-1$ & 0.0 & 0.0 & 1.0 & 134.0127 & $\begin{array}{l}\text { liquid and } \\
\text { vapor }\end{array}$ \\
\hline $3-2$ & & & & 67.00635 & liquid, \\
\hline vapor phase & 0.0 & 0.0 & 1.0 & & vapor, and \\
\hline liquid-phase adsorption & $4.989^{*} 10^{-3}$ & 0.0 & 1.0 & & sorbed \\
\hline 3-3 & & & & 67.24 & liquid, \\
\hline vapor phase & 0.0 & 0.0 & 1.0 & & vapor, and \\
\hline liquid phase & $9.4972^{*} 10^{-6}$ & 0.0 & 1.0 & & sorbed \\
\hline
\end{tabular}




\subsubsection{Summary of test cases}

\subsubsection{Air movement through stagnant water}

4.13.4.1.1 Function Tested. This test verifies that FEHM correctly simulates the transport of a species that partitions between a mobile air phase and immobile water.

4.13.4.1.2 Test Scope. This test case is a verification test.

4.13.4.1.3 Requirements Tested. Requirements 3.1, "Finite-Element Coefficient Generation," 3.2, "Formulate Transient Equations" (specifically Sections 3.2.4 and 3.2.6), 3.3, "Apply Constitutive Relationships" (specifically Section 3.3.5), 3.4, "Compute Solution to Transient Equations," and 3.5, "Provide Input/ Output Data Files," of Chapter I are verified by this test. 4.13.4.1.4 Required Inputs. Problem input is provided in the following files:

- henry1-1.in: basic input data,

- henry1-2.in: basic input data,

- henry1-3.in: basic input data, and

- henry.geom: geometry data (this two-dimensional grid contains 201 nodes in the flow direction and 2 in the direction perpendicular to flow, making this effectively a onedimensional simulation).

4.13.4.1.5 Expected Outputs. Values from FEHM for concentration versus time at the outlet node will be output and compared to the FEHM solution for a linearly sorbing solute with a retardation factor of 2 . Concentrations within 0.01 of the sorbing-solute solution and percent errors less than $10 \%$ when concentrations are greater than 0.1 will be considered acceptable.

\subsubsection{Water movement through stagnant air}

4.13.4.2.1 Function Tested. This test verifies that FEHM correctly simulates the transport of a species that partitions between a mobile water phase and immobile air.

4.13.4.2.2 Test Scope. This test case is a verification test.

4.13.4.2.3 Requirements Tested. Requirements 3.1, "Finite-Element Coefficient Generation," 3.2, "Formulate Transient Equations" (specifically Sections 3.2.4 and 3.2.6), 3.3, "Apply Constitutive Relationships" (specifically Section 3.3.5), 3.4, "Compute Solution to Transient Equations," and 3.5, "Provide Input/ Output Data Files," of Chapter I are verified by this test.

4.13.4.2.4 Required Inputs. Problem input is provided in the following files:

- henry2-1.in: basic input data,

- henry2-2.in: basic input data, 
- henry2-3.in: basic input data, and

- henry.geom: geometry data.

4.13.4.2.5 Expected Outputs. Values from FEHM for concentration versus time at the outlet node will be output and compared to the FEHM solution for a linearly sorbing solute with a retardation factor of 2 . Concentrations within 0.01 of the sorbing-solute solution and percent errors less than $10 \%$ when concentrations are greater than 0.1 will be considered acceptable.

\subsubsection{Air/water movement through stagnant water/air with chemical reaction}

4.13.4.3.1 Function Tested. This test verifies that FEHM correctly simulates the transport of a species that partitions between a mobile air phase and immobile water and for which the solute also undergoes an irreversible, first-order reaction.

4.13.4.3.2 Test Scope. This test case is a verification test.

4.13.4.3.3 Requirements Tested. Requirements 3.1, "Finite-Element Coefficient Generation," 3.2, "Formulate Transient Equations" (specifically Sections 3.2.4 and 3.2.6), 3.3, "Apply Constitutive Relationships" (specifically Sections 3.3.5 and 3.3.6), 3.4, "Compute Solution to Transient Equations," and 3.5, "Provide Input/Output Data Files," of Chapter I are verified by this test. 4.13.4.3.4 Required Inputs. Problem input is provided in the following files:

- henry3-1.in: basic input data,

- henry3-2.in: basic input data,

- henry3-3.in: basic input data, and

- henry.geom: geometry data.

4.13.4.3.5 Expected Outputs. Values from FEHM for concentration versus time at the outlet node will be output and compared to the FEHM solution for the input file henry3-1.in (species 1). Concentrations within $\mathbf{0 . 0 1}$ of the sorbing-solute solution and percent errors less than $10 \%$ when concentrations are greater than 0.1 will be considered acceptable. For input files henry3-1.in (species 2), henry3-2.in, and henry3-3.in, only the steady-state concentration at the end of the simulation will be compared to that for a one-dimensional, plug flow (constant velocity) system with reaction. Values within $5 \%$ of the plug flow solution will be considered acceptable. 


\subsection{Test of Fracture Transport with Matrix Diffusion}

\subsubsection{Purpose}

Matrix diffusion is an important process in the transport of contaminants in fractured porous media. Under certain limiting conditions, analytical solutions have been developed. The transport module of FEHM with equilibrium sorption can be tested in two dimensions against these analytical solutions to ensure that multidimensional transport problems with sorption are properly formulated.

\subsubsection{Functional description}

The test suite developed here consists of a two-dimensional grid with a permeability field set up to simulate one-dimensional flow in a fracture (a line of nodes along one edge of the model domain). Fluid in the surrounding matrix is stagnant. Tracers injected with the flowing fluid in the fracture can transport into the matrix via molecular diffusion. Sorption can occur either on the fracture, in the matrix, or both. The results for the breakthrough curve (concentration versus time at the outlet of the fracture) can be compared against analytical solutions to test the ability of the code to simulate solute transport with sorption.

\subsubsection{Assumptions and limitations}

Tang et al. (1981) present an analytical solution for the case of onedimensional axial dispersion in the fracture coupled to diffusion into an infinite medium (Eqn. 35 in Tang et al. (1981) revised for a fixed observation point a distance $L$ from the inlet and no radioactive decay):

$$
\frac{C}{C_{\text {in }}}=\frac{2 \cdot \exp \left(\frac{L}{2 \alpha}\right)}{\pi^{1 / 2}} \int_{l}^{\infty} \exp \left[-\xi^{2}-\frac{L^{2}}{4 \alpha^{2} \xi^{2}}\right] \operatorname{erfc}\left(\frac{R_{f} L \tau}{4 \alpha A \xi^{2}}\right) d \xi
$$

where $\xi$ is the integration variable, $R_{f}$ is the retardation factor on the fracture, and $\tau$ is the mean residence time of fluid through the column. The lower integration bound $l$ and the lumped parameter $A$ are given by

$$
l=\frac{L}{2}\left(\frac{R_{f}}{\alpha v t}\right)^{1 / 2}
$$

and

$$
A=\frac{b R_{f}}{\phi\left(R_{m} D_{m o l}\right)^{1 / 2}}
$$


In the above expressions, $v$ is the fluid velocity, $t$ is time, $b$ is the halfwidth of the fracture aperture, $\phi$ is the porosity of the matrix, $R_{m}$ is the retardation factor in the matrix, and $D_{m o l}$ is the molecular diffusion coefficient of the solute. If we select a molecular diffusion coefficient such that the tracer has insufficient time to diffuse to the edge of the model domain on the opposite side of the fracture, then the solution of Tang et al. should be replicated by FEHM. For sorption, the analytical solution is given in terms of retardation factors for the fracture and matrix. In FEHM, the expression used to duplicate a retardation factor for a saturated medium is

$$
R_{f}=1+\frac{\rho_{b} K_{d}}{\phi \rho_{f}}
$$

where $K_{d}$ is the sorption distribution coefficient. The problem geometry (symmetric about the fracture) is depicted in Fig. 15. Table 37 gives the sorption parameters and Table 38 lists the input parameters and conditions for this test suite. Separate cases are run with no sorption, sorption in the matrix, and sorption in both the fracture and matrix (flow occurs only in the fracture).

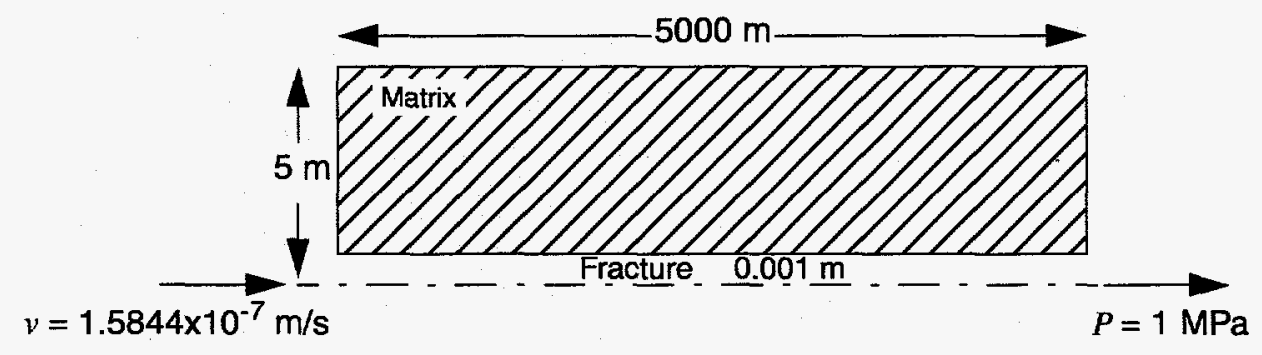

\section{Figure 15. Schematic drawing of the geometry and boundary conditions for the fracture transport problem.}

\subsubsection{Summary of test cases}

\subsubsection{Transport with matrix diffusion, no sorption}

4.14.4.1.1 Function Tested. This test verifies that FEHM correctly simulates the transport system consisting of flow and dispersion in a fracture with diffusion into the rock matrix.

4.14.4.1.2 Test Scope. This test case is a verification test.

4.14.4.1.3 Requirements Tested. Requirements 3.1, "Finite-Element Coefficient Generation," 3.2, "Formulate Transient Equations" (specifically Sections 3.2.4 and 3.2.6), 3.3, "Apply Constitutive Relationships" (specifically Section 3.3.5), 3.4, "Compute Solution to Transient Equations," and 3.5, "Provide Input/ Output Data Files," of Chapter I are verified by this test. 


\begin{tabular}{|c|c|c|c|c|}
\hline \multicolumn{5}{|c|}{$\begin{array}{l}\text { Table 37. Adsorption parameters for the fracture transport } \\
\text { problem }\end{array}$} \\
\hline Test & & $\alpha_{1}$ & $\alpha_{2}$ & $\beta$ \\
\hline $\begin{array}{l}\text { Transport with matrix } \\
\text { diffusion, no sorption }\end{array}$ & $\begin{array}{l}\text { fracture } \\
\text { matrix }\end{array}$ & $\begin{array}{l}0.0 \\
0.0\end{array}$ & $\begin{array}{l}0.0 \\
0.0\end{array}$ & $\begin{array}{l}1.0 \\
1.0\end{array}$ \\
\hline $\begin{array}{l}\text { Transport with matrix } \\
\text { diffusion, sorption } \\
\text { (linear) in the matrix }\end{array}$ & $\begin{array}{l}\text { fracture } \\
\text { matrix }\end{array}$ & $\begin{array}{l}0.0 \\
7.4074\left(10^{-2}\right)\end{array}$ & $\begin{array}{l}0.0 \\
0.0\end{array}$ & $\begin{array}{l}1.0 \\
1.0\end{array}$ \\
\hline $\begin{array}{l}\text { Transport with matrix } \\
\text { diffusion, sorption in the } \\
\text { fracture and matrix }\end{array}$ & $\begin{array}{l}\text { fracture } \\
\text { matrix }\end{array}$ & $\begin{array}{l}8.88889 \\
7.4074\left(10^{-2}\right)\end{array}$ & $\begin{array}{l}0.0 \\
0.0\end{array}$ & $\begin{array}{l}1.0 \\
1.0\end{array}$ \\
\hline
\end{tabular}

4.14.4.1.4 Required inputs. Problem input is provided in the following files:

- tangtest1.in: basic input data and

- tangtest.geom: coordinate and element information. The geometry is represented by a two-dimensional grid of $\mathbf{1 5 9 0}$ nodes ( 53 in the direction of flow and 30 in the matrix). The node spacing in the matrix is small near the fracture where concentration gradients are largest.

4.14.4.1.5 Expected Outputs. Values from FEHM for concentration breakthrough curves will be output and compared to the analytical solution results. A root-mean-square error of the difference between the FEHM and Tang solutions less than or equal to 0.01 for concentrations greater than 0.1 will be considered acceptable.

\subsubsection{Transport with matrix diffusion, sorption in the matrix}

4.14.4.2.1 Function Tested. This test verifies that FEHM correctly simulates the transport system consisting of flow and dispersion in a fracture with diffusion into the rock matrix and with sorption occurring in the matrix.

4.14.4.2.2 Test Scope. This test case is a verification test.

4.14.4.2.3 Requirements Tested. Requirements 3.1, "Finite-Element Coefficient Generation," 3.2, "Formulate Transient Equations" (specifically Sections 3.2.4 and 3.2.6), 3.3, "Apply Constitutive Relationships" (specifically Section 3.3.5), 3.4, "Compute Solution to Transient Equations," and 3.5, "Provide Input/ Output Data Files," of Chapter I are verified by this test. 


\begin{tabular}{|c|c|c|}
\hline \multicolumn{3}{|c|}{$\begin{array}{l}\text { Table 38. Input parameters for the test of the matrix- } \\
\text { diffusion problem }\end{array}$} \\
\hline Parameter & Symbol & Value \\
\hline Flow path length $(x)$ & $L$ & $5000 \mathrm{~m}$ \\
\hline Node spacing along flow path ${ }^{\ddagger}$ & $\Delta x$ & $100 \mathrm{~m}$ \\
\hline Model width & $y$ & $5 \mathrm{~m}$ \\
\hline Node spacings & $\Delta y$ & $0.001-0.5 \mathrm{~m}$ \\
\hline Fluid density & $\rho_{f}$ & $1000 \mathrm{~kg} / \mathrm{m}^{3}$ \\
\hline Bulk-rock density & $\rho_{b}$ & $2700 \mathrm{~kg} / \mathrm{m}^{3}$ \\
\hline Matrix porosity & $\phi$ & 0.05 \\
\hline Pore-water velocity & $v$ & $1.5844 \times 10^{-7} \mathrm{~m} / \mathrm{s}$ \\
\hline Dispersivity in fracture & $\alpha$ & $500 \mathrm{~m}$ \\
\hline Matrix diffusion coefficient & $D_{m o l}$ & $1.5 \times 10^{-12} \mathrm{~m}^{2} / \mathrm{s}$ \\
\hline Fracture retardation ractor & $R_{f}$ & 1 or 25 \\
\hline Matrix retardation factor & $R_{m}$ & 1 or 5 \\
\hline Time step (tracer) & $\Delta t$ & $0.001-5000$ days \\
\hline Total elapsed time & $t$ & 1500 years \\
\hline Pressure & $P_{0}$ & $1.0 \mathrm{MPa}$ \\
\hline Initial concentration & $C_{0}$ & 0.0 \\
\hline Inlet concentration & $C_{i n}$ & 1 \\
\hline Boundary conditions: & $\begin{array}{l}q=v \rho \\
P=1 \mathrm{M}\end{array}$ & $7.922 \times 10^{-6} \mathrm{~kg} / \mathrm{s}$ \\
\hline
\end{tabular}

4.14.4.2.4 Required Inputs. Problem input is provided in the following files:

- tangtest2.in: basic input data and

- tangtest.geom: coordinate and element information. The geometry is represented by a two-dimensional grid of 1590 nodes (53 in the direction of flow and 30 in the matrix). The 
node spacing in the matrix is small near the fracture where concentration gradients are largest.

4.14.4.2.5 Expected Outputs. Values from FEHM for concentration breakthrough curves will be output and compared to the analytical solution results. A root-mean-square error of the difference between the FEHM and Tang solutions less than or equal to 0.01 for concentrations greater than 0.1 will be considered acceptable.

\subsubsection{Transport with matrix diffusion and with sorption in the fracture and matrix}

4.14.4.3.1 Function Tested. This test verifies that FEHM correctly simulates the transport system consisting of flow and dispersion in a fracture with diffusion into the rock matrix and with sorption occurring in the matrix and on the fracture.

4.14.4.3.2 Test Scope. This test case is a verification test.

4.14.4.3.3 Requirements Tested. Requirements 3.1, "Finite-Element Coefficient Generation," 3.2, "Formulate Transient Equations" (specifically Sections 3.2.4 and 3.2.6), 3.3, "Apply Constitutive Relationships" (specifically Section 3.3.5), 3.4, "Compute Solution to Transient Equations," and 3.5, "Provide Input/ Output Data Files," of Chapter I are verified by this test.

4.14.4.3.4 Required Inputs. Problem input is provided in the following files:

- tangtest3.in: basic input data and

- tangtest.geom: coordinate and element information. The geometry is represented by a two-dimensional grid of 1590 nodes ( 53 in the direction of flow and 30 in the matrix). The node spacing in the matrix is small near the fracture where concentration gradients are largest.

4.14.4.3.5 Expected Outputs. Values from FEHM for concentration breakthrough curves will be output and compared to the analytical solution results. A root-mean-square error of the difference between the FEHM and Tang solutions less than or equal to 0.01 for concentrations greater than 0.1 will be considered acceptable. 


\subsection{Test of the Movement of a Dissolved Mineral Front}

\subsubsection{Purpose}

The ability of FEHM to model precipitation and dissolution reactions allows us to develop more sophisticated models to describe the rock-water interactions at the Yucca Mountain site. The analytical solution for a single, sharp-moving, equilibrium mineral front has been used to verify reactive-transport models in the past (i.e., Engesgaard 1991; Walsh et al. 1984). This analytical solution, which assumes no dispersion, is used to verify that FEHM is accurately predicting the velocity of a dissolved mineral front.

\subsubsection{Functional description}

A one-dimensional transport simulation of calcite $\left(\mathrm{CaCO}_{3}(\mathrm{~s})\right)$ dissolution is tested. Profiles of concentration versus reactor length, at selected times, will be compared against the analytical solution.

\subsubsection{Assumptions and limitations}

The precipitation and dissolution of calcite (a common mineral in many soils) are important processes that play a significant role in controlling the $\mathrm{pH}$ and alkalinity of groundwater. The dissolution reaction and the solubility product for this problem are

$$
\mathrm{CaCO}_{3(s)} \Leftrightarrow \mathrm{Ca} a_{(a q)}+\mathrm{CO}_{3(a q)} \text { and } K_{s p}=3.919 \times 10^{-9}(\mathrm{~mol} / \mathrm{kg})^{2} \text {. }
$$

Thus, the transport system (illustrated in Fig. 16) consists of one equilibrium reaction with three species.

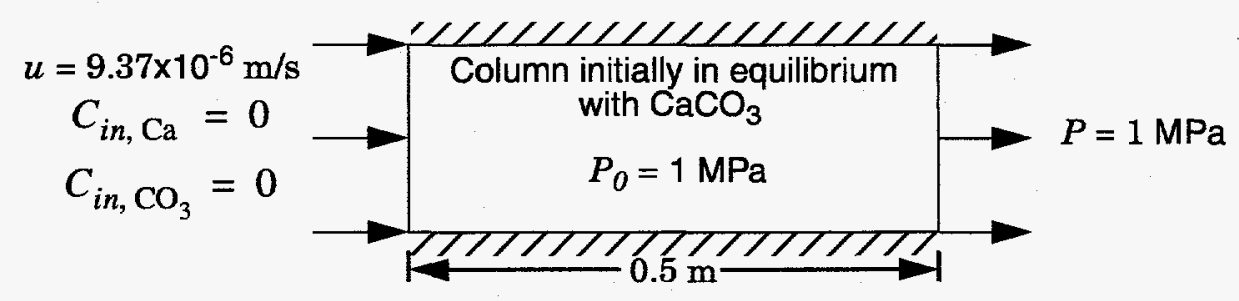

\section{Figure 16. Schematic drawing of the geometry and boundary conditions for the calcite-dissolution problem.}

The analytical solution for a single dissolved mineral front (Fig. 17) is given by

$$
u_{\text {mineral }}=\frac{u \Delta C_{a q}}{\Delta C_{a q}+\frac{\rho_{b}}{\phi} \Delta C_{s}},
$$

where $u$ is the pore-water velocity, $u_{\text {mineral }}$ is the velocity of the mineral front, $\rho_{b}$ is the bulk-rock density, $\phi$ is the porosity, $\Delta C_{s}$ is the change in solid concentration across the front, and $\Delta C_{a q}$ is the change in aqueous 
concentration across the front. A list of relevant input parameters and conditions is given in Table 39.

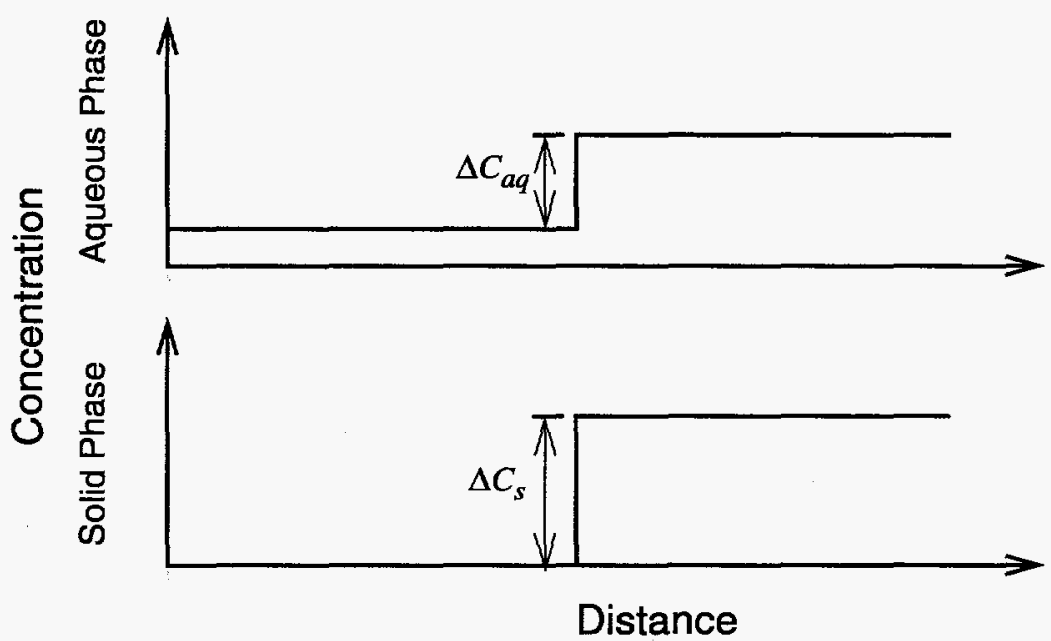

Figure 17. Aqueous and mineral-front profiles modeled by the analytical solution.

\subsubsection{Summary of test cases}

\subsubsection{Calcite dissolution in a one-dimensional system}

4.15.4.1.1 Function Tested. This test verifies that FEHM correctly simulates the dissolution of a mineral.

4.15.4.1.2 Test Scope. This test case is a verification test.

4.15.4.1.3 Requirements Tested. Requirements 3.1, "Finite-Element Coefficient Generation," 3.2, "Formulate Transient Equations" (specifically Section 3.2.4), 3.3, "Apply Constitutive Relationships" (specifically Section 3.3.6), 3.4, "Compute Solution to Transient Equations," and 3.5, "Provide Input/ Output Data Files," of Chapter I are verified by this test.

4.15.4.1.4 Required Inputs. Problem input is provided in the following files:

- dissolution.in: basic input data and

- dissolution.grid: coordinate and element information (102 nodes, 50 elements to simulate a one-dimensional flow system).

4.15.4.1.5 Expected Outputs. Values from FEHM for the mean concentration of the mineral front will be compared to the analytical solution. Position within 5\% of the predicted value will be considered acceptable. 


\section{Table 39. Input parameters for the calcite-dissolution problem}

\begin{tabular}{|c|c|c|}
\hline Parameter & Symbol & Value \\
\hline Reactor length & $L$ & $0.5 \mathrm{~m}$ \\
\hline Node spacing & $\Delta l$ & $0.01 \mathrm{~m}$ \\
\hline Fluid density & $\rho_{f}$ & $1000 \mathrm{~kg} / \mathrm{m}^{3}$ \\
\hline Bulk-rock density & $\rho_{b}$ & $1800 \mathrm{~kg} / \mathrm{m}^{3}$ \\
\hline Porosity & $\phi$ & 0.32 \\
\hline Pore-water velocity ${ }^{\ddagger}$ & $u$ & $9.37 \times 10^{-6} \mathrm{~m} / \mathrm{s}$ \\
\hline Dispersivity & $\alpha$ & $0.0067 \mathrm{~m}$ \\
\hline Time step & $\Delta t$ & $100 \mathrm{~s}$ \\
\hline Total elapsed time & $t$ & 2.157 days \\
\hline Pressure & $P_{0}$ & $1.0 \mathrm{MPa}$ \\
\hline $\mathrm{CaCO}_{3}$ initial concentration & $C_{0, \mathrm{CaCO}_{3}}$ & $2.0 \times 10^{-5} \mathrm{~mol} / \mathrm{kg}$-solid \\
\hline $\mathrm{Ca}$ initial concentration & $C_{0, \mathrm{Ca}}$ & $6.26 \times 10^{-5} \mathrm{~mol} / \mathrm{kg}$-water \\
\hline $\mathrm{CO}_{3}$ initial concentration & $C_{0, \mathrm{CO}_{3}}$ & $6.26 \times 10^{-5} \mathrm{~mol} / \mathrm{kg}$-water \\
\hline $\mathrm{Ca}$ inlet concentration & $C_{i n, \mathrm{Ca}}$ & 0 \\
\hline $\mathrm{CO}_{3}$ inlet concentration & $C_{i n, \mathrm{CO}_{3}}$ & 0 \\
\hline $\begin{aligned} \text { Boundary conditions: } & \text { At } l=0 \\
& \text { At } l=1\end{aligned}$ & & $\begin{array}{l}u=9.37 \times 10^{-6} \mathrm{~m} / \mathrm{s} \\
C_{i n, \mathrm{Ca}}=0, C_{i n, \mathrm{CO}_{3}}=0 \\
P=1 \mathrm{MPa}\end{array}$ \\
\hline
\end{tabular}




\subsection{Test of Multisolute Transport with Chemical Reaction}

\subsubsection{Purpose}

The coupled transport and chemical reaction of multiple species in solution is an important feature of FEHM that will allow us to incorporate more complex processes into radionuclide transport simulations, as well as to model rock-water interactions at the Yucca Mountain site. The most appropriate way to test this feature of the code is by comparison against a code that was designed specifically for such reactive transport simulations. The code we are using for this purpose is called PDREACT (Valocchi and Pastor 1994), a two-dimensional, isothermal, saturated-zone flow and transport code. This comparison will verify the species transport for a simple, one-dimensional saturated flow field for a complex, multipleinteracting species simulation.

\subsubsection{Functional description}

The suite of reactions described below are simulated for transport in a onedimensional flow system. Concentration-versus-time breakthrough curves at the flow path exit and concentration of solid species at the exit versus time will be compared for the two codes.

\subsubsection{Assumptions and limitations}

The application of this test case is the transport of cobalt (Co) in groundwater. Radioactive cobalt is present in the subsurface at several DOE sites. Although its presence as a divalent cation implies that it should sorb strongly to most soils, its migration rate has been shown to be greater than expected due to complexation with EDTA, a decontaminating agent also found in the subsurface of these sites. Much experimental work has gone into studying the transport of Co as CoEDTA, a much less strongly sorbed species. Figure 18 illustrates the transport problem.

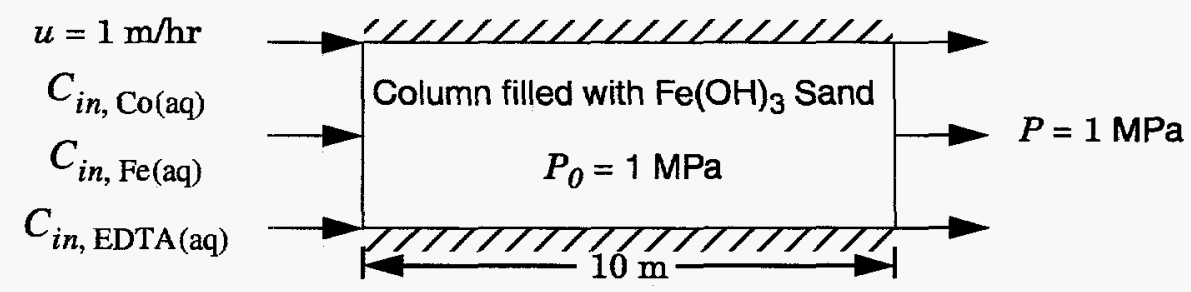

Figure 18. Schematic drawing of the geometry and boundary conditions for the cobalt transport problem.

The chemical reactions and equilibrium or rate constants used to perform this code comparison test are:

$\operatorname{CoEDTA}_{(a q)} \Leftrightarrow C o_{(a q)}+\operatorname{EDTA}_{(a q)}, K_{e q}=10^{-18} \mathrm{~kg} / \mathrm{mol} ;$ 


$$
\begin{aligned}
& F e_{(a q)}+\operatorname{EDTA}_{(a q)} \Leftrightarrow F e \operatorname{EDTA}_{(a q)}, K_{e q}=6.31 \times 10^{27} \mathrm{~kg} / \mathrm{mol} ; \\
& C o_{(a q)} \Leftrightarrow C o_{(s)}, k_{f}=2.78 \times 10^{-4} \mathrm{~s}^{-1}, k_{r}=5.48 \times 10^{-5} \mathrm{~s}^{-1} \\
& \operatorname{CoEDTA}_{(a q)} \Leftrightarrow \operatorname{CoEDTA}_{(s)}, k_{f}=2.78 \times 10^{-4} \mathrm{~s}^{-1}, k_{r}=5.21 \times 10^{-4} \mathrm{~s}^{-1} ; \\
& F e E D T A_{(a q)} \Leftrightarrow \operatorname{FeEDTA}_{(s)}, k_{f}=2.78 \times 10^{-4} \mathrm{~s}^{-1}, k_{r}=6.5 \times 10^{-4} \mathrm{~s}^{-1} ; \\
& \text { and }
\end{aligned}
$$$$
\operatorname{CoEDTA}_{(s)}+\mathrm{Fe}(\mathrm{OH})_{3(s)} \Rightarrow \mathrm{Co}_{(s)}+\mathrm{FeEDTA}_{(s)}, k_{f}=3.5 \times 10^{-6} s^{-1}
$$

Thus, the transport system consists of 8 species and six reactions, with reactions specified as either equilibrium or kinetically controlled. $\mathrm{Fe}(\mathrm{OH})_{3}$ is so prevalent in the sand that its concentration is assumed to be constant. In addition, this substance does not act as a true species in either simulation. A list of relevant input parameters and conditions for the code comparison are given in Table 40.

\subsubsection{Summary of test cases}

\subsubsection{Cobalt transport in a one-dimensional flow system}

4.16.4.1.1 Function Tested. This test verifies that FEHM correctly simulates the reactive transport system consisting of both kinetic and equilibrium reactions and with both immobile and aqueous species.

4.16.4.1.2 Test Scope. This test case is a verification test.

4.16.4.1.3 Requirements Tested. Requirements 3.1, "Finite-Element Coefficient Generation," 3.2, "Formulate Transient Equations" (specifically Sections 3.2.4 and 3.2.6), 3.3, "Apply Constitutive Relationships" (specifically Section 3.3.6), 3.4, "Compute Solution to Transient Equations," and 3.5, "Provide Input/ Output Data Files," of Chapter I are verified by this test. 4.16.4.1.4 Required Inputs. Problem input is provided in the following file:

- multi_solute.in: basic input data, including the finite-element grid with 202 nodes, 100 elements ( 51 x 2 nodes to simulate a one-dimensional flow system). 


\begin{tabular}{|c|c|c|c|}
\hline \multicolumn{4}{|c|}{$\begin{array}{l}\text { Table 40. Input parameters for test of the reactive } \\
\text { transport problem }\end{array}$} \\
\hline \multicolumn{2}{|c|}{ Parameter } & Symbol & Value \\
\hline \multicolumn{2}{|l|}{ Reactor length } & $L$ & $10 \mathrm{~m}$ \\
\hline \multicolumn{2}{|l|}{ Node spacing } & $\Delta l$ & $0.1 \mathrm{~m}$ \\
\hline \multicolumn{2}{|l|}{ Fluid density } & $\rho_{f}$ & $1000 \mathrm{~kg} / \mathrm{m}^{3}$ \\
\hline \multicolumn{2}{|l|}{ Bulk-rock density } & $\rho_{b}$ & $1500 \mathrm{~kg} / \mathrm{m}^{3}$ \\
\hline \multicolumn{2}{|l|}{ Porosity } & $\phi$ & 0.4 \\
\hline \multicolumn{2}{|l|}{ Pore-water velocity } & $u$ & $1 \mathrm{~m} / \mathrm{hr}$ \\
\hline \multicolumn{2}{|l|}{ Dispersivity } & $\alpha$ & $0.05 \mathrm{~m}$ \\
\hline \multicolumn{2}{|l|}{ Time step (tracer) } & $\Delta t$ & $0.09-360 \mathrm{~s}$ \\
\hline \multicolumn{2}{|l|}{ Total elapsed time } & $t$ & 7.25 days \\
\hline \multicolumn{2}{|l|}{ Pressure } & $P_{0}$ & $1.0 \mathrm{MPa}$ \\
\hline \multicolumn{2}{|l|}{ Co inlet concentration } & $C_{\text {in }, \mathrm{Co}}$ & $3.1623 \times 10^{-5} \mathrm{M}$ \\
\hline \multicolumn{2}{|l|}{ Fe inlet concentration } & $C_{\text {in }, \mathrm{Fe}}$ & $O M$ \\
\hline \multicolumn{2}{|c|}{ EDTA inlet concentration } & $C_{\text {in, } \mathrm{EDTA}}$ & $3.1623 \times 10^{-5} \mathrm{M}$ \\
\hline Boundary conditions & $\begin{array}{l}\text { At } l=0 \\
\text { At } l=1\end{array}$ & $\begin{array}{l}u=1 \mathrm{~m} \\
P=1 \mathrm{~N}\end{array}$ & \\
\hline
\end{tabular}

4.16.4.1.5 Expected Outputs. Values from FEHM for concentration breakthrough curves of aqueous species and concentration-time history at the outlet node for immobile (solid) species will be output and compared to the PDREACT results. Due to the low inlet concentrations, concentrations within $10 \%$ for all values that are greater than $10 \%$ of the peak value will be considered acceptable. 


\subsection{Test of Three-dimensional Radionuclide Transport}

\subsubsection{Purpose}

A comparison will be made with TRACRN (Travis and Birdsell 1988), another YMP code, on a three-dimensional, single-phase liquid problem. The problem simulates the transport of a tracer undergoing radioactive decay and thus is of particular interest to the Yucca Mountain Project. This comparison will verify the species transport in three dimensions. TRACRN has been compared against many known analytical solutions. Although no three-dimensional analytical solutions exist, a match between TRACRN and FEHM will give confidence that both are correct. Because the codes use different numerical techniques, the test provides a check for both codes.

\subsubsection{Functional description}

The transport system described below consists of one aqueous species undergoing radioactive decay. Concentration-time histories at several locations in the model domain will be used to make the comparison.

\subsubsection{Assumptions and limitations}

The radionuclide being simulated is Americium $\left({ }^{243} \mathrm{Am}\right)$, which has a halflife of 432 years. The model domain, depicted in Figure 19, is a cube (100 m on each side). Infiltration at a rate of $10^{-4} \mathrm{~kg} / \mathrm{s}$ occurs over a $100 \mathrm{~m}^{2}$ region (four nodes) on the top of the box, and outflow is allowed over a 900 $\mathrm{m}^{2}$ region (36 nodes) on the bottom. The inlet and outlet nodes are offset from each other in plan view so that flow will travel diagonally through the model domain. There is no flow on the remainder of the boundaries. The simulation is run in two parts. After a steady-state flow field is established, a restart run that solves the transport of the radionuclide is carried out. The ${ }^{243} \mathrm{Am}$ is injected with the inlet fluid at a concentration of $1 \mathrm{M}$. A conservative tracer is also injected with the inlet fluid as an additional check between the two codes. The problem is isothermal. Table 41 lists the input parameters and conditions for this test suite.

\subsubsection{Summary of test cases}

\subsubsection{Decay-chain transport in a three-dimensional system}

4.17.4.1.1 Function Tested. This test verifies that FEHM correctly simulates the reactive transport system consisting of a radionuclide decay in a three-dimensional flow system. A conservative tracer is also used to verify the three-dimensional tracer transport. In addition, the restart capabilities of the code are verified.

4.17.4.1.2 Test Scope. This test case is a verification test. 


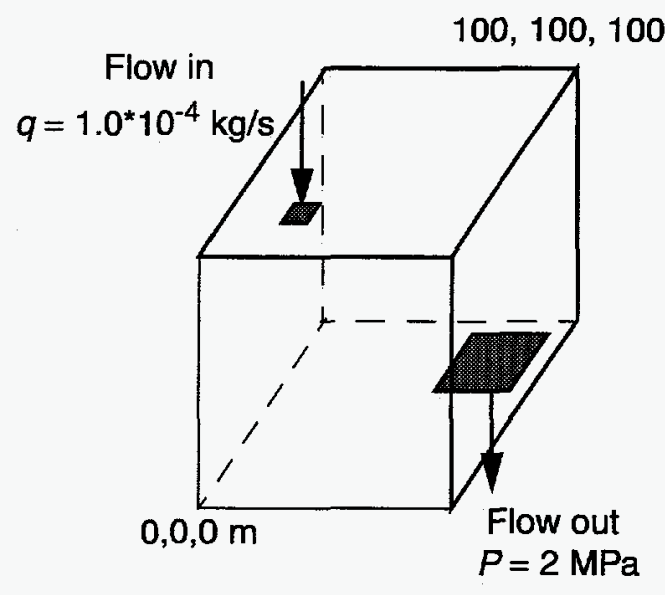

Figure 19. Model domain and flow boundary conditions for test of the radionuclide transport problem.

4.17.4.1.3 Requirements Tested. Requirements 3.1, "Finite-Element Coefficient Generation," 3.2, "Formulate Transient Equations" (specifically Sections 3.2.4 and 3.2.6), 3.3, "Apply Constitutive Relationships" (specifically Section 3.3.5), 3.4, "Compute Solution to Transient Equations," 3.5, "Provide Input/Output Data Files," and 3.6, "Provide Restart Capability," of Chapter I are verified by this test.

4.17.4.1.4 Required Inputs. Problem input is provided in the following files:

- 3d_trac.gen_ini.dat: basic input data for generating restart and coefficient storage files for the steady-state flow field,

- 3d_trac.grid: finite-element grid, a structured, threedimensional grid with 10,648 nodes ( $22 \times 22 \times 22)$ and 9261 elements,

- 3d_trac.dat: basic input data for transport portion of test run,

- 3d_trac.ini: steady-state flow initialization file (generated during first portion of test run), and

- 3d_trac.stor: coefficient storage file (generated during first portion of test run).

4.17.4.1.5 Expected Outputs. Values from FEHM for concentrationtime histories at specified nodes will be compared to the TRACRN results. A root-mean-square error between FEHM and TRACRN concentrations less than or equal to 0.05 , at concentrations greater than $10 \%$ of the peak value, will be considered acceptable. 


\begin{tabular}{|c|c|c|c|}
\hline \multicolumn{4}{|c|}{$\begin{array}{l}\text { Table 41. Input parameters and conditions for test of th } \\
\text { radionuclide transport problem }\end{array}$} \\
\hline \multicolumn{2}{|c|}{ Parameter } & Symbol & Value \\
\hline \multicolumn{2}{|l|}{ Reservoir dimensions } & $x, y, z$ & $100 \mathrm{~m}$ \\
\hline \multicolumn{2}{|l|}{ Node spacing ${ }^{\ddagger}$} & $\Delta x, \Delta y, \Delta z$ & $5 \mathrm{~m}$ \\
\hline \multicolumn{2}{|l|}{ Bulk-rock density } & $\rho_{b}$ & $2700 \mathrm{~kg} / \mathrm{m}^{3}$ \\
\hline \multicolumn{2}{|l|}{ Porosity } & $\phi$ & 0.3 \\
\hline \multicolumn{2}{|l|}{ Infiltration rate } & $q$ & $1.0^{*} 10^{-4} \mathrm{~kg} / \mathrm{s}$ \\
\hline \multicolumn{2}{|l|}{ Dispersivity } & $\alpha$ & $5.0 \mathrm{~m}$ \\
\hline \multicolumn{2}{|l|}{ Time step (tracer) } & $\Delta t$ & $2.74-10$ years \\
\hline \multicolumn{2}{|c|}{ Total elapsed time (tracer simulation) } & $t$ & 5000 years \\
\hline \multicolumn{2}{|l|}{ Pressure } & $P_{0}$ & $1.0 \mathrm{MPa}$ \\
\hline \multicolumn{2}{|l|}{ Reference pressure } & $P_{\text {ref }}$ & $0.1 \mathrm{MPa}$ \\
\hline \multicolumn{2}{|l|}{ Reference temperature } & $T_{r e f}$ & $20^{\circ} \mathrm{C}$ \\
\hline \multicolumn{2}{|l|}{ Initial water saturation } & $S_{l 0}$ & 1.0 \\
\hline \multicolumn{2}{|c|}{ Residual liquid saturation } & $S_{l r}$ & 0.277 \\
\hline \multicolumn{2}{|c|}{ Maximum liquid saturation } & $S_{\operatorname{lmax}}$ & 1.0 \\
\hline \multicolumn{2}{|c|}{$\begin{array}{l}\text { Inverse of air entry pressure } \\
\text { Power in formula }\end{array}$} & $\alpha_{G}$ & $\begin{array}{l}3.34 \mathrm{~m}^{-1} \\
1.982\end{array}$ \\
\hline \multicolumn{2}{|c|}{${ }^{243} \mathrm{Am}$ inlet concentration } & $C_{\text {in },{ }^{243} \mathrm{Am}}$ & $1 \mathrm{M}$ \\
\hline \multicolumn{2}{|c|}{ Conservative tracer inlet concentration } & $C_{i n, \text { Cons }}$ & $1 \mathrm{M}$ \\
\hline Boundary conditions: & \multicolumn{3}{|c|}{$\begin{array}{l}\text { At } x=20-30 \mathrm{~m}, \\
y=20-30 \mathrm{~m}, \mathrm{z}=100 \mathrm{~m} \\
\text { At } x=60-90 \mathrm{~m} \\
y=60-90 \mathrm{~m}, \mathrm{z}=0 \mathrm{~m}\end{array}$} \\
\hline
\end{tabular}




\section{Chapter IV:}

\section{Verification and Validation Report}




\subsection{SCOPE OF VERIFICATION AND VALIDATION ACTIVITIES}

The overall verification and validation (V\&V) effort for the FEHM application consists of rigorous and complete testing of the model, whenever possible, against known analytical solutions of the same problem. An alternative approach for more complex test cases for which no analytical solution exists is to benchmark the code against the results of other numerical models.

\subsection{DESCRIPTION OF ENVIRONMENT}

Verification of the FEHM application was performed on the following UNIX platforms: Sun SPARC (SunOS 4.3 and SunOS 5.5), SGI (Irix 5.2 and 5.3), HP (HP-UX A.09.05), and IBM (AIX 2), but FEHM should work on any standard UNIX system.

A series of test scripts have been developed to automate the verification procedure. These scripts are described in more detail in the Appendix "FEHM Verification Scripts" in the FEHM “User's Manual” (Zyvoloski et al. 1997b).

\subsection{ADDITIONAL VERIFICATION AND VALIDATION ISSUES}

This V\&V effort attempts to test each of the major submodels in FEHM against an analytical solution or the results of another flow and transport code. Test cases for heat transfer, isothermal fluid flow, coupled heat and mass transfer, and solute transport are included. For any of these individual runs, there are numerous "minor" options available, such as input/output options, the ability to restart calculations, and the ability to set properties on a node-by-node or zone-by-zone basis that are not included in this report. These options have been extensively debugged, tested, and documented, but in the interest of space and time limitations, they are outside the scope of the formal testing effort.

Model validation is another area that is outside the scope of this report. A large fieldtesting effort is being undertaken in the Yucca Mountain Project to test the validity of the conceptual models and build confidence in them. However, these studies are scientific studies that are not covered in this document, which focuses only on code verification, the process of determining that the physical models have been properly implemented in the computer code.

\subsection{DISCUSSION OF TEST RESULTS}

The problems discussed below correspond directly to those described in Section 4.0 of Chapter III, "Verification and Validation Plan." 


\subsection{Testing of Thermodynamic Functions}

\subsubsection{Enthalpy}

These tests verify that the FEHM enthalpy functions provide accurate values of enthalpy as illustrated in Figure 20. The results, compared numerically to the values used to generate the enthalpy functions (found in files thermo.steam_table_data.liq and thermo.steam_table_data.vap), are given in Table 42. The maximum absolute error for liquid enthalpy was less than $0.003 \mathrm{MJ} / \mathrm{kg}$, and the percent error was less than $0.2 \%$. The maximum absolute error for vapor enthalpy was $0.0001 \mathrm{MJ} / \mathrm{kg}$, and the percent error was less than $0.004 \%$. These results meet the acceptance criteria for this test suite developed in Chapter III, "Verification and Validation Plan."

\begin{tabular}{|cccc|}
\hline \multicolumn{4}{|c|}{ Table 42. Results of tests of thermodynamic functions } \\
\hline V\&V test & Maximum error & Maximum \% error & RMS error \\
\hline \hline Enthalpy & & & \\
Liquid & $0.2100 \mathrm{e}-02$ & 0.1319 & $0.1732 \mathrm{e}-04$ \\
Vapor & $0.9012 \mathrm{e}-04$ & $0.3129 \mathrm{e}-02$ & $0.3128 \mathrm{e}-05$ \\
\hline Density & & & \\
Liquid & 1.522 & 0.2482 & $0.2018 \mathrm{e}-04$ \\
Vapor & $0.2550 \mathrm{e}-01$ & $0.5793 \mathrm{e}-01$ & $0.6295 \mathrm{e}-04$ \\
\hline Compressibility & & & \\
Liquid & $0.2160 \mathrm{e}-02$ & 16.00 & $0.5182 \mathrm{e}-02$ \\
Vapor & 1.287 & 0.1297 & $0.4074 \mathrm{e}-03$ \\
\hline Viscosity & & & \\
Liquid & $0.3224 \mathrm{e}-05$ & 0.5244 & $0.9222 \mathrm{e}-04$ \\
Vapor & $0.3650 \mathrm{e}-07$ & 0.1601 & $0.1687 \mathrm{e}-03$ \\
\hline Saturation pressure and temperature & & \\
Pressure & $0.2575 \mathrm{e}-01$ & 0.3000 & $0.4687 \mathrm{e}-03$ \\
Temperature & 1.100 & 0.4000 & $0.5943 \mathrm{e}-03$ \\
\hline
\end{tabular}

\subsubsection{Density}

These tests verify that the FEHM density functions provide accurate values of density as illustrated in Figure 21. The results, compared numerically to the values used to generate the density functions (found in files thermo.steam_table_data.liq and thermo.steam_table_data.vap), are given in Table 42. The maximum absolute error for liquid density was less than $1.6 \mathrm{~m}^{3} / \mathrm{kg}$, and the percent error was less than $0.3 \%$. The maximum absolute error for vapor density was $0.026 \mathrm{~m}^{3} / \mathrm{kg}$, and the percent error was less than $0.06 \%$. These results meet the acceptance criteria for this test suite developed in Chapter III. 

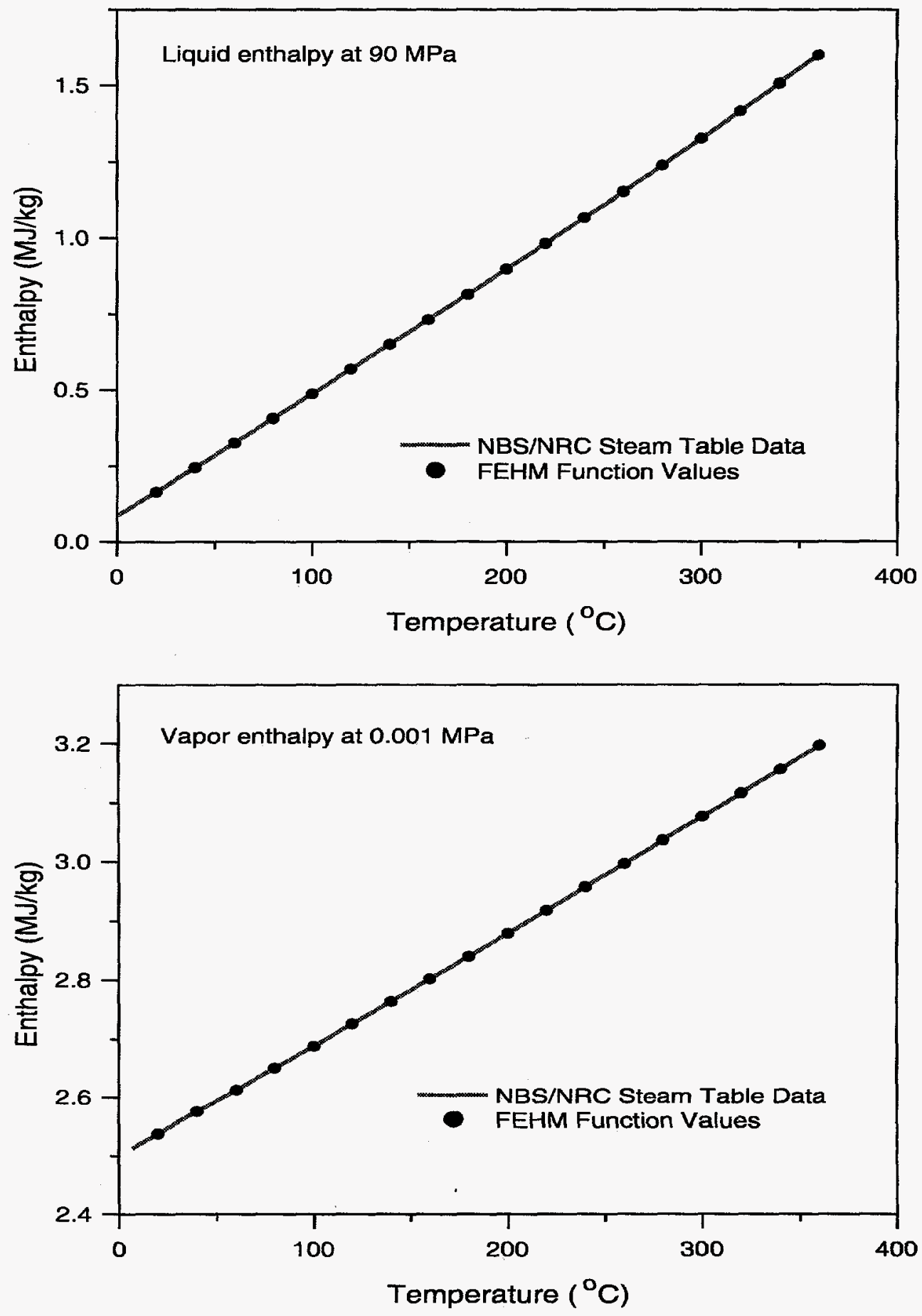

Figure 20. Comparison of FEHM enthalpies to the NBS/NRC Steam Tables data. 

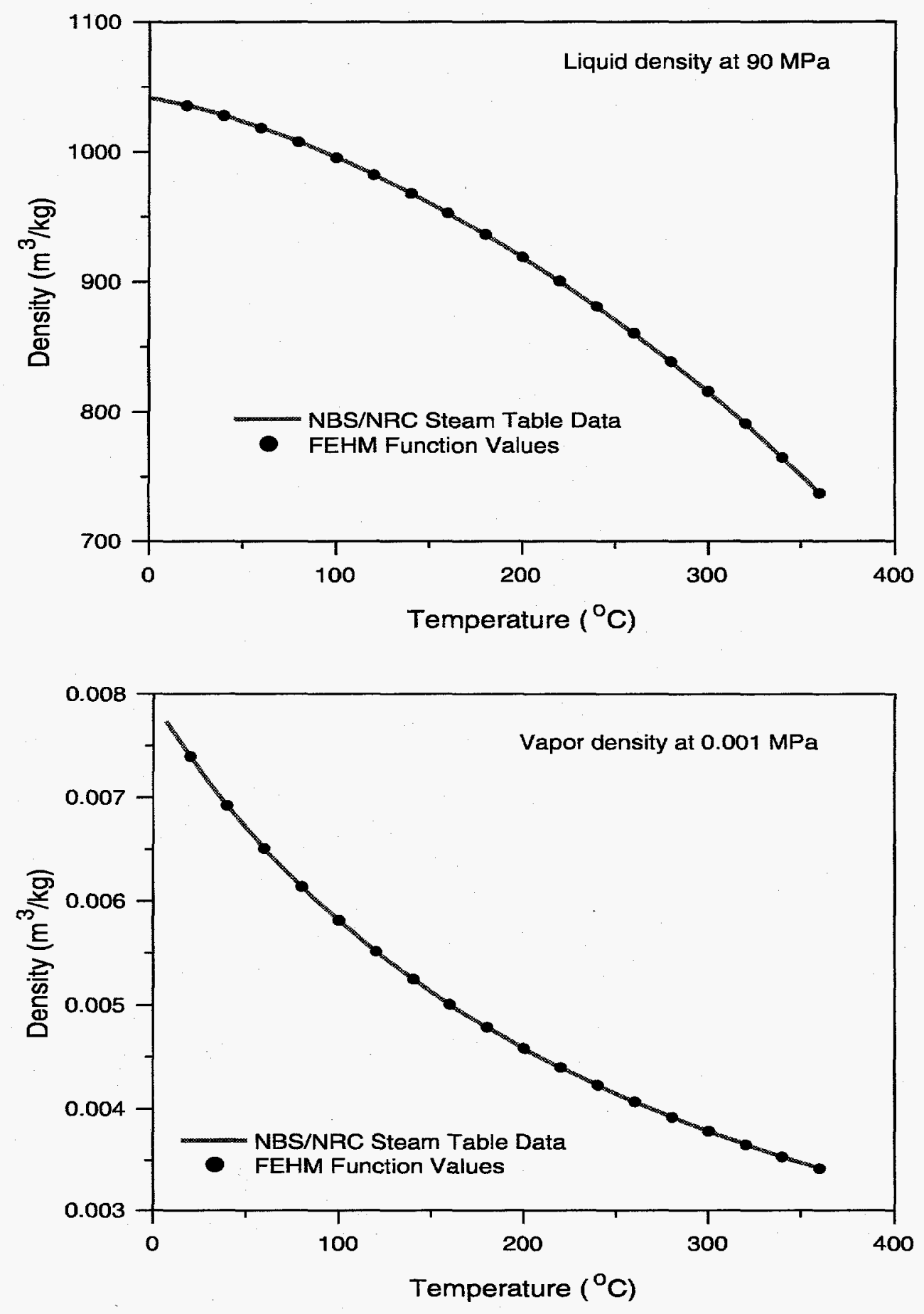

Figure 21. Comparison of FEHM densities to the NBS/NRC Steam Tables data.

\subsubsection{Compressibility (derivative of density with respect to pressure)}

These tests verify that the FEHM compressibility functions provide accurate values of compressibility as illustrated in Figure 22. The results, compared numerically to the values used to generate the compressibility 
functions (found in files thermo.compress_data.liq and thermo.compress_data.vap), are given in Table 42. The maximum absolute error for liquid compressibility was less than $0.0022 \mathrm{MPa}^{-1}$, and the percent error was less than $16 \%$. The maximum absolute error for vapor compressibility was $1.3 \mathrm{MPa}^{-1}$, and the percent error was less than $0.2 \%$. These results for vapor compressibility meet the acceptance criteria for this test suite developed in Chapter III. The liquid compressibility had a maximum error greater than the acceptance criteria but the root-meansquare (RMS) error was within acceptable limits. Although the absolute maximum error of liquid compressibility is outside the acceptance criteria, it is important to note that this calculated value of liquid compressibility is never used in the governing equations. This fact is shown best in the accurate solution of the fully saturated Theis problem (see Section 4.4), which would be most sensitive to liquid-compressibility deviations.

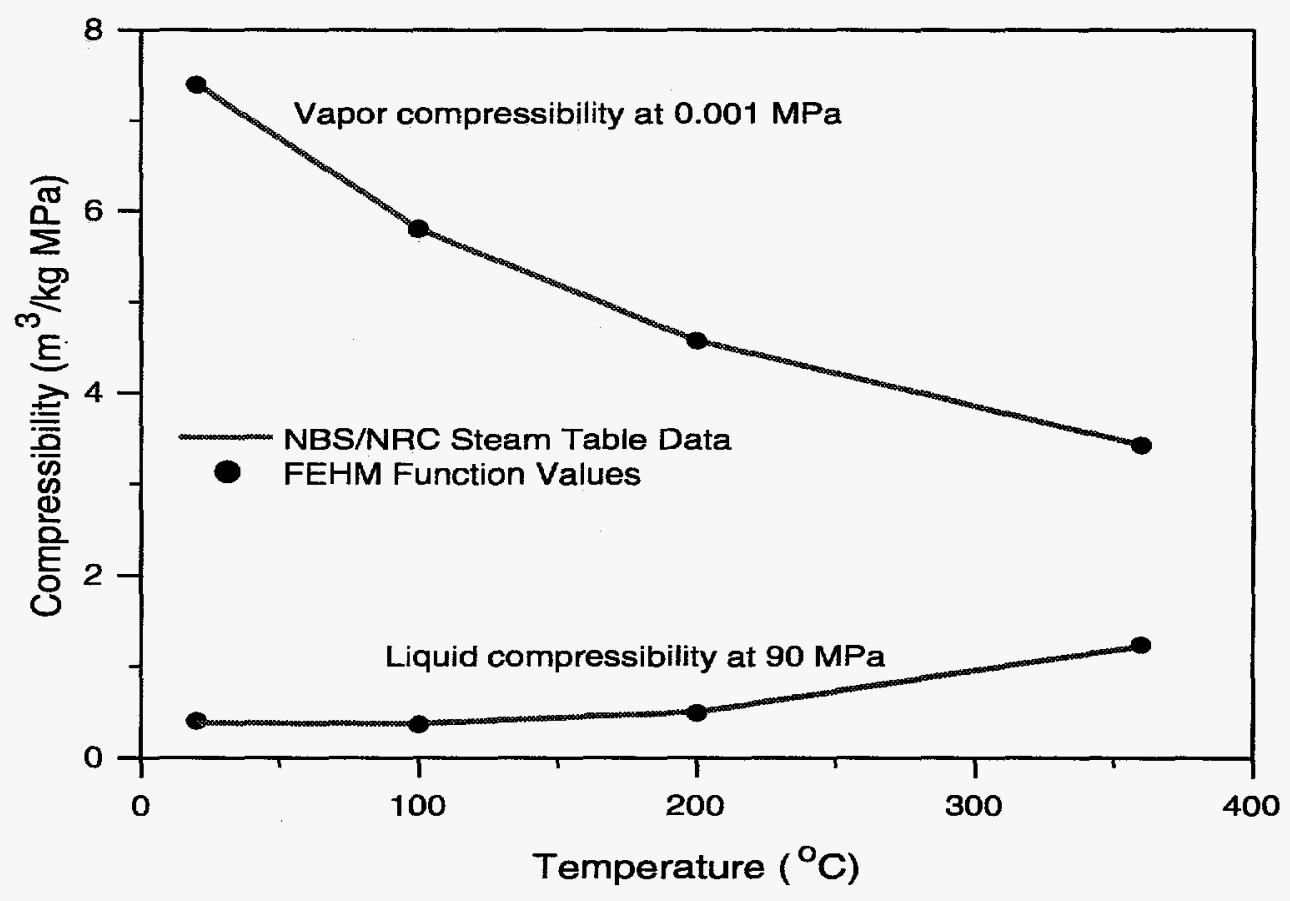

Figure 22. Comparison of FEHM compressibilities to the NBS/NRC Steam Tables data.

\subsubsection{Viscosity}

These tests verify that the FEHM viscosity functions provide accurate values of viscosity as illustrated in Figure 23. The results, compared numerically to the values used to generate the enthalpy functions (found in files thermo.steam_table_data.liq and thermo.steam_table_data.vap), are given in Table 42. The maximum absolute error for liquid viscosity was less than 3.2e-6 Pa.s, and the percent error was less than $0.6 \%$. The 
maximum absolute error for vapor viscosity was $3.65 \mathrm{e}-8 \mathrm{~Pa} \cdot \mathrm{s}$, and the percent error was less than $0.2 \%$. These results meet the acceptance criteria for this test suite developed in Chapter III.
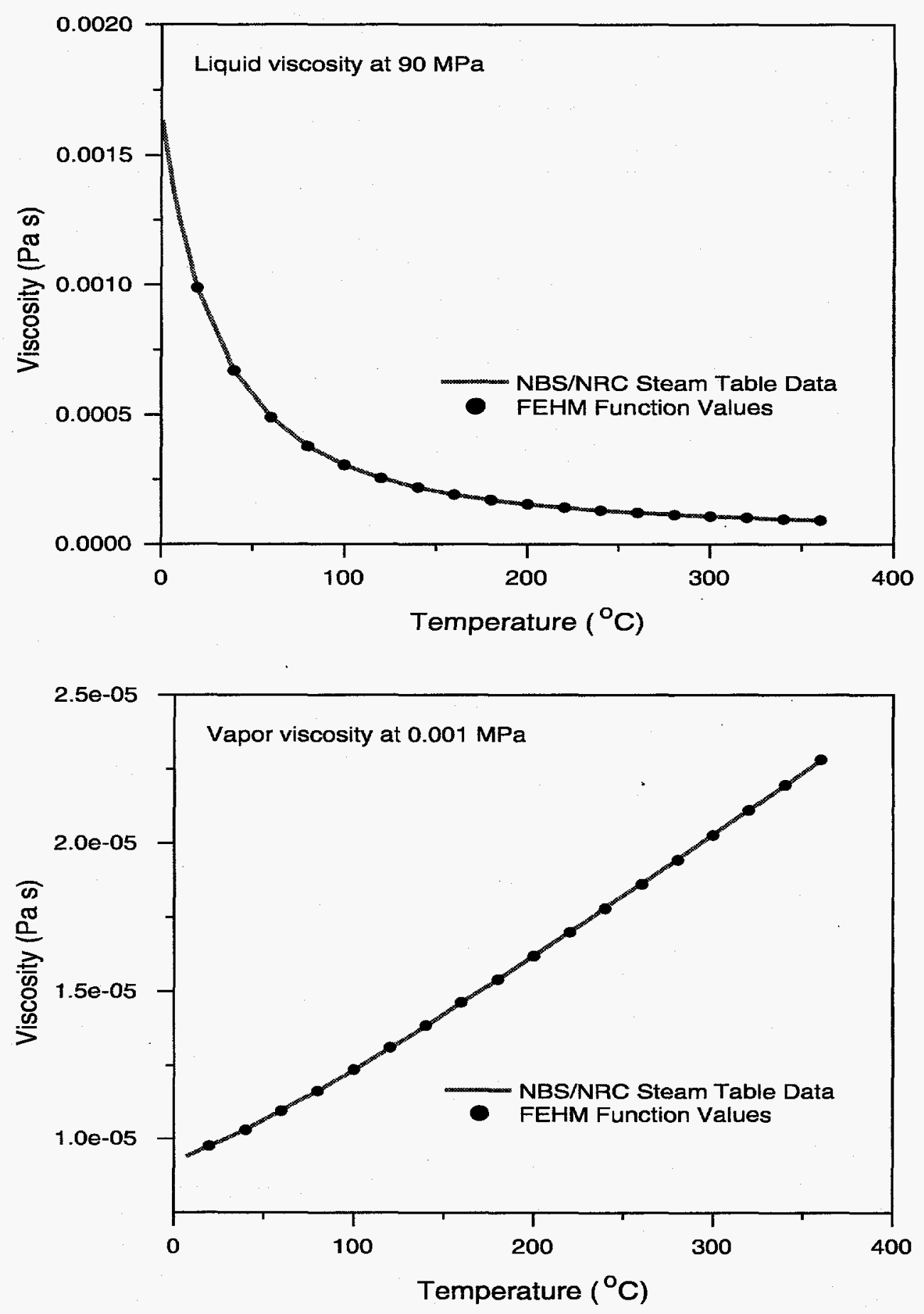

Figure 23. Comparison of FEHM viscosities to the NBS/NRC Steam Tables data. 


\subsubsection{Saturation pressure and temperature}

These tests verify that the FEHM saturation functions provide accurate values of pressure and temperature as illustrated in Figure 24. The results, compared numerically to the values used to generate the saturation functions (found in file thermo.saturation_data), are given in Table 42. The maximum absolute error for saturation pressure was less than $0.03 \mathrm{MPa}$, and the percent error was less than $0.3 \%$. The maximum absolute error for saturation temperature was $1.1^{\circ} \mathrm{C}$, and the percent error was less than $0.4 \%$. These results meet the acceptance criteria for this test suite developed in Chapter III.

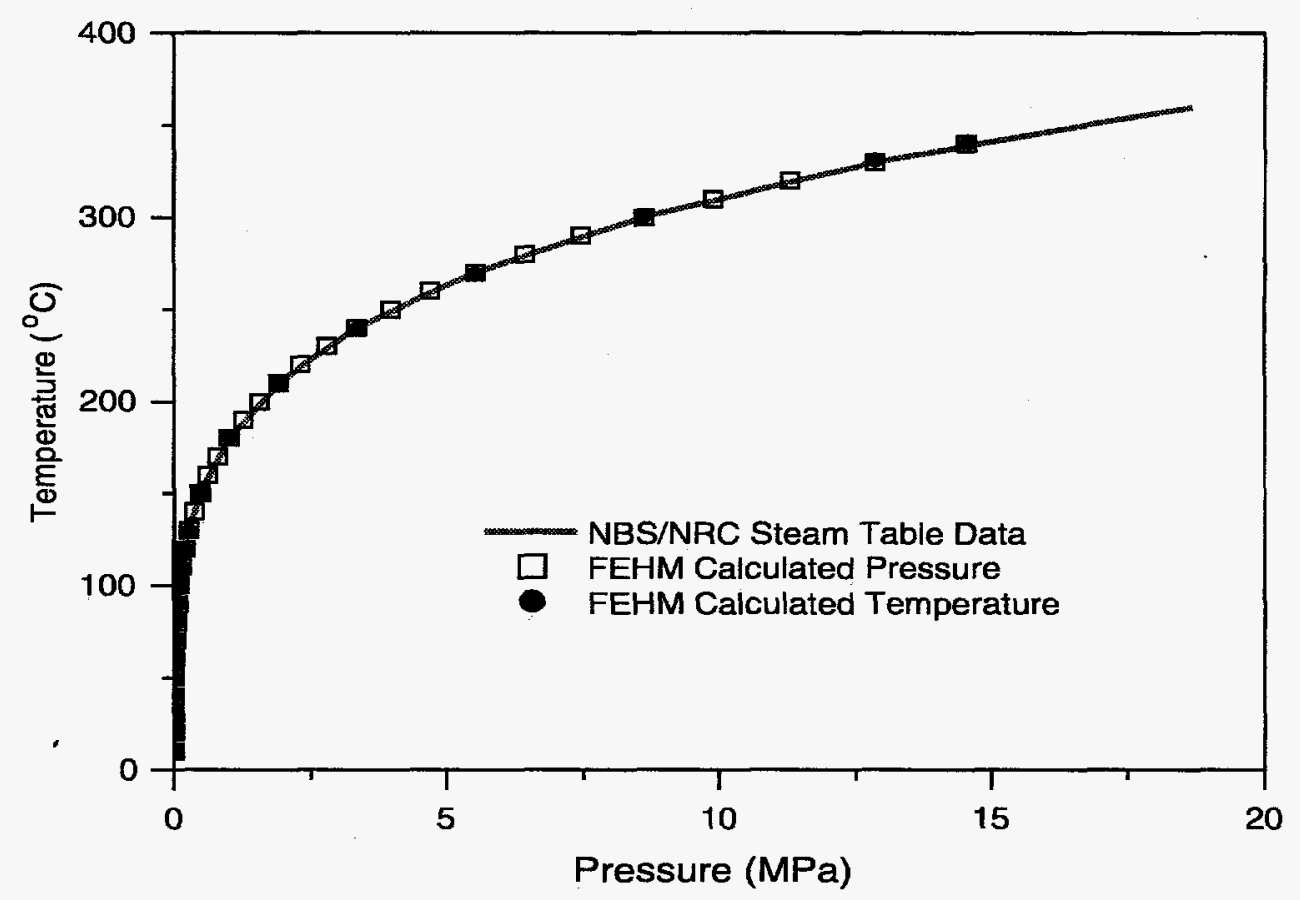

Figure 24. Comparison of FEHM saturation pressures and temperatures to the NBS/NRC Steam Tables data. 


\subsection{Test of Heat Conduction}

\subsubsection{2-D heat conduction in a square}

These tests verify that FEHM correctly models 2-dimensional heat conduction. They also verify that the finite-element representation of 2-D 3-node triangles (triangular-element meshes), 4-node quadrilaterals (rectangular-element meshes), mixed-element meshes (containing both triangular and rectangular elements), and refined-element meshes (containing rectangular and trapezoidal elements) have been correctly implemented. Figures 25 and 26 show that FEHM results are in good agreement with the analytical solution for the 2-D heat-conduction simulations. The results, compared numerically to the analytical solution (found in files heat2dout.analyt_pos and heat2dout.analyt_time), are given in Table 43. The maximum absolute error for these four runs was less than $0.9^{\circ} \mathrm{C}$, and the percent errors were less than $0.5 \%$. These results meet the acceptance criteria for this test suite developed in Chapter III.

\begin{tabular}{|c|c|c|c|}
\hline V\&V test & Maximum error & Maximum \% error & RMS error \\
\hline \multicolumn{4}{|c|}{ Temperature versus time at $x=y=0.0 m$} \\
\hline 3-node triangles & 0.5808 & 0.4166 & $0.7660 e-04$ \\
\hline 4-node quadrilaterals & 0.7141 & 0.3665 & $0.4060 \mathrm{e}-04$ \\
\hline mixed elements & 0.5526 & 0.2812 & $0.5129 \mathrm{e}-04$ \\
\hline refined elements & 0.8344 & 0.4315 & $0.4253 e-04$ \\
\hline \multicolumn{4}{|c|}{ Temperature versus position at $t=2.16 \mathrm{e} 4$ seconds } \\
\hline 3-node triangles & 0.5980 & 0.3421 & $0.7418 \mathrm{e}-03$ \\
\hline 4-node quadrilaterals & 0.7070 & 0.3651 & $0.8163 e-03$ \\
\hline mixed elements & 0.6670 & 0.3466 & $0.7643 e-03$ \\
\hline refined elements & 0.8615 & 0.4452 & $0.8726 e-03$ \\
\hline
\end{tabular}

\subsubsection{3-D heat conduction in a cube}

These tests verify that FEHM correctly models 3-dimensional heat conduction. They also verify that the finite-element representation of 3-D 6-node triangular prisms (prism elements), 8-node quadrilateral polyhedrons (brick elements), 4-node tetrahedrals, mixed-element meshes (containing both triangular prisms and quadrilateral polyhedrons), refinedelement meshes (containing quadrilateral polyhedrons and trapezoidal polyhedrons), and the finite-volume option have been correctly implemented. Figures 27 and 28 show that FEHM results are in good agreement with the analytical solution for the 3-D heat-conduction simulations. The results, compared numerically to the analytical solution (found in files heat3dout.analyt_pos and heat3dout.analyt_time), are given in Table 44. The maximum absolute error for these seven runs was less than $1.3^{\circ} \mathrm{C}$, and the percent errors were less than $0.7 \%$. These results meet the acceptance criteria for this test suite developed in Chapter III. 


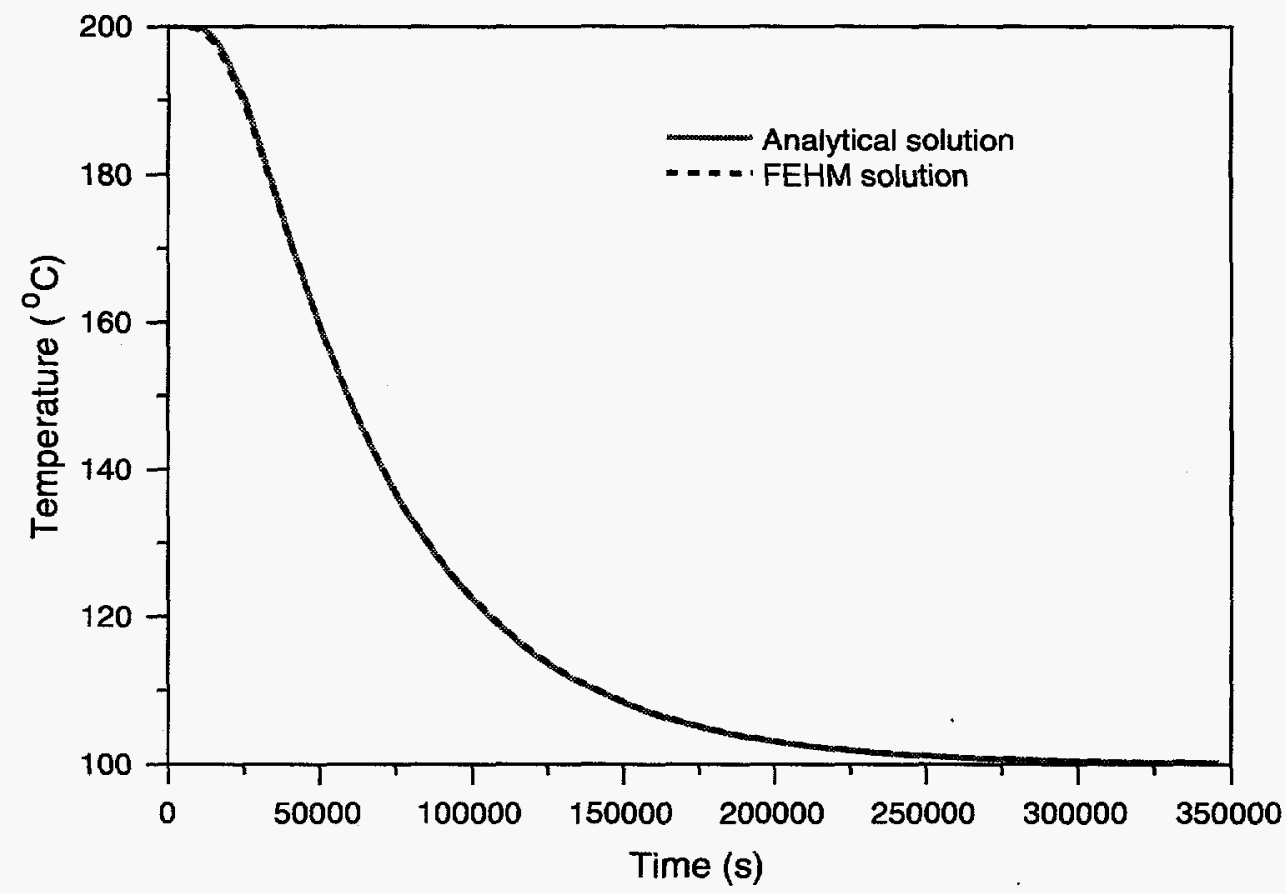

Figure 25. Comparison of FEHM and analytical solutions for 2-D heat conduction at coordinate position $x=y=0 \mathrm{~m}$.

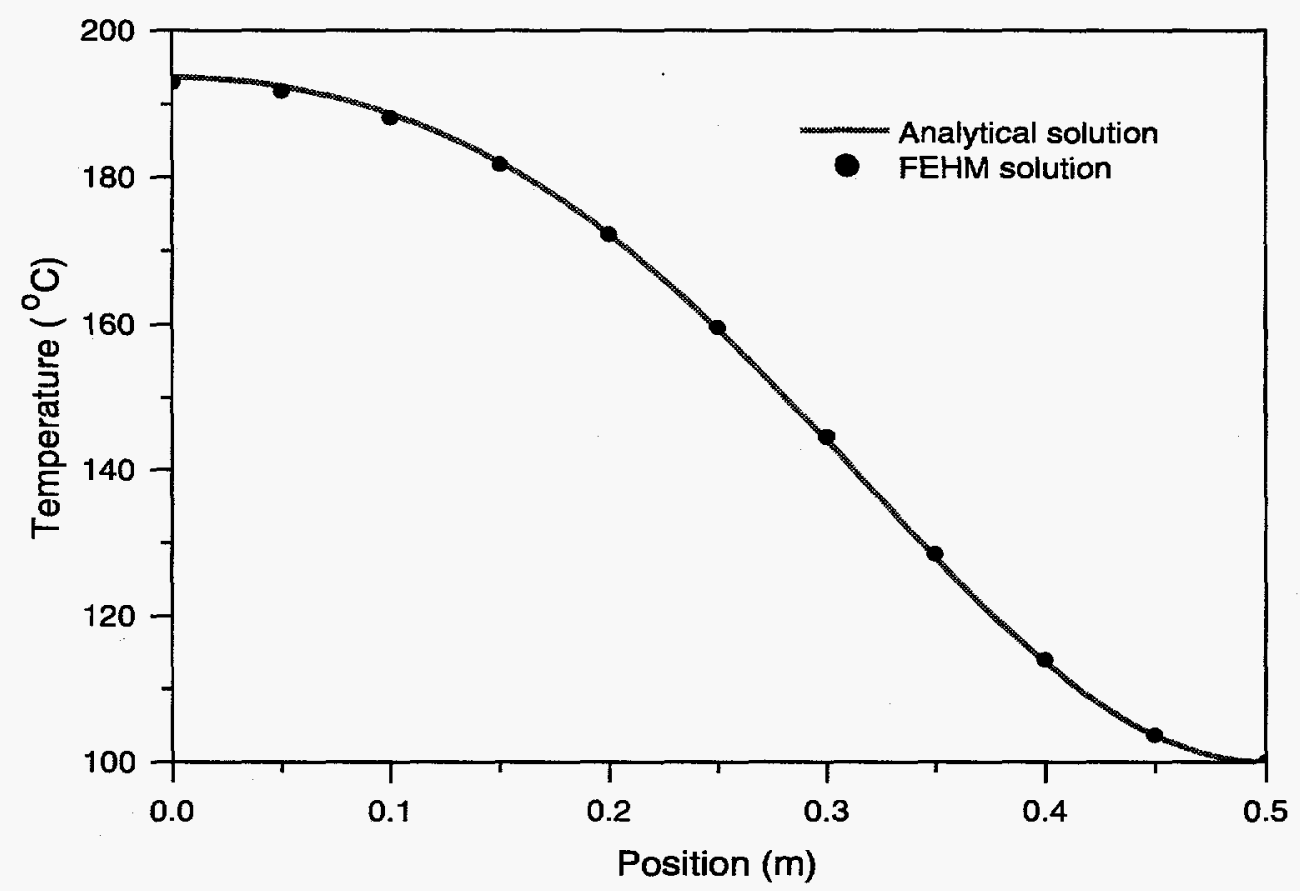

Figure 26. Comparison of FEHM and analytical solutions for 2-D heat conduction at time $\mathbf{t}=\mathbf{2 . 1 6 \mathrm { e }} 4$ seconds. 


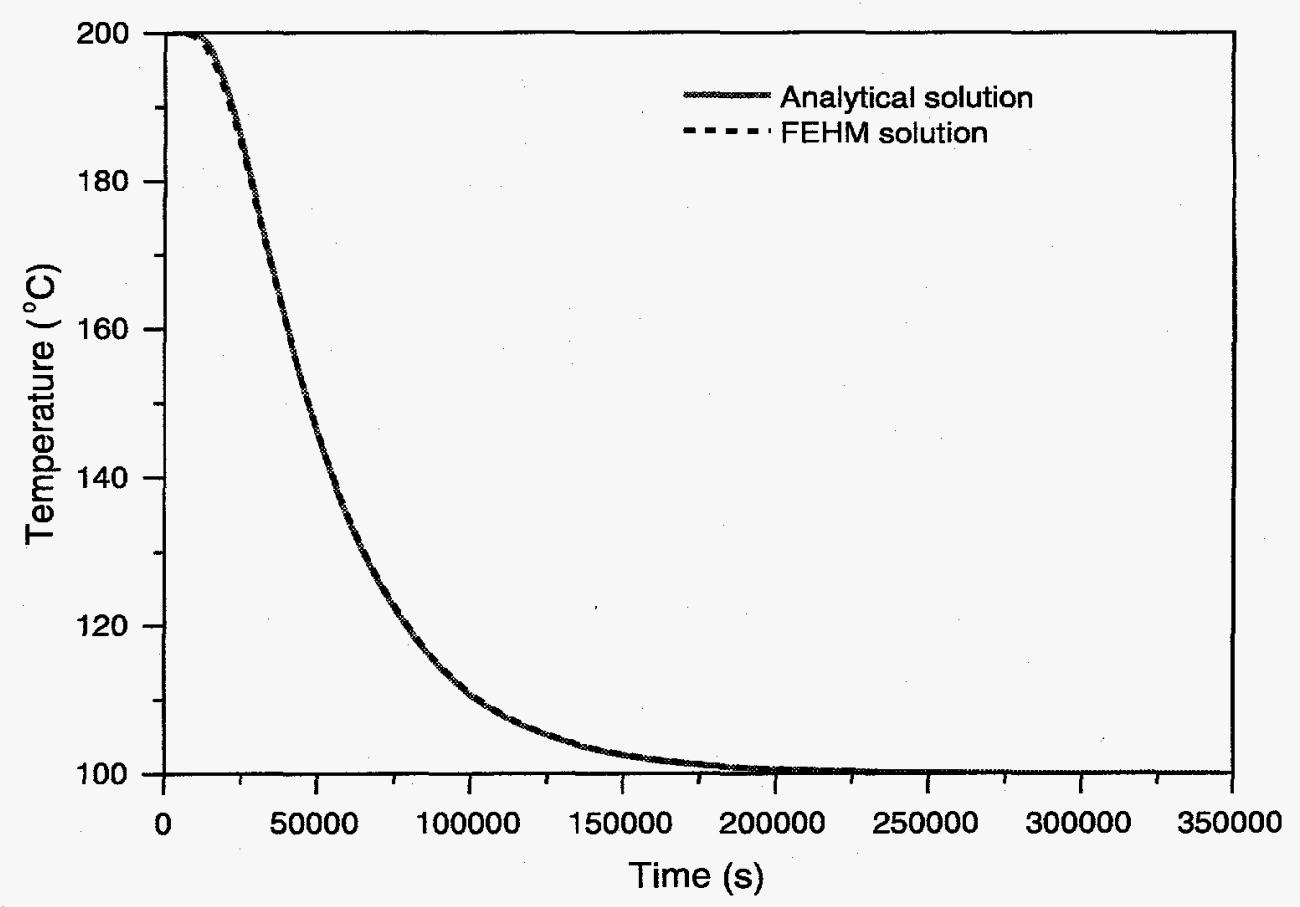

Figure 27. Comparison of FEHM and analytical solutions for 3-D heat conduction at coordinate position $x=y=z=0 \mathrm{~m}$.

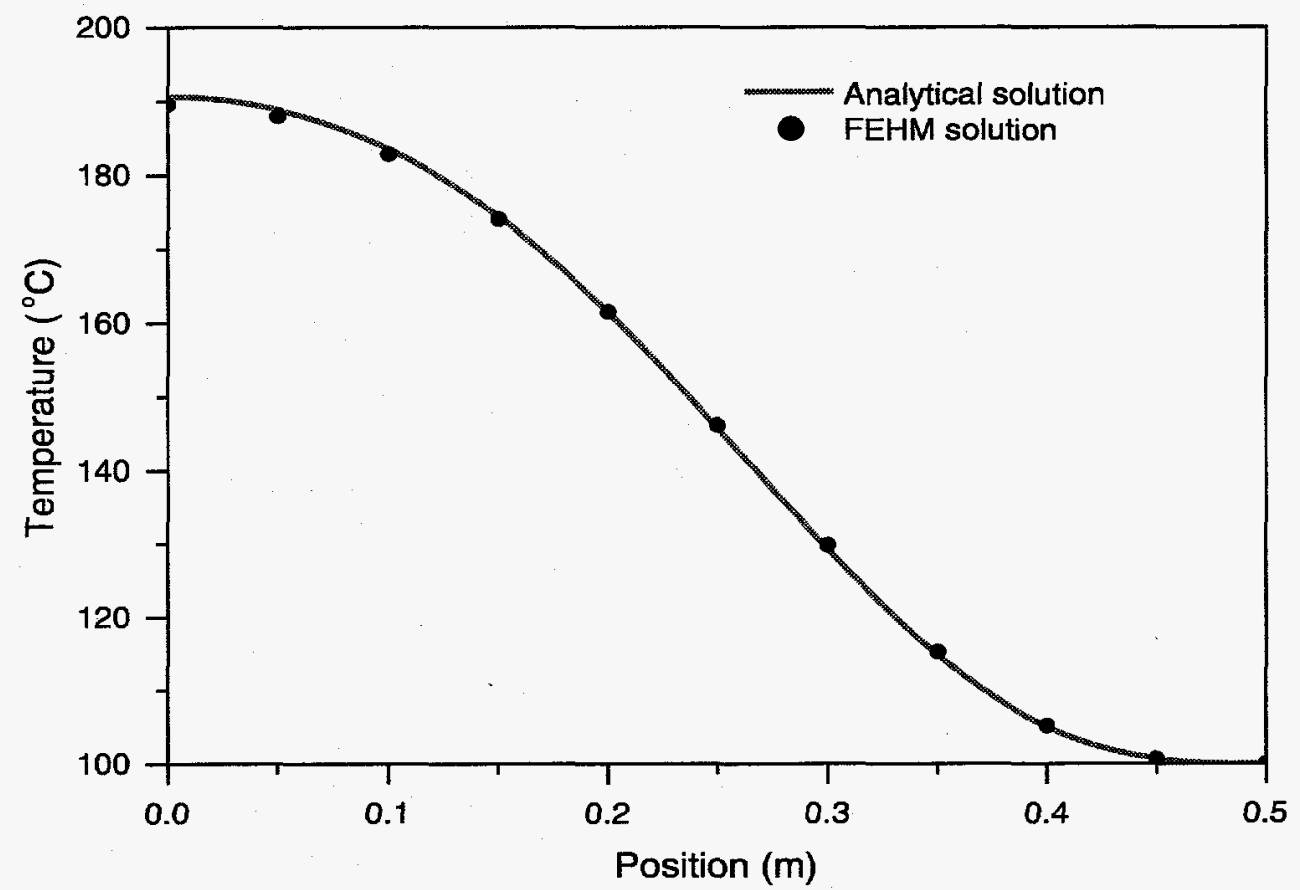

Figure 28. Comparison of FEHM and analytical solutions for 3-D heat conduction at time $t=2.16 e 4$ seconds. 


\begin{tabular}{|c|c|c|c|}
\hline V\&V test & Maximum error & Maximum \% error & RMS error \\
\hline \multicolumn{4}{|c|}{ Temperature verus time at $x=y=z=0.0 \mathrm{~m}$} \\
\hline $\begin{array}{l}\text { 6-node triangular } \\
\text { prisms }\end{array}$ & 0.7855 & 0.5670 & $0.1164 \mathrm{e}-03$ \\
\hline $\begin{array}{l}\text { 8-node quadrilateral } \\
\text { polyhedrons }\end{array}$ & 1.018 & 0.5273 & $0.6811 e-04$ \\
\hline 4-node tetrahedral & 1.245 & 0.6523 & $0.7690 \mathrm{e}-04$ \\
\hline mixed elements & 0.8470 & 0.4347 & $0.7936 \mathrm{e}-04$ \\
\hline refined elements & 1.267 & 0.6634 & $0.7874 \mathrm{e}-04$ \\
\hline $\begin{array}{l}\text { 8-node quadrilateral } \\
\text { polyhedrons with } \\
\text { finite-volume option }\end{array}$ & 1.018 & 0.5273 & $0.6811 e-04$ \\
\hline $\begin{array}{l}\text { refined elements with } \\
\text { finite-volume option }\end{array}$ & 1.031 & 0.5341 & $0.6892 \mathrm{e}-04$ \\
\hline \multicolumn{4}{|c|}{ Temperature versus position at $t=2.16 e 4$ seconds } \\
\hline $\begin{array}{l}\text { 6-node triangular } \\
\text { prisms }\end{array}$ & 0.7960 & 0.5284 & $0.1056 e-02$ \\
\hline $\begin{array}{l}\text { 8-node quadrilateral } \\
\text { polyhedrons }\end{array}$ & 0.9910 & 0.5199 & $0.1065 e-02$ \\
\hline 4-node tetrahedral & 1.243 & 0.6521 & $0.1158 \mathrm{e}-02$ \\
\hline mixed elements & 0.8210 & 0.4402 & $0.9981 \mathrm{e}-03$ \\
\hline refined elements & 1.265 & 0.6636 & $0.1124 \mathrm{e}-02$ \\
\hline $\begin{array}{l}\text { 8-node quadrilateral } \\
\text { polyhedrons with } \\
\text { finite-volume option }\end{array}$ & 0.9910 & 0.5199 & $0.1065 e-02$ \\
\hline $\begin{array}{l}\text { refined elements with } \\
\text { finite-volume option }\end{array}$ & 1.005 & 0.5272 & $0.1076 e-02$ \\
\hline
\end{tabular}




\subsection{Test of Temperature in a Wellbore}

This test verifies that FEHM has correctly implemented the heat- and masstransfer problem and 2-D radial geometry. Figures 29 and 30 show that FEHM results are in good agreement with the analytical solution. The results, compared numerically to the analytical solution (found in files rameyout.analyt_pos and rameyout.analyt_time), are given in Table 45 . The maximum absolute error for this run was less than $1.4^{\circ} \mathrm{C}$, and the percent errors were less than $3 \%$. These results meet the acceptance criteria for this test suite developed Chapter III.

\begin{tabular}{|c|c|c|c|}
\hline V\&V test & Maximum error & Maximum \% error & RMS error \\
\hline \multicolumn{4}{|c|}{ Temperature versus time } \\
\hline $\mathrm{d}=0 \mathrm{~m}$ & $0.2570 e-01$ & 0.1285 & $0.3110 \mathrm{e}-04$ \\
\hline$d=1000 \mathrm{~m}$ & 1.345 & 2.815 & $0.1556 e-02$ \\
\hline$d=2000 m$ & 1.057 & 1.358 & $0.1061 \mathrm{e}-02$ \\
\hline \multicolumn{4}{|c|}{ Temperature versus depth } \\
\hline $\mathrm{t}=25$ days & 0.6971 & 1.026 & $0.5203 e-03$ \\
\hline
\end{tabular}

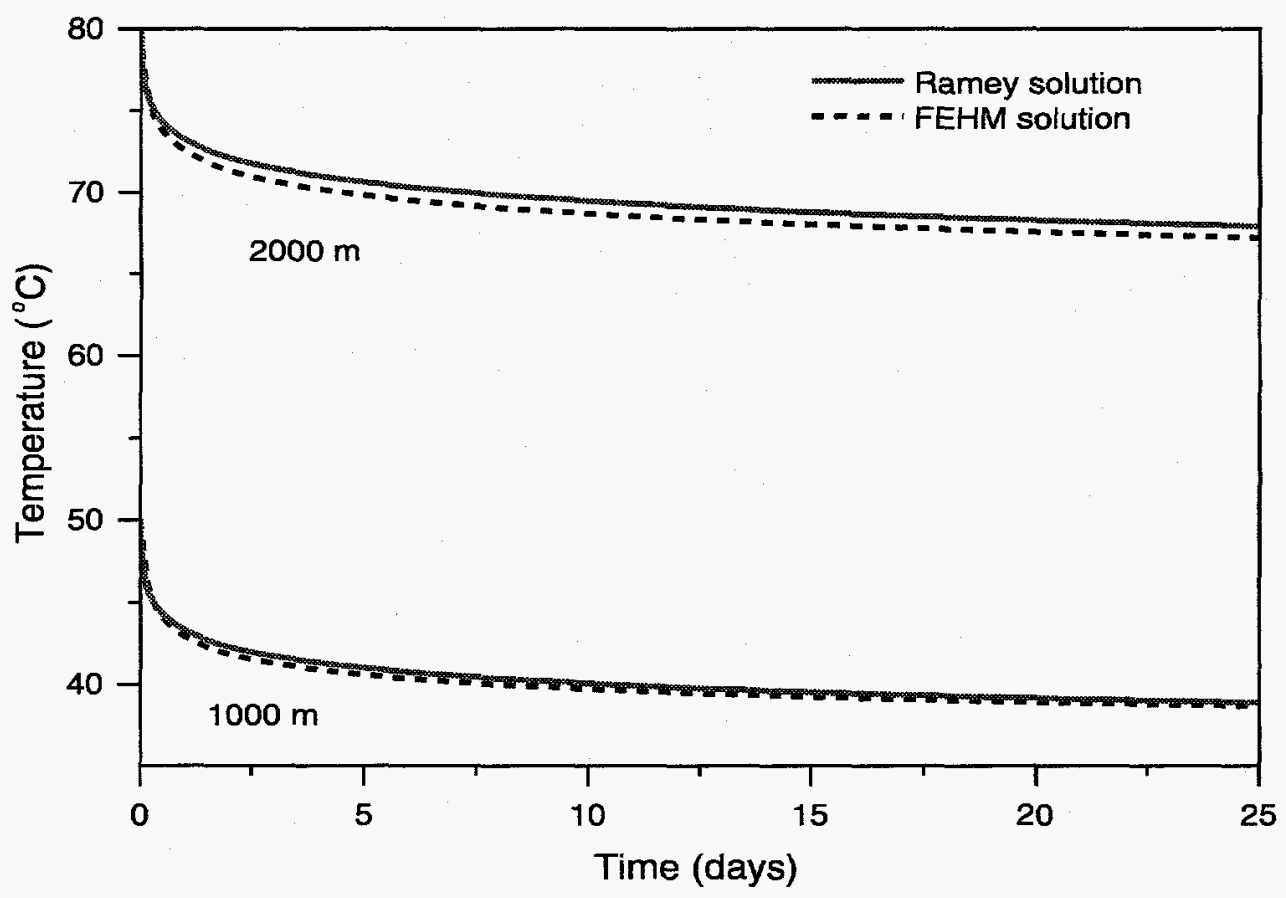

Figure 29. Comparison of FEHM and Ramey analytical solutions for temperature versus time at $d=1000 \mathrm{~m}$ and $d=2000 \mathrm{~m}$. 


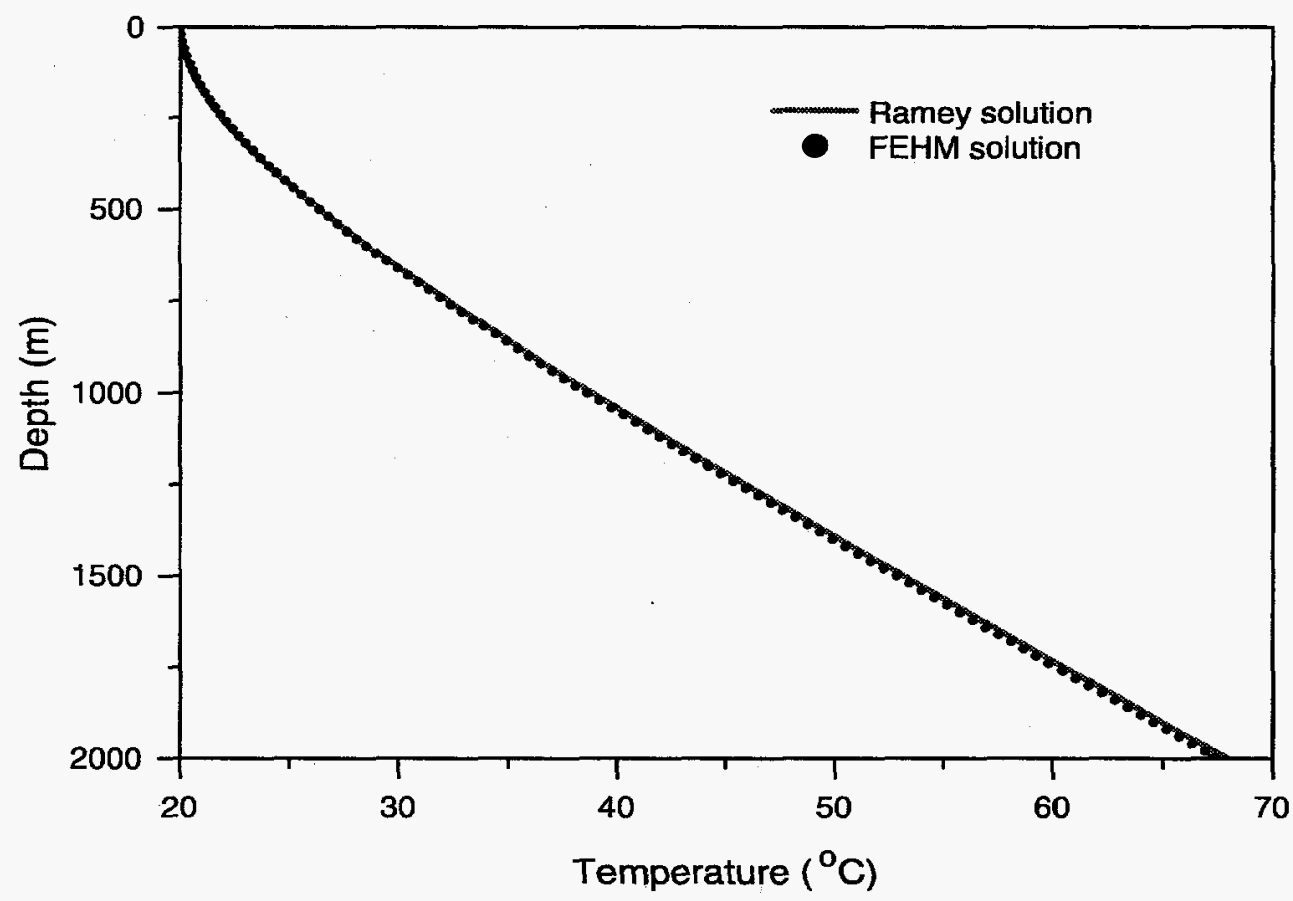

Figure 30. Comparison of FEHM and Ramey analytical solutions for temperature versus depth at $\mathbf{t}=\mathbf{2 5}$ days. 


\subsection{Test of Pressure Transient Analysis}

This test verifies that FEHM has correctly implemented the pressure equations, i.e., the conservation of mass with Darcy's law, and that radial geometry has been correctly implemented. Figures 31 and 32 show that the FEHM results are in good agreement with the analytical solution. The results, compared numerically to the analytical solution (found in files theisout.analyt_pos and theisout.analyt_time) are given in Table 46. The maximum absolute error for this simulation was less than $0.0003 \mathrm{MPa}$, and the percent errors were less than $0.03 \%$. These results meet the acceptance criteria for this test suite developed in Chapter III.

\begin{tabular}{|c|c|c|c|}
\hline V\&V test & Maximum error & Maximum \% error & RMS error \\
\hline \multicolumn{4}{|l|}{ Pressure versus time } \\
\hline at $r=0.00144 \mathrm{~m}$ & $0.1594 \mathrm{e}-04$ & $0.1593 e-02$ & $0.6169 e-06$ \\
\hline at $r=3.44825 \mathrm{~m}$ & $0.1548 \mathrm{e}-04$ & $0.1548 \mathrm{e}-02$ & $0.5902 e-06$ \\
\hline \multicolumn{4}{|c|}{ Pressure versus position } \\
\hline at $t=1$ day & $0.1564 \mathrm{e}-04$ & $0.1564 \mathrm{e}-02$ & $0.1439 e-05$ \\
\hline
\end{tabular}

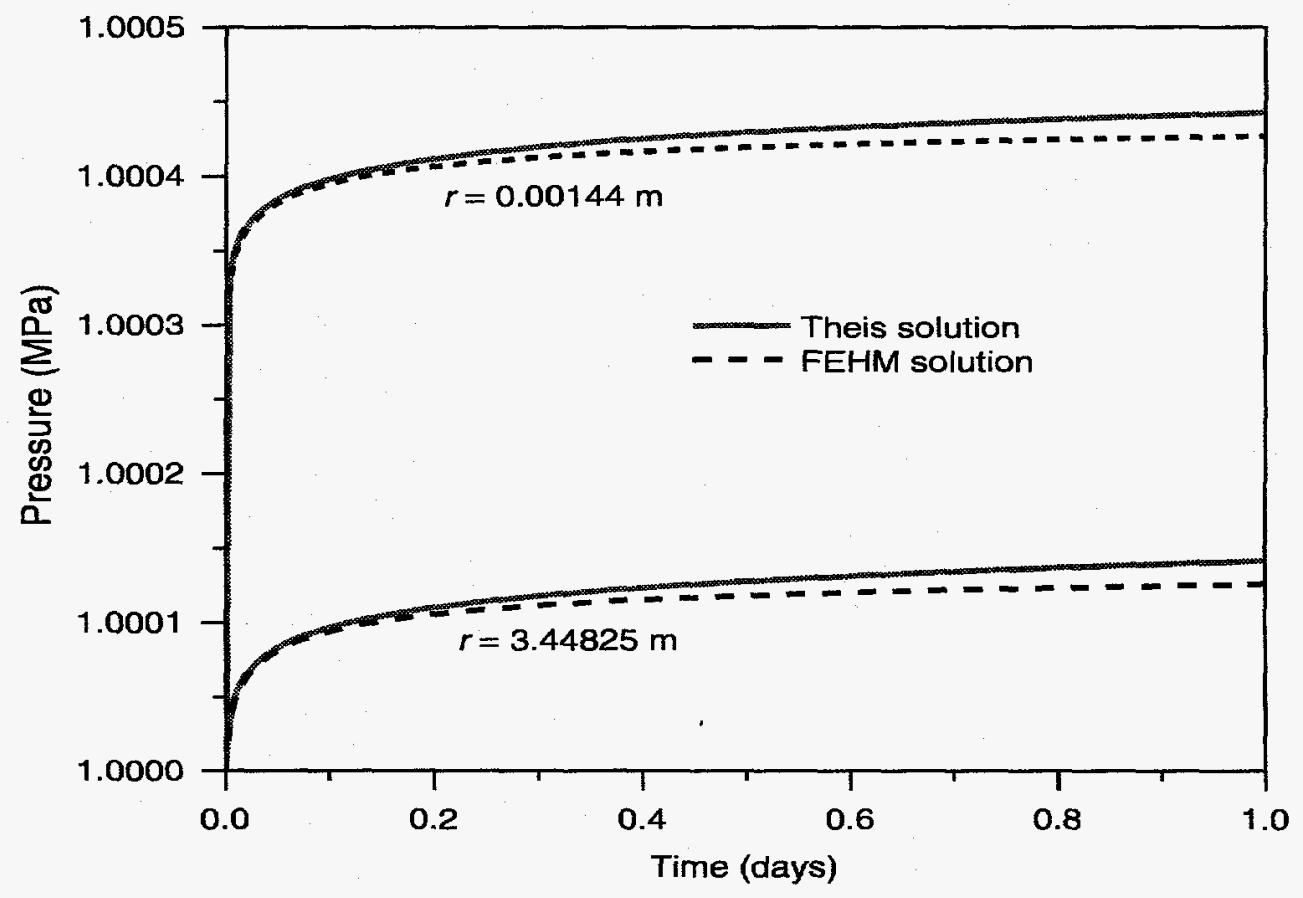

Figure 31.Comparison of FEHM and Theis solutions for pressure versus time at $r=0.00144 \mathrm{~m}$ and $r=3.44825 \mathrm{~m}$ from the wellbore. 


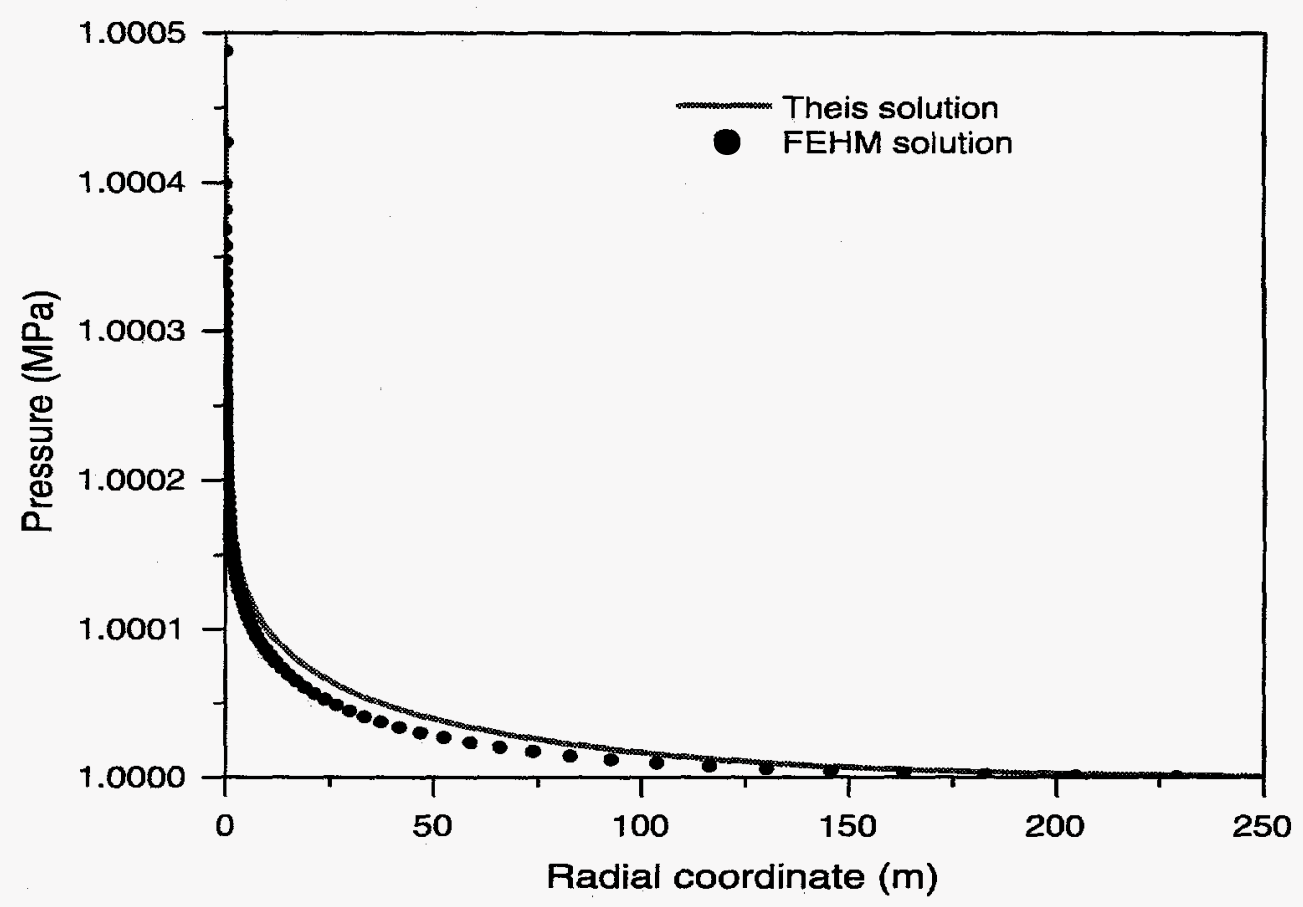

Figure 32. Comparison of FEHM and Theis solutions for pressure versus position at $t=1$ day. 


\subsection{Test of Infiltration into a One-dimensional, Layered, Unsaturated Medium}

This test verifies that FEHM has correctly simulated the saturation profile for the infiltration into a one-dimensional, layered, unsaturated medium. Figures 33, 34, and 35 show that the FEHM results are in good agreement with the TOUGH2 simulations. Please note that the expanded saturation scale in Fig. 35 exaggerates differences in fracture saturation at low elevations. The results for the equivalent-continuum model (ECM) and double-porosity/double-permeability model (DKM), compared numerically to results from TOUGH2 (found in files infiltration.tough2.ecm, infiltration.tough2.frac, and infiltration.tough2.mat), are shown in Table 47. The RMS error for the equivalent-continuum model simulation was less than $1 \%$, and the maximum percent error was less than $7 \%$. As expected, significant deviations existed at material interfaces for the double-porosity/doublepermeability model. These were the result of differences in model formulation for the fracture-matrix interaction terms. It should also be noted that the van Genuchten capillary-pressure functions are singular at $S=0$, and all codes must use extrapolation techniques to model values approaching 0 . Differences in the extrapolation had the greatest effect in the lowest zone where the fracture saturations approach liquid residual values. Although the maximum percent errors for the double-porosity/double-permeability model were large, the RMS errors for this simulation were less than $4 \%$. These results meet the acceptance criteria for this test suite developed in Chapter III.

\begin{tabular}{|cccc|}
\hline $\begin{array}{l}\text { Table 47. } \\
\text { Results of the test of infiltration into a one-dimensional, } \\
\text { layered, unsaturated medium }\end{array}$ \\
\hline V\&V test & Maximum error & Maximum \% error & RMS error \\
\hline \hline Saturation versus elevation & & & \\
ECM & $0.5660 \mathrm{e}-01$ & 6.192 & $0.1430 \mathrm{e}-02$ \\
DKM - matrix saturation & $0.8153 \mathrm{e}-01$ & 17.13 & $0.2069 \mathrm{e}-02$ \\
DKM - fracture saturation & $0.1022 \mathrm{e}-01$ & 355.0 & $0.3679 \mathrm{e}-01$ \\
\hline
\end{tabular}




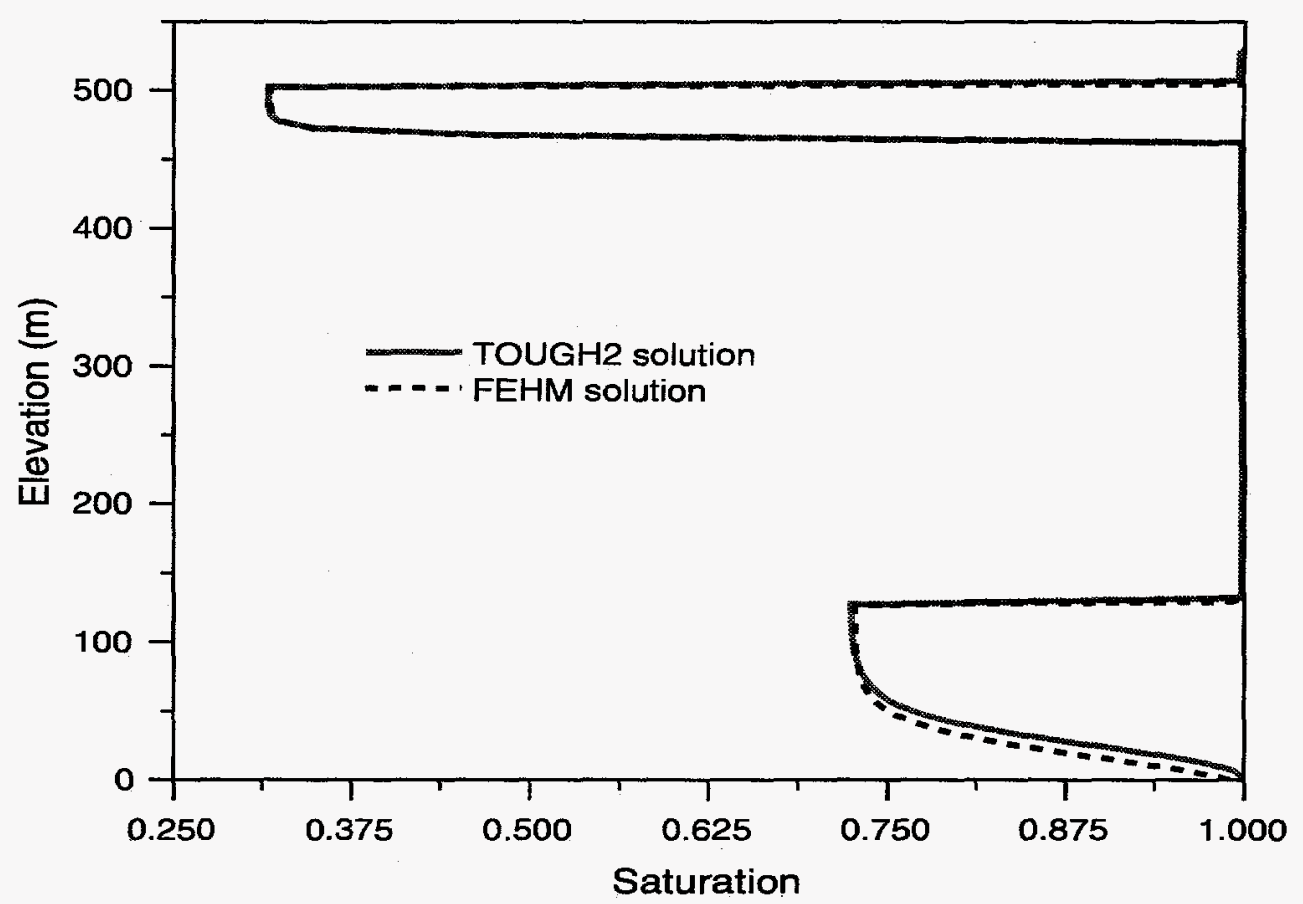

Figure 33. Comparison of FEHM and TOUGH2 saturations for an equivalent-continuum model.

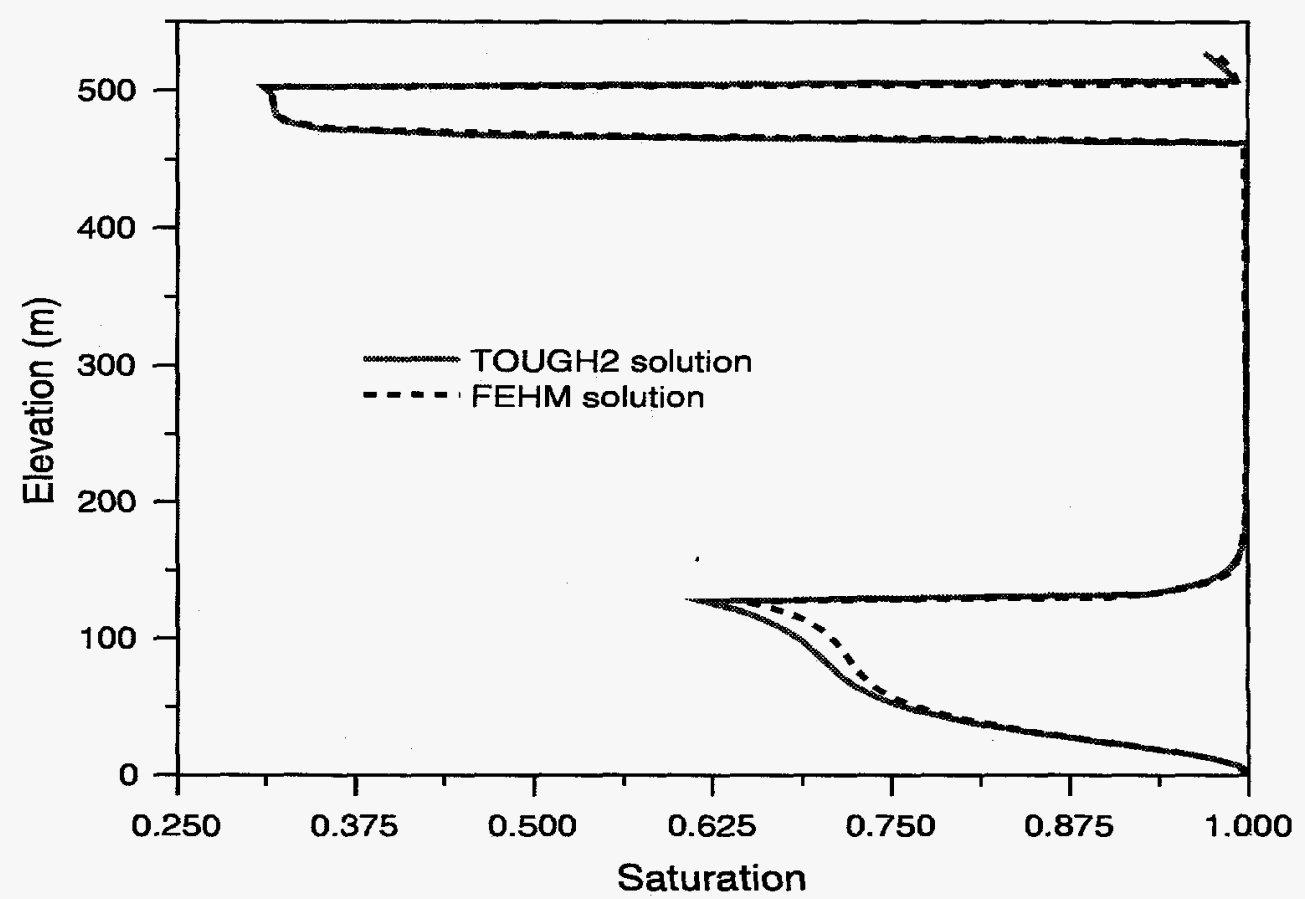

Figure 34. Comparison of FEHM and TOUGH2 matrix saturation for a double-porosity/double-permeability model. 
IV. Verification and Validation Report DISCUSSION OF TEST RESULTS

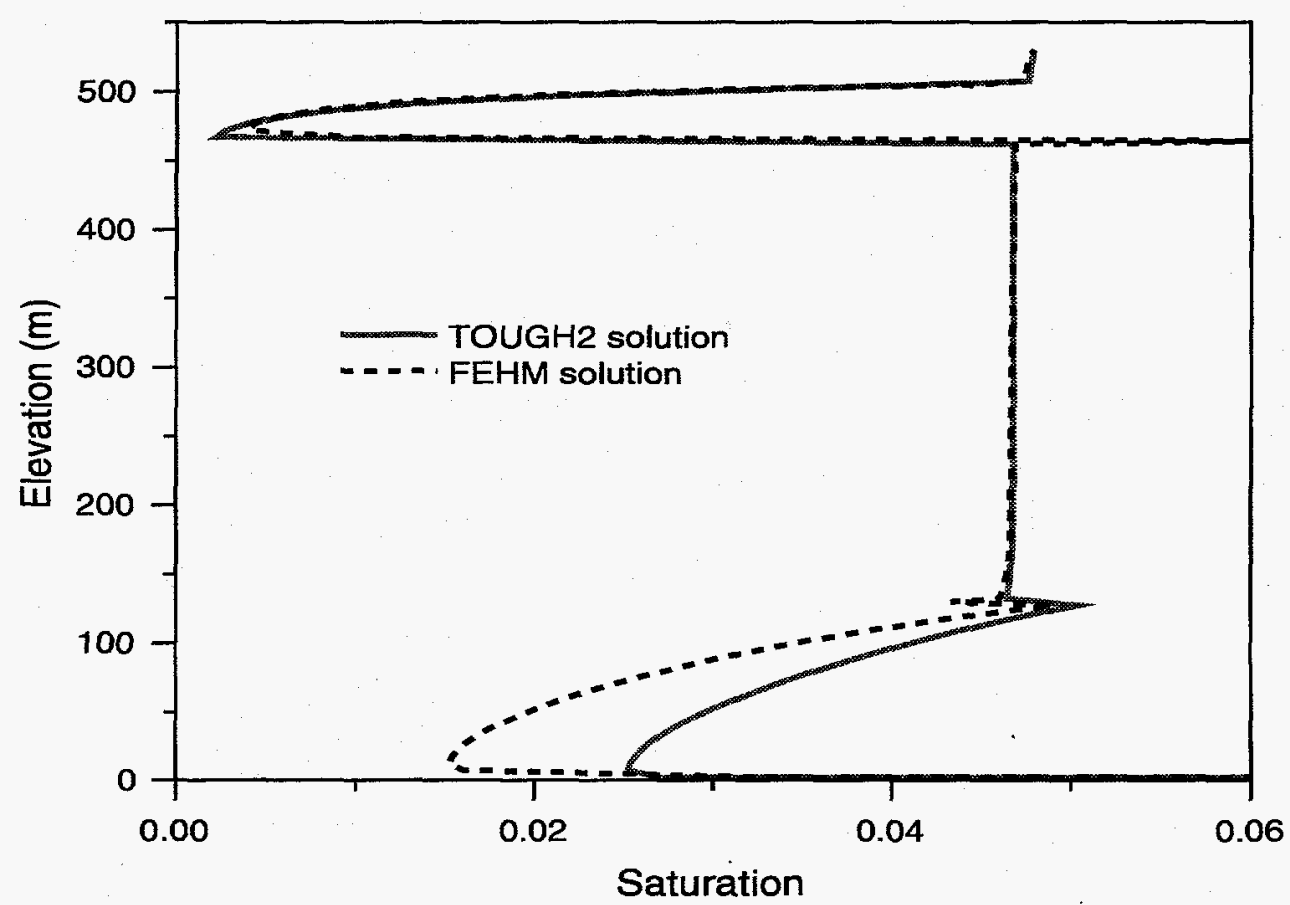

Figure 35. Comparison of FEHM and TOUGH2 fracture saturation for a double-porosity/double-permeability model. 


\subsection{Test of Vapor Extraction from an Unsaturated Reservoir}

This test verifies that FEHM has correctly implemented steady-state gas flow in a $2-D$ radial system with an isotropic and an anisotropic permeability model. Figures 36 and 37 show that FEHM results are in good agreement with the analytical solutions (found in files vapextractout_aniso.analyt and vapextractout_iso.analyt) for the vapor-extraction simulations. The results of the numerical comparison to the analytical solutions are given in Table 48 . The maximum absolute error in vapor pressure for the isotropic case was less than $0.002 \mathrm{MPa}$, and for the anisotropic case, it was less than 0.004 MPa. The maximum percent errors were less than $4 \%$, and the RMS errors were less than 0.01 for both models. These results meet the acceptance criteria for this test suite developed in Chapter III.
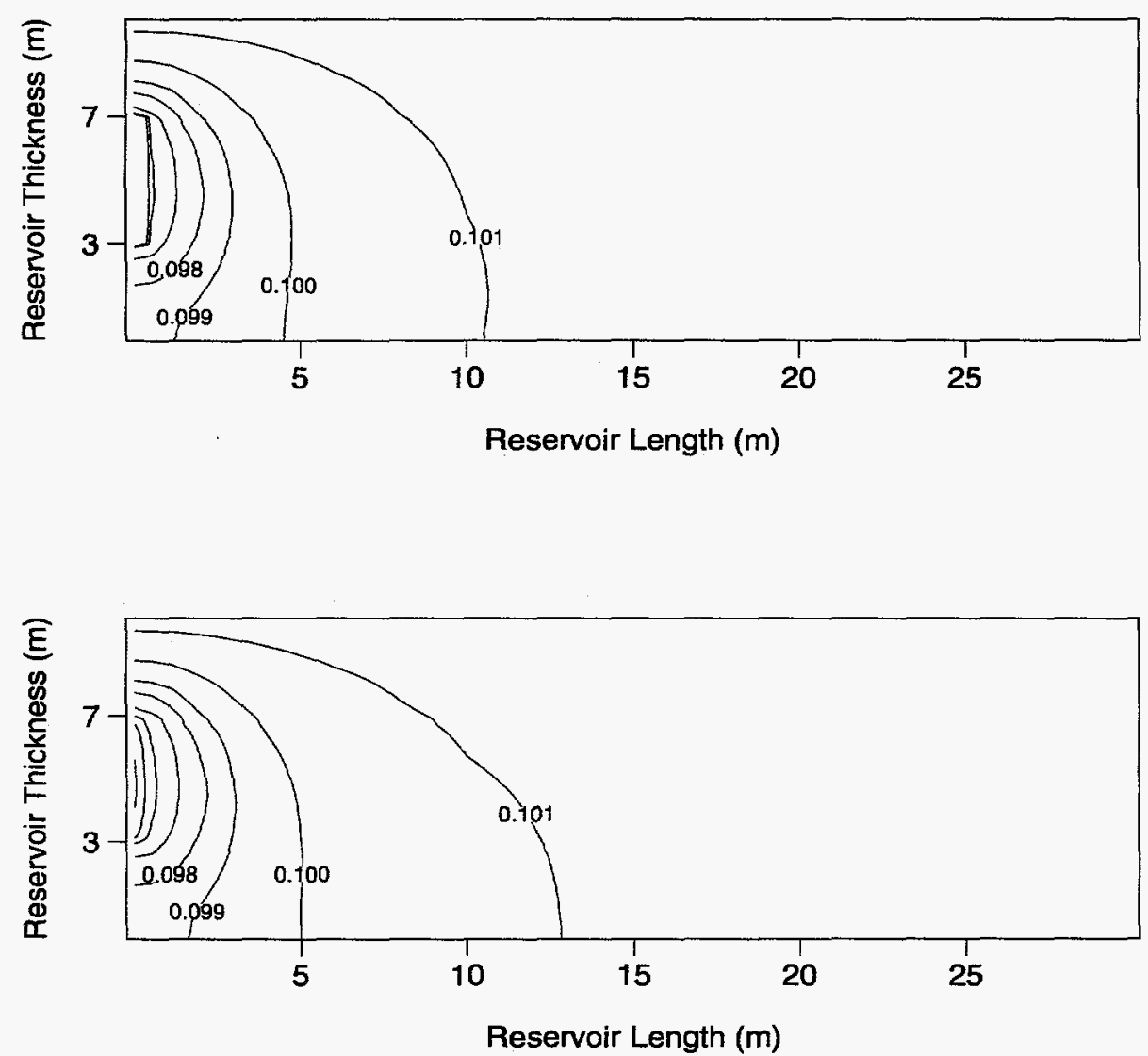

Figure 36. Comparison of FEHM steady-state vapor pressure (top) with Shan analytical solution (bottom) for an isotropic reservoir. 


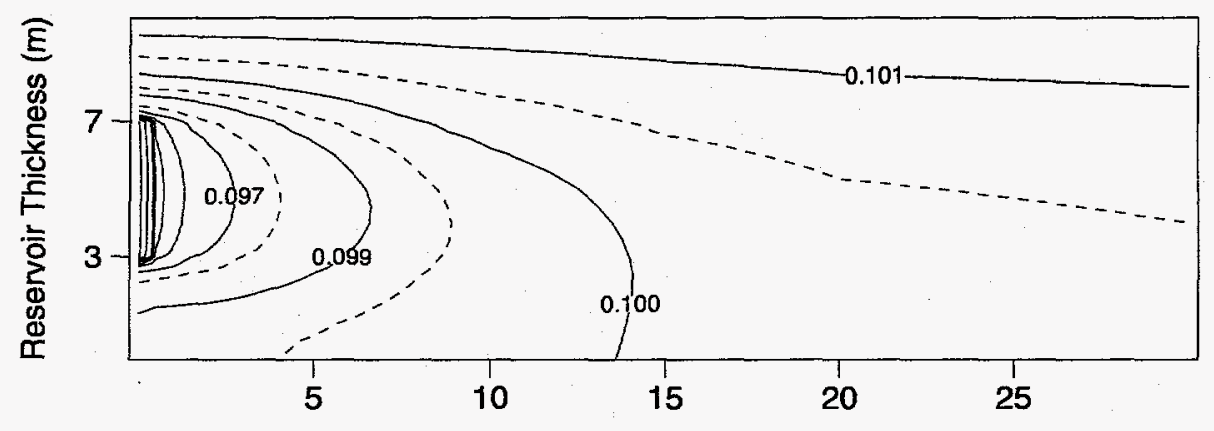

Reservoir Length (m)

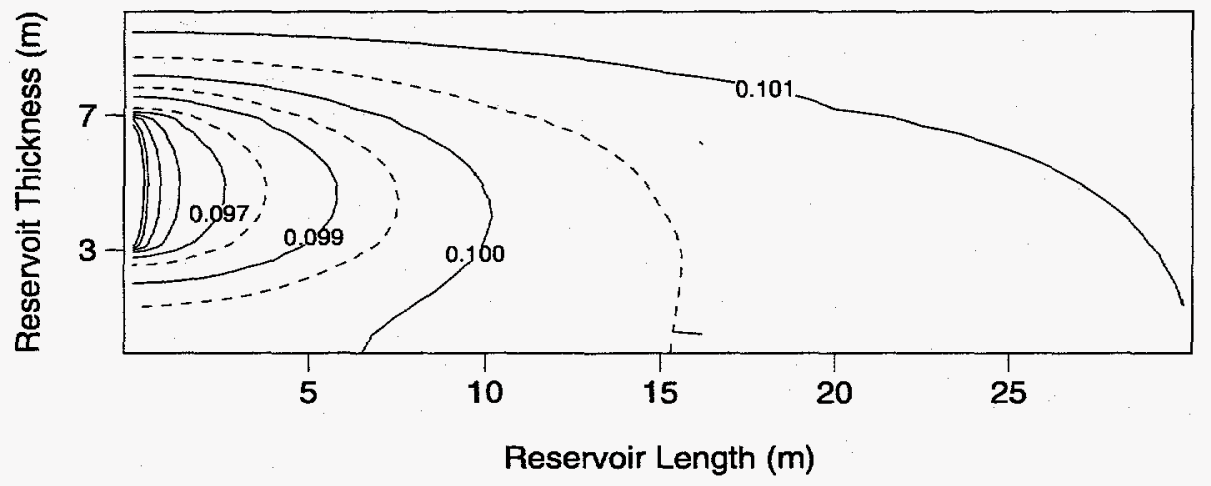

Figure 37. Comparison of FEHM steady-state vapor pressure (top) with Shan analytical solution (bottom) for an anisotropic reservoir.

\begin{tabular}{|c|c|c|c|}
\hline $\begin{array}{l}\text { Table 48. Result } \\
\text { reserve }\end{array}$ & he test of vap & extraction from & unsatura \\
\hline V\&V test & Maximum error & Maximum \% error & RMS error \\
\hline Vapor pressures at $e$ & & & \\
\hline Isotropic case & $0.1983 \mathrm{e}-02$ & 2.195 & $0.8838 \mathrm{e}-04$ \\
\hline Anisotropic case & $0.3066 \mathrm{e}-02$ & 3.311 & $0.1436 \mathrm{e}-03$ \\
\hline
\end{tabular}




\subsection{Test of Dual Porosity}

This test verifies that FEHM has correctly implemented the dual-porosity formulation. Figures 38, 39, and 40 show that FEHM results are in good agreement with the analytical solution for the dual-porosity simulations. The differences between the analytical and FEHM solutions can be attributed primarily to the fact that the analytical solution uses a steady-state approximation for the matrix flow (lumped 1 node) whereas FEHM uses a transient approximation ( 2 node) for the matrix material. The results, compared numerically to the analytical solution (found in files dual1_out.analyt, dual2_out.analyt, and dual3_out.analyt), are given in Table 49. The maximum absolute error for these three runs for nondimensional pressure was less than 0.021 , and the percent errors were less than $0.8 \%$. These results meet the acceptance criteria for this test suite developed in Chapter III.

\section{Table 49. Results of the dual-porosity test}

\begin{tabular}{|cccc|}
\hline V\&V test & Maximum error & Maximum \% error & RMS error \\
\hline \hline \multicolumn{1}{|c|}{ Dimensionless pressure versus dimensionless time at $r_{w}=0.17528 \mathrm{~m}$} \\
Case 1 & $0.1945 \mathrm{e}-01$ & 0.3530 & $0.4143 \mathrm{e}-03$ \\
Case 2 & $0.2070 \mathrm{e}-01$ & 0.7086 & $0.5725 \mathrm{e}-03$ \\
Case 3 & $0.1931 \mathrm{e}-01$ & 0.6997 & $0.5360 \mathrm{e}-03$ \\
\hline
\end{tabular}

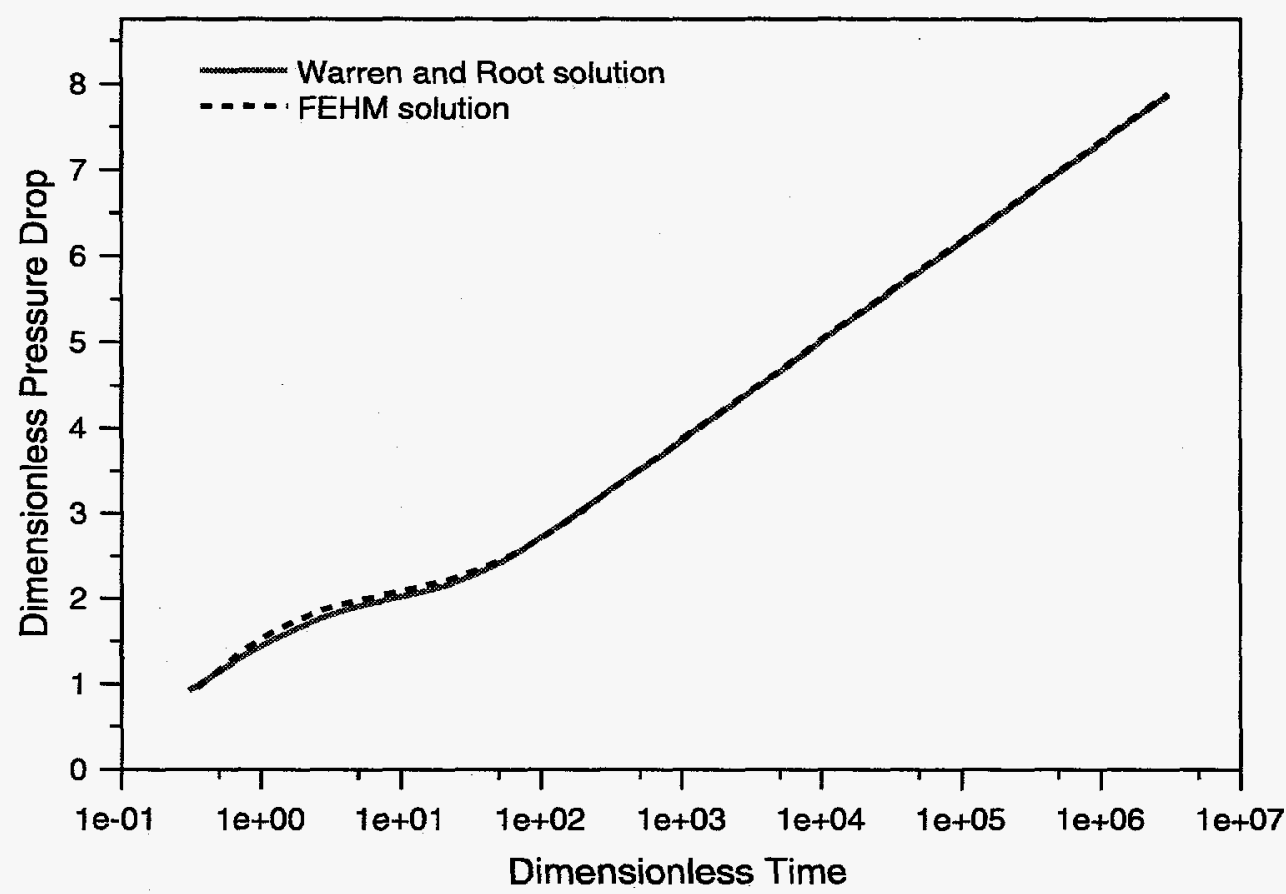

Figure 38. Comparison of FEHM and analytical solution for dualporosity case $1, \lambda=0.02546, \omega=0.1000$. 


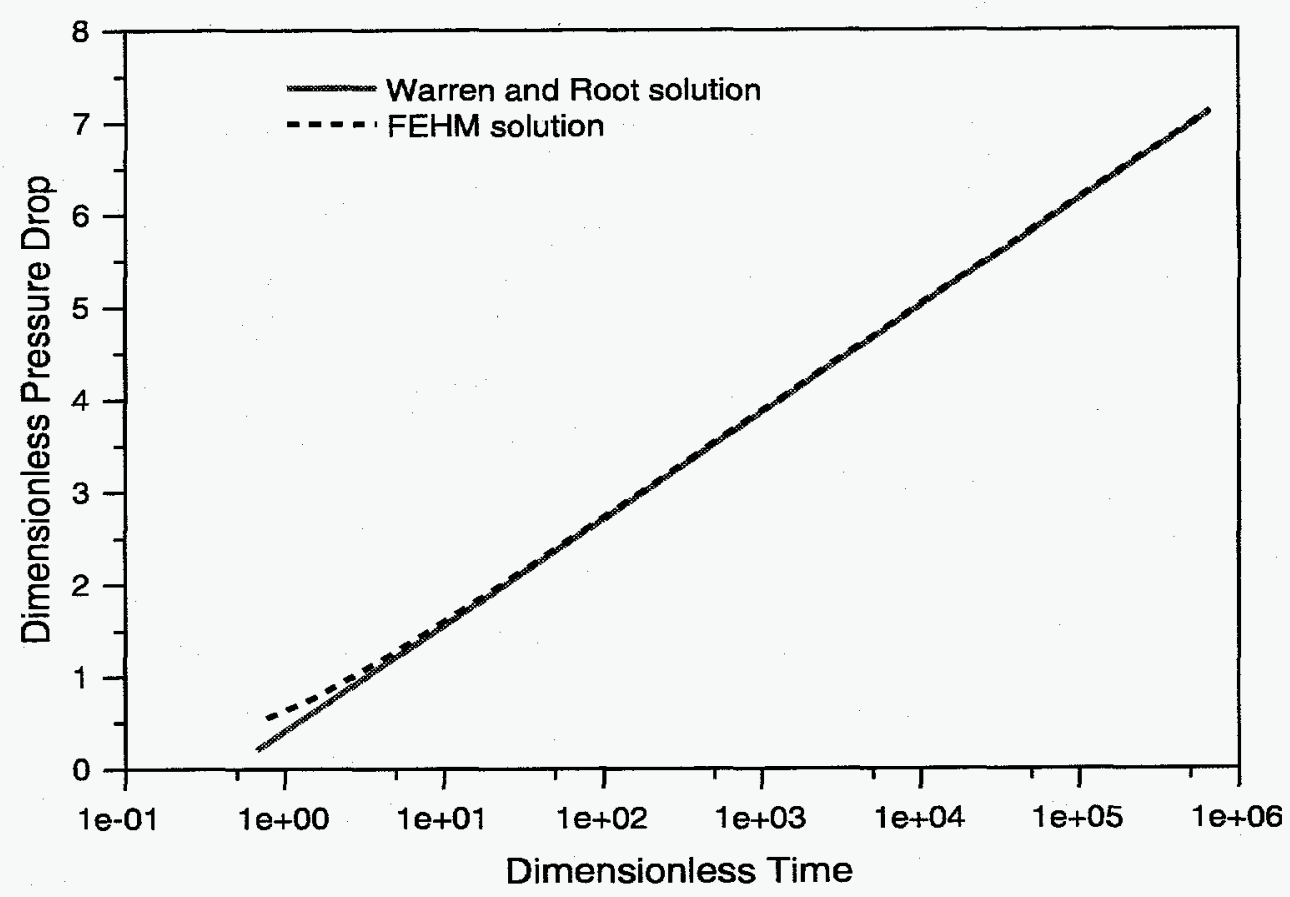

Figure 39. Comparison of FEHM and analytical solution for dualporosity case $2, \lambda=25.46, \omega=\mathbf{0 . 0 1 0 9 9}$.

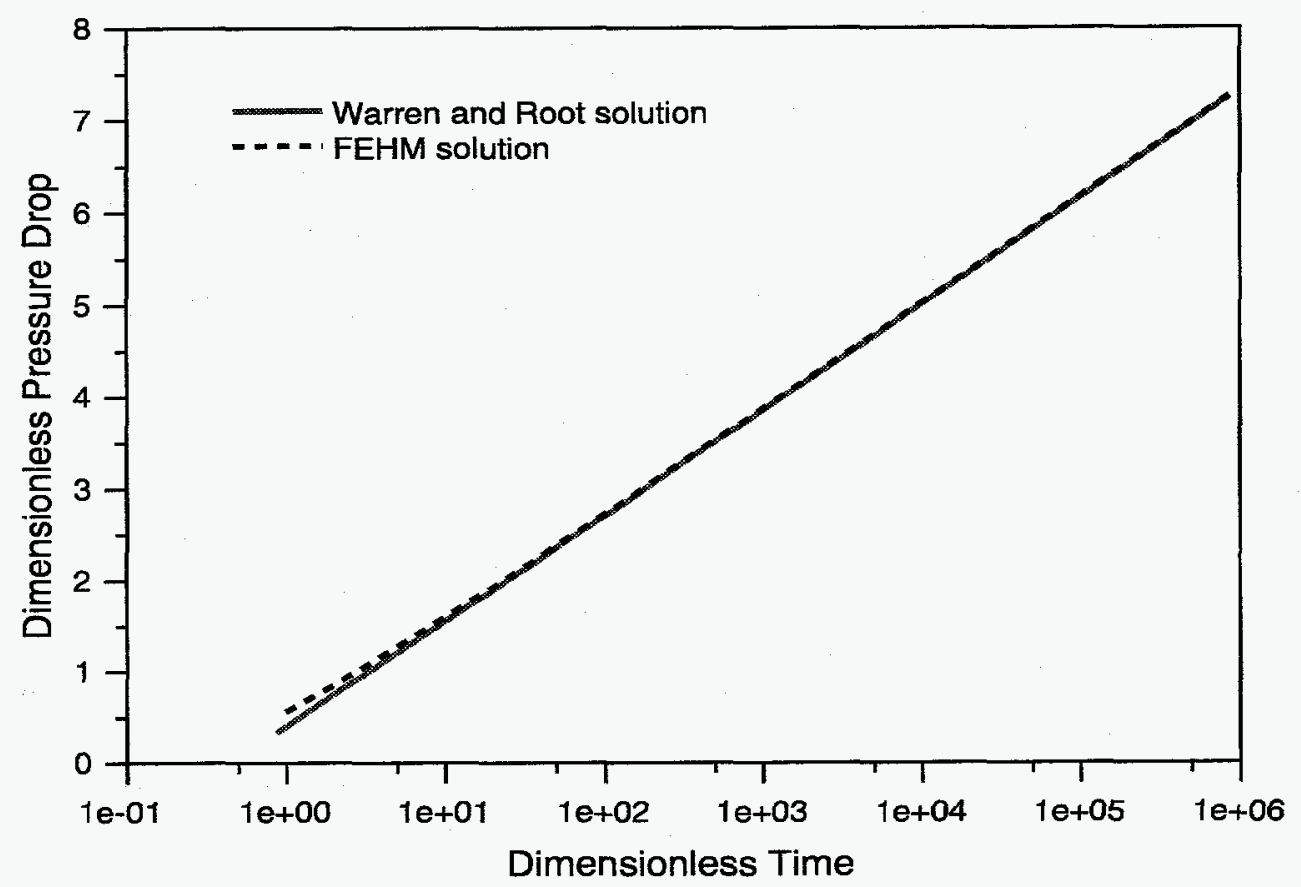

Figure 40. Comparison of FEHM and analytical solution for dualporosity case $3, \lambda=164.7, \omega=\mathbf{0 . 0 0 1 0 1 3}$. 


\subsection{Test of Heat and Mass Transfer in Porous Media}

This test suite verifies that the heat- and mass-transfer problem has been correctly formulated, that radial geometry has been correctly implemented and that finer meshes can improve accuracy. Figures 41 and 42 show that FEHM results are in good agreement with the analytical solution. For the 84-node test grid, meshdiscretization errors are apparent. Other differences are probably due to slight differences in the calculation of thermodynamic properties (the analytical solution uses constant properties). The results, compared numerically to the analytical solution (found in files avdoninout.analyt_pos and avdoninout.analyt_time) are given in Table 50. The maximum absolute error for these three runs was less than $1.3^{\circ} \mathrm{C}$, and the percent errors were less than $0.8 \%$. These results meet the acceptance criteria for this test suite developed in Chapter III.

Table 50. Results of the test of heat and mass transfer in porous media

\begin{tabular}{|cccc|}
\hline V\&V test & Maximum error & Maximum \% error & RMS error \\
\hline \hline Temperature versus time at $r=37.5 \mathrm{~m}$ & & \\
84-node grid & 1.262 & 0.7776 & $0.2169 \mathrm{e}-03$ \\
400-node grid & 0.4060 & 0.2487 & $0.6973 \mathrm{e}-04$ \\
800-node grid & 0.3899 & 0.2384 & $0.6742 \mathrm{e}-04$ \\
\hline Temperature versus position at $\mathrm{t}=1 . \mathrm{e} 9$ seconds & & \\
84-node grid & 0.5230 & 0.3237 & $0.1745 \mathrm{e}-03$ \\
400-node grid & 0.2815 & 0.1744 & $0.3416 \mathrm{e}-04$ \\
800-node grid & 0.2815 & 0.1744 & $0.2213 \mathrm{e}-04$ \\
\hline
\end{tabular}




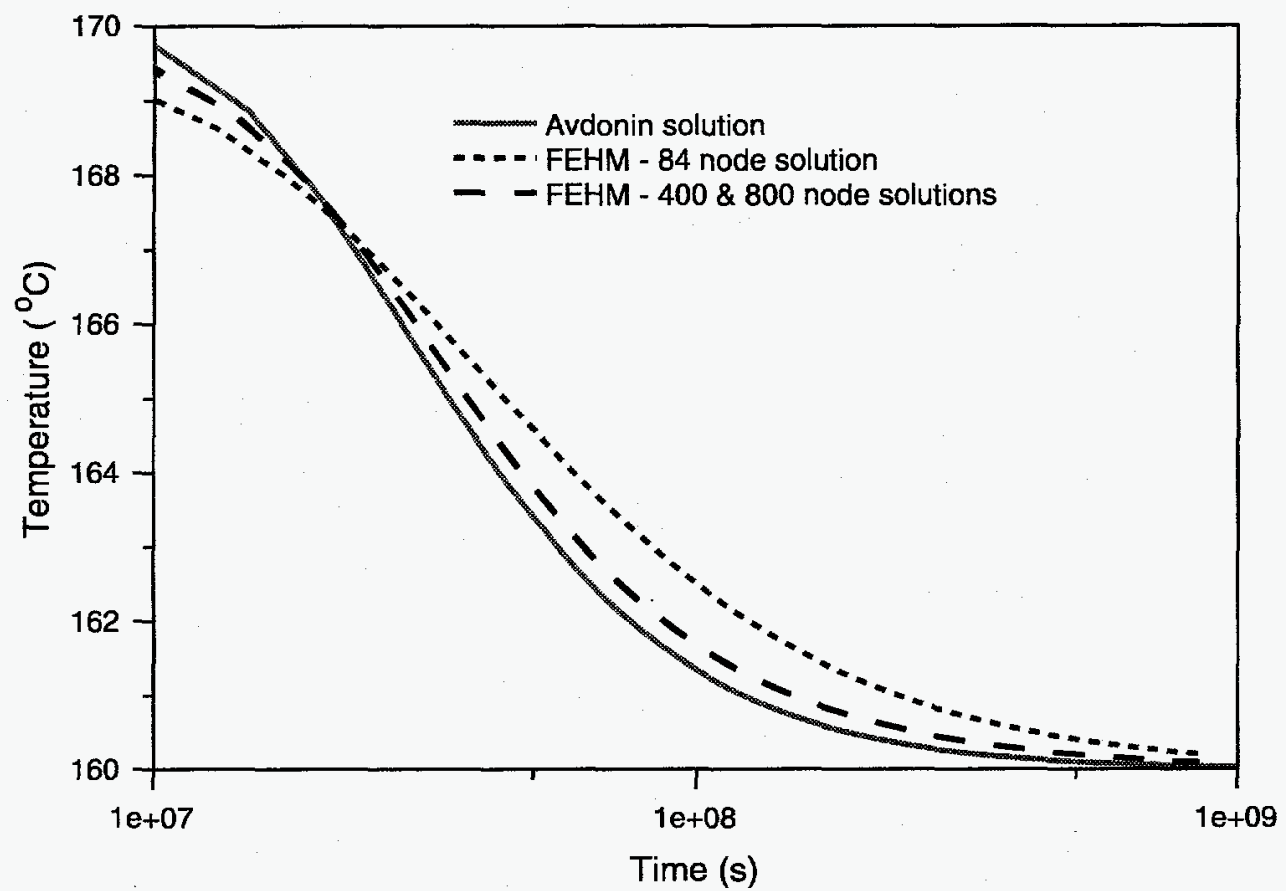

Figure 41. Comparison of FEHM and Avdonin analytical solutions for temperature versus time at $\mathbf{r}=\mathbf{3 7 . 5} \mathbf{m}$ from injection well.

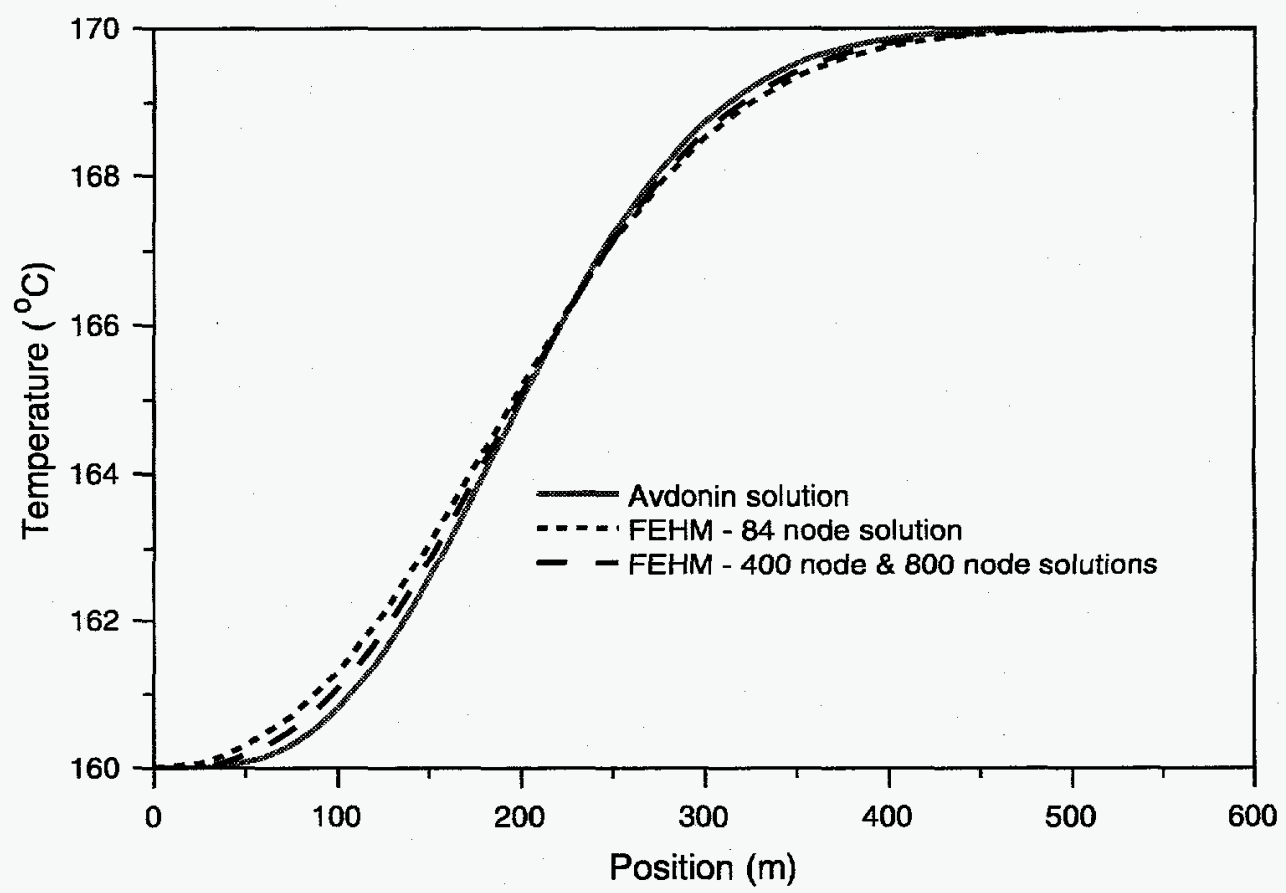

Figure 42. Comparison of FEHM and Avdonin analytical solutions for temperature versus position at $t=1 . e 9$ seconds. 


\subsection{Test of Toronyi Two-phase Problem}

This test verifies that FEHM has correctly implemented heat and mass transfer and phase partitioning. The results of the numerical comparison to the Thomas and Pierson (1978) solution (found in file toronyi.saturations) are given in Table 51. The maximum absolute error in saturation for this run was less than 0.002 , and the percent errors were less than $2 \%$. These results meet the acceptance criteria for this test suite developed in Chapter III. Figures 43 and 44 show the Toronyi and FEHM saturation fields for comparison.

Table 51. Results of the test of the Toronyi two-phase problem

\begin{tabular}{|cccc|}
\hline V\&V test & Maximum error & Maximum \% error & RMS error \\
\hline \hline $\begin{array}{l}\text { Final saturation at } \\
\text { each node }\end{array}$ & $0.1542 \mathrm{e}-02$ & 1.318 & $0.7718 \mathrm{e}-03$ \\
\hline
\end{tabular}

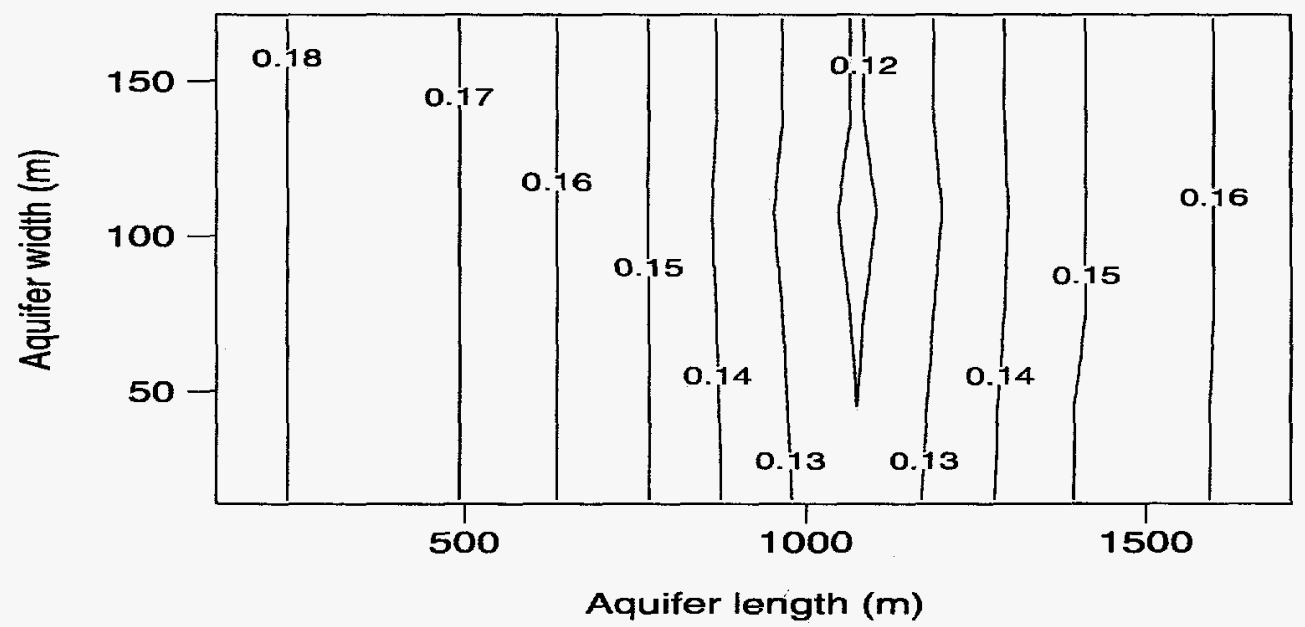

Figure 43. Toronyi saturation field at $t=78.31$ days.

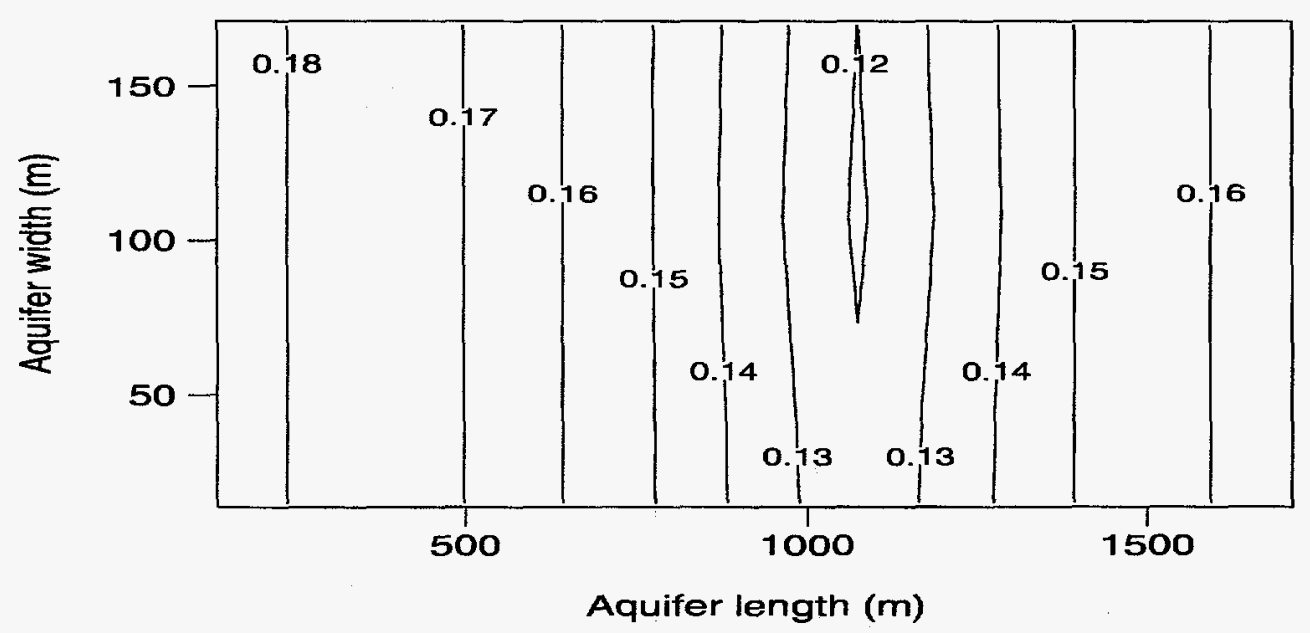

Figure 44. FEHM saturation field at $t=78.31$ days. 


\subsection{Test of DOE Code Comparison Project, Problem Five, Case A}

This test verifies that FEHM has correctly implemented heat and mass transfer and phase partitioning. Figures 45 and 46 show that FEHM results are in good agreement with the other code solutions for the simulation of the DOE Code Comparison Project Problem. The results of the numerical comparison to the other code solutions are given in Table 52. The maximum absolute error in temperature at the production well for this run was less than $2.1^{\circ} \mathrm{C}$, the maximum absolute error in pressure at the production well for this run was less than $0.07 \mathrm{MPa}$, the maximum absolute error in pressure at the observation well for this run was less than $0.04 \mathrm{MPa}$, and the percent errors were all less than $3 \%$. These results meet the acceptance criteria for this test suite developed in Chapter III.

\begin{tabular}{|c|c|c|c|}
\hline \multicolumn{4}{|c|}{$\begin{array}{l}\text { Table 52. Results of the test of the DOE Code Comparison Project } \\
\text { Problem }\end{array}$} \\
\hline V\&V test & Maximum error & Maximum \% error & RMS error \\
\hline \multicolumn{4}{|c|}{ Temperature at production node } \\
\hline Code 1 & 1.356 & 0.6531 & $0.7746 e-03$ \\
\hline Code 2 & 1.519 & 0.6469 & $0.1070 e-02$ \\
\hline Code 3 & 1.623 & 0.6867 & $0.1259 e-02$ \\
\hline Code 4 & 2.003 & 0.8526 & $0.1139 e-02$ \\
\hline Code 5 & 1.498 & 0.7299 & $0.9932 e-03$ \\
\hline Code 6 & 1.368 & 0.5906 & $0.1379 e-02$ \\
\hline \multicolumn{4}{|c|}{ Pressure at production node } \\
\hline Code 1 & $0.5123 e-01$ & 1.581 & $0.1908 e-02$ \\
\hline Code 2 & $0.6127 e-01$ & 2.022 & $0.3137 e-02$ \\
\hline Code 3 & $0.5347 e-01$ & 1.770 & $0.3235 e-02$ \\
\hline Code 4 & $0.6234 \mathrm{e}-01$ & 2.057 & $0.3017 e-02$ \\
\hline Code 5 & $0.2150 \mathrm{e}-01$ & 0.7165 & $0.1199 e-02$ \\
\hline Code 6 & $0.2828 e-01$ & 0.9396 & $0.1637 e-02$ \\
\hline \multicolumn{4}{|c|}{ Pressure at observation node } \\
\hline Code 1 & $0.2530 \mathrm{e}-01$ & 0.7312 & $0.8879 e-03$ \\
\hline Code 2 & $0.2534 \mathrm{e}-01$ & 0.7610 & $0.7676 e-03$ \\
\hline Code 3 & $0.1656 \mathrm{e}-01$ & 0.4841 & $0.8250 e-03$ \\
\hline Code 4 & $0.2215 \mathrm{e}-01$ & 0.6652 & $0.7065 e-03$ \\
\hline Code 5 & $0.3449 \mathrm{e}-01$ & 1.042 & $0.1879 e-02$ \\
\hline Code 6 & $0.3446 \mathrm{e}-01$ & 1.041 & $0.2547 e-02$ \\
\hline \multicolumn{4}{|c|}{$\begin{array}{l}\text { FModelers } \\
\text { Code } 1 \text { - Geotrans, Inc. } \\
\text { Code } 2 \text { - Intercomp } \\
\text { Code } 3 \text { - Lawrence Berkeley Laboratory (LBL) } \\
\text { Code } 4 \text { - Systems, Science and Software (S-Cubed) } \\
\text { Code } 5 \text { - Stanford University } \\
\text { Code } 6 \text { - University of Auckland, New Zealand }\end{array}$} \\
\hline
\end{tabular}




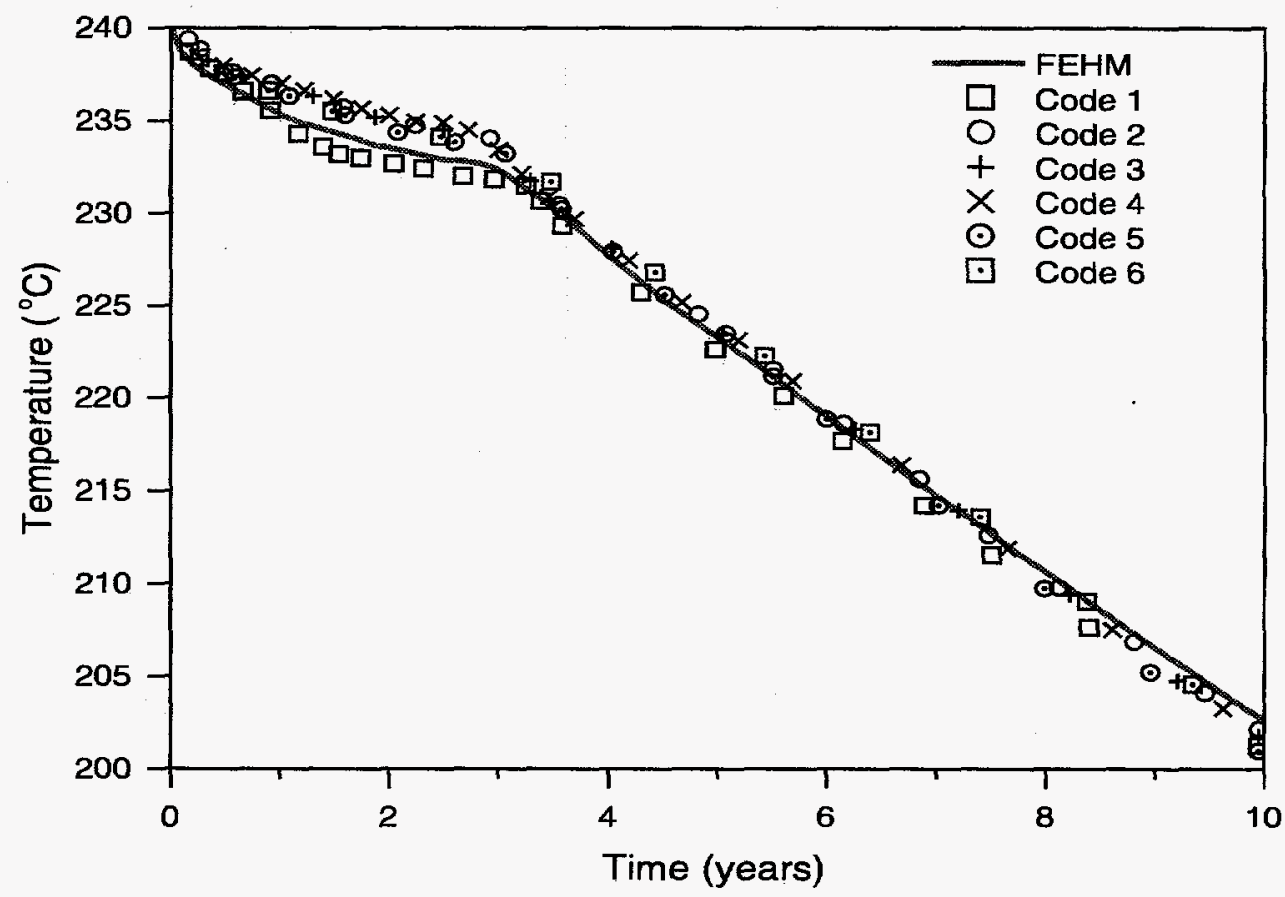

Figure 45. Comparison of FEHM production-well temperatures with results from other codes.

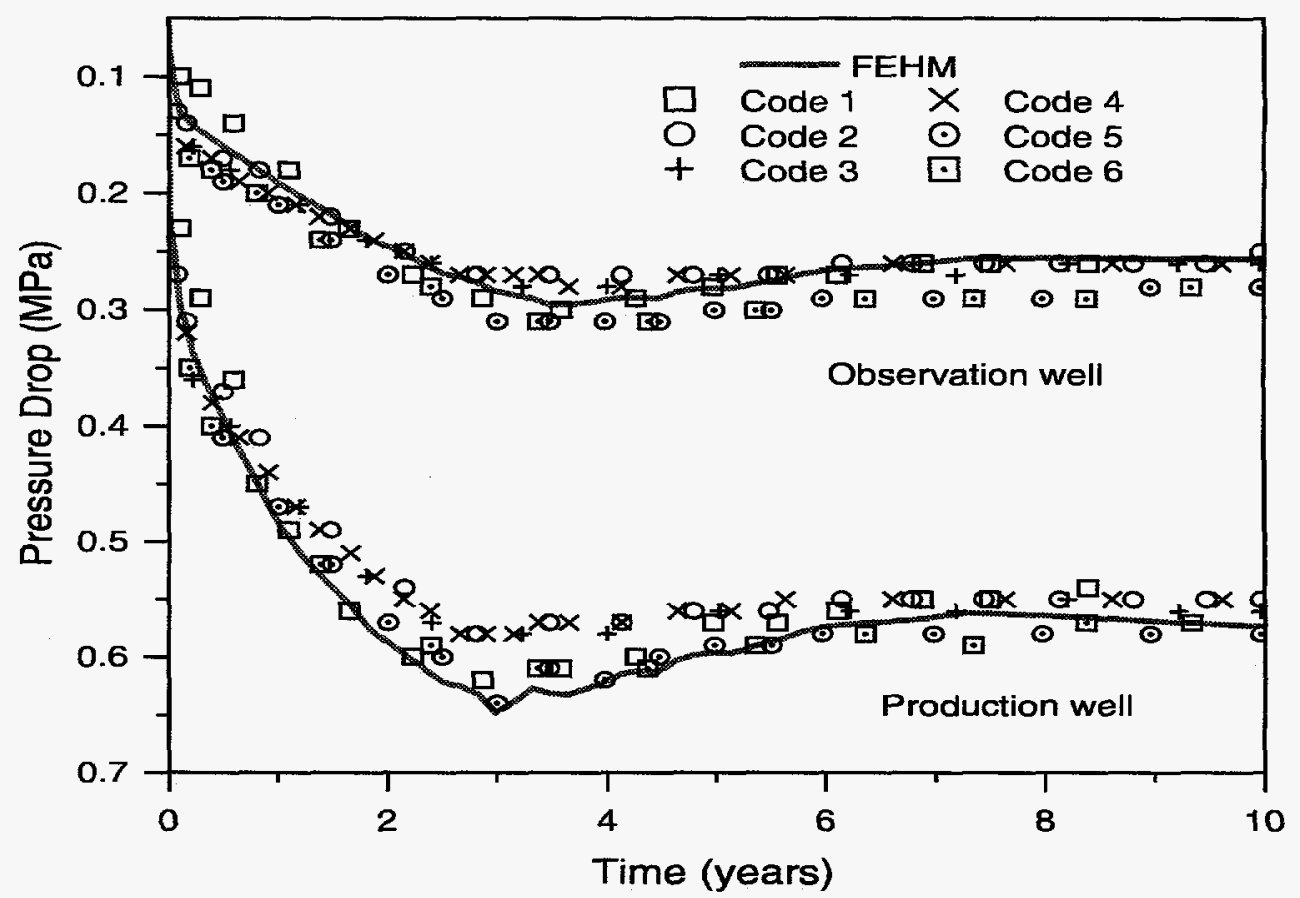

Figure 46. Comparison of FEHM production- and observation-well pressure drops with results from other codes. 


\subsection{Test of Dry-out of a Partially Saturated Medium}

This test verifies that FEHM has correctly implemented the heat- and masstransfer problem that combines water, water vapor, air, and heat transport. Figure 47 shows that the dry-out front computed using FEHM agrees closely with the analytical solution (results found in files dryout.analyt2-6) presented in Chapter III for systems with and without vapor-pressure lowering. The region of dried-out rock proceeds as a sharp front with little spreading, and the rate of movement predicted by the code agrees well with the analytical solution. The maximum percent errors in the positions of the front (the position at which the saturation is 0.1 , or dried to $50 \%$ of its initial value of 0.2 ) are $1.3 \%$ for both the vapor-pressure lowering case and the case without vapor-pressure lowering (Table 53). Both of these errors are less than 5\%, and thus these results meet the acceptance criteria for this test suite developed in Chapter III.

\begin{tabular}{|cccc|}
\hline $\begin{array}{l}\text { Table 53. } \\
\text { Results of the test of dry-out of a partially saturated } \\
\text { medium }\end{array}$ & \multicolumn{3}{l|}{} \\
\hline V\&V test & Maximum error & Maximum \% error & RMS error \\
\hline \hline Dryout front versus time w/o vapor-pressure lowering & \\
Time 100 days & $0.6392 \mathrm{e}-04$ & 0.2623 & $0.1311 \mathrm{e}-02$ \\
Time 200 days & $0.2675 \mathrm{e}-03$ & 0.5489 & $0.2744 \mathrm{e}-02$ \\
Time 300 days & $0.6338 \mathrm{e}-03$ & 0.8669 & $0.4334 \mathrm{e}-02$ \\
Time 400 days & $0.1076 \mathrm{e}-02$ & 1.104 & $0.5518 \mathrm{e}-02$ \\
Time 500 days & $0.1585 \mathrm{e}-02$ & 1.301 & $0.6504 \mathrm{e}-02$ \\
\hline Dryout front versus time with vapor-pressure lowering & & \\
Time 200 days & $0.3110 \mathrm{e}-03$ & 1.276 & $0.6380 \mathrm{e}-02$ \\
Time 400 days & $0.2973 \mathrm{e}-03$ & 0.6099 & $0.3050 \mathrm{e}-02$ \\
Time 600 days & $0.8632 \mathrm{e}-04$ & 0.1181 & $0.5903 \mathrm{e}-03$ \\
Time 800 days & $0.2393 \mathrm{e}-03$ & 0.2454 & $0.1227 \mathrm{e}-02$ \\
Time 1000 days & $0.6580 \mathrm{e}-03$ & 0.5399 & $0.2700 \mathrm{e}-02$ \\
\hline
\end{tabular}



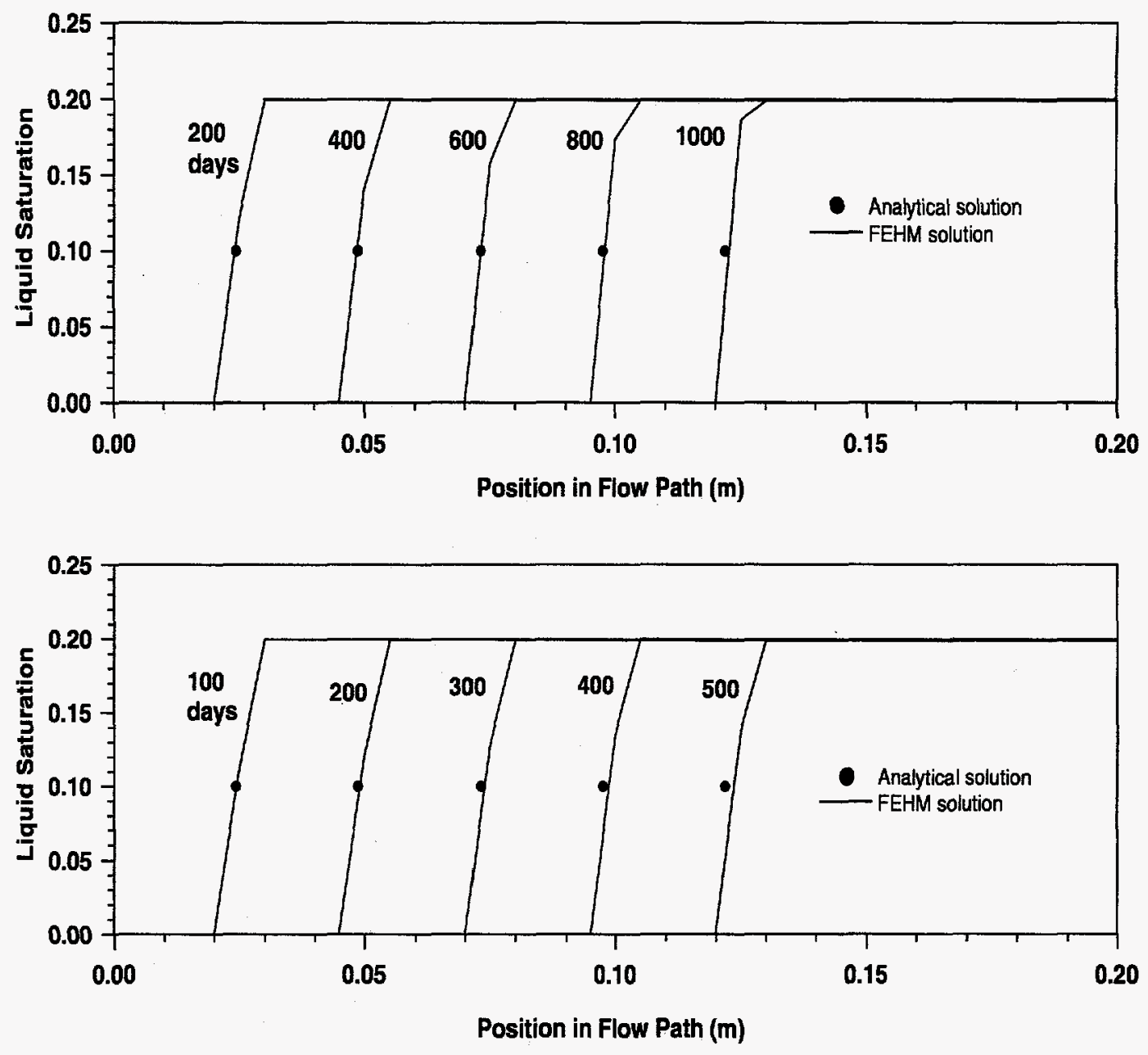

Figure 47. Comparison of FEHM and analytical solutions for the position of a dry-out front in a partially saturated medium. Cases with (top) and without (bottom) the effects of vaporpressure lowering are included. 


\section{4:12 Test of Reactive-Tracer Transport}

This test verifies that FEHM has correctly implemented reactive-tracer transport. Figures 48 to 52 show that FEHM results are in good agreement with the SORBEQ solutions. The results, compared numerically to the SORBEQ solutions (found in files sorbeq_out.cons, sorbeq_out.fr, sorbeq_out.lang, sorbeq_out.lin, and sorbeq_out.mfr) are given in Table 54. The maximum absolute error in concentration for the five isotherms was less than 0.0104 , and the percent errors were less than $10 \%$ when concentrations were greater than 0.1 . These results meet the acceptance criteria for this test suite developed in Chapter III.

\section{Table 54. Results of the test of reactive-tracer transport}

\begin{tabular}{|lccc|}
\hline \multicolumn{1}{|c}{ V\&V test } & Maximum error & Maximum \% error & RMS error \\
\hline \hline Concentration versus time at the outlet node & & \\
Conservative & $0.9809 \mathrm{e}-02$ & 9.599 & $0.2936 \mathrm{e}-03$ \\
Linear & $0.4474 \mathrm{e}-02$ & 2.258 & $0.1798 \mathrm{e}-03$ \\
Langmuir & $0.9049 \mathrm{e}-02$ & 5.486 & $0.2411 \mathrm{e}-03$ \\
Freundlich & $0.6322 \mathrm{e}-02$ & 6.252 & $0.2531 \mathrm{e}-03$ \\
Modified Freundlich & $0.1040 \mathrm{e}-01$ & 3.060 & $0.2269 \mathrm{e}-03$ \\
\hline
\end{tabular}

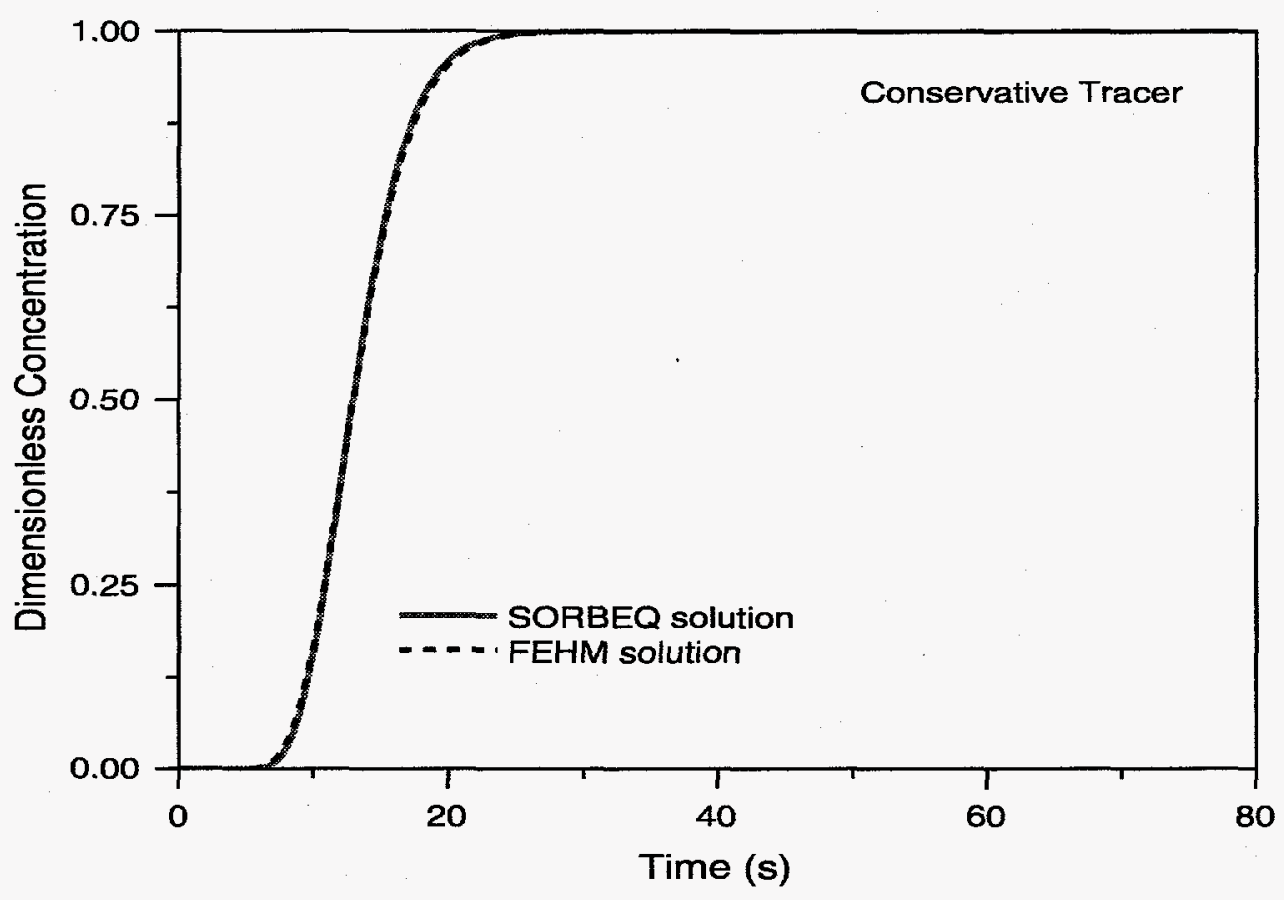

Figure 48. Comparison of FEHM and SORBEQ outlet concentrations for the conservative tracer. 


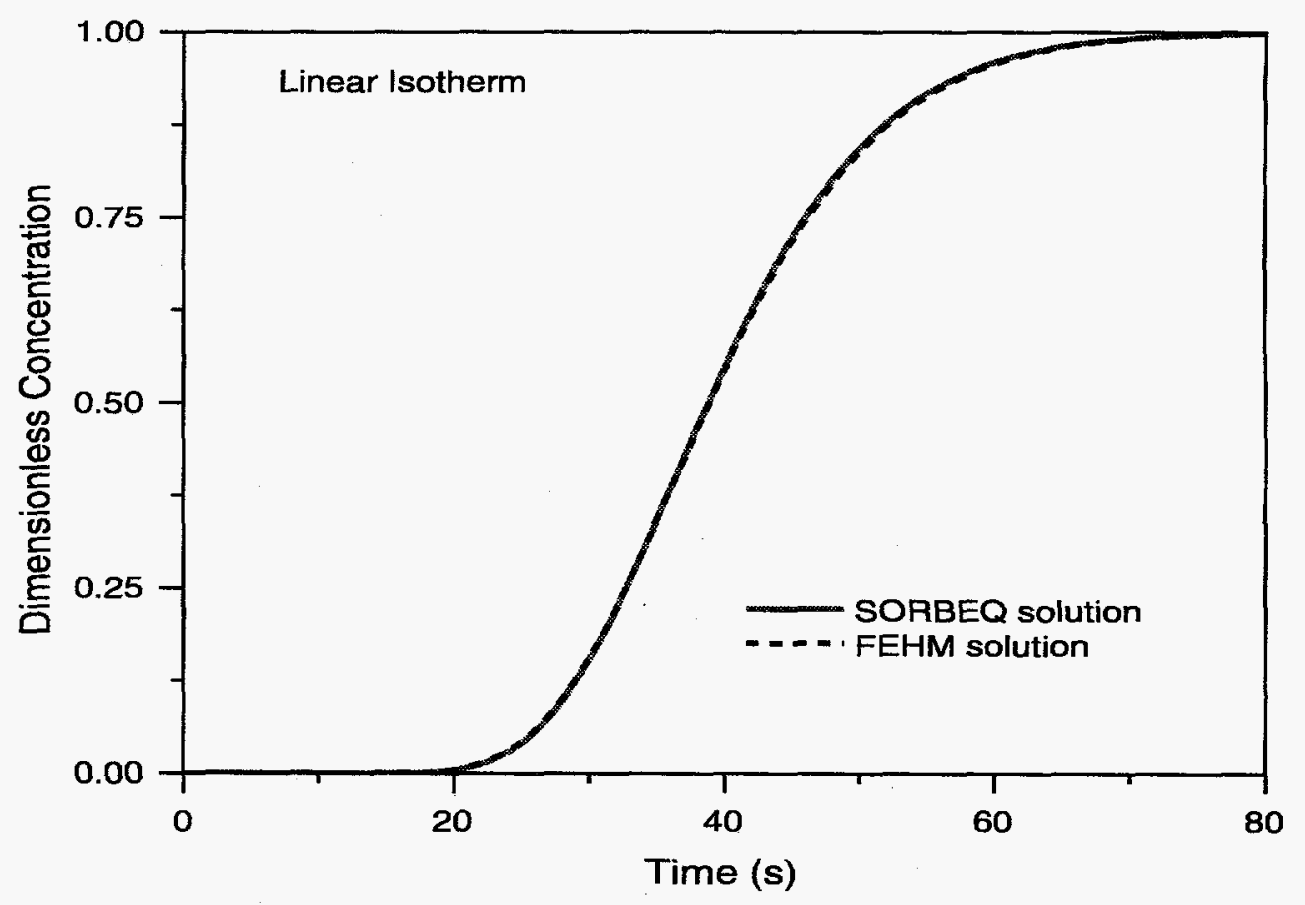

Figure 49. Comparison of FEHM and SORBEQ outlet concentrations for the linear isotherm.

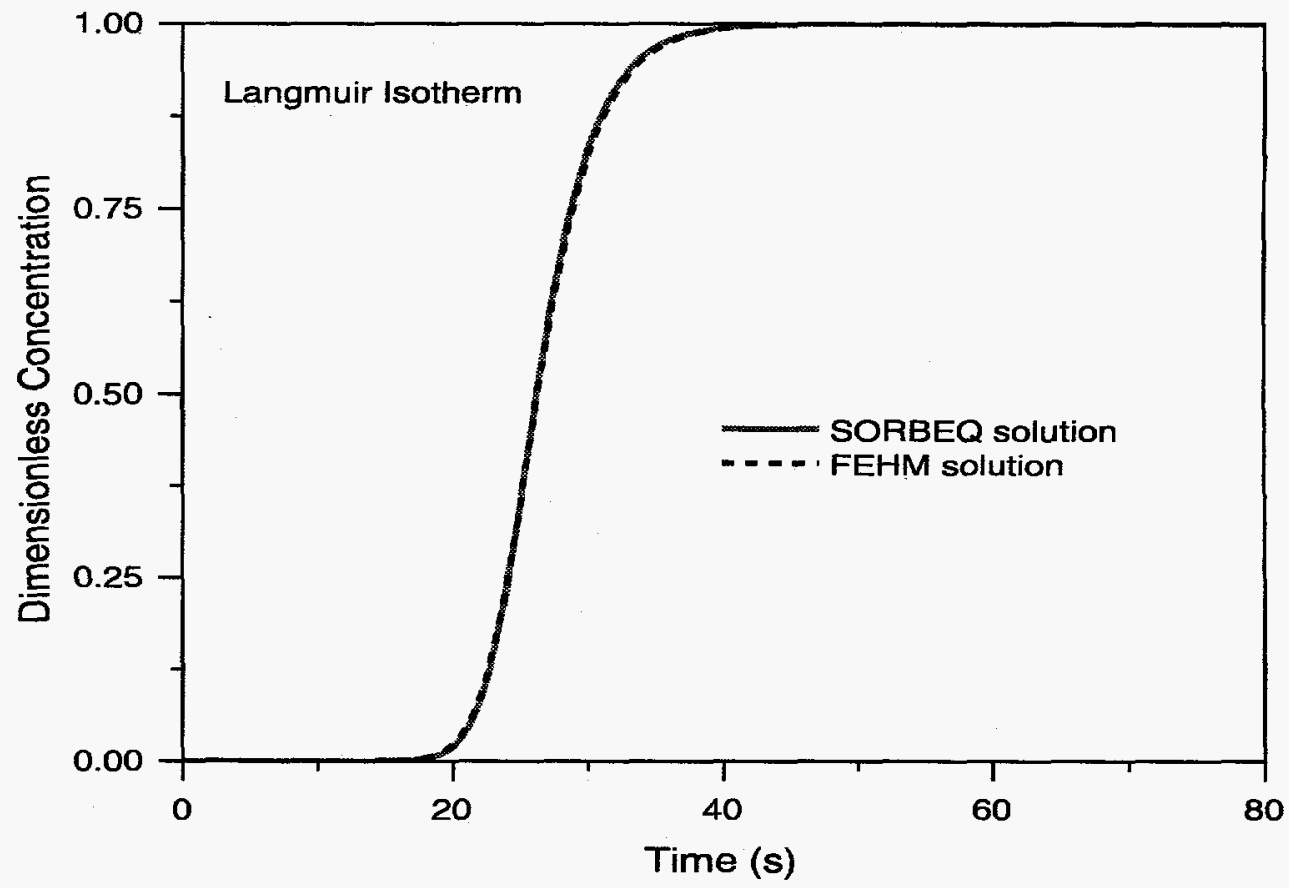

Figure 50. Comparison of FEHM and SORBEQ outlet concentrations for the Langmuir isotherm. 


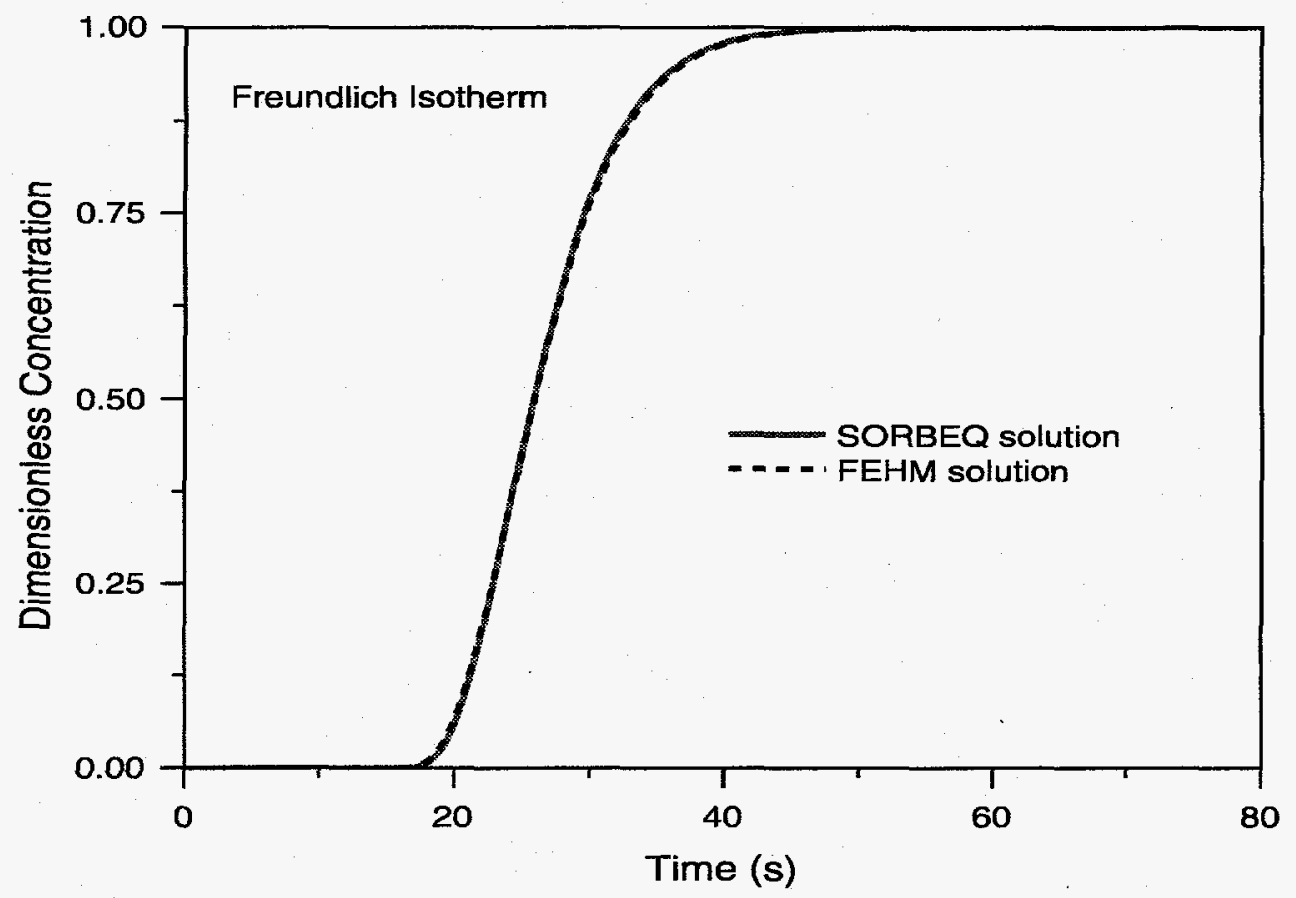

Figure 51. Comparison of FEHM and SORBEQ outlet concentrations for the Freundlich isotherm.

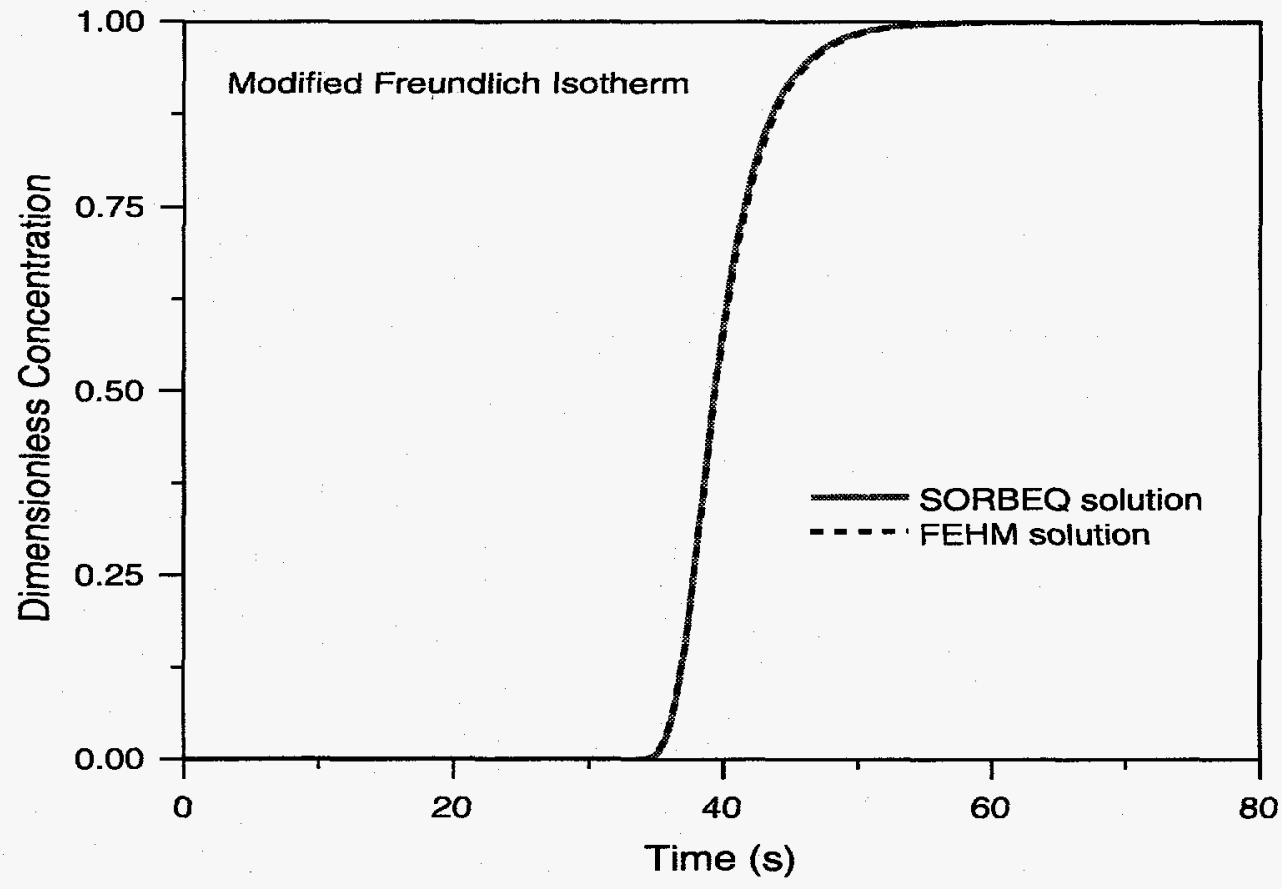

Figure 52. Comparison of FEHM and SORBEQ outlet concentrations for the modified Freundlich isotherm. 


\subsection{Test of Henry's Law Species}

\subsubsection{Air movement through stagnant water}

This test verifies that FEHM has correctly implemented Henry's law solutes for air moving through a stagnant fluid phase. Figure 53 shows that FEHM results are in good agreement with the analytical solution. The results, compared numerically to the analytical solution (found in file henry1_out.analyt), are given in Table 55. The maximum absolute error for cases 1-1, 1-2, and 1-3 was less than 0.0027, and the percent errors were less than $3 \%$ for concentrations greater than 0.1 . These results meet the acceptance criteria for this test suite developed in Chapter III.

\begin{tabular}{|c|c|c|c|}
\hline V\&V test & Maximum error & Maximum \% error & RMS error \\
\hline \multicolumn{4}{|c|}{ Concentration versus time at the outlet node } \\
\hline $1-1$ & $0.2594 \mathrm{e}-02$ & 1.877 & $0.2024 \mathrm{e}-03$ \\
\hline $1-2$ & $0.2615 e-02$ & 2.144 & $0.2336 e-03$ \\
\hline $1-3$ & $0.2583 e-02$ & 2.122 & $0.2309 e-03$ \\
\hline $2-1$ & $0.3281 e-02$ & 6.645 & $0.3447 e-03$ \\
\hline $2-2$ & $0.2837 e-02$ & 4.858 & $0.2306 e-03$ \\
\hline $2-3$ & $0.2910 \mathrm{e}-02$ & 4.927 & $0.2358 e-03$ \\
\hline 3-1, species 1 & $0.8266 e-03$ & 7.030 & $0.1795 e-03$ \\
\hline \multicolumn{4}{|c|}{ Final concentration at the outlet node } \\
\hline $3-1$, species 2 & $0.8190 \mathrm{e}-03$ & 0.2158 & $0.2158 e-02$ \\
\hline 3-2, species 1 & $0.5993 e-03$ & 0.1579 & $0.1579 e-02$ \\
\hline 3-2, species 2 & $0.3797 e-03$ & 0.1000 & $0.1000 e-02$ \\
\hline 3-3, species 1 & $0.1727 e-03$ & $0.4549 \mathrm{e}-01$ & $0.3164 e-03$ \\
\hline 3-3, species 2 & $0.4240 \mathrm{e}-03$ & 0.1117 & $0.7845 e-03$ \\
\hline
\end{tabular}

\subsubsection{Water movement through stagnant air}

This test verifies that FEHM has correctly implemented Henry's Law solutes for water moving through a stagnant air phase. Figure 54 shows that FEHM results are in good agreement with the analytical solution. The results, compared numerically to the analytical solution (found in file henry2_out.analyt), are given in Table 55. The maximum absolute error for cases 2-1, 2-2, and 2-3 was less than 0.0033 , and the percent errors were less than $7 \%$ when concentrations were greater than 0.1 . These results meet the acceptance criteria for this test suite developed in Chapter III. 


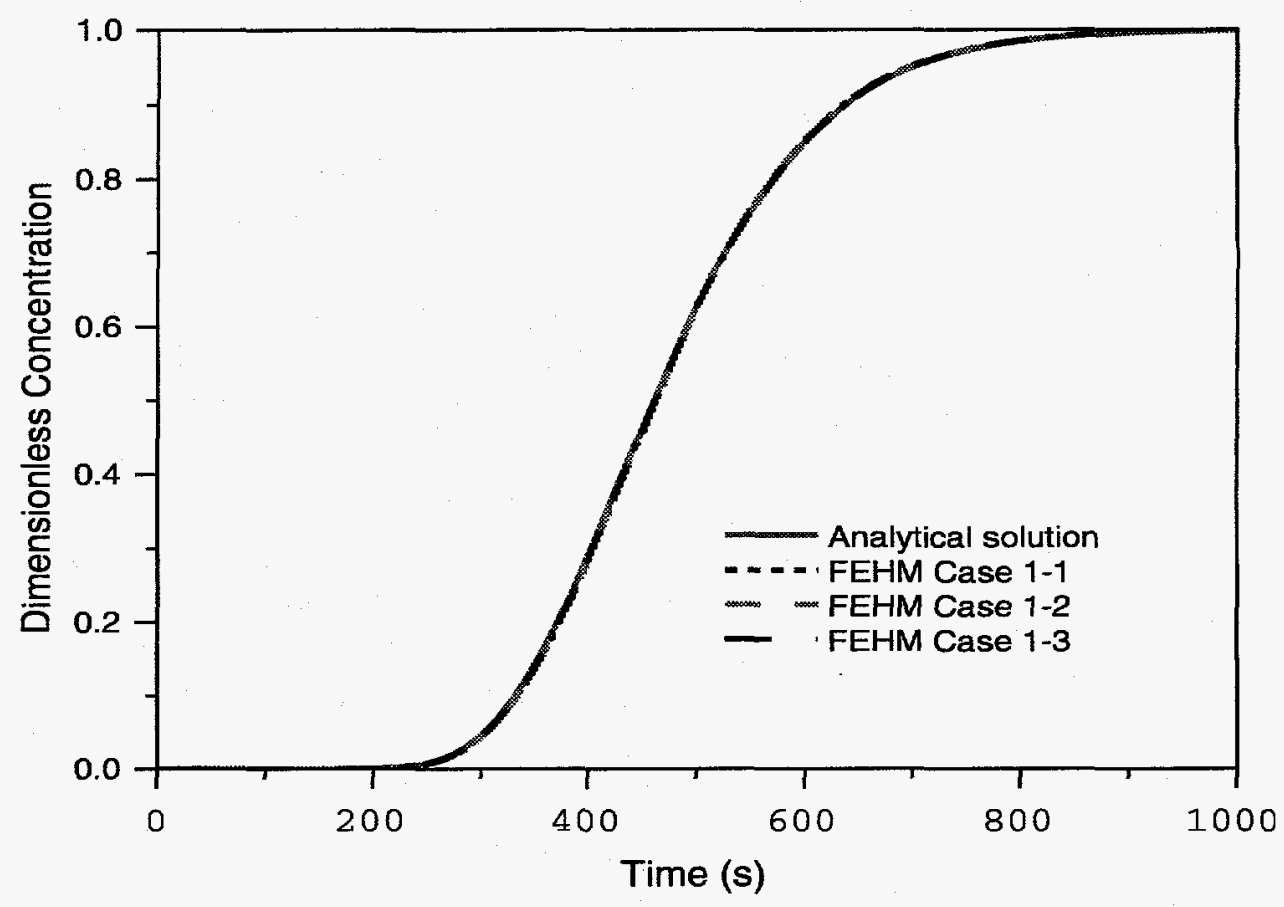

Figure 53. Comparison of FEHM results with the analytical solution for a mobile air phase.

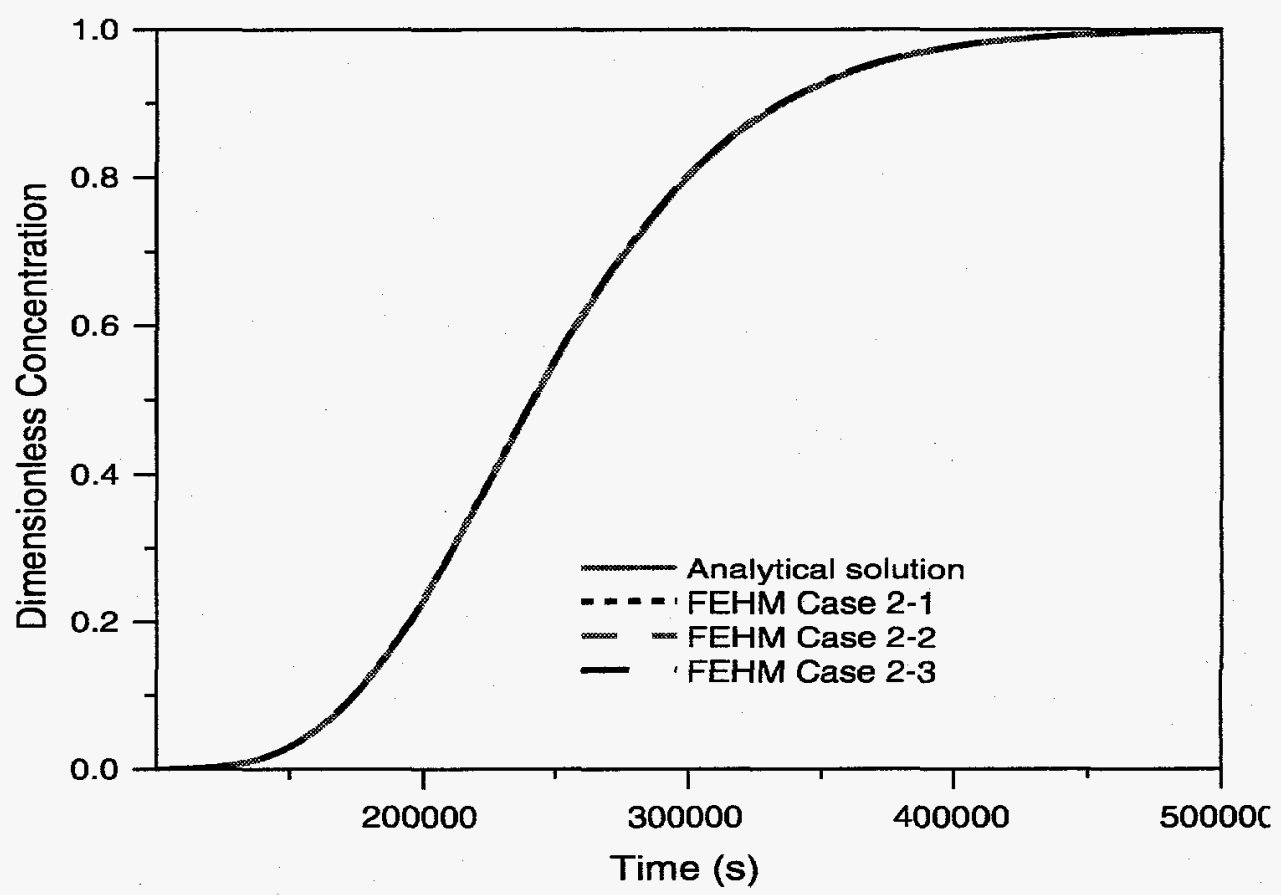

Figure 54. Comparison of FEHM results with the analytical solution for a mobile water phase. 


\subsubsection{Air/water movement through stagnant water/air with chemical reaction}

This test verifies that FEHM has correctly implemented Henry's Law solutes that may sorb or undergo chemical reaction. Figure 55 shows that FEHM results are in good agreement with the analytical solution, i.e., for case $3-1$, species 1 , the breakthrough curve appears the same as the analytical solution. The results, compared numerically to the analytical solution (found in file henry3_out.analyt), are given in Table 55. The maximum absolute error for case $3-1$, species 1 , was less than 0.00083 , and the percent error was less than $8 \%$ when concentrations were greater than 0.1. The maximum absolute error for cases 3-1, 3-2, and 3-3 for the final concentration was less than 0.00082 , and the percent errors were less than $\mathbf{0 . 3 \%}$. It should be noted for these cases that the RMS error is essentially a single point average. These results meet the acceptance criteria for this test suite developed in Chapter III.

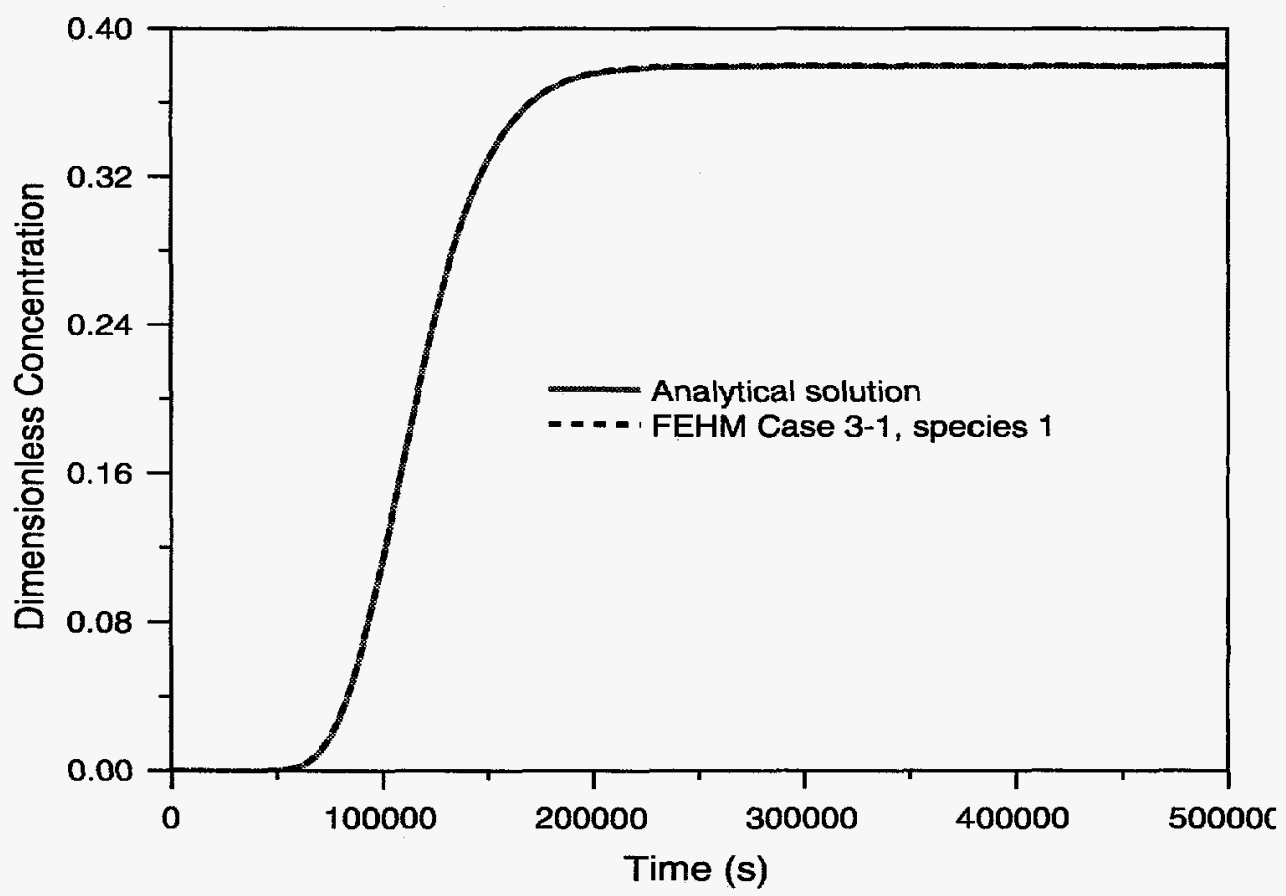

Figure 55. Comparison of FEHM results with the analytical solution for a mobile water phase with reactions. 


\subsection{Test of Fracture Transport With Matrix Diffusion}

This test verifies that FEHM has correctly implemented the solute transport solution with equilibrium sorption in two dimensions. Figure 56 shows that FEHM's numerical solution is in good agreement with the analytical solution of Tang et al. (1981) for test cases that include matrix diffusion with no sorption, sorption in the matrix, and sorption on the fracture surfaces and in the matrix. The slight discrepancies are probably due to numerical errors associated with insufficiently small grid spacings adjacent to the fracture. This would render the solution inaccurate at early times in the simulation when concentration gradients near the fracture are largest. Nonetheless, the agreement is almost certainly adequate for any analysis that would be made using these model results. The results, compared numerically to the analytical solution (found in files tang1.analyt, tang2.analyt, and tang3.analyt), are given in Table 56. The maximum absolute error for these runs was less than 0.028 , and the maximum percent errors ranged from 4.7 to $13.4 \%$ for concentration values greater than 0.1 . The RMS error ranged from 0.0014 to 0.0022 . These results meet the acceptance criteria for this test suite developed in Chapter III.

\begin{tabular}{|cccc|}
\hline \multicolumn{4}{|c|}{ Table 56. Results of the fracture-transport/matrix-diffusion test } \\
\hline V\&V test & Maximum error & Maximum \% error & RMS error \\
\hline \hline Concentration versus time at the outlet node & & \\
No sorption & $0.2810 \mathrm{e}-01$ & 9.094 & $0.1412 \mathrm{e}-02$ \\
Matrix sorption & $0.1759 \mathrm{e}-01$ & 13.38 & $0.2205 \mathrm{e}-02$ \\
Fracture and matrix sorption & $0.1707 \mathrm{e}-01$ & 4.662 & $0.2108 \mathrm{e}-02$ \\
\hline
\end{tabular}

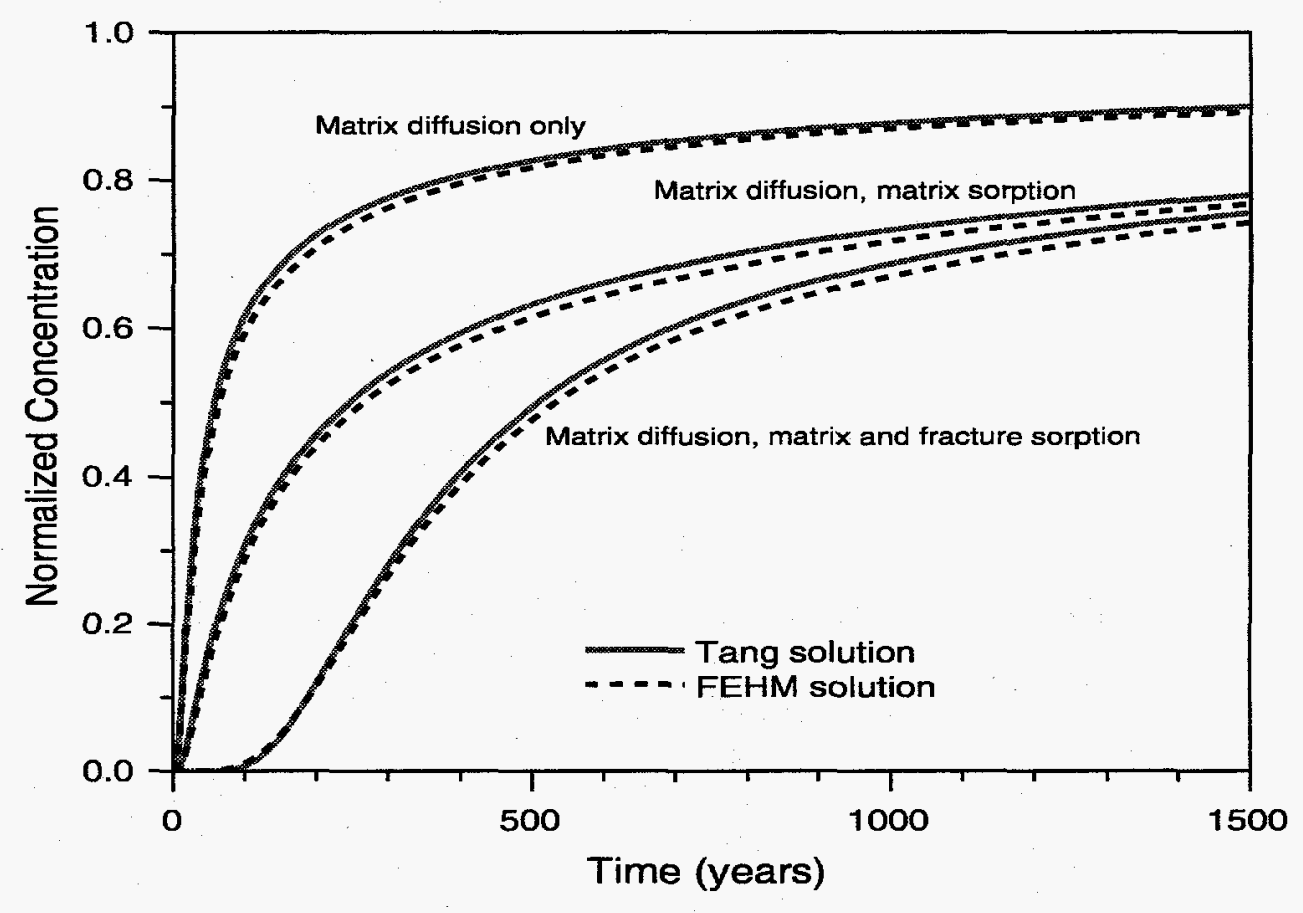

Figure 56. Comparison of FEHM and Tang analytical solutions for concentration versus time for the matrix-diffusion model. 


\subsection{Test of the Movement of a Dissolved Mineral Front}

This test verifies that FEHM has correctly implemented the reactive transport system consisting of one-dimensional transport with the movement of a dissolved mineral front. Figure 57 compares the front location and shape simulated using FEHM to that predicted from the analytical solution. The results agree closely, with FEHM's numerical results exhibiting a very slight spreading of the dissolution front. Nonetheless, the position of the front agrees with the predicted value (found in files dissolution.analyt2, dissolution.analyt3, and dissolution.analyt4) to within a maximum error of $3.9 \%$. This error is less than $5 \%$, and these results meet the acceptance criteria for this test suite developed in Chapter III. It should be noted for this problem that the RMS error is a single point average for each time.

\begin{tabular}{|cccc|}
\hline $\begin{array}{c}\text { Table 57. Results of a test of the movement of a dissolved mineral } \\
\text { front }\end{array}$ & & & \\
\hline V\&V test & Maximum error & Maximum \% error & RMS error \\
\hline \hline Dissolution front versus time & & & \\
Time 20000.s & $0.2606 e-02$ & 3.889 & $0.3889 e-01$ \\
Time 60000.s & $0.3516 e-02$ & 1.749 & $0.1749 e-01$ \\
Time 100000.s & $0.7230 e-03$ & 0.2158 & $0.2158 \mathrm{e}-02$ \\
\hline
\end{tabular}

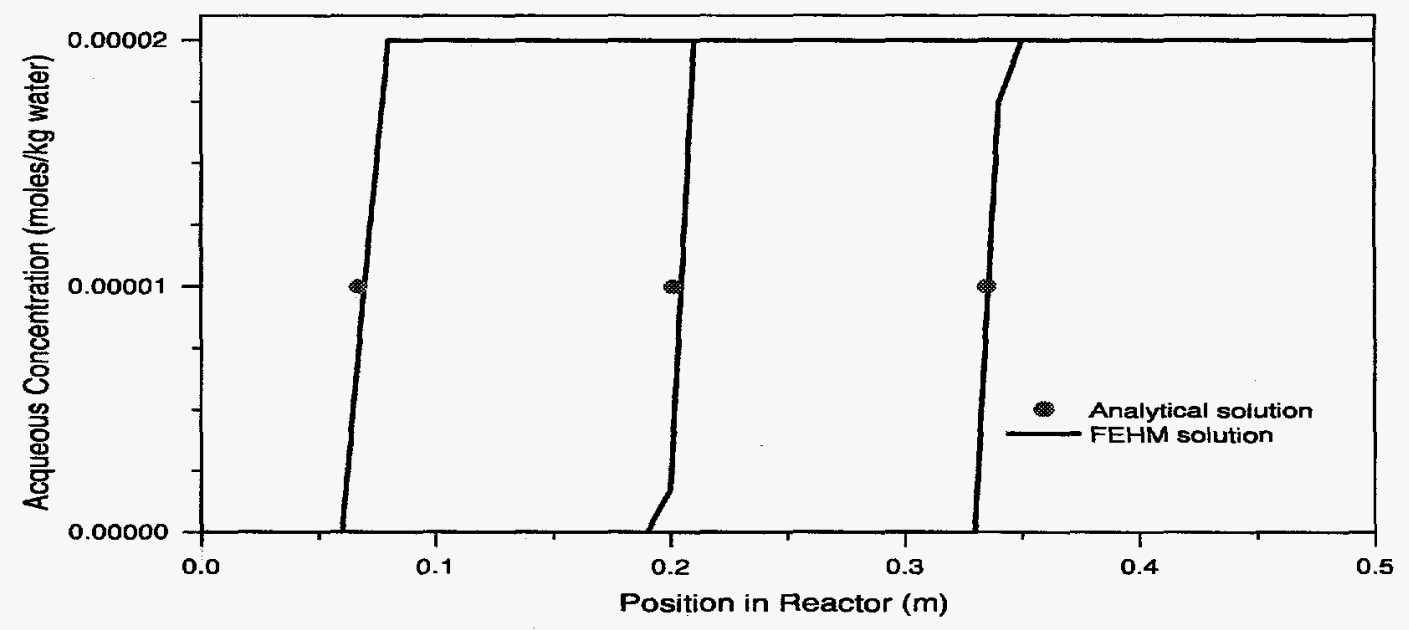

Figure 57. Comparison of FEHM and the analytical solution for the position of the dissolved mineral front at the final time of the simulation. 


\subsection{Test of Multisolute Transport with Chemical Reaction}

This test verifies that FEHM has correctly implemented the transport of multiple, chemically interacting species in solution for a mixed kinetic and equilibrium reaction system. Figure 58 compares the breakthrough curves for aqueous species for FEHM and PDREACT, the code used for the comparison. Figure 59 compares the solid concentrations versus time at the outlet of the system for the two codes. There is excellent agreement between the two codes for this reactive-transport problem. The PDREACT ouput is found in files multi.pdreact_CoEDTA_aq.out, multi.pdreact_CoEDTA_s.out, multi.pdreact_Co_aq.out, multi.pdreact_Co_s.out, multi.pdreact_EDTA_aq.out, multi.pdreact_FeEDTA_aq.out, multi.pdreact_FeEDTA_s.out, and multi.pdreact_Fe_aq.out. Table 58 indicates that the percent errors of all species at the outlet were less than $6 \%$ for concentrations greater than $10 \%$ of their peak values. These results meet the acceptance criteria for this test suite developed in Chapter III. Numerical results for aqueous EDTA and $F e$ are not considered because the concentrations are very near zero, and at such low concentrations, a good measure of error is not available.

\begin{tabular}{|c|c|c|c|}
\hline V\&V test & Maximum error & Maximum \% error & RMS error \\
\hline \multicolumn{4}{|c|}{ Aqueous-species concentration versus time } \\
\hline Co & $0.4797 e-05$ & 1.591 & $0.9782 \mathrm{e}-03$ \\
\hline CoEDTA & $0.1389 \mathrm{e}-03$ & 3.386 & $0.2229 e-02$ \\
\hline FeEDTA & $0.4176 e-04$ & 2.238 & $0.1602 \mathrm{e}-02$ \\
\hline \multicolumn{4}{|c|}{ Solid-species concentration versus time } \\
\hline $\mathrm{Co}$ & $0.2270 \mathrm{e}-04$ & 1.660 & $0.9846 e-03$ \\
\hline CoEDTA & $0.7516 e-04$ & 5.608 & $0.3216 e-02$ \\
\hline FeEDTA & $0.2771 e-04$ & 3.199 & $0.2135 \mathrm{e}-02$ \\
\hline
\end{tabular}




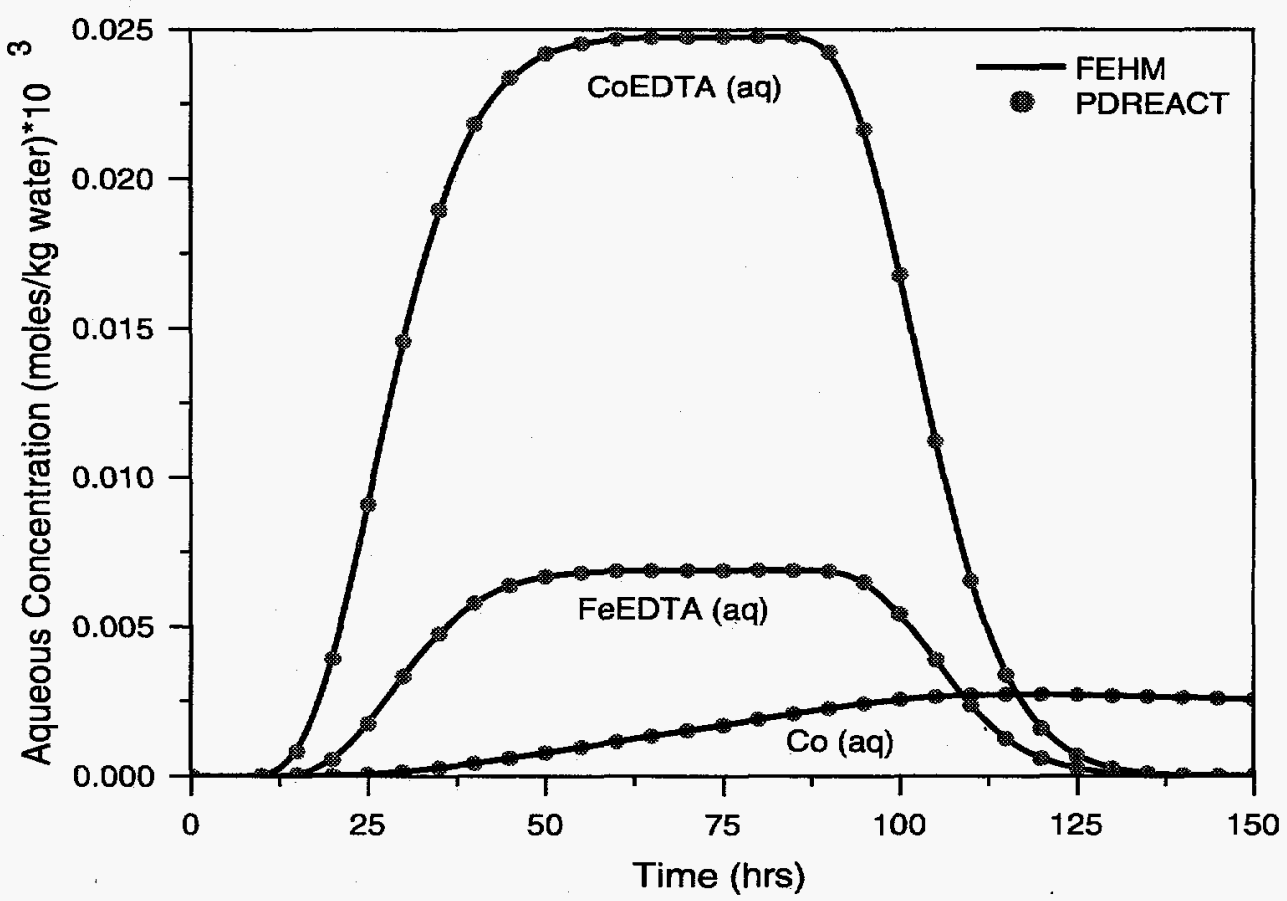

Figure 58. Comparison of FEHM and PDREACT for the breakthrough curves of aqueous species.

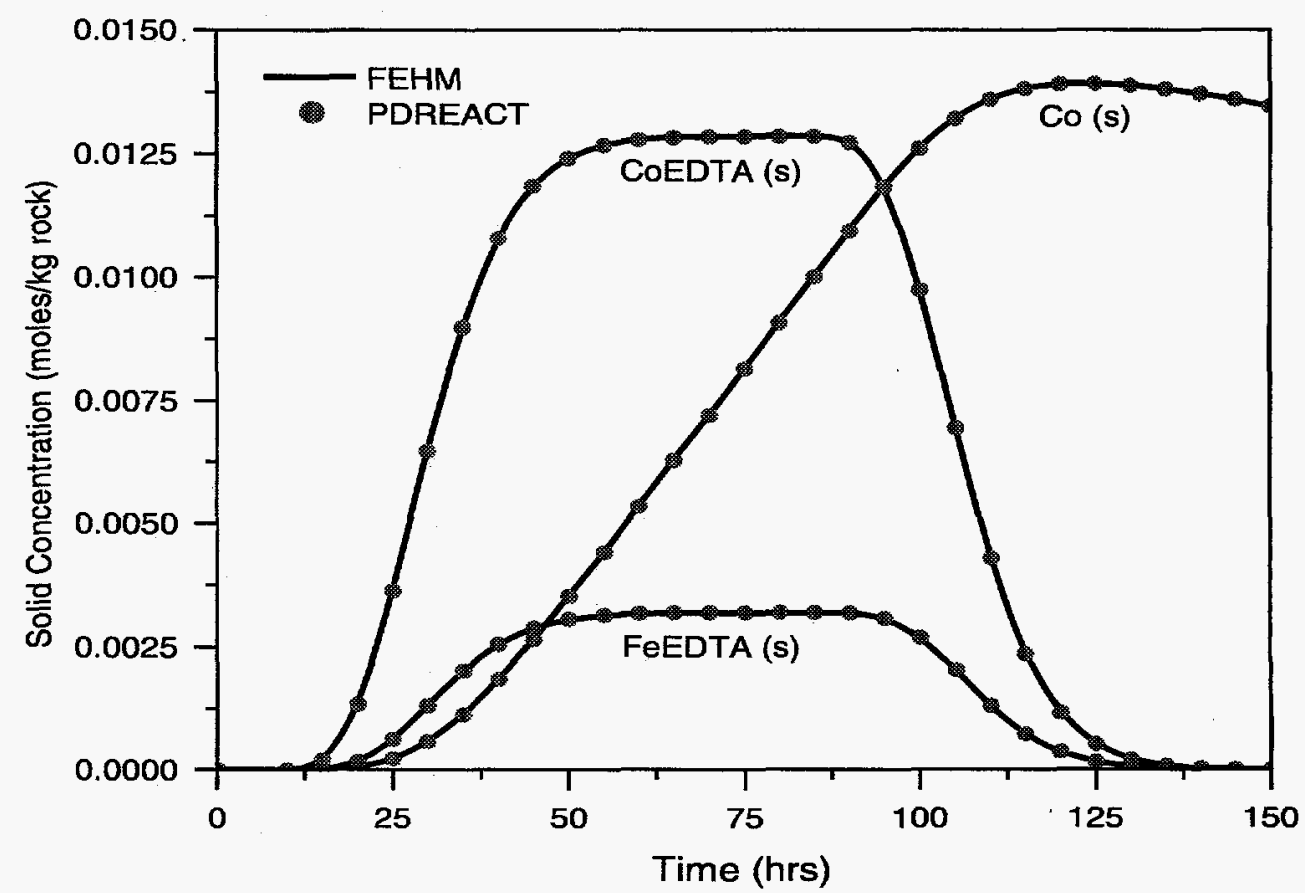

Figure 59. Comparison of FEHM and PDREACT for the exit concentration versus time for solid species. 


\subsection{Test of Three-dimensional Radionuclide Transport with Decay Chain}

This test verifies that FEHM has correctly implemented the transport module when used to simulate a radionuclide decay-chain transport problem in three dimensions. Figures $60,61,62$, and 62 compare the concentration-time curves for the radionuclide and conservative tracer that were simulated using both FEHM and TRACRN, the code used for comparison, at four different positions. Regarding the code comparison, the plots indicate that FEHM and TRACRN concentrations agree quite closely at the comparison points. Results from TRACRN are found in files 3d_tracr3d_cons.out and 3d_tracr3d_am.out. Considerable concentration errors can result from only a small displacement of a breakthrough curve along the time axis because of the steep rise or fall of the concentration-time curve for a typical case, as seen by the maximum percent errors, which varied from 3 to $15 \%$. However, Table 59 indicates that the RMS errors of all species at each comparison point were less than 0.0042 (or $0.5 \%$ ) for concentrations greater than $10 \%$ of their peak values. These results meet the acceptance criteria for this test suite developed in Chapter III.

\begin{tabular}{|c|c|c|c|}
\hline \multicolumn{4}{|c|}{$\begin{array}{l}\text { Table 59. Results of the test of the three-dimensional decay-chair } \\
\text { problem }\end{array}$} \\
\hline V\&V test & Maximum error & Maximum \% error & RMS error \\
\hline \multicolumn{4}{|c|}{ Conservative-tracer concentration versus time } \\
\hline Point 1 & $0.5278 e-01$ & 6.878 & $0.1268 e-02$ \\
\hline Point 2 & $0.1590 e-01$ & 10.98 & $0.1834 e-02$ \\
\hline Point 3 & $0.3643 e-02$ & 4.605 & $0.8533 e-03$ \\
\hline Point 4 & $0.1006 \mathrm{e}-02$ & 2.840 & $0.1245 e-02$ \\
\hline \multicolumn{4}{|c|}{${ }^{243} \mathrm{Am}$ concentration versus time } \\
\hline Point 1 & $0.4776 \mathrm{e}-01$ & 7.290 & $0.1468 e-02$ \\
\hline Point 2 & $0.1569 \mathrm{e}-01$ & 15.14 & $0.3431 e-02$ \\
\hline Point 3 & $0.1033 e-02$ & 12.77 & $0.3291 e-02$ \\
\hline Point 4 & $0.1965 e-04$ & 14.99 & $0.4166 e-02$ \\
\hline
\end{tabular}




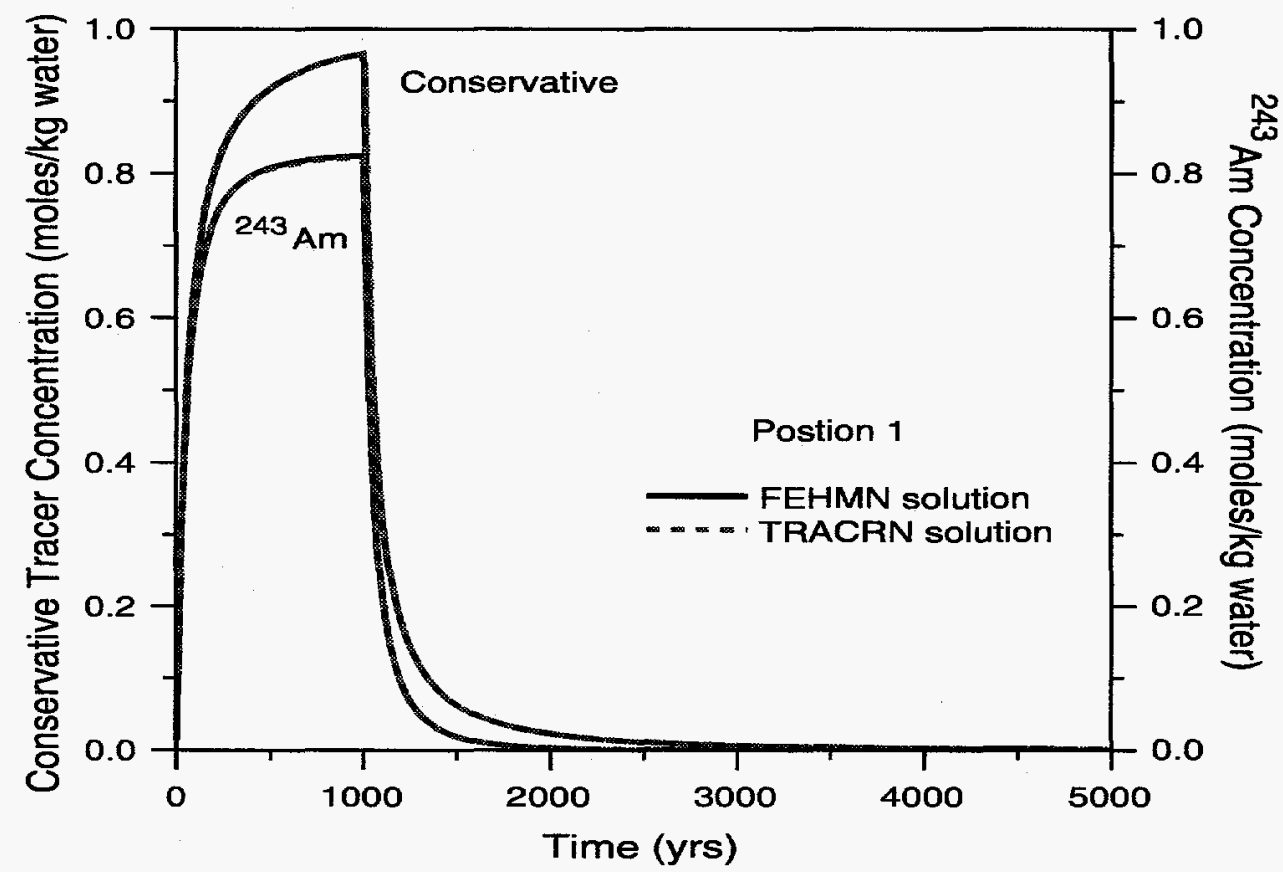

Figure 60. Comparison of FEHM and TRACRN results for the concentration-time history at position 1.

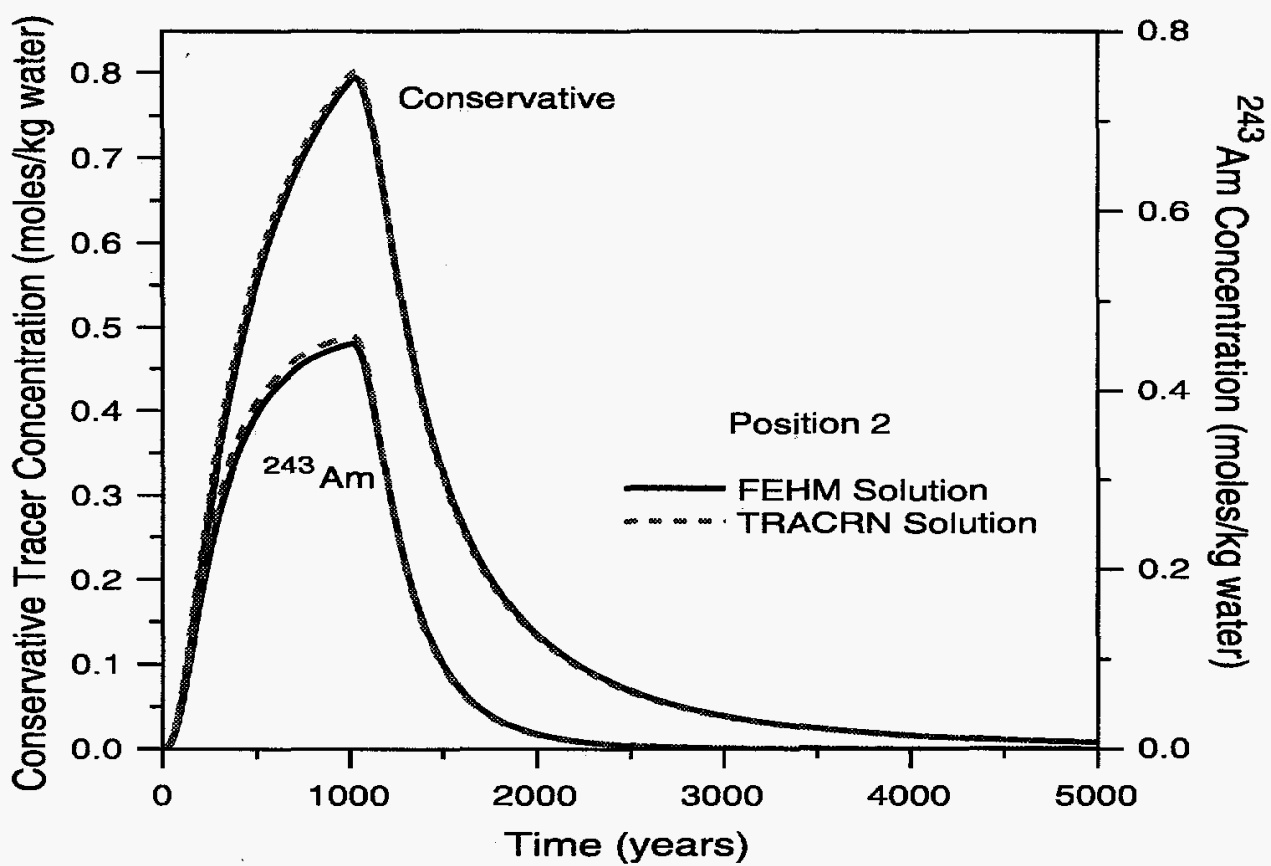

Figure 61. Comparison of FEHM and TRACRN results for the concentration-time history at position 2. 


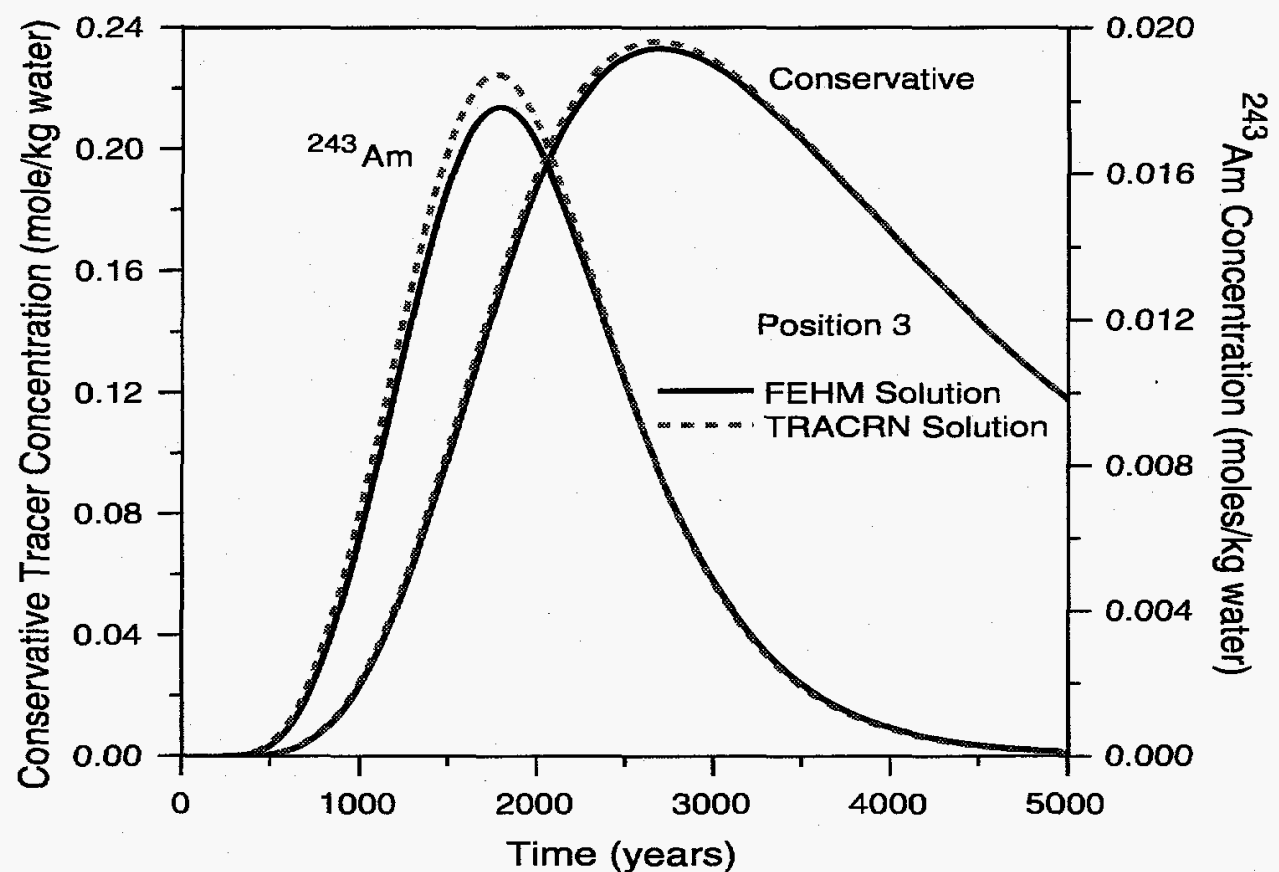

Figure 62. Comparison of FEHM and TRACRN results for the concentration-time history at position 3.

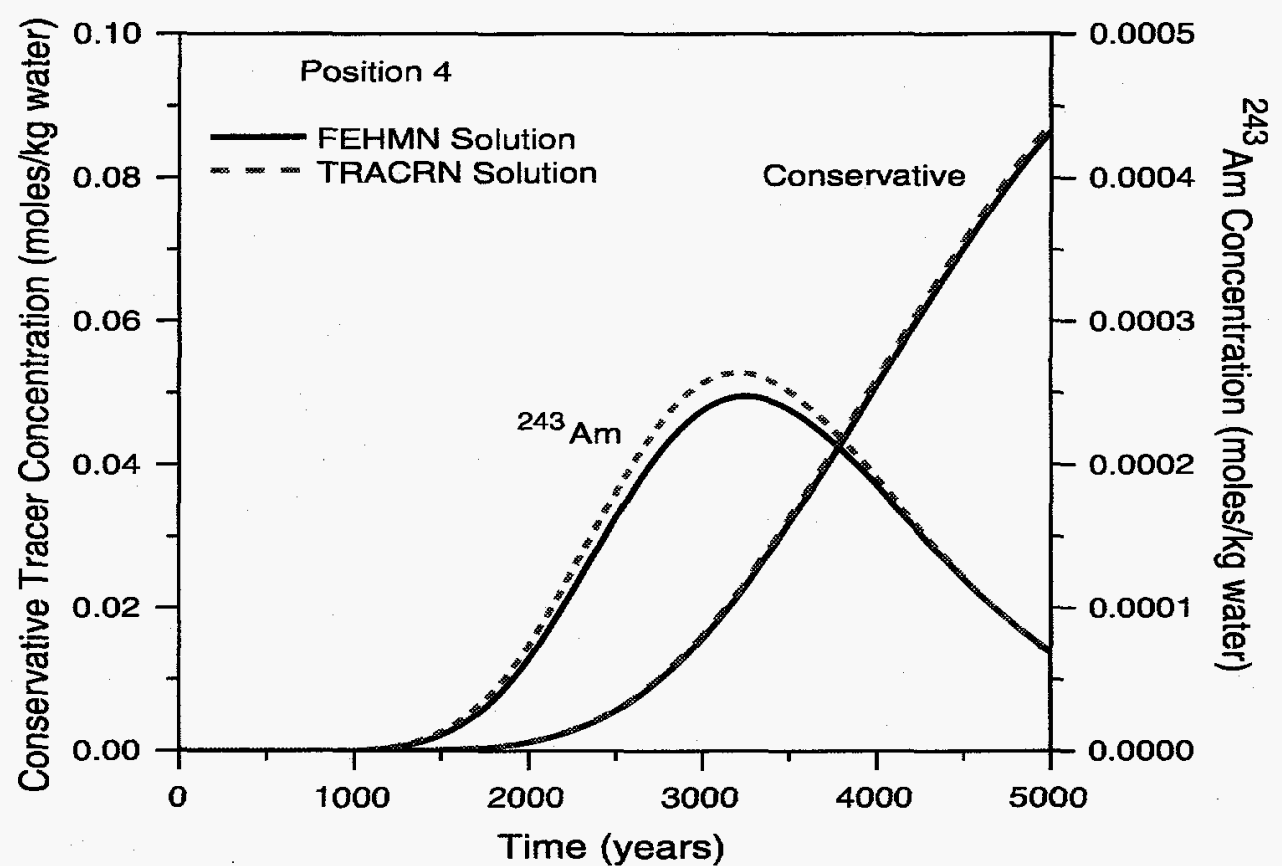

Figure 63. Comparison of FEHM and TRACRN results for the concentration-time history at position 4. 


\subsection{CONCLUSIONS AND RECOMMENDATIONS}

The computer code FEHM has been subjected to a wide range of comparison tests. The tests have been designed to verify that the underlying equations described in the FEHM document "Summary of Models and Methods" (Zyvoloski et al. 1997a) are correctly and accurately solved. FEHM proved accurate and passed all the criteria tests except one. That test involved liquid compressibility and was discussed in Section 4.1.3 of this chapter. The endeavor has been to be as complete as possible, but there are some capabilities such as particle tracking, air/water diffusion, and use of unstructured grids and some constitutive relationships (such as rock compressibility, variable thermal conductivity, and equation-of-state models) that still need testing. The testing of these features and new capabilities will be covered in future revisions of this document.

Based on the results of the verification runs specified in Chapter III, it is recommended that the FEHM Application be sanctioned for use within the Yucca Mountain Site Characterization Project for problems of the types currently tested. 
Appendix A:

\title{
Subroutine and Function Calls
}

\author{
within FEHM
}




\begin{tabular}{|c|c|c|c|}
\hline \multicolumn{4}{|c|}{ Table 1. Subroutine and function calls within FEHMN } \\
\hline Routine & Description & Calls & Called by \\
\hline main & $\begin{array}{l}\text { Program main was added above fehmn so that all } \\
\text { arrays would be allocated before being used } \\
\text { (required for the IBM). }\end{array}$ & fehmn & \\
\hline air_cp & $\begin{array}{l}\text { Compute the heat capacity of air and the derivative } \\
\text { with respect to temperature. }\end{array}$ & & thrmwc \\
\hline air_rdof & $\begin{array}{l}\text { Reduce the two-degree-of-freedom solution to } \\
\text { Richard's equation. }\end{array}$ & interblock_iso, thrair & airctr, gens 12 \\
\hline airctr & Manage the isothermal air/water calculations. & $\begin{array}{l}\text { air_rdof, gens } 12 \text {, headctr, } \\
\text { thermw, thrair, mino }\end{array}$ & $\begin{array}{l}\text { bnswer, input, startup, varchk, } \\
\text { wrtout }\end{array}$ \\
\hline allocmem & Allocate memory to dynamic variable arrays. & mmgetblk, storage_derivatives & fehmn \\
\hline angle3 & $\begin{array}{l}\text { Determine the angles of rotation needed to point the } \\
\mathrm{z} \text {-axis from mass point ' } \mathrm{i} \text { ' to neighbor ' } \mathrm{j} \text { '. }\end{array}$ & sqrt & eullag3 \\
\hline anonp & $\begin{array}{l}\text { Categorize elements and call routines to generate } \\
\text { finite-element coefficients. }\end{array}$ & $\begin{array}{l}\text { determ, gencof, md_nodes, } \\
\text { mmgetblk, mmrelblk, } \\
\text { sx_combine, } \\
\text { storage_derivatives, zeroi_out, } \\
\text { abs, iabs, maxo, sqrt }\end{array}$ & startup \\
\hline area2d_tri & $\begin{array}{l}\text { Calculate the total area of a triangle and the three } \\
\text { Voronoi areas along each of the three sides. }\end{array}$ & sqrt & anonp, gncf3 \\
\hline area_vol_gaz & $\begin{array}{l}\text { Calculate the area/distance and volume of a } \\
\text { tetrahedral. }\end{array}$ & & gncf3 \\
\hline
\end{tabular}




\begin{tabular}{|c|c|c|c|}
\hline Routine & Description & Calls & Called by \\
\hline avs_io & $\begin{array}{l}\text { Produce FEHM output in AVS UCD or binary } \\
\text { format. }\end{array}$ & $\begin{array}{l}\text { avs_write_cord, } \\
\text { avs_write_struc, c_close, } \\
\text { file_prefix, namefile2, } \\
\text { write_avs_node_con, } \\
\text { write_avs_node_mat, } \\
\text { write_avs_node_s, } \\
\text { write_avs_node_v, } \\
\text { write_avs_ucd_header, } \\
\text { write_binary_geo, } \\
\text { write_binary_header, } \\
\text { write_binary_node_con, } \\
\text { write_binary_node_mat, } \\
\text { write_binary_node_s, } \\
\text { write_binary_node_v }\end{array}$ & contr \\
\hline avs_write_cord & Output AVS coordinate information for FEHM. & & avs_io \\
\hline avs_write_struc & $\begin{array}{l}\text { Output AVS mesh-connectivity information for } \\
\text { FEHM. }\end{array}$ & elem_type & avs_io \\
\hline bcon & Manage boundary conditions. & $a b s$ & csolve, fehmn, startup \\
\hline bcrlp & $\begin{array}{l}\text { Calculate Brooks Corey relative permeabilities and } \\
\text { capillary pressures. }\end{array}$ & & rlperm \\
\hline binghm & Calculate pressure drop for Bingham fluid. & cubic, asin, sin, sqrt & permp \\
\hline bit & Set specified bit to the input state. & and, iand, ishft & geneq1, geneq2, geneqc \\
\hline bnswer & $\begin{array}{l}\text { Call routines to assemble finite-element equations } \\
\text { and solve for the Newton-Raphson equations. }\end{array}$ & $\begin{array}{l}\text { airctr, dpdp, gens } 1 \text {, gens } \mid 3 \text {, } \\
\text { gens } 14 \text {, outbnd, varchk, abs }\end{array}$ & fehmn, steady \\
\hline c_close & C routine to close AVS binary format output file. & close & avs_io \\
\hline c_open & C routine to open AVS binary format output file. & creat & namefile2 \\
\hline cappr & Calculate capillary-pressure functions. & initdata, null & thermw, thrair, thrmwc \\
\hline casson & $\begin{array}{l}\text { Calculate equivalent Darcy permeability for a } \\
\text { Casson fluid. }\end{array}$ & cubic, fourth, sqrt & permp \\
\hline
\end{tabular}




\begin{tabular}{|c|c|c|c|}
\hline cell_time & $\begin{array}{l}\text { Compute fluid residence time for cell and calculate } \\
\text { probability of a particle moving to a neighbor node. }\end{array}$ & & part_track \\
\hline check_sx & Check volumes and finite-element flow coefficients. & $\max$ & datchk \\
\hline close_files & Close all open files. & & termio \\
\hline cnswer & $\begin{array}{l}\text { Call routine to generate tracer transport equations } \\
\text { and call tracer equation-of-state routines. }\end{array}$ & $\begin{array}{l}\text { coneq1, dualta, gencon, } \\
\text { gentdp, react, thermc, } \\
\text { zeror_out, abs, max }\end{array}$ & csolve \\
\hline entlin & $\begin{array}{l}\text { Read I/O file names from control file, set unit } \\
\text { numbers, and open files. }\end{array}$ & null, setunits & cntlio \\
\hline cntlio & $\begin{array}{l}\text { Manage the opening and closing of files using } \\
\text { control file input. }\end{array}$ & cntlin, writeio & iofile, termio \\
\hline co2ctr & $\begin{array}{l}\text { Provide overall control for an isothermal air/water } \\
\text { simulation. }\end{array}$ & $\begin{array}{l}\text { humidity, initdata, psatl, abs, } \\
\text { exit }\end{array}$ & $\begin{array}{l}\text { fehmn, input, startup, timcrl, } \\
\text { wrtout }\end{array}$ \\
\hline coeffc & $\begin{array}{l}\text { Change coefficients of polynomial fits of the } \\
\text { thermodynamic properties specified. }\end{array}$ & & startup \\
\hline concadiff & $\begin{array}{l}\text { Compute diffusion coefficient based on volumetric } \\
\text { water content. }\end{array}$ & & coneq1, csolve, rdcon \\
\hline concen & Provide overall control for a tracer simulation. & $\begin{array}{l}\text { contrc, csolve, diskc, diskp, } \\
\text { plotc1, part_track, rdcon, } \\
\text { wrtcon, wrtptrk }\end{array}$ & $\begin{array}{l}\text { contr, contrj, disk, fehmn, input, } \\
\text { startup, wrtout }\end{array}$ \\
\hline coneq1 & Generate the equations of tracer transport. & abs, max, sqrt & cnswer, gentdp \\
\hline coneq1 1 manode & $\begin{array}{l}\text { Compute the Jacobian and residual terms of the } \\
\text { concentration equation associated with multiply } \\
\text { defined node connections. }\end{array}$ & & cnswer, gentdp \\
\hline contr & Write out data for contour plots at specified times. & $\begin{array}{l}\text { avs_io, concen, contrj, veloc, } \\
\max \end{array}$ & fehmn, startup, timerl \\
\hline contrc & Write out tracer data for contour plots. & & concen \\
\hline contrj & Write to contour plot tape using PATRAN format. & concen, veloc & contr \\
\hline
\end{tabular}




\begin{tabular}{|c|c|c|c|}
\hline \multicolumn{4}{|c|}{ Table 1. Subroutine and function calls within FEHMN (continued) } \\
\hline Routine & Description & Calls & Called by \\
\hline crdpdp & $\begin{array}{l}\text { Update solution for double-porosity/double- } \\
\text { permeability problem. }\end{array}$ & & dpdp \\
\hline csolve & $\begin{array}{l}\text { Organize tracer solution so smaller time steps can } \\
\text { be used for the tracer solution than for the flow } \\
\text { solution. }\end{array}$ & $\begin{array}{l}\text { bcon, cnswer, node_rxn, } \\
\text { plotc1, resettrc, solstore, } \\
\text { tyming, wrtcon, abs, dlog10, } \\
\text { exp, max, min }\end{array}$ & concen \\
\hline ctdpdp & $\begin{array}{l}\text { Update concentrations for double-porosity/double- } \\
\text { permeability solution. }\end{array}$ & & dpdp \\
\hline cubic & Solve cubic equation. & $a b s$, sqrt & binghm, casson \\
\hline data & $\begin{array}{l}\text { Initialize scalar variables, zero all arrays, and load } \\
\text { thermodynamic coefficients. }\end{array}$ & zeroi_out, zeror_out & fehmn \\
\hline datchk & Initial value analysis and data check. & $\begin{array}{l}\text { check_sx, min_max, abs, max, } \\
\text { min }\end{array}$ & fehmn \\
\hline dated & Determine the current date and time. & $\begin{array}{l}\text { dateh (cray), idate, itime, mod } \\
\text { (hp, sun), fdate_(ibm) }\end{array}$ & disk, fehmn \\
\hline daycrl & $\begin{array}{l}\text { Compute new time-step size using adjusted time- } \\
\text { step multiplier if necessary. }\end{array}$ & $\log 10$ & timcrl \\
\hline determ & Evaluate determinates. & & anonp \\
\hline diagnostics & Print out worst residuals. & $a b s$ & fehmn \\
\hline disk & Read and/or write files for restart purposes. & concen, dated, stress, $\max$ & fehmn, startup, timcrl \\
\hline diskc & Read and/or write restart files for tracer variables. & & concen \\
\hline diskp & $\begin{array}{l}\text { Read and/or write restart files for particle-tracking } \\
\text { variables. }\end{array}$ & & concen \\
\hline done_macro & Close optional input file. & & input, scanin \\
\hline dpdp & $\begin{array}{l}\text { Provide overall control for a dual-porosity/dual- } \\
\text { permeability solution. }\end{array}$ & $\begin{array}{l}\text { crdpdp, ctdpdp, gensdp, } \\
\text { gensdp3, indpdp, rddpdp, } \\
\text { varchk }\end{array}$ & $\begin{array}{l}\text { bnswer, gensdp, gensdp3, } \\
\text { input, startup }\end{array}$ \\
\hline
\end{tabular}




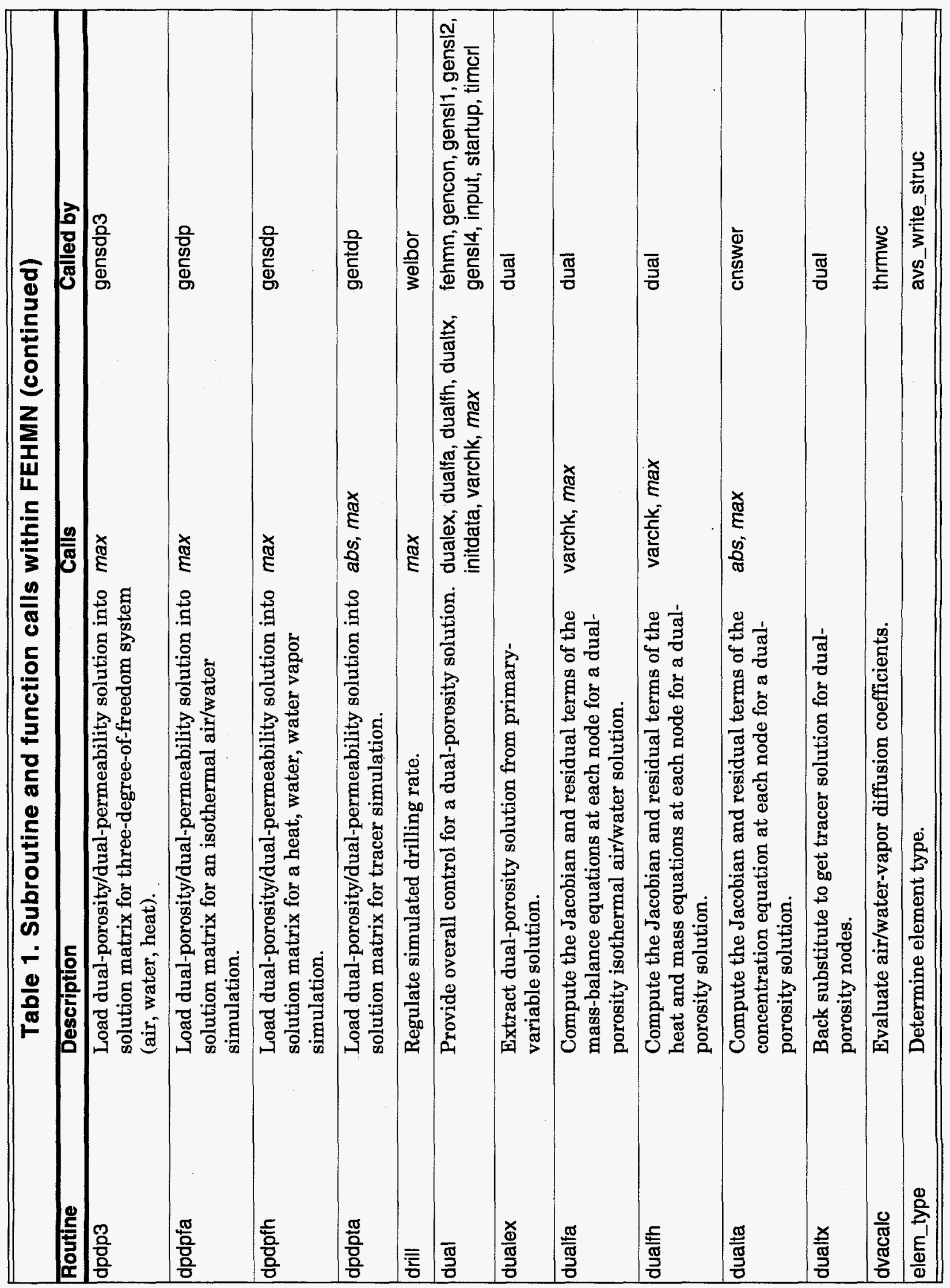




\begin{tabular}{|c|c|c|c|}
\hline \multicolumn{4}{|c|}{ Table 1. Subroutine and function calls within FEHMN (continued) } \\
\hline Routine & Description & Calls & Called by \\
\hline elem_type_binary & $\mathrm{C}$ routine to determine element type. & & write_binary_geo \\
\hline enthp & $\begin{array}{l}\text { Calculate enthalpy at a node as a function of } \\
\text { temperature and pressure. }\end{array}$ & & fehmn, steady, welbor \\
\hline eullag3 & $\begin{array}{l}\text { Convert between two geometric reference frames: } \\
\text { given a point } i \text {, a nearest neighbor } j \text {, and a vector, } \\
\text { rotate the vector from } x, y, z \text { space to } a, b, c \text { space. }\end{array}$ & angle3 & rotate \\
\hline explicit & Make the equations explicit. & $a b s, \max , \min$ & gens 12 \\
\hline fehmn & $\begin{array}{l}\text { Primary controlling routine for finite-element heat } \\
\text { and mass transfer in porous media. }\end{array}$ & $\begin{array}{l}\text { tyming, dated, iofile, } \\
\text { setparams, allocmem, data, } \\
\text { infiles, } \\
\text { flow_boundary_conditions, } \\
\text { startup, datchk, timcrl, user, } \\
\text { welbor, enthp, bnswer, resetv, } \\
\text { varchk, dual, diagnostics, fimpf, } \\
\text { bcon, steady, co2ctr, sice, } \\
\text { veloc, concen, wrtout, plot, } \\
\text { contr, disk, pest, abs, max, mod }\end{array}$ & main \\
\hline file_prefix & Determine prefix of input file name. & & avs_io, termin \\
\hline film & Regulate film coefficient. & htcchg, abs, max, sqrt & welbor \\
\hline fimpf & $\begin{array}{l}\text { Calculate fraction of variables over a given } \\
\text { tolerance. }\end{array}$ & $a b s$ & fehmn \\
\hline flow_boundary_conditions & $\begin{array}{l}\text { Provide flow boundary condition including time- } \\
\text { dependent and distributed (by volume) sources. }\end{array}$ & $\begin{array}{l}\text { flow_boun, headctr, initdata, } \\
\text { mmgetblk, mmreblk, zeroi_out, } \\
\text { zeror_out, abs, max }\end{array}$ & fehmn, input, setparams, timcrl \\
\hline flow_boun & Read and apply boundary and source conditions. & model_setup, time_adjust, $a b s$ & flow_boundary_conditions \\
\hline flxo & Calculate internode fluxes. & near3, abs, max, sqrt & input, wrtout \\
\hline fourth & Solve fourth-order equation. & $a b s$, sqrt & casson \\
\hline fprop & Change fluid properties in wellbore and annulus. & & welbor \\
\hline freef & C routine to free allocated memory. & free & mmrelblk \\
\hline
\end{tabular}




\begin{tabular}{|c|c|c|c|}
\hline \multicolumn{4}{|c|}{ Table 1. Subroutine and function calls within FEHMN (continued) } \\
\hline Routine & Description & Calls & Called by \\
\hline gencof & $\begin{array}{l}\text { Call routines to generate finite-element coefficients, } \\
\text { perform the numerical integration of the elements. }\end{array}$ & $\begin{array}{l}\text { gncf2, gncf3, mmgetblk, } \\
\text { mmrelblk, zeror_out }\end{array}$ & anonp \\
\hline gencon & $\begin{array}{l}\text { Call routines to generate tracer equations and call } \\
\text { solver to obtain Newton-Raphson equations for } \\
\text { tracer variables. }\end{array}$ & $\begin{array}{l}\text { dual, mmgetblk, mmrelblk, } \\
\text { rd1dof, solve_new, } \\
\text { storage_derivatives, max, min, } \\
\text { sqrt }\end{array}$ & cnswer \\
\hline gendat & $\begin{array}{l}\text { Generate coordinates and element information in } \\
\text { simple geometric problems. }\end{array}$ & & incoord \\
\hline geneq1 & $\begin{array}{l}\text { Generate equations for Newton-Raphson } \\
\text { corrections for water/vapor flow without } \\
\text { noncondensible gas. }\end{array}$ & bit, setbit & gensdp, gensdp3, gensl1 \\
\hline geneq2 & $\begin{array}{l}\text { Generate equations for Newton-Raphson } \\
\text { corrections for isothermal air/water solution. }\end{array}$ & bit, setbit & gensdp, gensl2 \\
\hline geneq3 & $\begin{array}{l}\text { Generate equations for Newton-Raphson } \\
\text { corrections for heat conduction only (i.e., } \\
\text { permeability). }\end{array}$ & & $\begin{array}{l}\text { gensdp, gensdp3, gens|2, } \\
\text { gens/3 }\end{array}$ \\
\hline geneqc & $\begin{array}{l}\text { Generate equations for Newton-Raphson } \\
\text { corrections for water and noncondensible gas flow. }\end{array}$ & bit, psat, setbit, zeolites & gensdp3, gens|4 \\
\hline geneqmanode & Generate equations to multiply defined nodes. & bit, setbit & manodes \\
\hline gensdp & $\begin{array}{l}\text { Solve isothermal air/water equations with full } \\
\text { Jacobian (unsymmetrical, } 2 n \text { by } 2 n \text { ). }\end{array}$ & $\begin{array}{l}\text { dpdp, dpdpfa, dpdpfh, geneq1, } \\
\text { geneq2, geneq3, mmgetblk, } \\
\text { mmrelblk, nrmlz4, rdof_new, } \\
\text { solve_new, } \\
\text { storage_derivatives, switch, } \\
\text { switchb, abs, max, min, sqrt }\end{array}$ & dpdp \\
\hline gensdp3 & $\begin{array}{l}\text { Solve nonisothermal air/water equations with full } \\
\text { Jacobian (unsymmetrical, } 3 \mathrm{n} \text { by } 3 \mathrm{n} \text { ). }\end{array}$ & $\begin{array}{l}\text { dpdp, dpdp3, geneq1, geneq3, } \\
\text { geneqc, mmgetblk, mmrelblk, } \\
\text { normal_dof, rdof_new, } \\
\text { solve_new, } \\
\text { storage_derivatives, switch, } \\
\text { switchb, abs, max, min, sqrt }\end{array}$ & dpdp \\
\hline
\end{tabular}




\begin{tabular}{|c|c|c|c|}
\hline \multicolumn{4}{|c|}{ Table 1. Subroutine and function calls within FEHMN (continued) } \\
\hline Routine & Description & Calls & Called by \\
\hline gensl1 & $\begin{array}{l}\text { Call routines to generate the Newton-Raphson } \\
\text { equations for water-only problems and call } \\
\text { equation-solver subroutine to solve the heat- and } \\
\text { mass-transfer equations with full Jacobian } \\
\text { (unsymmetric, } 2 n \text { by } 2 n \text { ). }\end{array}$ & $\begin{array}{l}\text { dual, geneq1, mmgetblk, } \\
\text { mmrelblk, normal, rdof_new, } \\
\text { solve_new, } \\
\text { storage_derivatives, switch, } \\
\text { switchb, abs, max, min, sqrt }\end{array}$ & bnswer \\
\hline gensl2 & $\begin{array}{l}\text { Call routines to generate the Newton-Raphson } \\
\text { equations for isothermal air/water problems and } \\
\text { call equation-solver subroutine to solve with full } \\
\text { Jacobian. }\end{array}$ & $\begin{array}{l}\text { air_rdof, dual, geneq2, geneq3, } \\
\text { explicit, mmgetblk, mmrelblk, } \\
\text { normal, rdof_new, solve_new, } \\
\text { storage_derivatives, switch, } \\
\text { switchb, abs, max, min, sqrt }\end{array}$ & airctr \\
\hline gens/3 & $\begin{array}{l}\text { Call routines to generate the Newton-Raphson } \\
\text { equations for heat conduction only and call } \\
\text { equation-solver subroutine. }\end{array}$ & $\begin{array}{l}\text { geneq3, mmgetblk, mmrelblk, } \\
\text { rd1dof, solve_new, } \\
\text { storage_derivatives, abs, max, } \\
\text { min, sqrt }\end{array}$ & bnswer \\
\hline gens|4 & $\begin{array}{l}\text { Call routines to generate equations for water/ } \\
\text { noncondensible-gas problems and call equation- } \\
\text { solver subroutine to solve the heat and mass } \\
\text { equations with noncondensible gas (full Jacobian, } \\
\text { unsymmetric } 3 \text { n by } 3 n \text { ). }\end{array}$ & $\begin{array}{l}\text { dual, geneqc, mmgetblk, } \\
\text { mmrelblk, normal, rdof_new, } \\
\text { solve_new, } \\
\text { storage_derivatives, switch, } \\
\text { switchb, abs, max, min, sqrt }\end{array}$ & bnswer \\
\hline gentdp & $\begin{array}{l}\text { Solve tracer equations with full Jacobian } \\
\text { (unsymmetrical, } 2 n \text { by } 2 n \text { ). }\end{array}$ & $\begin{array}{l}\text { coneq1, dpdpta, mmgetblk, } \\
\text { mmrelblk, normal, rdof_new, } \\
\text { solve_new, } \\
\text { storage_derivatives, thermc, } \\
\text { max, min, sqrt }\end{array}$ & cnswer \\
\hline getconc & $\begin{array}{l}\text { Interpolate between background levels of input } \\
\text { concentration for use with the particle tracking. }\end{array}$ & & part_track \\
\hline geoin & $\begin{array}{l}\text { Read element and coordinate information from } \\
\text { preprocessor with alternate format. }\end{array}$ & inmentat, inpatran & incoord \\
\hline gncf2 & Generate 2-D finite-element coefficients. & pebi, shap $2 r$ & gencof \\
\hline
\end{tabular}




\begin{tabular}{|c|c|c|c|}
\hline \multicolumn{4}{|c|}{ Table 1. Subroutine and function calls within FEHMN (continued) } \\
\hline Routine & Description & Calls & Called by \\
\hline gncf3 & Generate 3-D finite-element coefficients. & $\begin{array}{l}\text { area_vol_gaz, lubksb0, } \\
\text { ludcmp0, pebi3, shap3p, } \\
\text { shap3r }\end{array}$ & gencof \\
\hline headctr & $\begin{array}{l}\text { Manage the head input and change pressures into } \\
\text { heads and vice versa. }\end{array}$ & mmgetblk & $\begin{array}{l}\text { airctr, } \\
\text { flow_boundary_conditions, } \\
\text { input, wrtout }\end{array}$ \\
\hline heatb & $\begin{array}{l}\text { Modify energy source to account for heat generation } \\
\text { at the drill bit. }\end{array}$ & qhuser, abs & permp, welbor \\
\hline htcchg & $\begin{array}{l}\text { Change the fouling coefficients of drill pipe and } \\
\text { casing as function of time and depth. }\end{array}$ & & film \\
\hline humidity & Calculate the saturation for a given humidity value. & $\log$ & co2ctr \\
\hline incond & Read thermal-conductivity data. & initdata, $\max$ & input \\
\hline incoord & Control reading of input coordinate data. & gendat, geoin, null, iabs & infiles \\
\hline inctrl & Read control variables. & initdata, abs mino & input \\
\hline indpdp & $\begin{array}{l}\text { Modify fracture volume at nodes for dpdp } \\
\text { calculations. }\end{array}$ & & dpdp \\
\hline infiles & Control reading of input data files. & $\begin{array}{l}\text { incoord, input, rarng, writeio, } \\
\text { zone }\end{array}$ & fehmn \\
\hline inflo2 & Read flow data input by planes for 3-D models. & null, $a b s, \max 0$ & input \\
\hline inflow & Read flow data. & $\begin{array}{l}\text { initdata, mmgetblk, mmrelblk, } \\
\text { abs }\end{array}$ & input \\
\hline inhflx & Read heat-flux data. & initdata & input \\
\hline initdata & $\begin{array}{l}\text { Read in an arbitrary number of lines of data and set } \\
\text { parameter values at given nodes. }\end{array}$ & $\begin{array}{l}\text { mmgetblk, mmrelblk, null, } \\
\text { zeroi_out, abs, nint }\end{array}$ & $\begin{array}{l}\text { co2ctr, dual, } \\
\text { flow_boundary_conditions, } \\
\text { incond, inctrl, inflow, inhflx, } \\
\text { inperm, inpres, inptrk, inrock, } \\
\text { inzeol, porosi, rdcon, rddpdp, } \\
\text { rdthick, renum, rlperm, sice, } \\
\text { vcon }\end{array}$ \\
\hline
\end{tabular}




\begin{tabular}{|c|c|c|c|}
\hline \multicolumn{4}{|c|}{ Table 1. Subroutine and function calls within FEHMN (continued) } \\
\hline Routine & Description & Calls & Called by \\
\hline inmentat & $\begin{array}{l}\text { Read in geometric data generated by mentat mesh } \\
\text { generator. }\end{array}$ & & geoin \\
\hline innode & Read/find node numbers for output. & near3, null, abs & input \\
\hline inpatran & $\begin{array}{l}\text { Read in geometric data generated by patran mesh } \\
\text { generator. }\end{array}$ & & geoin \\
\hline inperm & Read permeability data. & initdata, $\max$ & input \\
\hline inpres & $\begin{array}{l}\text { Read nonuniform pressure and temperature or } \\
\text { saturation data. }\end{array}$ & $\begin{array}{l}\text { initdata, mmgetblk, mmrelblk, } \\
\text { psat, abs }\end{array}$ & input \\
\hline inptrk & Read particle-tracking data. & initdata, null & input \\
\hline input & Control reading of input data file. & $\begin{array}{l}\text { airctr, co2ctr, concen, } \\
\text { done_macro, dpdp, dual, } \\
\text { flow_boundary_conditions, } \\
\text { flxo, headctr, incond, inctrl, } \\
\text { inflo2, inflow, inhflx, innode, } \\
\text { inperm, inpres, inptrk, inrock, } \\
\text { intime, inzeol, md_nodes, null, } \\
\text { parse_string, pest, porosi, } \\
\text { read_avs_io, read_rxn, renum, } \\
\text { rlperm, sice, start_macro, } \\
\text { sther, stress, thickness, user, } \\
\text { varctr, vcon, welbor, zone, abs }\end{array}$ & infiles \\
\hline inrock & Read rock-property data. & initdata & input \\
\hline interblock_iso & Generate interblock flow for air/water equations. & & air_rdof \\
\hline intime & Read time-step input. & null & input \\
\hline inverf & $\begin{array}{l}\text { Calculate the inverse of the error function for a } \\
\text { value of } x \text { between } 0 \text { and } 1 \text {. }\end{array}$ & $\operatorname{alog} 10$ & time_diff \\
\hline inzeol & Read zeolite-hydration data. & $\begin{array}{l}\text { initdata, psat, zeolites, } \\
\text { zeror_out }\end{array}$ & input \\
\hline iofile & Manage the opening of input and output files. & cntlio, termio & fehmn \\
\hline
\end{tabular}




\begin{tabular}{|c|c|c|c|}
\hline \multicolumn{4}{|c|}{ Table 1. Subroutine and function calls within FEHMN (continued) } \\
\hline Routine & Description & Calls & Called by \\
\hline lubksb & $\begin{array}{l}\text { Perform forward and back substitution for } \mathrm{N} \text { - } \\
\text { degree-of-freedom matrix elements. }\end{array}$ & & node_rxn \\
\hline lubksb0 & $\begin{array}{l}\text { Perform forward and back substitution for } \mathrm{N}- \\
\text { degree-of-freedom matrix elements. }\end{array}$ & & gnci3, normal_dof, pebi3 \\
\hline ludemp & $\begin{array}{l}\text { Perform Gauss elimination on } \mathrm{N} \text {-degree-of-freedom } \\
\text { matrix elements. }\end{array}$ & abs & node_rxn \\
\hline ludemp0 & $\begin{array}{l}\text { Perform Gauss elimination on } \mathrm{N} \text {-degree-of-freedom } \\
\text { matrix elements. }\end{array}$ & $a b s$ & gncł3, normal_dof, pebi3 \\
\hline mallocf & C routine to allocate memory. & exit, malloc, printf & mmgetblk \\
\hline md_nodes & Manage multiply defined nodes. & mmgetblk & anonp, input, startup \\
\hline $\min \_\max$ & $\begin{array}{l}\text { Find the minimum and maximum parameter values } \\
\text { and their location. }\end{array}$ & & datchk \\
\hline mmgetblk & Allocate memory to an array. & mallocf & $\begin{array}{l}\text { allocmem, anonp, } \\
\text { flow_boundary_conditions, } \\
\text { gencof, gencon, gensdp, } \\
\text { gensdp3, gens } 1 \text {, gens } 12 \text {, } \\
\text { gens } 3 \text {, gens } 14 \text {, gentdp, } \\
\text { headctr, inflow, initdata, inpres, } \\
\text { md_nodes, pest, set_ptrk, split, } \\
\text { startup, storage_derivatives, } \\
\text { storsx, thermw, thickness, } \\
\text { varctr, zone }\end{array}$ \\
\hline mmrelblk & Deallocate array memory. & freef & $\begin{array}{l}\text { anonp, } \\
\text { flow_boundary_conditions, } \\
\text { gencof, gencon, gensdp, } \\
\text { gensdp3, gensl1, gensl2, } \\
\text { gens } 3 \text {, gens } 14 \text {, gentdp, inflow, } \\
\text { initdata, inpres, split, startup, } \\
\text { thermw, storage_derivatives, } \\
\text { storsx, thickness, zone }\end{array}$ \\
\hline mod_eqs_ngas & Modify equations if no gas is present. & $a b s$ & gens/4 \\
\hline
\end{tabular}




\begin{tabular}{|c|c|c|c|}
\hline \multicolumn{4}{|c|}{ Table 1. Subroutine and function calls within FEHMN (continued) } \\
\hline Routine & Description & Calls & Called by \\
\hline model_setup & Read in parameters for boundary models. & & flow_boun \\
\hline mult_rxn & $\begin{array}{l}\text { Compute the reaction-rate terms for each reaction } \\
\text { for the given species and node point. }\end{array}$ & $\begin{array}{l}\text { rxn_product, abs, dlog10, exp, } \\
\max , \min \end{array}$ & node_rxn, react \\
\hline namefile2 & Generate name for AVS format output file. & c_open & avs_io \\
\hline near3 & Find nearest node to a set of coordinates $(x, y, z)$. & sqrt & flxo, innode, pest, zone \\
\hline nearn & $\begin{array}{l}\text { Determine the nearest node ( } \mathrm{n}) \text { to a given set of } \\
\text { coordinates }(x, y) \text {. }\end{array}$ & sqrt & welbor \\
\hline newton & Calculate pressure drop for Newtonian fluid. & $\log , \log 10$ & permp \\
\hline node_rxn & $\begin{array}{l}\text { Compute the updated concentrations of all species } \\
\text { at a given node after constructing an } n \text { speci } x \text { nspeci } \\
\text { matrix that includes coupling of the concentrations. }\end{array}$ & lubksb, ludcmp, mult_rxn & csolve \\
\hline normal & $\begin{array}{l}\text { Normalize Newton-Raphson equations and } \\
\text { calculate sum-squared sum of residuals. }\end{array}$ & & gens|1, gens|2, gens $\mid 4$, gentdp \\
\hline normal_dof & Normalize equations for coupled problems. & lubksb0, ludcmp0 & gensdp3 \\
\hline nrmlz4 & Normalize the matrix equations. & $a b s, \max$ & gensdp \\
\hline null & Check for null lines or all 0's in lines. & char, len & $\begin{array}{l}\text { cntlin, incoord, inflo2, initdata, } \\
\text { innode, inptrk, input, intime, } \\
\text { rdcon, read_rxn, rlperm, } \\
\text { scanin, vcon, zone }\end{array}$ \\
\hline outbnd & $\begin{array}{l}\text { Test the dependent variables to determine if they } \\
\text { are within the bounds set by the thermodynamic } \\
\text { properties. }\end{array}$ & & bnswer \\
\hline parse_string & $\begin{array}{l}\text { C routine to parse input line with character, } \\
\text { integer, and real input. }\end{array}$ & & input, rdcon, read_rxn \\
\hline part_track & Control particle-tracking simulation. & $\begin{array}{l}\text { cell_time, getconc, ran_sp, } \\
\text { set_ptrk, time_diff, time_disp, } \\
\text { abs, dble, exp, max, mod, real, } \\
\text { sqrt }\end{array}$ & concen \\
\hline
\end{tabular}




\begin{tabular}{|c|c|c|c|}
\hline Routine & Description & Calls & Called by \\
\hline pebi & $\begin{array}{l}\text { Calculate internodal area using perpendicular } \\
\text { bisectors (2-D). }\end{array}$ & mod, sqrt & gncf2 \\
\hline pebi3 & $\begin{array}{l}\text { Calculate internodal volume using perpendicular } \\
\text { bisectors (3-D). }\end{array}$ & ludemp0, lubksb0, abs & gncf3 \\
\hline peint & $\begin{array}{l}\text { Set up initial temperature gradients where gradient } \\
\text { information is user specified. }\end{array}$ & $a b s, \max$ & startup \\
\hline permp & $\begin{array}{l}\text { Calculate equivalent Darcy permeability for pipe } \\
\text { flow. }\end{array}$ & $\begin{array}{l}\text { binghm, casson, heatb, } \\
\text { newton, power, abs, max }\end{array}$ & welbor \\
\hline pest & Parameter estimation $\mathrm{I} / \mathrm{O}$ routine. & mmgetblk, near3 & fehmn, input \\
\hline plot & $\begin{array}{l}\text { Write out data for time-history plots at particular } \\
\text { nodes. }\end{array}$ & & fehmn, startup, timcrl \\
\hline plotc1 & $\begin{array}{l}\text { Write out tracer data for time-history plots. Print } \\
\text { out at flow time steps. }\end{array}$ & & concen, csolve, rdcon, set_ptrk \\
\hline porosi & $\begin{array}{l}\text { Read in data for pressure-dependent porosity and } \\
\text { permeability models and calculate porosity and } \\
\text { permeability functions. }\end{array}$ & initdata, welbor, iabs & $\begin{array}{l}\text { input, startup, thermw, thrair, } \\
\text { wrtout }\end{array}$ \\
\hline power & $\begin{array}{l}\text { Calculate equivalent permeability for power-law } \\
\text { fluid. }\end{array}$ & $\log , \log 10$ & permp \\
\hline psat & $\begin{array}{l}\text { Calculate the saturation pressure of water for a } \\
\text { given temperature. }\end{array}$ & $a b s$ & geneqc, inpres, inzeol, thermw \\
\hline psatl & Calculate the saturation temperature or pressure. & vaporl, abs & co2ctr, thrmwc, varchk \\
\hline qhuser & User-specified dissipation rate. & & heatb \\
\hline radius & $\begin{array}{l}\text { Modify finite-element coefficients to obtain a radial } \\
\text { model. }\end{array}$ & $\min , \max$ & startup \\
\hline ran_sp & $\begin{array}{l}\text { Generate a pseudorandom number with a uniform } \\
\text { distribution between } 0 \text { and } 1 .\end{array}$ & mod, real & part_track, time_diff \\
\hline rarng & $\begin{array}{l}\text { Rearrange 3-D coordinates to obtain } 2-\mathrm{D} \text { problems } \\
\text { when enabled. }\end{array}$ & & infiles \\
\hline
\end{tabular}




\begin{tabular}{|c|c|c|c|}
\hline \multicolumn{4}{|c|}{ Table 1. Subroutine and function calls within FEHMN (continued) } \\
\hline Routine & Description & Calls & Called by \\
\hline rd1dof & $\begin{array}{l}\text { Solve the equations generated for heat conduction } \\
\text { by a reduced degree-of-freedom method. }\end{array}$ & solve, sqrt & gencon, gens|3 \\
\hline rdcon & Read in tracer data and initialize tracer variables. & $\begin{array}{l}\text { initdata, null, parse_string, } \\
\text { plotc1, thermc, userc, abs, } \\
\text { dlog10, exit, exp, max, } \min \end{array}$ & concen \\
\hline rddpdp & Read the input data for a dpdp solution. & initdata & dpdp \\
\hline rdof_new & $\begin{array}{l}\text { Reduce a } 3 n \times 3 n \text { matrix into a } 2 n \times 2 n \text { matrix or an } \\
n \times n \text { matrix using the RDOF or IRDOF algorithms. }\end{array}$ & solve_new & $\begin{array}{l}\text { gensdp, gensdp3, gens } 11, \\
\text { gens } \mid 2, \text { gens } \mid 4, \text { gentdp }\end{array}$ \\
\hline rdthick & Read input data for variable thickness. & initdata & thickness \\
\hline react & $\begin{array}{l}\text { Compute the reaction terms and add to the Jacobian } \\
\text { and the residual for each node. }\end{array}$ & mult_rxn, abs, max & cnswer \\
\hline read_avs_io & Read input file and set io flags. & & input \\
\hline read_rxn & Read the data for multiple, interacting solutes. & $\begin{array}{l}\text { null, parse_string, setup_rxn, } \\
\text { abs }\end{array}$ & input \\
\hline read_sx & Read finite-element coefficients. & & storsx \\
\hline renum & Read node-renumbering data. & initdata & input \\
\hline resettrc & $\begin{array}{l}\text { Reduce time step of the solute-transport calculation } \\
\text { and reset the values of all parameters before } \\
\text { reinitiating the calculation. }\end{array}$ & & csolve \\
\hline resetv & $\begin{array}{l}\text { Reset the dependent variables to the last time step } \\
\text { value. Used when iteration limits are exceeded and } \\
\text { a particular time step is restarted. }\end{array}$ & & fehmn \\
\hline rlperm & $\begin{array}{l}\text { Calculate relative-permeability functions for vapor } \\
\text { and liquid. }\end{array}$ & $\begin{array}{l}\text { bcrlp, null, initdata, vgcap, } \\
\text { vgcap_fit, vgrlp, welbor, max }\end{array}$ & input, thermw, thrair, thrmwc \\
\hline rock & Regulate rock properties. & $\max 0$ & welbor \\
\hline rotate & Initiate $3-\mathrm{D}$ matrix rotation. & eullag3 & coneq1, csolve \\
\hline rxn_product & $\begin{array}{l}\text { Compute the reaction-rate terms for each reaction } \\
\text { for the given species and node point. }\end{array}$ & $\max$ & mult_rxn \\
\hline
\end{tabular}




\begin{tabular}{|c|c|c|c|}
\hline \multicolumn{4}{|c|}{ Table 1. Subroutine and function calls within FEHMN (continued) } \\
\hline Routine & Description & Calls & Called by \\
\hline scanin & $\begin{array}{l}\text { Scan input file for parameters needed prior to data } \\
\text { input. }\end{array}$ & $\begin{array}{l}\text { done_macro, null, start_macro, } \\
\max \end{array}$ & setparams \\
\hline set_ptrk & $\begin{array}{l}\text { Set up starting nodes and times for particle } \\
\text { tracking. }\end{array}$ & mmgetblk, plotc1, abs, int & part_track \\
\hline setbit & Set specified bit to the input state. & and, iand, ior, ishft, not, or & geneq1, geneq2, geneqc \\
\hline setord & $\begin{array}{l}\text { Set up the order of solution for the equations at each } \\
\text { node. }\end{array}$ & & startup \\
\hline setparams & Initialize/set parameter values. & $\begin{array}{l}\text { flow_boundary_conditions, } \\
\text { scanin, } \max \end{array}$ & fehmn \\
\hline setunits & Set file unit numbers. & & cntlin, termin \\
\hline setup_rxn & $\begin{array}{l}\text { Set up arrays identifying the location and type of a } \\
\text { particular species in a reaction. }\end{array}$ & & read_rxn \\
\hline setzone & Enter properties using geometric zone description. & sfn2r, sfn3r, abs, max, min, sqrt & zone \\
\hline sfn2r & $\begin{array}{l}\text { Evaluate shape functions for } 2-D \text { calculations. } \\
\text { (Interpolation routine used by zone.) }\end{array}$ & & setzone \\
\hline $\operatorname{sfn} 3 r$ & $\begin{array}{l}\text { Evaluate shape functions for 3-D calculations. } \\
\text { (Interpolation routine used by zone.) }\end{array}$ & & setzone \\
\hline shap2r & $\begin{array}{l}\text { Evaluate } 2-D \text { finite-element shape functions at } \\
\text { quadrature points. }\end{array}$ & sqrt & gncf2 \\
\hline shap3p & $\begin{array}{l}\text { Evaluate } 3 \text {-D prism-element shape functions at } \\
\text { quadrature points. }\end{array}$ & & gncf3 \\
\hline shap3r & $\begin{array}{l}\text { Evaluate 3-D quadralateral-element shape } \\
\text { functions at quadrature points. }\end{array}$ & sqrt & gncf3 \\
\hline sice & Read in data for simulation with ice present. & initdata, sther & fehmn, input, startup, wrtout \\
\hline solstore & $\begin{array}{l}\text { Compute the tracer mass storage and sorption } \\
\text { terms of the residuals equations and their } \\
\text { derivatives. }\end{array}$ & abs, dlog10, exp, $\max$ & csolve, thermc \\
\hline
\end{tabular}




\begin{tabular}{|c|c|c|c|}
\hline \multicolumn{4}{|c|}{ Table 1. Subroutine and function calls within FEHMN (continued) } \\
\hline Routine & Description & Calls & Called by \\
\hline solve & $\begin{array}{l}\text { Solve the one-degree-of-freedom linear system of } \\
\text { equations. }\end{array}$ & $a b s, \max , s q r t$ & rd1dof \\
\hline split & $\begin{array}{l}\text { Split rectangles/bricks into triangles/tetrahedrals } \\
\text { and average so grid orientation is not present. }\end{array}$ & mmgetblk, mmrelblk, abs, $\min$ & startup \\
\hline start_macro & Allow input to be read from any file. & & input, scanin \\
\hline startup & Perform miscellaneous startup calculations. & $\begin{array}{l}\text { airctr, anonp, bcon, co2ctr, } \\
\text { coeffc, concen, contr, disk, } \\
\text { dpdp, dual, md_nodes, } \\
\text { mmgetblk, mmrelblk, peint, } \\
\text { plot, porosi, radius, setord, } \\
\text { sice, slvesu, split, storsx, } \\
\text { steady, thickness, tyming, } \\
\text { varchk, welbor, zeror_out, abs, } \\
\text { max, maxo }\end{array}$ & fehmn \\
\hline steady & $\begin{array}{l}\text { Set up initial pressure distribution when gravity is } \\
\text { present (enabled). }\end{array}$ & bnswer, enthp, abs & startup \\
\hline sther & $\begin{array}{l}\text { Set thermodynamic parameters when simple } \\
\text { thermodynamics are invoked. }\end{array}$ & & input, sice \\
\hline storage_derivatives & $\begin{array}{l}\text { Allocate memory for derivative arrays and initialize } \\
\text { values, or deallocate derivative arrays. }\end{array}$ & mmgetblk, mmrelblk, zeror_out & $\begin{array}{l}\text { allocmem, anonp, gencon, } \\
\text { genspd, genspd3, gens } 11 \text {, } \\
\text { gensi2, gens } 3 \text {, gens } 4, \text { gentdp }\end{array}$ \\
\hline stors $\mathrm{x}$ & $\begin{array}{l}\text { Manage the storage or retrieval of element } \\
\text { coefficients from auxiliary file. }\end{array}$ & mmgetblk, mmrelblk, read_sx & startup \\
\hline stress & $\begin{array}{l}\text { Blank routine that returns without doing anything } \\
\text { (for compatibility with other versions of FEHM). }\end{array}$ & & disk, input, wrtout \\
\hline switch & Reorder the "a" matrix. & & $\begin{array}{l}\text { genspd, genspd3, gensl1, } \\
\text { gens12, gens } 14\end{array}$ \\
\hline switchb & Reorder the " $b$ " matrix. & & $\begin{array}{l}\text { genspd, genspd3, gensl1, } \\
\text { gens/2, gens/4 }\end{array}$ \\
\hline sx_combine & Combine dimensions of a variable. & & anonp \\
\hline
\end{tabular}




\begin{tabular}{|c|c|c|c|}
\hline \multicolumn{4}{|c|}{ Table 1. Subroutine and function calls within FEHMN (continued) } \\
\hline Routine & Description & Calls & Called by \\
\hline termin & $\begin{array}{l}\text { Read I/O file names from terminal, set unit } \\
\text { numbers, and open files. }\end{array}$ & file_prefix, setunits & termio \\
\hline termio & $\begin{array}{l}\text { Manage the opening and closing of files using } \\
\text { terminal input. }\end{array}$ & $\begin{array}{l}\text { close_files, cntlio, termin, } \\
\text { writeio }\end{array}$ & iofile \\
\hline thermc & Evaluate tracer equation-of-state information. & $\begin{array}{l}\text { solstore, userc, abs, dlog10, } \\
\text { exp, max }\end{array}$ & cnswer, gentdp, rdcon \\
\hline thermw & $\begin{array}{l}\text { Evaluate the thermodynamic properties (density, } \\
\text { enthalpy, and viscosity) as a function of pressure } \\
\text { and temperature (or saturation). }\end{array}$ & $\begin{array}{l}\text { cappr, mmgetblk, mmrelblk, } \\
\text { porosi, psat, rlperm, vfcal, } \\
\text { welbor, abs }\end{array}$ & airctr, varchk \\
\hline thickness & $\begin{array}{l}\text { Modify volumes and finite-element coefficients to } \\
\text { account for variable thickness. }\end{array}$ & mmgetblk, mmrelblk, rdthick & input, startup \\
\hline thrair & $\begin{array}{l}\text { Calculate coefficients and derivatives for isothermal } \\
\text { air/water system. }\end{array}$ & cappr, porosi, riperm & airctr, air_rdof \\
\hline thrmwc & $\begin{array}{l}\text { Evaluate the thermodynamic properties (density, } \\
\text { enthalpy, and viscosity) as a function of pressure, } \\
\text { temperature, and partial pressure of noncondensible } \\
\text { gas for water/noncondensible-gas problems. }\end{array}$ & $\begin{array}{l}\text { air_cp, cappr, dvacalc, psatl, } \\
\text { rlperm, vfcal, max }\end{array}$ & varchk \\
\hline time_adjust & Adjust time if necessary for boundary models. & & flow_boun \\
\hline timcrl & Control time-step information and stopping criteria. & $\begin{array}{l}\text { co2ctr, contr, daycrl, disk, dual, } \\
\text { flow_boundary_conditions, } \\
\text { plot, abs, iabs }\end{array}$ & fehmn \\
\hline time_diff & Compute diffusion time for a particle. & inverf, ran_sp & part_track \\
\hline time_disp2 & Compute dispersion time for a particle. & & part_track \\
\hline tyming & $\begin{array}{l}\text { Calculate CPU time for a particular computer run. } \\
\text { Call is made to the system clock of the computer on } \\
\text { which it is run. }\end{array}$ & $\begin{array}{l}\text { second (cray), secnds (hp), } \\
\text { etime_(ibm), dble, etime (sun) }\end{array}$ & csolve, fehmn, startup \\
\hline
\end{tabular}




\begin{tabular}{|c|c|c|c|}
\hline \multicolumn{4}{|c|}{ Table 1. Subroutine and function calls within FEHMN (continued) } \\
\hline Routine & Description & Calls & Called by \\
\hline user & $\begin{array}{l}\text { A user-programmed subroutine that provides for } \\
\text { changing common block variables every time step. } \\
\text { Disabled (i.e., not certified as part of this baseline) } \\
\text { for YMP project. }\end{array}$ & & fehmn, input \\
\hline userc & $\begin{array}{l}\text { User-defined subroutine for changing common } \\
\text { variables associated with tracer transport. } \\
\text { Disabled (i.e., not certified as part of this baseline) } \\
\text { for YMP project. }\end{array}$ & & thermc, rdcon \\
\hline vaporl & $\begin{array}{l}\text { Calculate the vapor-pressure-lowering contribution } \\
\text { to saturation pressure. }\end{array}$ & $\exp$ & psatl \\
\hline varchk & $\begin{array}{l}\text { Decide, based on current pressure, temperature, } \\
\text { and saturation values, on the current phase state } \\
\text { (fully saturated, partially saturated). Call routine } \\
\text { THERMW or THRMWC to update thermodynamic } \\
\text { properties of density, enthalpy, and viscosity. Add } \\
\text { the Newton-Raphson corrections to the dependent } \\
\text { variables. }\end{array}$ & $\begin{array}{l}\text { airctr, psatl, thermw, thrmwc, } \\
\text { vcon, max, maxo }\end{array}$ & $\begin{array}{l}\text { bnswer, dpdp, dual, dualfa, } \\
\text { dualfh, fehmn, startup }\end{array}$ \\
\hline varctr & $\begin{array}{l}\text { Convert equations between pressure enthalpy and } \\
\text { pressure temperature. }\end{array}$ & mmgetblk & input \\
\hline vcon & Calculate variable thermal conductivity. & initdata, null, sqrt & input, varchk \\
\hline veloc & Calculate fluid velocities in coordinate directions. & abs, max, sqrt & contr, contri, fehmn \\
\hline vical & $\begin{array}{l}\text { Change porosity and permeability as functions of } \\
\text { pressure. }\end{array}$ & exp, log & thermw, thrmwc \\
\hline vgcap & $\begin{array}{l}\text { Compute the capillary pressure and derivatives for } \\
\text { the van Genuchten model. }\end{array}$ & . & rlperm \\
\hline vgcap_fit & Provide linear or cubic fit to capillary pressure data. & & rlperm \\
\hline vgrip & $\begin{array}{l}\text { Compute the liquid relative permeability and } \\
\text { derivative for the van Genuchten model. }\end{array}$ & & rlperm \\
\hline
\end{tabular}




\begin{tabular}{|c|c|c|c|}
\hline Routine & Description & Calls & Called by \\
\hline volume_tet_voronoi & $\begin{array}{l}\text { Find the volume of a tet-element defined by } 4 \\
\text { coordinate nodes. }\end{array}$ & $\begin{array}{l}\text { drill, enthp, film, fprop, heatb, } \\
\text { nearn, permp, rock, abs, int, } \\
\text { log, } \min \end{array}$ & $\begin{array}{l}\text { fehm, input, porosi, rlperm, } \\
\text { startup, thermw }\end{array}$ \\
\hline welbor & Do wellbore input and simulation. & $\begin{array}{l}\text { drill, enthp, film, fprop, heatb, } \\
\text { nearn, permp, rock, abs, int, } \\
\text { log, min }\end{array}$ & $\begin{array}{l}\text { fehmn, input, porosi, rlperm, } \\
\text { startup, thermw }\end{array}$ \\
\hline write_avs_node_con & Output AVS concentration fields from FEHM. & $\min , \max$ & avs_io \\
\hline write_avs_node_mat & $\begin{array}{l}\text { Output AVS scalar-node information for FEHM } \\
\text { mesh materials. }\end{array}$ & float & avs_io \\
\hline write_avs_node_s & Output AVS scalar-node information for FEHM. & & avs_io \\
\hline write_avs_node_v & Output AVS vector-node information for FEHM. & & avs_io \\
\hline write_avs_ucd_header & Output AVS UCD header information. & & avs_io \\
\hline write_binary_geo & $\begin{array}{l}\text { C routine to write AVS binary-coordinate and mesh- } \\
\text { connectivity information for FEHM. }\end{array}$ & elem_type_binary, Iseek, write & avs_io \\
\hline write_binary_header & $\begin{array}{l}\text { C routine to write AVS binary UCD header } \\
\text { information. }\end{array}$ & write & avs_io \\
\hline write_binary_node_con & $\begin{array}{l}\text { C routine to write AVS binary concentration fields } \\
\text { from FEHM. }\end{array}$ & Iseek, printf, strcat, write & avs_io \\
\hline write_binary_node_mat & $\begin{array}{l}\text { C routine to write AVS binary scalar-node } \\
\text { information for FEHM mesh materials. }\end{array}$ & Iseek, printf, strcat, write & avs_io \\
\hline write_binary_node_s & $\begin{array}{l}\text { C routine to write AVS binary scalar-node } \\
\text { information for FEHM. }\end{array}$ & Iseek, printf, strcat, write & avs_io \\
\hline write_binary_node_v & $\begin{array}{l}\text { C routine to write AVS binary vector-node } \\
\text { information for FEHM. }\end{array}$ & Iseek, printf, strcat, write & avs_io \\
\hline writeio & $\begin{array}{l}\text { Write assigned file names, unit numbers, and file } \\
\text { purpose to specified output unit. }\end{array}$ & & cntlio, infiles, termio \\
\hline wrtcon & Write output for tracer at specified intervals. & $a b s$ & concen, csolve \\
\hline
\end{tabular}




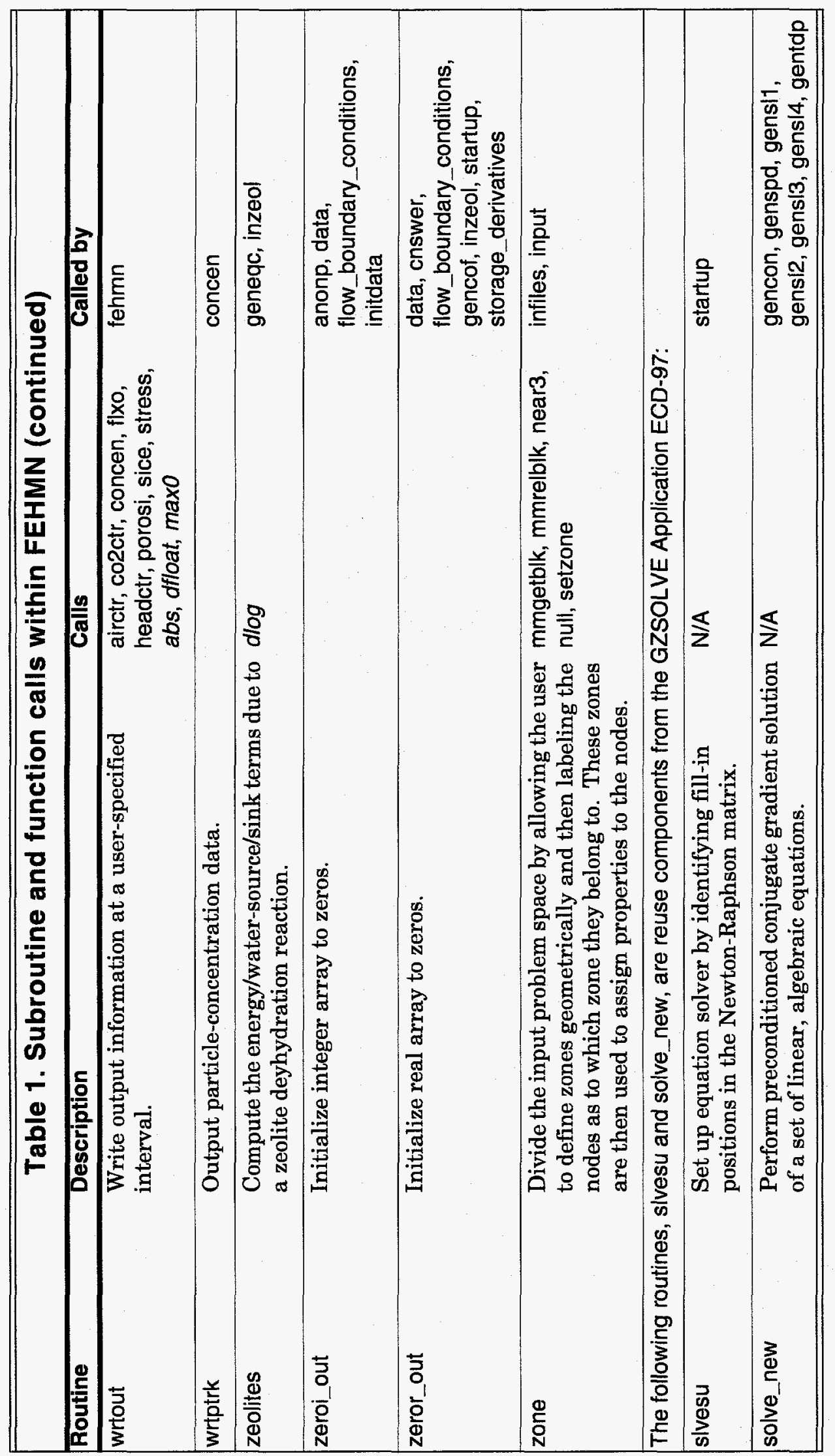


200 


\title{
Appendix B:
}

\section{Tests of the Functional Requirements}

and Macro Control Statements of

\author{
the FEHM Application
}




\subsection{APPENDIX B DESCRIPTION}

This appendix contains two tables. Table 1 lists the functional requirements of the FEHM application and, for each requirement, the section in Chapter I that describes that requirement and the sections in Chapter III that describe how that requirement will be tested. Table 2 lists the FEHM macro control statements used by test problems and, for each control statement, the section in the FEHM User's Manual (Zyvoloski et al. 1997b) that describes that macro control statement and the sections in Chapter III that use the control statement in the testing process.

\begin{tabular}{|c|c|c|}
\hline Requirement & $\begin{array}{c}\text { Chp. I } \\
\text { Section }\end{array}$ & Tested by (Chp. III section ${ }^{\ddagger}$ ) \\
\hline Finite-element coefficient generation & 3.1 & $\begin{array}{l}4.2,4.3,4.4,4.5,4.6,4.7,4.8,4.9,4.10 \\
4.11,4.12,4.13,4.14,4.15,4.16,4.17\end{array}$ \\
\hline Formulate transient equations & 3.2 & \\
\hline Heat-conduction equations & 3.2 .1 & 4.2 \\
\hline Heat- and mass-transfer equations & 3.2 .2 & $4.3,4.4,4.5,4.7,4.8,4.9,4.10$ \\
\hline Noncondensible gas flow equations & 3.2 .3 & $4.6,4.11$ \\
\hline Solute-transport equations & 3.2 .4 & $4.12,4.13,4.14,4.15,4.16,4.17$ \\
\hline Particle-tracking module & 3.2 .5 & To be developed \\
\hline Sources and sinks & 3.2 .6 & $\begin{array}{l}4.3,4.4,4.5,4.6,4.7,4.8,4.9,4.10,4.11 \\
4.12,4.13,4.14,4.15,4.16,4.17\end{array}$ \\
\hline Apply constitutive relationships & 3.3 & \\
\hline $\begin{array}{l}\text { Pressure- and temperature-dependent } \\
\text { water properties }\end{array}$ & 3.3.1 & $4.1,4.3,4.4,4.7,4.8,4.9,4.10$ \\
\hline $\begin{array}{l}\text { Properties of air and air/water-vapor } \\
\text { mixtures }\end{array}$ & 3.3.2 & $4.6,4.11$ \\
\hline Equation-of-state models & 3.3.3 & To be developed \\
\hline $\begin{array}{l}\text { Relative-permeability and capillary- } \\
\text { pressure functions }\end{array}$ & 3.3 .4 & $4.5,4.6,4.11$ \\
\hline Adsorbing solutes & 3.3 .5 & $4.12,4.13,4.14$ \\
\hline Multiple, interacting solutes & 3.3.6 & $4.13,4.15,4.16,4.17$ \\
\hline Dual-porosity formulation & 3.3.7 & 4.7 \\
\hline $\begin{array}{l}\text { Double-porosity/double-permeability } \\
\text { formulation }\end{array}$ & 3.3.8 & 4.5 \\
\hline Stress-dependent properties & 3.3.9 & To be developed \\
\hline Variable thermal conductivity & 3.3.10 & To be developed \\
\hline
\end{tabular}




\begin{tabular}{|c|c|c|}
\hline Requirement & $\begin{array}{l}\text { Chp. I } \\
\text { Section }\end{array}$ & Tested by (Chp. III section ${ }^{\ddagger}$ ) \\
\hline $\begin{array}{l}\text { Compute solution to transient equations } \\
\text { Implement time-step mechanism } \\
\text { Solve nonlinear equation set at each time } \\
\text { step }\end{array}$ & $\begin{array}{l}3.4 \\
3.4 .1 \\
3.4 .2\end{array}$ & $\begin{array}{l}4.2,4.3,4.4,4.5,4.6,4.7,4.8,4.9,4.10 \\
4.11,4.12,4.13,4.14,4.15,4.16,4.17\end{array}$ \\
\hline $\begin{array}{l}\text { Provide input/output data files } \\
\text { Inputs } \\
\text { Outputs }\end{array}$ & $\begin{array}{l}3.5 \\
3.4 .2 \\
3.4 .4\end{array}$ & $\begin{array}{l}4.2,4.3,4.4,4.5,4.6,4.7,4.8,4.9,4.10 \\
4.11,4.12,4.13,4.14,4.15,4.16,4.17\end{array}$ \\
\hline $\begin{array}{l}\text { Provide restart capability } \\
\text { Write information needed for restart to } \\
\text { output file }\end{array}$ & $\begin{array}{l}3.6 \\
3.6 .1\end{array}$ & 4.17 \\
\hline $\begin{array}{l}\text { Read information needed for restart from } \\
\text { restart file }\end{array}$ & 3.6 .2 & $4.10,4.17$ \\
\hline Resume the calculation & 3.6 .3 & $4.10,4.17$ \\
\hline $\begin{array}{l}\text { FChapter III sections (Verification and Validatio } \\
\text { 4.1 Testing of Thermodynamic Functions } \\
\text { 4.2 Test of Heat Conduction } \\
\text { 4.3 Test of Temperature in a Wellbore } \\
\text { 4.4 Test of Pressure Transient Analysis } \\
\text { 4.5 Test of Infiltration into a One-dimensior } \\
\text { 4.6 Test of Vapor Extraction from an Unsat } \\
\text { 4.7 Test of Dual Porosity } \\
\text { 4.8 Test of Heat and Mass Transfer in Poro } \\
\text { 4.9 Test of Toronyi Two-phase Problem } \\
\text { 4.10 Test of DOE Code Comparison Proje } \\
\text { 4.11 Test of Dry-out of a Partially Saturate } \\
\text { 4.12 Test of One-dimensional Reactive-So } \\
\text { 4.13 Test of Henry's Law Species } \\
\text { 4.14 Test of Fracture Transport with Matrix } \\
\text { 4.15 Test of the Movement of a Dissolved } \\
\text { 4.16 Test of Multisolute Transport with Che } \\
\text { 4.17 Test of Three-dimensional Radionucli }\end{array}$ & $\begin{array}{l}\text { Plan) } \\
\text {, Layered, } \\
\text { ated Rese } \\
\text { Media } \\
\text { Problem } \\
\text { Uedium } \\
\text { Te Transpo } \\
\text { iffusion } \\
\text { neral Fron } \\
\text { ical React } \\
\text { Transport }\end{array}$ & $\begin{array}{l}\text { Unsaturated Medium } \\
\text { rvoir } \\
\text { Eive, Case A } \\
\text { it }\end{array}$ \\
\hline
\end{tabular}




\section{Table 2. FEHM macro control statements used by test problems}

\begin{tabular}{|c|c|c|}
\hline $\begin{array}{c}\text { Control } \\
\text { statement }\end{array}$ & $\begin{array}{c}\text { User's } \\
\text { Manual } \\
\text { section }\end{array}$ & Used by (Chp. III section) (see footnote in Table I) \\
\hline adif & 6.2 .3 & Not used \\
\hline airwater & 6.2 .4 & $4.6,4.13,4.17$ \\
\hline alti & 6.2 .5 & Not used \\
\hline boun & 6.2 .6 & Not used \\
\hline bous & 6.2 .7 & Not used \\
\hline cap & 6.2 .8 & No longer used, see macro rlp \\
\hline cond & 6.2 .9 & $4.2,4.3,4.4,4.6,4.7,4.8,4.9,4.10,4.11,4.12,4.13,4.14,4.15,4.16,4.17$ \\
\hline cont & 6.2 .10 & $4.2,4.3,4.4,4.5,4.6,4.8,4.9,4.10,4.11,4.13,4.15$ \\
\hline coor & 6.2.11 & $4.2,4.3,4.4,4.5,4.6,4.7,4.8,4.9,4.10,4.11,4.12,4.13,4.14,4.15,4.16,4.17$ \\
\hline ctrl & 6.2.12 & $4.2,4.3,4.4,4.5,4.6,4.7,4.8,4.9,4.10,4.11,4.12,4.13,4.14,4.15,4.16,4.17$ \\
\hline dof & 6.2 .13 & Not implemented \\
\hline dpdp & 6.2 .14 & 4.5 \\
\hline dual & 6.2 .15 & 4.7 \\
\hline elem & 6.2.16 & $4.2,4.3,4.4,4.5,4.6,4.7,4.8,4.9,4.10,4.11,4.12,4.13,4.14,4.15,4.16,4.17$ \\
\hline eos & 6.2.17 & Not used \\
\hline exrl & 6.2.18 & Not used \\
\hline finv & 6.2 .19 & 4.2 \\
\hline flow & 6.2 .20 & $4.2,4.3,4.4,4.5,4.6,4.7,4.8,4.9,4.10,4.11,4.12,4.13,4.14,4.15,4.16,4.17$ \\
\hline flo2 & 6.2 .21 & Not used \\
\hline flxo & 6.2 .22 & Not used \\
\hline head & 6.2 .23 & Not used \\
\hline hflx & 6.2 .24 & 4.11 \\
\hline ice & 6.2 .25 & Not used \\
\hline init & 6.2 .26 & $4.2,4.3,4.4,4.7,4.8,4.9,4.10,4.12,4.14,4.15,4.16,4.17$ \\
\hline iter & 6.2.27 & $4.5,4.6,4.7,4.11,4.15,4.16,4.17$ \\
\hline itup & 6.2 .28 & $4.11,4.17$ \\
\hline iupk & 6.2 .29 & Not used \\
\hline ivfc & 6.2 .30 & Not used \\
\hline mdnode & 6.2 .31 & Not used \\
\hline
\end{tabular}




\begin{tabular}{|c|c|c|}
\hline Table 2. & FEHM n & lacro control statements used by test problems (continued) \\
\hline $\begin{array}{l}\text { Control } \\
\text { statement }\end{array}$ & $\begin{array}{c}\text { User's } \\
\text { Manual } \\
\text { section }\end{array}$ & Used by (Chp. III section) (see footnote in Table I) \\
\hline ngas & 6.2 .32 & 4.11 \\
\hline nod2 & 6.2 .33 & Not used \\
\hline node & 6.2 .34 & $4.2,4.3,4.4,4.5,4.6,4.7,4.8,4.9,4.10,4.11,4.12,4.13,4.14,4.15,4.16,4.17$ \\
\hline perm & 6.2 .35 & $4.2,4.3,4.4,4.5,4.6,4.7,4.8,4.9,4.10,4.11,4.12,4.13,4.14,4.15,4.16,4.17$ \\
\hline pest & 6.2 .36 & Not used \\
\hline ppor & 6.2 .37 & Not used \\
\hline pres & 6.2 .38 & $4.5,4.6,4.9,4.11,4.13,4.17$ \\
\hline ptrk & 6.2 .39 & Not used \\
\hline renm & 6.2 .40 & Not used \\
\hline rflx & 6.2 .41 & Not used \\
\hline rlp & 6.2 .42 & $4.5,4.6,4.9,4.10,4.11,4.13,4.17$ \\
\hline rock & 6.2 .43 & $4.2,4.3,4.4,4.5,4.6,4.7,4.8,4.9,4.10,4.11,4.12,4.13,4.14,4.15,4.16,4.17$ \\
\hline $\mathbf{r x n}$ & 6.2 .44 & $4.13,4.15,4.16,4.17$ \\
\hline sol & 6.2 .45 & $4.2,4.3,4.4,4.5,4.6,4.7,4.8,4.9,4.10,4.11,4.12,4.13,4.14,4.15,4.16,4.17$ \\
\hline solv & 6.2 .46 & Not implemented \\
\hline stea & 6.2 .47 & Not used \\
\hline stop & 6.2 .48 & $4.2,4.3,4.4,4.5,4.6,4.7,4.8,4.9,4.10,4.11,4.12,4.13,4.14,4.15,4.16,4.17$ \\
\hline strs & 6.2 .49 & Not implemented in this version of FEHM \\
\hline svar & 6.2 .50 & Not used \\
\hline text & 6.2 .51 & $4.5,4.17$ \\
\hline thic & 6.2 .52 & Not used \\
\hline time & 6.2 .53 & $4.2,4.3,4.4,4.5,4.6,4.7,4.8,4.9,4.10,4.11,4.12,4.13,4.14,4.15,4.16,4.17$ \\
\hline trac & 6.2 .54 & $4.12,4.13,4.14,4.15,4.16,4.17$ \\
\hline user & 6.2 .55 & Not used \\
\hline veon & 6.2 .56 & Not used \\
\hline velo & 6.2 .57 & Not used \\
\hline
\end{tabular}


Table 2. FEHM macro control statements used by test problems (continued)

\begin{tabular}{|l|l|l|}
\hline $\begin{array}{c}\text { Control } \\
\text { statement }\end{array}$ & $\begin{array}{c}\text { User's } \\
\text { Manual } \\
\text { section }\end{array}$ & Used by (Chp. Ill section) (see footnote in Table I) \\
\hline \hline wlbr & 6.2 .58 & Not used \\
zone & 6.2 .59 & $4.2,4.3,4.5,4.8,4.17$ \\
$\#$ & 6.1 .1 .2 & $4.5,4.6,4.13$ \\
file & 6.2 .2 & Not used \\
\hline \multirow{2}{|l|}{ ‡Zyvoloski et al. (1997b) } \\
\hline
\end{tabular}

